\title{
ROL SOCIAL Y POLÍTICO EN EL SISTEMA DE PROTECCIÓN SOCIAL DE MUJERES CUIDADORAS DE NIÑOS CON DISCAPACIDAD LOCALIDAD DE BOSA, BOGOTÁ D.C., COLOMBIA, 2016
}

\section{ANGGIE TATIANA RODRÍGUEZ ÁLVAREZ}

Trabajo de investigación para optar el título de Magíster en

\author{
Protección Social
}

Línea de investigación Programas de Atención Social

\author{
Asesora \\ Ivonne Andrea Ordóñez Monak
}

UNIVERSIDAD SANTO TOMÁS DE BOGOTÁ

DIVISIÓN CIENCIAS ECONÓMICAS Y

ADMINISTRATIVAS

MAESTRÍA EL PROTECCIÓN SOCIAL

Bogotá, Colombia

2018 
ANGGIE TATIANA RODRÍGUEZ ÁLVAREZ

\section{ROL SOCIAL Y POLÍTICO EN EL SISTEMA DE}

\section{PROTECCIÓN SOCIAL DE MUJERES CUIDADORAS DE NIÑOS CON DISCAPACIDAD LOCALIDAD DE BOSA, BOGOTÁ D.C. COLOMBIA, 2016}

Esta tesis fue evaluada y aprobada para la obtención del título de Magíster en Protección Social por la Universidad Santo Tomás de Bogotá

Nombres y firmas de quienes aprueba: 


\section{SALVEDAD INSTITUCIONAL}

La Universidad Santo Tomás de Bogotá no se hace responsable de los conceptos emitidos

por la investigadora en su trabajo, solo velará por el rigor científico, metodológico y ético del mismo, en aras de la búsqueda de la verdad y la justicia. 


\section{AGRADECIMIENTOS}

Esta investigación me ha convencido aún más de la noble misión que quiero seguir cumpliendo, buscar mejores senderos y demostrar que es a partir de la educación en donde se gestan las verdaderas transformaciones. En estos tiempos de melancolía y desánimo social, me siento privilegiada de ser una mujer que logra culminar sus estudios de Maestría, un logro que solo a través de la gracia de Dios pudo darse.

A mis padres y hermano de quienes aprendo día a día, a quienes amo profundamente y en donde he encontrado el apoyo más significativo y leal. Para ellos, que fueron testigos de este largo trasegar y que a pesar de las adversidades estuvieron allí para demostrarme el amor de Dios en la tierra.

A los Docentes Ivonne Ordóñez, Manuel Vega y Sandra Barrios, quienes con su apoyo incondicional y profesionalismo guiaron mis intereses, comprendieron mi sentir e hicieron suya esta propuesta investigativa.

A cada una de los funcionarios con los que tuve la oportunidad de compartir, pues sin su conocimiento, este estudio carecería de sentido y valor social. 


\section{DEDICATORIA}

Esta investigación está dedicada a todas las mujeres que demuestran que la perfección y el valor no están en las cosas tangibles y predecibles; a cada madre, abuela, tía y hermana que con su labor diaria forman seres humanos felices, a ellas, a quienes las fuerzas les sobran aun cuando la dificultad se apodera de sus vidas. Para ellas, este pequeño y muy sentido reconocimiento. 


\section{TABLA DE CONTENIDO}

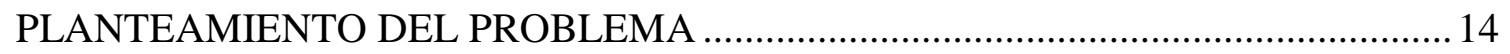

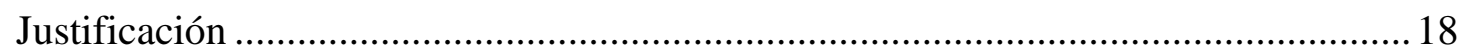

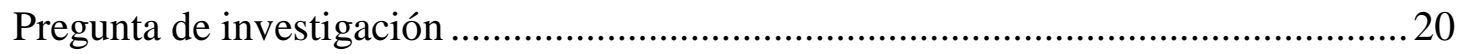

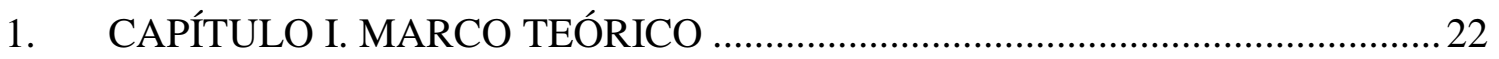

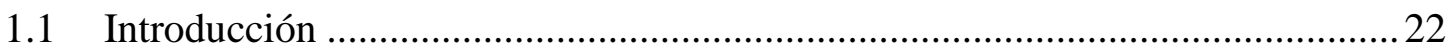

1.2 Conceptualización y funciones del Sistema de Protección Social ........................24

1.3 El Estado y su injerencia en el Sistema de Protección Social ..............................30

1.3.1 La intervención del Estado a través de las Políticas Públicas.......................32

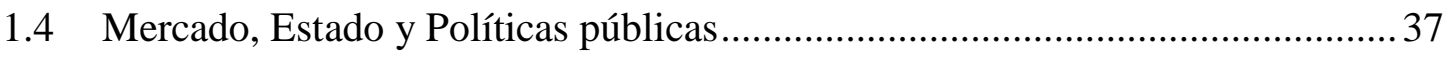

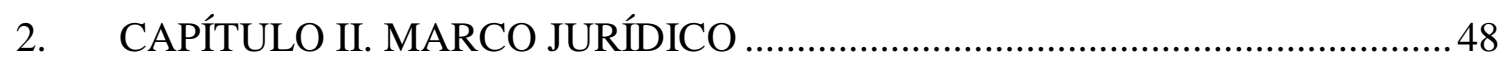

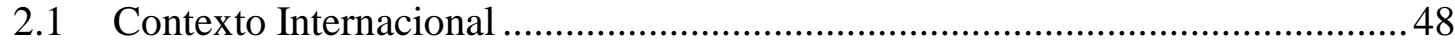

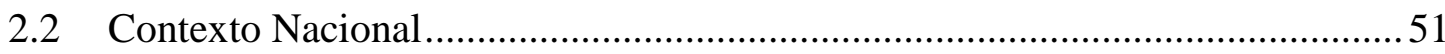

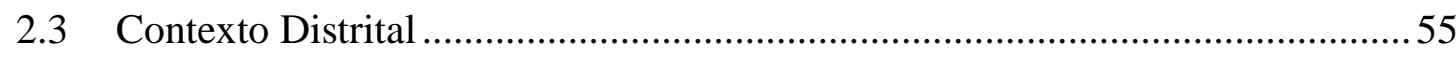

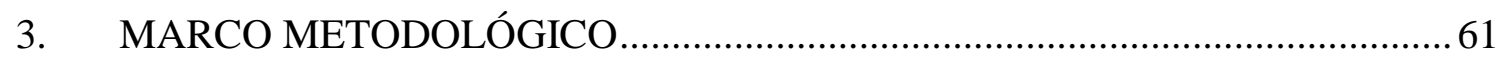

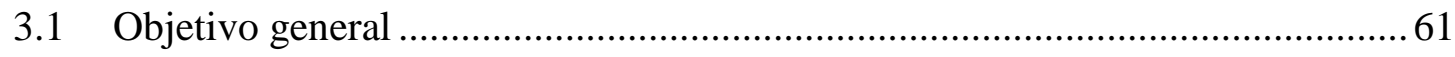

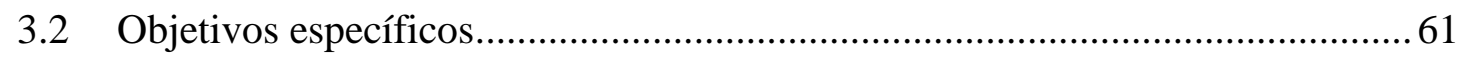

3.3 Fase I: Enfoque cuantitativo, Método descriptivo ................................................67

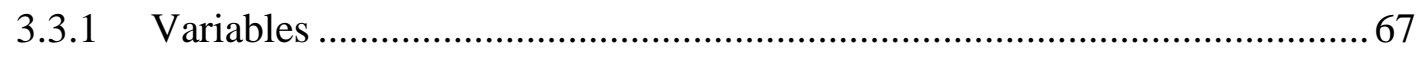

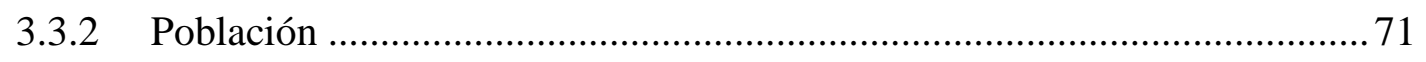




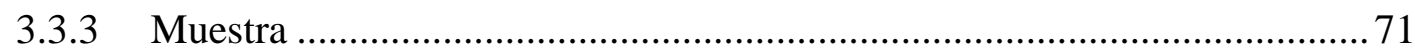

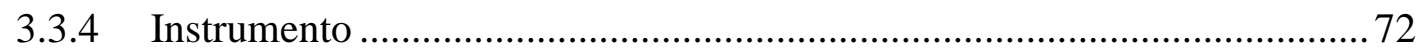

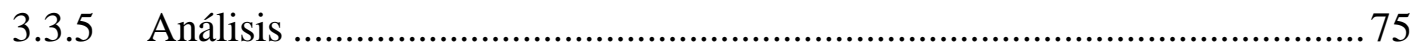

3.4 Fase II: Enfoque cualitativo, Método biográfico .............................................. 75

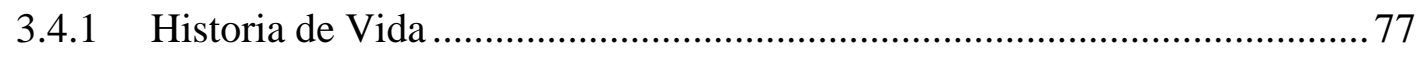

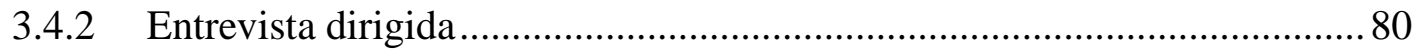

4. CAPÍTULO IV. LA REALIDAD DE LAS MUJERES CUIDADORAS DE LA LOCALIDAD DE BOSA Y LA CONSTRUCCIÓN DE SUS ROLES SOCIALES Y

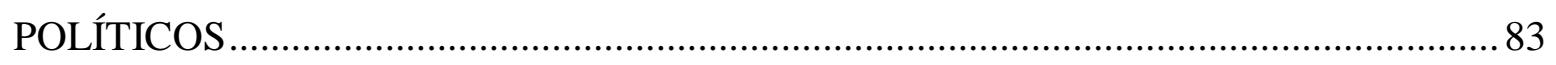

4.1 Caracterización socioeconómica, política, familiar y comunitaria ......................83

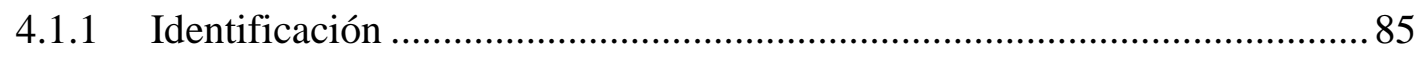

4.1.2 Protección Social ...................................................................................... 91

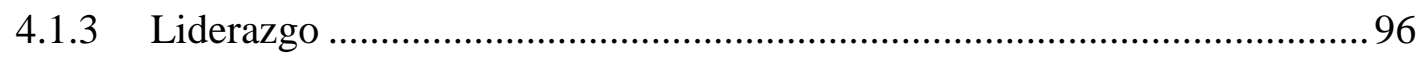

4.1.4 Conflictividad ...................................................................................... 98

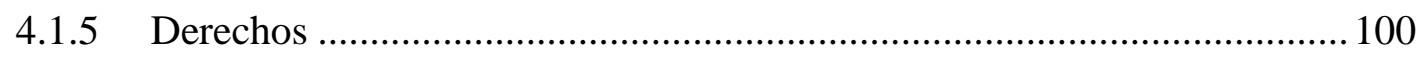

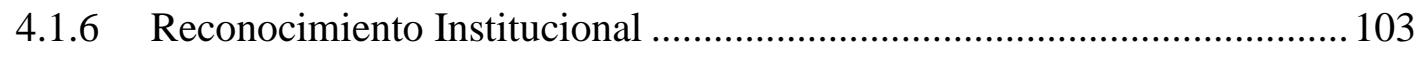

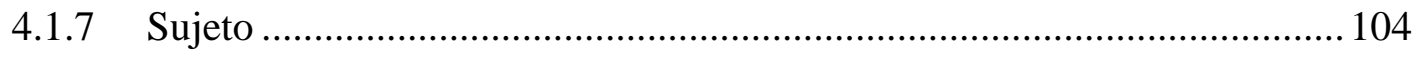

4.2 Descripción de roles sociales y políticos........................................................... 106

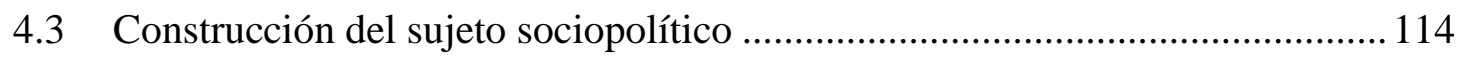

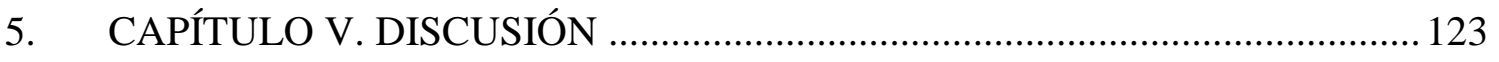

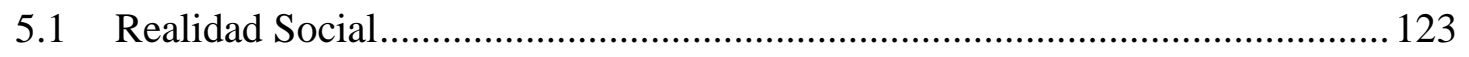




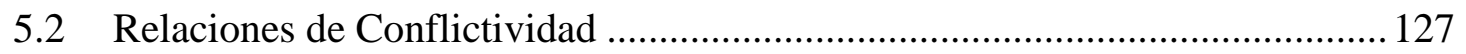

6. CAPÍTULOVI. CONCLUSIONES .......................................................... 131

7. CAPÍTULO VII. CONSIDERACIONES ÉTICAS ......................................... 134

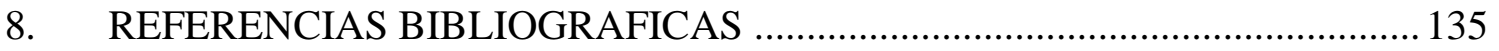




\section{LISTA DE FIGURAS}

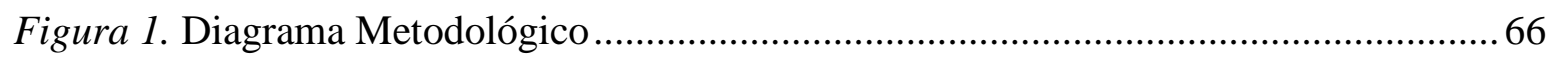

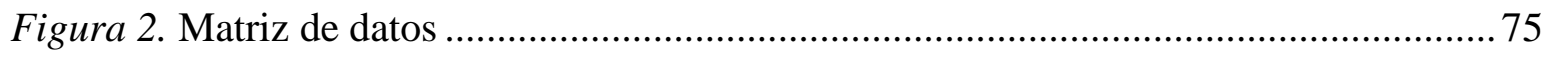

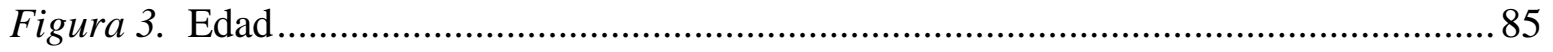

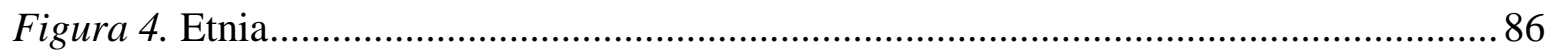

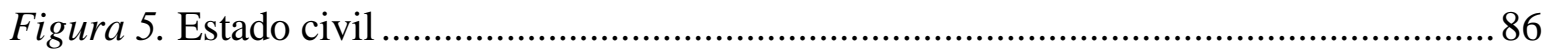

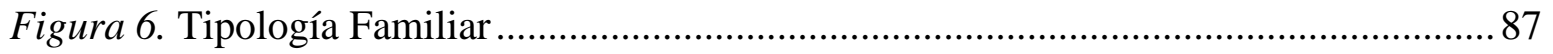

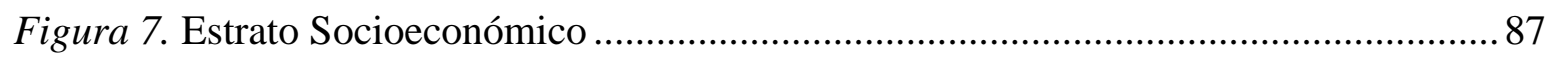

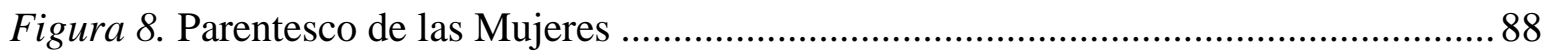

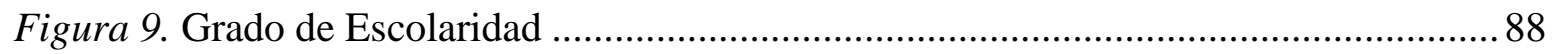

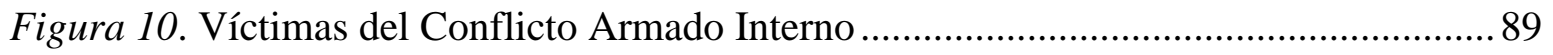

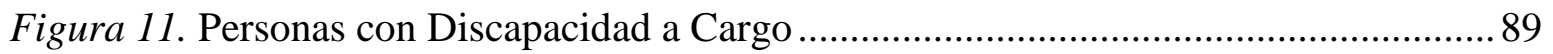

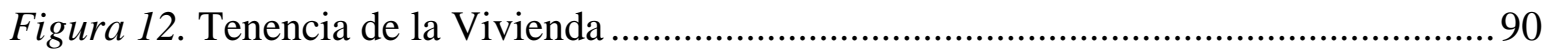

Figura 13. Acceso a Servicios Públicos.......................................................................... 90

Figura 14. Ocupación de las mujeres cuidadoras además del Cuidado .................................91

Figura 15. Vinculación Laboral .................................................................................... 91

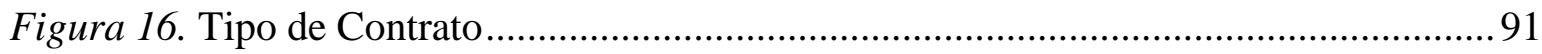

Figura 17. Dificultades para el Acceso Laboral ............................................................... 92

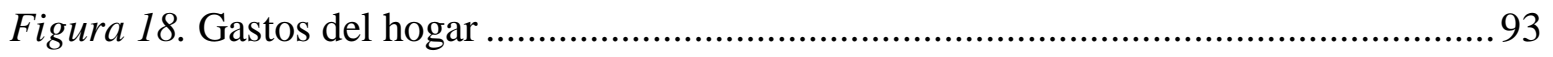

Figura 19. Provisión de ingresos en el hogar...................................................................... 93

Figura 20. Acceso a las Instituciones............................................................................. 94

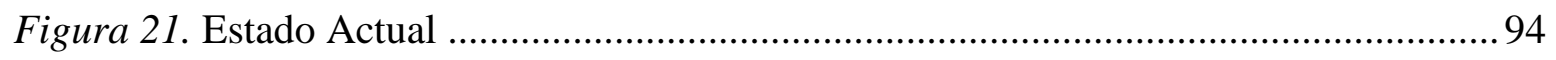

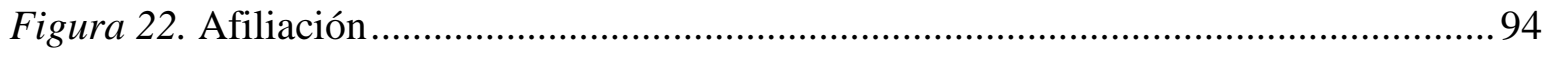


Figura 23. Régimen de Cotización............................................................................. 95

Figura 25. Estado Actual .................................................................................... 95

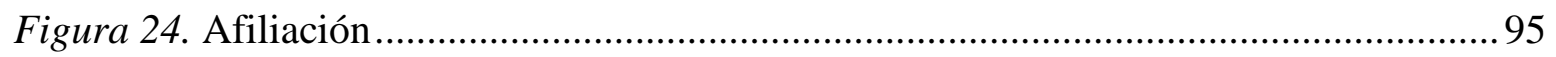

Figura 26. Percepción de Reconocimiento de las Cuidadoras .........................................96

Figura 27. Conocimiento de Cuidado ........................................................................... 96

Figura 28. Apoyo Comunitario ............................................................................ 97

Figura 29. Conflictos por el ejercicio del Cuidado ........................................................ 98

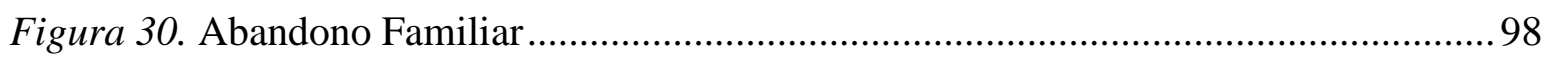

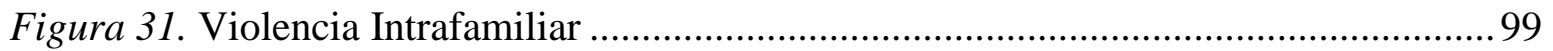

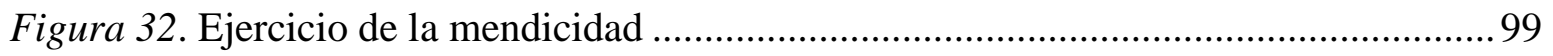

Figura 33. Percepción de Estado............................................................................. 100

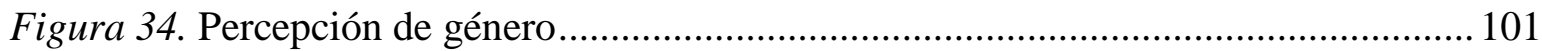

Figura 35. Dificultades de Asociación Comunitaria.................................................. 101

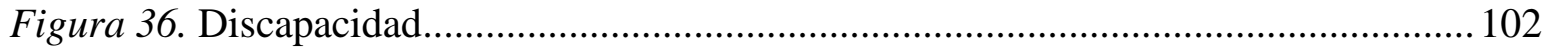

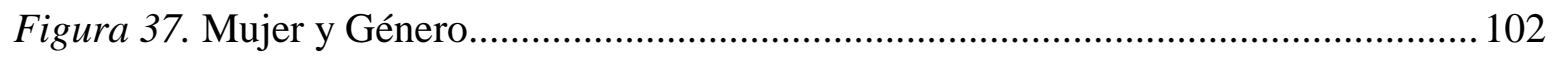

Figura 38. Acceso a bienes y servicios del Estado ................................................... 102

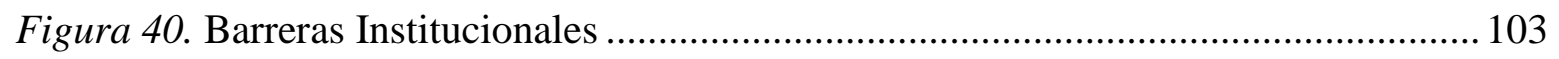

Figura 39. Mecanismos de Protección ....................................................................... 103

Figura 41. Estabilidad Emocional......................................................................... 104

Figura 42. Percepción del Cuidado...................................................................... 105

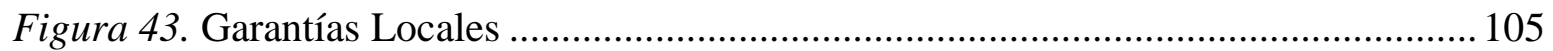




\section{LISTA DE TABLAS}

Tabla 1. El Rol Sociopolítico desde el Contexto Local. Síntesis ..................................... 107

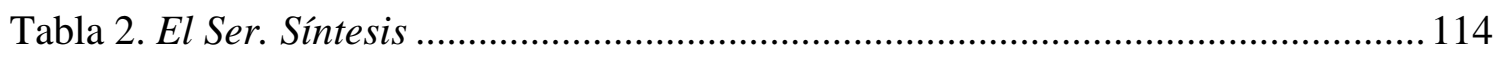




\section{RESUMEN}

El progreso de la igualdad entre los géneros se ha visto obstaculizado por factores predominantemente políticos y económicos. Los avances han sido lentos para las mujeres y niñas más marginadas, que sufren diferentes formas de discriminación. Las cuidadoras de menores en condición de discapacidad -especialmente en situación de pobreza-, no solo deben sortear con este panorama, sino además lidiar con las limitaciones físicas, mentales, intelectuales o sensoriales de las personas a cargo. La presente investigación pretende analizar el rol social y político que cumplen las mujeres como cuidadoras cuando en su núcleo familiar existe una persona en condición de discapacidad, en un contexto de exclusión como consecuencia de la pobreza, la desigualdad y la discriminación de género.

En ese sentido, se busca además identificar cómo el Estado garantiza protección social a estos hogares no solo desde la seguridad y la asistencia social, sino también desde la construcción de otros mecanismos alternos y el ejercicio de los derechos por parte de las cuidadoras y su empoderamiento. Se propone un estudio transversal mixto, con un componente cuantitativo que caracterice el rol de las cuidadoras desde esta perspectiva y con un componente cualitativo que profundice en las dinámicas, determinantes sociales y mecanismos alternos de Protección Social de estas personas. Se espera que los resultados sirvan de insumo académico y político para evaluar la pertinencia actual de las políticas públicas de Protección Social dirigidas a la población de menores en condición de discapacidad y pobreza, y a sus cuidadoras con un enfoque de equidad. 
PALABRAS ClAVE: Sistema de Protección Social, Cuidado, Cuidadoras, Discapacidad, Género, Rol, Pobreza, Estado, Mercado.

\begin{abstract}
The progress of gender equality has been hampered by predominantly political and economic factors. Progress has been slow for the most marginalized women and girls, who suffer different forms of discrimination. The caregivers of minors in disability condition especially in poverty situation-, must not only deal with this situation, but also deal with the physical, mental, intellectual or sensory limitations of the people in charge. This research aims to analyze the social and political role of women as caregivers when there is a disabled person in their family, in a context of exclusion as a consequence of poverty, inequality and gender discrimination. In this perspective, it is also sought to identify how the State guarantees social protection to these households not only from security and social assistance, but also from the construction of other alternative mechanisms and the exercise of rights by caregivers and their empowerment. A mixed cross-sectional study is proposed, with a quantitative component that characterizes the role of caregivers from this perspective and with a qualitative component that delves into the dynamics, social determinants and alternative mechanisms of Social Protection of these people. It is expected that the results serve as an academic and political input to assess the current relevance of public policies of Social Protection aimed at the population of children in disability and poverty, and their carers with an equity focus.
\end{abstract}

KEYWORDS: Social Protection System, Care, Caregivers, Disability, Gender, Role, Poverty, State, Market 


\section{PLANTEAMIENTO DEL PROBLEMA}

El problema de investigación de la presente propuesta se relaciona con dos ejes temáticos principales: la construcción de mujeres como sujetos políticos y sociales, y el ejercicio de cuidado de niños, niñas y adolescentes en condición de discapacidad en el marco de la pobreza, exclusión y desigualdad social.

El tema de género e igualdad de derechos entre mujeres y hombres alrededor del mundo ha sido una de las discusiones más complejas y con diversos matices que ha permitido el desarrollo de momentos históricos importantes para la mujer, la trasformación de realidades y el empoderamiento progresivo de la misma dentro de su contexto inmediato (Domínguez, 2004; Guzmán, 1997). A nivel global, se ha dado prioridad al tema de equidad de género y al monitoreo permanente de organismos internacionales en la garantía de derechos a las mujeres. Uno de estos referentes históricos fue la Declaración y la Plataforma de Acción de Beijing, que tras haber cumplido 20 años de su promulgación, evidencia un panorama poco alentador: actualmente existen mejores leyes para promover la igualdad entre los géneros y abordar la violencia contra niñas y mujeres; sin embargo, se debe reconocer que muchas de las barreras y limitaciones ya observadas por los firmantes de Beijing siguen vigentes de forma global; aunque existen apreciables excepciones en las que sí se ha logrado progreso, ningún país ha alcanzado la igualdad entre los géneros.

El panorama general es el de una implementación lenta y desigual, con un grave estancamiento e incluso una regresión en diversos ámbitos. Los avances han sido especialmente lentos para las mujeres y niñas más marginadas, que sufren formas múltiples e interrelacionadas de discriminación. (ONU Mujeres, 2015, p. 6) 
Colombia no es ajena a esta dinámica, pues aunque se han generado algunos avances, el tema de la equidad de género es relativamente reciente, lo que ha redundado en una pobre sensibilización de la sociedad y unas políticas públicas discretas en relación con este aspecto. En términos educativos, las mujeres evidencian un nivel académico ligeramente mayor al de los hombres. Según el DANE, para el período 2007 - 2011, las tasas de analfabetismo en mujeres de 15 años y más ha estado entre uno y cuatro puntos porcentuales por debajo de la tasa de analfabetismo en hombres.

El promedio de años de escolaridad para las mujeres de 15 años o más ha estado entre uno y dos puntos porcentuales por encima de los hombres, y la tasa neta de asistencia de mujeres a primaria, secundaria y educación superior para el 2011 era superior a la de los hombres en $0.7,8.6$ y 3.6 puntos porcentuales, respectivamente. (Fucsia, s.f., párr. 8, palabras en negrita propias del autor)

A pesar de los esfuerzos de las mujeres por mejorar sus condiciones de formación académica, el contexto socioeconómico continúa siendo excluyente, ya que existe una mayor incidencia de la pobreza en las mujeres. De acuerdo con los resultados de la Gran Encuesta Integrada de Hogares (GEIH), para el año 2011, las mujeres evidencian una tasa de incidencia de la pobreza monetaria de $34,7 \%$, y los hombres de $33,5 \%$. Por otra parte, las mujeres en Colombia participan menos que los hombres en el mercado laboral y se ven más afectadas por el desempleo: para el 2013, la tasa de ocupación de los hombres fue superior a la de las mujeres en 21,8 puntos porcentuales. Teniendo en cuenta los datos consolidados por el DANE del 2007 al 2011, la tasa de ocupación de los hombres había sido superior a las de las mujeres en un rango de 25.7 a 23.8 puntos (ONU Mujeres, 2015). 
Ahora, esta inequidad laboral genera otras problemáticas para las mujeres en términos de Protección Social, puesto que hay más mujeres afiliadas a la seguridad social en salud en el régimen subsidiado que en el régimen contributivo, y en este último hay un menor porcentaje de mujeres cotizantes y un mayor porcentaje de mujeres beneficiarias. Según el DANE (2011), de las personas pertenecientes al régimen contributivo en calidad de cotizantes, 55,1 $\%$ son hombres y $39,1 \%$ son mujeres, mientras que en calidad de beneficiarios, $44,5 \%$ son hombres y $60.5 \%$ son mujeres.

Con relación a la problemática de la discapacidad -no solo en menores en situación de pobreza-, es posible afirmar que la misma tiene consecuencias personales, familiares y sociales que llevan a la exclusión social. En uno de los primeros estudios realizados por la Presidencia de la República, se encontró que el 9,6 \% de las personas con discapacidad presentaban necesidades básicas insatisfechas (NBI), el $55 \%$ de los hogares debían subsistir con 1 a 3 salarios mínimos, y el 57,6 \% de ellos no tenía acceso a servicios de salud (Moreno, Rodríguez, Gutiérrez, Ramírez, \& Barrera, 2006). Si bien los programas asistenciales y las coberturas en salud para la población con discapacidad han mejorado en la última década (Departamento Nacional de Planeación, 2013), la complejidad del fenómeno continúa generando unas necesidades importantes desde las políticas públicas y la sincronía del trabajo intersectorial.

Es de señalar que la condición de discapacidad causa diversos cambios en la vida de una persona y de sus familiares, los cuales se relacionan con el estado de dependencia asociado a una limitación física o mental, a una alteración del estado de salud, y a la modificación en las actividades sociales. En ese mismo sentido, el núcleo familiar también debe afrontar 
cambios importantes en su estilo de vida, que se ven directamente afectados por las condiciones socioeconómicas de la familia y por la severidad y características de la discapacidad (Cabra, 2004; Moreno, Náder, \& López, 2004, Moreno et al., 2006).

Es evidente que el modelo social típico de la postguerra (hombre como proveedor y mujer como cuidadora) influye notablemente en las dinámicas familiares actuales, y por lo tanto, el cuidado de personas en el hogar incide en la tasa de ocupación y de desempleo de las mujeres. De acuerdo con las cifras del DANE para el año 2011, las mujeres que hacen parte de hogares con personas de menos de cinco años o más de 65 años de edad observaron una tasa de ocupación menor en 10,3 puntos porcentuales, frente a la tasa de ocupación de mujeres que pertenecen a hogares sin personas de cuidado (ONU Mujeres, 2015; Guzmán, 1997). Aunque estos datos no discriminan los hogares con niños, niñas o adolescentes en condición de discapacidad, es bastante probable que las problemáticas de las cuidadoras sean similares e incluso peores, teniendo en cuenta los niveles de dependencia que ellos generan. En general, la mayoría de las investigaciones se centran en la población con discapacidad, pero no tanto en sus cuidadoras, quienes tienen una función social primordial a la hora de garantizar bienestar y velar por los derechos de las personas a cargo. 


\section{Justificación}

Según datos de la Organización Mundial de la Salud [OMS] (2011), se estima que la prevalencia de personas en condición de discapacidad puede llegar a ser del $15 \%$. Esto significa una proporción importante de la población, que además de presentar unas necesidades socioeconómicas y sanitarias específicas, conforme al tipo de discapacidad (físicas, mentales, intelectuales o sensoriales), se enfrentan a múltiples barreras sociales, políticas, institucionales y urbanísticas que no solo limitan su participación plena, efectiva y equitativa en la sociedad, sino que además agravan sus condiciones de bienestar cuando los mecanismos estatales de Protección Social del Estado, en algunos casos, resultan insuficientes para asegurarles calidad de vida. Adicionalmente, cuando la persona con discapacidad es un menor de edad en condición de pobreza, se produce una suma de determinantes sociales que complejiza sus posibilidades de inclusión, no solo por la falta de recursos económicos de su núcleo familiar, sino por la necesidad permanente de la presencia de un cuidador (Friel \& Marmot, 2011).

Por otra parte, el quinto objetivo ("Igualdad de Género") planteado en los objetivos de desarrollo sostenible está dirigido a poner fin a toda forma de discriminación contra las mujeres y las niñas, pues para los organismos internacionales sigue siendo alarmante, los niveles de desigualdad laboral que enfrentan las mujeres, el no reconocimiento de las labores desarrolladas en el ámbito privado, las bajas oportunidades que tienen las niñas para ingresar a la educación, la explotación sexual y violencia sistemática. No obstante, el PNUD reconoce 
que empoderar a las mujeres y niñas tiene un efecto multiplicador y ayuda a promover el crecimiento económico y el desarrollo a nivel mundial (Programa de las Naciones Unidas para el Desarrollo [PNUD], 2015).

En Colombia, sin embargo, este proceso de igualdad de derechos entre hombres y mujeres se ha regido por la realidad sociopolítica del país en diferentes momentos; es decir, no ha existido una voluntad propia del Estado por reconocer la dignidad y el valor de la mujer. Los reconocimientos que se han hecho han estado relacionados, por un lado, con intereses electorales una estrategia con valor electoral y por otro lado, una oportunidad para que el gobierno demuestre los tenues avances y logros que ha tenido para mejorar la calidad de vida de sus habitantes, y más aun de sus mujeres ante organismos internacionales. Es claro que desde la equidad y oportunidades de empoderamiento que se dé a las mujeres, existirá de igual manera más opciones de enfrentar otras problemáticas sociales, entre ellas la morbimortalidad y calidad de vida en la infancia y adolescencia (Lara, 2006).

Por ende, conocer el rol social y político de las cuidadoras y los mecanismos alternos de Protección Social que ellas generan para subsanar las necesidades de estos menores, resulta no solo interesante al generar una visión integradora de dos problemáticas (la discapacidad en menores en condición de pobreza y el empoderamiento de las mujeres como sus cuidadoras en contextos de inequidad), sino además indispensable para identificar dinámicas y generar insumos que nutran propuestas políticas eficaces y pertinentes a este binomio poblacional. 


\section{Pregunta de investigación}

¿Cuál es el rol social y político en el sistema de protección social de mujeres cuidadoras de niños con discapacidad en la localidad de Bosa, Bogotá D.C., Colombia, 2016?

\section{CONTEXTO LOCAL}

La localidad de Bosa es la séptima del Distrito Capital, ubicada geográficamente al sur Occidente de la Ciudad limitando, con las localidades de Kennedy, Ciudad Bolívar y el municipio de Soacha. Es una de las cinco localidades más pobladas de Bogotá, con un estimado de 709.039 habitantes y a su vez, la cuarta con mayores condiciones de vulnerabilidad socioeconómica, toda vez que el $95 \%$ de sus habitantes pertenecen a los estratos ( 1 y 2 ), y el otro $5 \%$ se encuentra en condiciones de indigencia (Secretaría de Cultura, Recreación y Deporte, 2016).

De otro lado, sus principales las problemáticas sociales están asociadas al alto índice de desempleo e informalidad para las personas potencialmente activas, el acceso deficiente con el que cuenta la comunidad a los servicios públicos básicos, como derecho primario, el consumo y distribución de Sustancias Psicoactivas, la creación y existencia de grupos delincuenciales organizados, la recepción permanente de víctimas del conflicto armado interno así como familias étnicas (afrocolombianas e indígenas) que migran a la Capital con el fin de mejorar sus condiciones de vida, la desescolarización y deserción escolar e incremento de violencia intrafamiliar. 
Igualmente, presenta riesgos ambientales significativos, pues el territorio se encuentra en medio de los ríos Tunjuelito y Bogotá, recepcionando los residuos provenientes de la explotación minera y las ladrilleras de la localidad de Ciudad Bolívar, así como el vertimiento de los desechos de las curtiembres de la localidad de Tunjuelito y el mal manejo de los residuos internos, lo que ocasiona que la comunidad se encuentre en situaciones de extrema emergencia a diferencia de la mayoría de Localidades del Distrito.

Por otra parte y según el diagnóstico de aspectos físicos, demográficos y socioeconómicos desarrollado por la Secretaría Distrital de Planeación (2009), Bosa cuenta actualmente con 381 barrios de los cuales, el $63 \%$ ya están legalizados y el $37 \%$ se hallan en proceso, es una de las pocas localidades de la ciudad que aun cuenta con terrenos físicos para la construcción de vivienda.

Por esto último, desde el año 2012, la localidad ha presentado un incremento poblacional importante, dada la migración de centenares de familias a los proyectos de vivienda de interés social promovidos por la nación. Situación que pone en alerta a la Administración local, toda vez que el presupuesto asignado no ha sido modificado para cubrir las necesidades de toda la población actualmente identificada.

Finalmente y de allí el interés por abordar a esta población como sujeto en la presente investigación, Bosa es la tercera localidad con mayor concentración de población en condición de discapacidad con 16.520 personas identificadas, siendo el $20 \%$ población infantil. Es decir que no solamente es una de los territorios más pobres de la ciudad sino que también, alberga a un grupo poblacional significativo que presenta una condición de exclusión social permanente como lo es la discapacidad. 


\section{CAPÍTULO I. MARCO TEÓRICO}

\section{El Estado, el Mercado y la Familia vistos desde la cotidianidad de las Mujeres \\ Cuidadoras de la Localidad de Bosa.}

\subsection{Introducción}

Durante los últimos años, el cuidado ha tomado una fuerza importante en la agenda pública de América Latina, puesto que urge redireccionar los actuales Sistemas de Protección Social -SPS-, sus mecanismos de respuesta ante los múltiples riesgos socioeconómicos, laborales, familiares, médicos, sociales y políticos, así como los factores que promueven y perpetúan la pobreza, la desigualdad social, la inequidad de género y la exclusión social a las que se ven enfrentadas día a día las personas que ejercen el cuidado, al igual que los que necesitan ser cuidados.

Entonces, concebir al cuidado como una responsabilidad exclusiva del ámbito privado promueve el paradigma clásico de orden social y económico, en el cual, el aporte que realizan los cuidadores desde su rol familiar, afectivo, político y comunitario es ajeno a la dinámica del mercado y a las políticas económicas que promulgan los diferentes Estados. Es decir, no tiene ningún tipo de injerencia o repercusión esa labor desarrollada desde el anonimato y la falta de garantías para hacerlo.

En ese orden de ideas, para los Estados el ejercicio del cuidado sigue siendo una obligación enmarcada en el género y en las tradiciones culturales, lo que sin duda vulnera los 
derechos sociales, laborales, económicos y políticos de las mujeres, teniendo en cuenta que su acceso a la vida pública (trabajo) es una obligación y una necesidad, en la medida en que las estructuras familiares de hoy carecen de presencia masculina que apoye el ejercicio económico en el hogar. Empero, las mujeres no cuentan con ningún tipo de garantía que les permita construir un proyecto de vida a la luz del acceso a la educación superior, a empleos dignos, bien remunerados y cuyas condiciones les ayude a mejorar su calidad de vida y por consiguiente, la de su familia, la cual se constituye principalmente por niños, niñas, adolescentes y personas mayores a cargo.

En otras palabras, las mujeres deben estar preparadas física y psicológicamente para acceder a cualquier tipo de empleo que les permita generar algún recurso para su hogar, pero al mismo tiempo, están obligadas a renunciar o solicitar permisos reiterativos cada vez que sea necesario atender a su hijo en condición de discapacidad, participar de los procesos de rehabilitación, asistir al sistema de salud para lograr la garantía del derecho y a su vez, ser parte de la formación personal de sus demás familiares, ya sean hijos o padres.

Es fundamental indicar que América Latina aún está en el proceso de reformulación de sus políticas laborales, por tanto, estas mujeres siguen estando expuestas a una vejez desprotegida y a una condición de exclusión social, toda vez que su salud desmejora, sus redes de apoyo sociales y familiares desaparecen, son más vulnerables a vivenciar situaciones de conflicto intrafamiliar, son víctimas de violencias y discriminación.

Es por ello que la relación entre Estado, Mercado y Familia debe transformarse y estar orientada a entrelazar nuevas y mejores formas de intervención en los diferentes ámbitos, mejorando la calidad de vida de las personas cuidadoras a través del acceso al empleo, a la 
educación superior, a programas de apoyo al cuidado; pero también de aquellas que presentan una dependencia, dado que son personas que por la discapacidad o limitación requieren de políticas públicas adecuadas a sus necesidades pero también que sean capaces de promover, la autonomía, la independencia y el diálogo de saberes. Ahora bien, validar el cuidado como un derecho universal implica para cada agente, asumir responsabilidades específicas, distribuir cargas y facilitar el ejercicio del cuidado como doble obligación en el derecho (tanto el que cuida como el que necesita ser cuidado).

Por todo lo anterior, el presente proyecto de investigación pretende realizar un acercamiento conceptual del actual Sistema de Protección Social - SPS- colombiano, en relación a las mujeres que se dedican al cuidado de niños con discapacidad, en la localidad de Bosa, ilustrando con ello, la relación que emerge entre el Estado, el Mercado y la Familia, así como la construcción progresiva de roles sociales y políticos de las mujeres cuidadoras, en respuesta a las condiciones de vulnerabilidad en las que ellas y sus familias se encuentran, además de la falta de garantías gubernamentales y las políticas sociales ineficaces.

\subsection{Conceptualización y funciones del Sistema de Protección Social}

Inicialmente, el Banco de Desarrollo Asiático (2001), como se citó en Guerrero (2006), indicó que un Sistema de Protección social es un

Conjunto de políticas y programas diseñados para reducir la pobreza y la vulnerabilidad, promoviendo la eficiencia de los mercados laborales, disminuyendo la exposición de las personas a riesgos y fortaleciendo su capacidad para protegerse de interrupciones o pérdidas de ingreso. (p. 21) 
Concibe a la Protección Social no desde una postura tradicional, sino desde la necesidad que tienen los Estados de formular y ejecutar políticas públicas, orientadas a mejorar la capacidad del mercado laboral y que genere a su vez procesos de mitigación al riesgo y al cambio de condiciones económicas.

El Banco Mundial (2001) como se citó en Guerrero (2006), por su parte, mencionó que un SPS puede entenderse como el "conjunto de intervenciones que buscan disminuir la vulnerabilidad de los individuos pobres, las familias o las comunidades, a través de un mejor manejo del riesgo" (p. 21). Aquí, el énfasis está en buscar alternativas sociales que les permitan a las personas en condición de pobreza darle, desde su responsabilidad, un mejor manejo a aquellas situaciones que representan un riesgo.

En tanto, Hagemejer, K. (s.f.) como se citó en Guerrero (2006) planteó al SPS como “todas aquellas intervenciones públicas o privadas que buscan mitigar (relieve) la carga de un conjunto de riesgos y necesidades de los hogares y de los individuos, sin que exista un acuerdo recíproco simultáneo o un acuerdo individual" (p. 21); es decir que la protección debe existir de manera transversal en todas las intervenciones que se generen al interior de los Estados.

Para el caso colombiano, la Ley 789 de 2002 definió el Sistema de Protección Social como “el conjunto de políticas públicas orientadas a disminuir la vulnerabilidad y a mejorar la calidad de vida de los colombianos, especialmente de los más desprotegidos" (Guerrero, 2006, p. 21). Es por ello que el SPS “debe crear las condiciones para que los trabajadores puedan asumir las nuevas formas de trabajo, organización, jornada laboral y simultáneamente 
se socialicen los riesgos que implican los cambios económicos y sociales" (Guerrero, 2006, p. 21).

Pese a tener características y elementos similares en las conceptualizaciones anteriores, para Ayala (2001) como se citó en Guerrero (2006), un Sistema de Protección social "responde por la formación de capital humano necesario para superar la pobreza, pero la acción Estatal no se debe agotar en ello" (p. 21). Se evidencia entonces, que para el autor no es responsabilidad de los Estados garantizar que sus políticas sociales, económicas y labores mejoren las condiciones de existencia de sus ciudadanos, sino que por el contrario, se deben promover algunas acciones en cuanto al acceso laboral, pero no debe haber un esfuerzo considerable en ello.

Así las cosas y luego de identificar posturas internacionales y nacionales frente al Sistema de Protección Social, Marcus. R (2004) como se citó en Guerrero (2006) hizo algunas claridades frente a los objetivos específicos a los que este debe responder:

1. En primera instancia, su enfoque debe ser "proteger a las personas de choques que los puedan llevar a la pobreza" (Guerrero, 2006, p. 21); es decir, articular esfuerzos para que la transición y los posibles cambios que se puedan generar en las políticas económicas, sociales y laborales no impacten negativamente a los ciudadanos y no se vean obligados a vivir en condiciones de extrema urgencia.

2. Por otro lado, su misionalidad está en "proteger a la gente contra la pobreza extrema y sus efectos sobre el bienestar", esto implica según Acosta, O y Ramírez, J (2004) como se citó en Guerrero (2006), "reducir la vulnerabilidad de los hogares con ingresos muy bajos ante caídas del consumo y garantizar su acceso a servicios básicos” (p. 21). Visibilizar, 
entonces, la existencia de comunidades en condiciones de extrema pobreza y asegurarse de construir todo un plan de intervención Estatal, que le permita a partir de las necesidades particulares de la población, otorgar garantías de disfrute a los servicios básicos.

3. Finalmente, el marco transversal de cualquier SPS debe ser "proteger el bienestar durante períodos de vulnerabilidad del ciclo de vida" (Guerrero, 2006, p. 21). Esta premisa es fundamental para comprender que la sociedad pasa toda clase de cambios, desde lo cultural, económico, político, comunitario y social, hasta cambios etarios, ambientales y biológicos. Por tanto, prevalecer las condiciones de bienestar y garantía de derechos desde la especificidad social promueve mejores prácticas, en cuanto al manejo y la prevención de situaciones de riesgo y amenaza que finalizan con el aumento de las tasas de pobreza y pobreza extrema.

En consecuencia de lo anterior, el Ministerio de Salud y Protección Social (2005) estableció también, las funciones específicas que tiene el Sistema de Protección Social dentro del contexto Estatal y que validan los objetivos descritos con antelación, a saber.

a. Generar estímulo al desarrollo de la "Salud" entre los ciudadanos, contemplándola desde una postura biopsicosocial y no meramente médica.

b. Involucrar a la sociedad dentro del diseño y planificación de las políticas públicas, teniendo en cuenta el conocimiento propio de las comunidades frente a sus contextos inmediatos. 
c. Garantizar la corresponsabilidad entre los sectores que conforman la sociedad, pues el Estado debe asignar también tareas específicas tanto al mercado, la familia y las comunidades.

d. Tener como línea de acción el modelo del Manejo Social de Riesgo.

Esto último, según Holzmann y Jorgensen (2003), obedece a la

Idea fundamental de que todas las personas, hogares y comunidades son vulnerables a múltiples riesgos de diferentes orígenes, ya sean estos naturales (como terremotos, inundaciones y enfermedades) o producidos por el hombre (como desempleo, deterioro ambiental y guerra). Estos eventos afectan a las personas, comunidades y regiones de una manera impredecible o no se pueden evitar, por ende, generan y profundizan la pobreza. (p. 4)

De igual modo, los autores plantearon dos premisas en cuanto al Manejo Social del Riesgo en los Sistemas de Protección Social, siendo uno de ellos, asistir a personas, hogares y comunidades a mejorar su manejo del riesgo y por otro lado, proporcionar apoyo a quienes se encuentran en la extrema pobreza. Es decir, el objetivo fundamental para los Estados es intentar combinar los instrumentos tradicionales del SPS bajo un esquema unificador, incluidas intervenciones en el mercado laboral, programas de seguro social y redes de protección social; abarcando acciones para mejorar los instrumentos de manejo del riesgo.

Lo interesante del modelo, según los autores, es presentar una red de protección para todos, pero al mismo tiempo ofrecer a las personas en condición de pobreza, la capacidad de salir de ella o al menos retomar un trabajo lucrativo que le permita al mercado recuperarse progresivamente de los diferentes choques sociales. Busca entonces, dejar de pensar que el 
Sistema de Protección Social es un costo para los Estados, convirtiéndose en un tipo de inversión que forma capital humano para la productividad dentro de este.

En conclusión, se podría afirmar que el Sistema de Protección Social está directamente relacionado con las responsabilidades que tiene el Estado de diseñar y ejecutar las políticas públicas dentro de los territorios, pensando entonces, en un enfoque integral, en donde cada una de las políticas ya sean económicas, mercantiles o de cualquier otra índole estén dirigidas a mejorar las condiciones de vida de los ciudadanos, y estén a su vez, enfocadas en las particularidades de los territorios y las comunidades. Tal como lo aseguró Artigas (2005), quien estableció que "la protección social no es solamente una cuestión de solidaridad o generosidad, sino una responsabilidad básica de los Estados” (p. 14). Cecchini, Filgueira, Martínez y Rossel (2015) consideraron lo siguiente:

Los Sistemas de Protección Social son una política fundamental para contribuir a la plena realización de los derechos económicos y sociales de la población, reconocidos en una serie de instrumentos legales nacionales e internacionales, como la Declaración Universal de Derechos Humanos de las Naciones Unidas, de 1948, y el Pacto Internacional de Derechos Económicos, Sociales y Culturales, de 1966. (p. 28)

Bajo la anterior premisa, América Latina ha entendido que los Sistemas de Protección Social dejaron de tener el carácter caritativo inicial y han pasado a ser un mecanismo fundamental en la planificación social, económica y política de las naciones. 


\subsection{El Estado y su injerencia en el Sistema de Protección Social}

Tener claridad frente al concepto de Estado permite identificar los elementos, la influencia y sus determinantes a la hora de hablar del SPS pues como ha de suponerse, existe una relación intrínseca que establece modelos propios de intervención entre la sociedad; no obstante, para los académicos sigue siendo un reto establecer una sola definición que abarque tanto los elementos que conforman este, como las relaciones internas que se generan entre sí (García, 1986).

A pesar de ello, existen aproximaciones conceptuales interesantes en la medida en que abordan un elemento clave (jurídico, Social y Político) como base de la estructura del Estado. Inicialmente entonces, se podría pensar el Estado como:

Una sociedad humana establecida en un territorio que le corresponde, estructurada y regida por un orden jurídico que es creado, definido y aplicado por un poder soberano para obtener el bien público temporal formando una institución con personalidad moral y jurídica. (Torrecilla, 2006, p. 25)

Es decir, el planteamiento relevante dentro de esta instancia, además del territorio y la ciudadanía, se centra en el orden jurídico establecido, toda vez que es el elemento que estructura su funcionamiento y le permite adquirir una forma específica en su actividad; en otras palabras, enmarca al Estado como sujeto de derechos y deberes pues lo considera como una persona jurídica.

Ahora bien, García (1986) también precisó que si bien el Estado es una sociedad territorial, jurídicamente organizada y con poder soberano, hace hincapié en que su objetivo fundamental es perseguir el bienestar general de los ciudadanos promoviendo, la satisfacción 
de las necesidades a través de una organización administrativa. Esto es asignar desde la conceptualización propia del término, las responsabilidades sociales que debe cumplir el Estado y los mecanismos pertinentes para lograrlo, que en este caso sería la organización administrativa, partiendo de la creación de instituciones de carácter oficial.

Por tal razón, hasta ahora se ha hablado de un concepto de Estado someramente integral en donde se reconoce la importancia de su accionar desde lo jurídico (regulador), en el plano de satisfacción de necesidades (derechos), y de acuerdo con Calduch (1991), "la conformación también, de un conjunto de instituciones, organizaciones y fuerzas sociales para una comunidad política que se desarrolla" (social). Así, conviene subrayar el otro elemento fundamental dentro de lo que podría definirse como Estado y es el carácter político pues, en su estructura surgen y se establecen relaciones de poder entre quienes gobiernan y quienes son gobernados, implicando la actuación de un poder público dentro de la sociedad que regula comportamientos y somete a unas reglas jurídicas definidas y de obligatorio cumplimiento.

Dicho de otro modo y teniendo en cuenta lo manifestado por Marx como se citó en Calduch (1991), el Estado constituye la máxima organización política de la sociedad, en donde se hacen valer intereses comunes y en donde las instituciones enmarcan su actuar de acuerdo con lo ordenado por este.

En consonancia con lo anterior, nació también la necesidad de pensar en las funciones del Estado, con el propósito de comprender cómo se integran los elementos ya descritos y con ello, cómo evidenciar a modo general sus intervenciones. Su tarea inicialmente consiste 
en formular normas de carácter colectivo que deben por supuesto dar consistencia al propio Estado y al mismo tiempo, reglamentar las interacciones permanentes entre el Estado y la sociedad; esto es la construcción de un ordenamiento jurídico capaz de regular y reglamentar la visión interna y externa de la sociedad. Además, en segunda instancia, está encaminada a desarrollar una labor administrativa que promueva la satisfacción de necesidades como se había mencionado, permitiendo así el progreso de la colectividad.

A modo de conclusión, se establece que las funciones básicas del Estado son de carácter jurídico, reglamentando las interacciones dadas entre unos y otros, y un carácter administrativo que establezca, los parámetros bajo los cuales se logra intervenir permanentemente en la sociedad. En definitiva, es la instancia en la cual los Estados reconocen cuáles son sus necesidades y en qué momento debe intervenir para mejorar las condiciones de vida de sus ciudadanos y de las actividades propias desarrollados por él.

\subsubsection{La intervención del Estado a través de las Políticas Públicas}

Comprender el carácter administrativo del Estado y su intervención en la sociedad implica aproximarse a una conceptualización de las políticas públicas, siendo estas la respuesta más utilizada por el mandato soberano frente a sus ciudadanos y la satisfacción plena de sus necesidades. Por ende, las políticas públicas se convierten en la materialización de los intereses del Estado, a partir de estrategias, mecanismos, programas y proyectos específicos dirigidos a mejorar las condiciones de vida de los ciudadanos, perfeccionar sus modelos económicos y posicionarse a nivel global.

Sobre ello, Torres-Melo y Santander (2013) argumentaron: 
[Que] la política pública es una construcción social que puede ser definida como una estrategia con la cual el Estado coordina y articula el comportamiento de los actores a través de un conjunto de sucesivas acciones intencionales, que representan además la toma concreta de decisiones en torno a uno o varios objetivos colectivos, considerados necesarios o deseables en la medida en que hacen frente a situaciones socialmente relevantes. (p. 56)

Es decir, se podría pensar que las políticas públicas como construcción social, no solamente pueden ser consideradas como herramientas de intervención del Estado hacia los ciudadanos, sino que por sus reestructuraciones permanentes, llegan a ser un mecanismo mediante el cual, el Estado mismo resignifica sus elementos de injerencia en la sociedad.

De igual manera, diversos autores citados por Olovarría (2007) señalaron que una política pública también "es un curso de acción (o inacción) que el Estado toma en respuesta a problemas sociales" (p. 16). Dicho de otra forma, las políticas públicas, por una parte, son adaptadas para recibir una serie de valores dentro de una escala determinada de prioridades, logrando con ello, la toma de decisiones. Por otra parte, se evidencia que la inacción del Estado también se enmarca dentro de las políticas públicas dirigidas a la satisfacción de necesidades y bienestar colectivo, mostrando de este modo, las carencias y dificultades del mismo para hacer frente a las responsabilidades sociales, políticas y económicas.

Por su parte, Jenkins (1978) como se citó en Olovarría (2007) aseveró, además, que "la mayoría de las políticas públicas involucran una serie de decisiones, algunas de las cuales pueden ser inadvertidas antes que deliberadas, pero acumulativamente, todas estas decisiones constituyen una política pública" (p. 16). En este caso, el autor reflejó la situación actual de 
las políticas públicas en la mayoría de los países en condiciones de pobreza y vulnerabilidad social, puesto que inicialmente se enfocan en intervenir en una problemática o situación claramente estudiada y focalizada pero que como resultado, se obtienen menores beneficios, otros aspectos por revisar o una política pública ineficiente en la medida en que abarca varios aspectos pero no los fundamentales para mejorar las condiciones de vida. Podría también pensarse, en un proceso en donde la planificación se vuelve el dilema más importante por resolver para los Estados.

Al igual que el concepto de Estado, Birkland (2005) como se citó en Olovarría (2007) estableció que no hay consenso entre los expertos respecto de una definición en cuanto a la política pública, sin embargo, constantemente se hacen esfuerzos para intentar describir los elementos centrales en esta. En ese orden de ideas, Olovarría (2007) consideró que dichos elementos están enfocados en lo siguiente:

- El actor privilegiado en ellas es el Estado.

- Involucran una decisión fundamental sobe hacer o no hacer algo.

- Tienen una finalidad pública: los destinatarios son los ciudadanos.

- Se activan a través de decisiones de autoridades investidas con poder público.

- Involucran un conjunto de decisiones interrelacionadas.

- Afectan - positiva o negativamente - intereses.

- Requieren instrumentos, definiciones institucionales, organizaciones y recursos para ser implementadas. (pp. 17-18)

De esa manera, logrando una aproximación conceptual frente a lo que se denomina política pública, es importante evidenciar las funciones que tiene el Estado en relación a ellas, 
sabiendo que como se ha dicho, las políticas públicas son las respuestas del Estado hacia las necesidades de sus ciudadanos.

En ese sentido, los autores Torres-Melo y Santander (2013) establecieron tres funciones principales del Estado, las cuales están relacionadas con Bienestar Social, Desarrollo Económico y Seguridad. A continuación se realiza una descripción de cada una de ellas:

El primer marco tiene que ver con Bienestar Social a través, primeramente, de la "Función de asignación, la cual busca asegurar la provisión de bienes y servicios sociales o la división entre bienes privados y sociales" (Torres-Melo \& Santander, 2013, p. 25). Con ello, el Estado intenta distribuir de manera efectiva los recursos que posee para dar garantía de derechos a los ciudadanos y cubrir todas las necesidades requeridas en los aspectos económicos, políticos y territoriales.

Igualmente, la Función de Distribución aparece afirmando la responsabilidad del Estado para distribuir con carácter equitativo y justo tanto la renta como la riqueza obtenida. Esta función es quizá para todos los Estados la más compleja de cumplir a cabalidad, en tanto, las desigualdades socioeconómicas y el acaparamiento de riquezas aparecen para poner a prueba el organismo supremo de las sociedades, pues los intereses particulares sobrepasan los colectivos (Torres-Melo \& Santander, 2013).

Por otra parte, la función subsidiaria en donde los autores ponen al Estado en un punto intermedio para administrar los equilibrios o desequilibrios que se presentan frente a la sociedad civil; aquí por supuesto, es donde se refleja la capacidad interna de un Estado para disponer acciones consecutivas encaminadas a mantener los equilibrios dentro de la sociedad 
pero también debe estar preparado para intervenir cuando existen fenómenos sociales, económicos, culturales y políticos que pongan en riesgo la calidad de vida de los ciudadanos.

En un segundo momento, los autores plantearon el Desarrollo Económico desde la Planeación y Promoción del Desarrollo, en donde el Estado se basa en un enfoque social siendo el responsable de dar cumplimiento a las demandas sociales en el marco del pluralismo, la cohesión y la igualdad de oportunidades. En este espacio se evidencia entonces, la importancia de la economía como generador principal de igualdad, equidad y garantía desde el enfoque de derechos (Torres-Melo \& Santander, 2013).

En ese mismo escenario, proponen a la Regulación como responsabilidad propia del Estado, sugiriendo ser permanentemente instrumento o mediador al servicio de clases sociales o grupos específicos, fundamentalmente aquellos que requieren especial protección por sus condiciones de vulnerabilidad y fragilidad social.

También, dentro del aspecto del Desarrollo Económico se le asigna la Función de Estabilidad, la cual consiste en garantizar desde el sector económico la permanencia de buena calidad de vida para los ciudadanos, mediante la utilización tanto de la política presupuestaria como de la estabilidad social a través de la resolución de conflictos (Torres-Melo \& Santander, 2013).

Finalizando, se encuentra la Función de Seguridad en donde se establecen dos premisas básicas para los Estados, por un lado, tiene que ver con evitar y garantizar que no existan opresiones militares de carácter legal e ilegal en sus territorios, coerción económica o presión política en sus decisiones, de forma que pueda seguir libremente su desarrollo o progreso; y por otro lado, garantizar la seguridad de las personas, tanto a nivel de propiedades, integridad 
y bienestar. Esta función es un reto permanente para las sociedades actuales, teniendo en cuenta que pese a la finalización de las guerras mundiales se presentan paulatinamente Estados con niveles de violencias, conflictos armados y guerras civiles que no solamente violentan los derechos humanos de los ciudadanos, sino que al mismo tiempo fragmentan al Estado en su soberanía y legitimidad.

\subsection{Mercado, Estado y Políticas públicas}

Este proyecto de investigación está interesado en identificar y describir cómo se desarrollan las interacciones sociales, en los escenarios en donde la formalidad no está presente, es decir, los sectores sociales en donde no cuentan con presencia efectiva del Estado, las políticas públicas son inoperantes y el mercado desigual y excluyente, encontrando un fenómenos social que se desarrolla principalmente en los países en vía de desarrollo, el cual se configura en la informalidad, un medio de empleo en donde las personas desde sus propios recursos económicos e intelectuales construyen una forma de percibir ingresos, sin tener acceso a las garantías laborales del Estado y regulación por parte del mismo.

Al implementar dichas actividades, la sociedad está más propensa a caer en la pobreza y desigualdad estando expuestas, también a la falta de acceso a bienes y servicios, aumento en enfermedades de carácter laboral, no aportes al sistema pensional, sobrecarga para el régimen de salud subsidiado y mayores oportunidades para desarrollar actividades de carácter ilegal o delincuencial. 
A pesar de lo anterior, sigue existiendo la falta de reconocimiento e intervención pública por parte de los Estados frente a lo que se denomina el trabajo informal, no obstante aparece un agravante, que se configura en el trabajo informal no remunerado y que se presenta principalmente en el ámbito privado o doméstico, entendiendo este como "la producción de bienes y servicios dentro del hogar, como resultado de la combinación del trabajo no remunerado y la adquisición de bienes duraderos y no duraderos" (OCDE como se citó en Baanante, s.f., p. 2).

Ahora bien, este trabajo informal no remunerado y desarrollado desde lo doméstico implica, como lo mencionó Baanante (s.f.):

Una tarea diaria dentro del espacio de la vivienda, en la cual, por medio del trabajo físico y en combinación con algunos bienes de capital, la persona encargada de los oficios de la casa realiza las actividades propias del hogar, esto es, aquellas necesarias para dar satisfacción a las necesidades de sus miembros, como alimento, vestido, descanso, entre otras, y así permitir el rendimiento de cada miembro de la unidad familiar fuera del hogar en sus respectivas tareas remuneradas. (p. 10)

Es así como dentro de las actividades propias del hogar aparece principalmente la labor del cuidado, entendiendo este como las actividades y medidas desarrolladas por una persona para satisfacer las necesidades de otras personas, durante todos los momentos del ciclo vital permitiendo con ello, la sostenibilidad de la vida (Izquierdo como se citó en Maravall, 2009).

Así mismo, la gestión y el mantenimiento cotidiano de la vida y de la salud que presenta, además una doble dimensión corporal y afectiva podría denominarse cuidado (Esecé \& Pérez como se citó en Maravall, 2009). Por ello, Lagarde (2003) refirió que el "cuidado es el 
conjunto de actividades y el uso de recursos para lograr que la vida de cada persona esté basada en la vigencia de los derechos humanos. Principalmente, el derecho a la vida" (p. 5).

Simultáneamente, Urra, Jana y García (2011) definieron el cuidado desde la enfermería y los cuidados médicos como "el trabajo profesional destinado a la satisfacción de necesidades humanas en el ámbito de la salud de un individuo, comunidad o población, como también integrativo y holístico, porque abarca los diferentes estratos de necesidades” (p. 18).

Es decir, estas labores de cuidado constituyen para el trabajo doméstico no solamente un trabajo reproductivo entendiéndolo "como el conjunto de tareas cotidianas de cuidado físico, intelectual y emocional de los miembros del grupo familiar así como su crianza" (Valenzuela \& Mora, 2009, p. 13), sino como el medio mediante el cual se constituyen nuevas fuerzas de trabajo para el mercado.

En ese orden, Bustos (2009) teorizó "históricamente se ha construido el lugar de la mujer circunscripto al ámbito de lo doméstico, reservando el espacio de lo público para los hombres en función de las jerarquías establecidas por la cultura patriarcal” (p. 3). De ahí que Bonder citado por el mismo autor concluyó en que la mujer finalmente es la más afectada en la dinámica entre el Estado, el Mercado y la Sociedad, ya que es educada en estas sociedades bajo la ética del cuidado.

En esta instancia se empieza entonces a hablar acerca del papel de las mujeres en relación al Estado, el Mercado y la Familia pero, desde un enfoque de género, siendo este la imposición social de unas funciones determinadas para ellas dentro del ámbito privado y público, tal como lo indicó la Fundación para la Promoción de la Mujer (1997) el género es 
un concepto de la tradición inglesa que se emplea para designar las diferencias y aprendizajes que hombres y mujeres asumen en la sociedad.

Por su parte, Ortega (2005) aseveró que "no se nace mujer: llega una a serlo" (p. 23), esta premisa supone pensar a hombres y mujeres desde el contexto del sexo y del género, explicando que "sexo podría definirse como aquello que expresa las diferencias biológicas, mientras que género incluye una serie de categorías socialmente construidas"(p. 23). La misma autora infirió que el hecho de nacer hombre o mujer ya provoca una clara especificidad que viene dada por la dimensión de género, considerándolo como un criterio básico para la organización social: reparto de responsabilidades familiares, laborales, roles, atributos psicológicos, actitudes internas, entre otras.

El género, además, no tiene unas características univocas en todas las sociedades existentes, puesto que los roles atribuidos a los hombres y mujeres dependen básicamente de su organización social, económica y cultural que al mismo tiempo esta mediado por los sistemas religiosos y jurídicos. Entiéndase Rol desde la sociología como "posición del individuo en la vida social común que condiciona una determinada conducta y que, por otra parte, despierta expectativas entre las partes sociales" (Fundación para la Promoción de la Mujer, 1997, p. 12). Quiere decir, una serie de funciones o papeles socialmente establecidos que reflejan una posición de las personas en el sistema social, económico, político y cultural en donde existen y se les asigna derechos, obligaciones, responsabilidades y poderes.

Frente a ello, Pérez y Bao (2011) definieron el rol de la siguiente forma.

El papel, función o representación que juega un a persona dentro de la sociedad, basado en un sistema de valores y costumbres, que determinan el tipo de actividades 
que ésta debe desarrollar. Triple rol: Como triple rol se entiende la participación femenina tanto en funciones productivas como reproductivas y de gestión comunal a la vez. (p. 44)

Asimismo, la Fundación para la Promoción de la Mujer (1997) establece que se aprende a ser varón y mujer en el transcurso de un proceso que comienza con el nacimiento, en el seno de la familia y que prosigue en las instituciones de la sociedad. Por lo tanto, lo masculino y lo femenino, lejos de ser pensados como un legado a priori de la naturaleza, deben ser interpretados como construcciones histórico-sociales.

Debido a lo anterior, se refleja el hecho de que las mujeres al ser definidas desde su "debilidad" y enfocadas desde niñas en la importancia y necesidad de ser protectoras, cuidadoras y responsables emocionalmente de los demás, sean las más afectadas por las construcciones económicas de producción y consumo, toda vez que se contempla aun, como una percepción de orden natural para el Estado y el Mercado.

Corroborando esto, se evidencia que "las tasas de actividades y de ocupación presentan en general en todos los Estados, diferencias bien claras entre hombres y mujeres, siendo siempre las más bajas las tasas femeninas" (Bustos, 2009, p. 4). Este mismo autor indicó que las estadísticas utilizadas por los Estados no dan cuenta del trabajo de las mujeres, puesto que tradicionalmente el concepto de trabajo ha estado asociado con el trabajo asalariado, excluyendo el trabajo doméstico y el trabajo de subsistencia no remunerado.

De ahí que las mujeres estén más presentes en el mercado de trabajo informal, donde las condiciones laborales son peores que en el formal y sus niveles de ingresos suelen ser menores que los de los hombres, de igual modo, es más difícil para las mujeres el acceso a la 
educación y a percibir los pagos salariales conforme a sus niveles educativos alcanzados (Rodríguez, como se citó en Bustos, 2009).

Es importante entender que la informalidad se presenta en la medida en que las mujeres por diferentes situaciones no cuentan con el apoyo económico y afectivo de un conyugue que pueda aportar a la satisfacción de las necesidades de las familias y por otro lado, las condiciones de pobreza y desigualdad social conllevan a que todos los integrantes de las familias incluyendo los niños, empiecen por desarrollar actividades productivas que les genere ingresos siendo estos adquiridos en la informalidad e inclusive en la mendicidad.

Para este proyecto de investigación es fundamental entender tal como lo señaló Terrero como se citó en Bustos (2009):

En la mayoría de los hogares principalmente de bajos ingresos, la mujer no solo incluye el trabajo reproductivo (responsabilidad de la maternidad y cuidado de los niños) necesario para garantizar el mantenimiento y reproducción de la fuerza laboral, sino también el trabajo productivo, generalmente en calidad de generadora secundaria de ingresos. Además, que las mujeres se involucran en trabajos de gestión comunal en contextos tanto urbanos como rurales. (p.4)

Sumado a ello, es relevante explicar cómo se desarrollan los tres roles descritos por el autor anterior, en el contexto de las mujeres cuidadoras de niños en condición de discapacidad entendiendo lo siguiente:

Las deficiencias, las limitaciones de la actividad y las restricciones de la participación. Las deficiencias son problemas que afectan a una estructura o función corporal; las 
limitaciones de la actividad son dificultades para ejecutar acciones o tareas, y las restricciones de la participación son problemas para participar en situaciones vitales. Por consiguiente, la discapacidad es un fenómeno complejo que refleja una interacción entre las características del organismo humano y las características de la sociedad en la que vive. (Hermida \& Borregón, 2010, p. 2)

Por otra parte, González (2008) conceptuó la discapacidad como "deficiencias físicas, mentales, intelectuales o sensoriales a largo plazo que, al interactuar con diversas barreras, puedan impedir su participación plena y efectiva en la sociedad, en igualdad de condiciones con las demás” (p. 533). En ese orden de ideas, Martínez (2013) consideró la discapacidad como "cualquier restricción o falta de capacidad para llevar a cabo una actividad en la forma, o dentro del rango, considerados adecuados para las personas que se estiman como normales o no discapacitadas" (p. 4).

Similarmente, la OMS como se citó en Ministerio de Salud y Protección Social (s.f.) estableció lo siguiente:

La discapacidad es el resultado de interacciones complejas entre las limitaciones funcionales (físicas, intelectuales o mentales) de la persona y del ambiente social y físico que representan las circunstancias en las que vive esa persona, es decir, deficiencias, limitaciones en la actividad y restricciones en la participación. (párr. 2)

Partiendo de lo abordado, Lagarde (2003) señaló que el cuidado de las personas varía de acuerdo al ciclo vital y a las características propias desde lo médico y lo cultural, considerando, señalando por tanto que las mujeres cuidadoras de personas en condiciones de discapacidad además de invertir sus mejores energías en dicha labor, y cumplir con el 
desarrollo de las otras funciones ya descritas, tienen que empezar por apropiarse de otros aspectos para intentar que las condiciones de bienestar de su persona a cargo mejoren, como podría llegar a ser el liderazgo y el empoderamiento.

Es por ello que se aborda el sujeto político como rol fundamental dentro de la Protección Social, desarrollado por las mujeres cuidadoras comprendiendo este de la siguiente forma:

Un hombre de convicciones, ideales, con capacidad reflexiva y critica, que posea el misterio del carisma, y sobre todo con un gran sentido de servicio social, en pro del bien común, encauzado en la construcción de ciudadanías y sociedades consientes y dueñas de sus propias realidades. (Fernández, 2009, p. 7)

Esta construcción reflexiva y crítica, de acuerdo con el mismo autor, se da en dos formas específicas que le permiten desarrollar al sujeto sus objetivos dentro de una comunidad y tienen que ver, por un lado con la tradición, la cual básicamente se ciñe en las creencias cotidianas que se han construido a lo largo del tiempo por un grupo mínimo de personas que comparten parentescos y que de alguna manera adquieren autoridad y poder, lo que lleva por ejemplo, a las mismas familias a ocupar altos cargos en el gobierno por un tiempo indeterminado, muestran también para la sociedad respeto y admiración por las políticas infundadas.

En otra instancia, se encuentra el carisma que tiene que ver más con las construcciones sociales comunitarias, en donde no existe preferencia de un solo grupo de personas, sino que por el contrario es la manifestación individual en la cual se muestran siempre atentos a apoyar en caso de necesidades, se ven permanentemente dispuestos a cooperar en medio de dificultades y evidencia siempre en su actuar valores de legalidad, justicia, respeto y 
honradez. Por otra parte, es en esencia la presencia de esas cualidades personales que reflejan interés, liderazgo positivo y propositividad.

Si bien existen estos factores dentro de la construcción y desarrollo de un sujeto político, Samaddar (2014) puntualizó en unos aspectos fundamentales tanto para la creación del sujeto en su función política como en el desarrollo activo de este. En primer lugar, refirió que "hay una función crítica implicada en la disposición para hacer política -“desaprender” el estado presente del conocimiento (académico, sentimental, teológico, espiritual, económico, etcétera) y prepararse para hacer política aprendiendo nuevas cuestiones sobre la sociedad y sus relaciones de poder-" (p. 15).

Es decir, tener la disposición de comprender otras realidades personales, familiares y comunitarias, es estar al mismo tiempo dispuesto a escuchar y analizar otras posturas que pueden aportar a los conocimientos ya adquiridos por el sujeto político. En un segundo plano:

El conocimiento tiene, por lo tanto, una función de lucha. La práctica de la política se concibe, así como una guerra en marcha. Los individuos deben tener los instrumentos políticos requeridos, que les permitirán pelear a lo largo de la vida. Así, el ejercicio y el aprendizaje de la política se vuelven importante como actividad humana. La pedagogía política se torna indispensable. (p. 15)

En este caso en particular, es lo que el proyecto de investigación pretende explicar, en la medida en que como ya a lo largo de este capítulo se ha descrito, existen una serie de condiciones de vulnerabilidad y desigualdad social que particularmente no le permitirían a las mujeres cuidadoras de niños con discapacidad reconocer y aplicar nuevos conocimientos 
de carácter jurídico- políticos. No obstante, en la realidad de este grupo de mujeres lo que se observa es que el aprendizaje de la política y de lo jurídico se ha convertido en el objetivo principal para ellas en aras de mejorar las condiciones de vida de sus hijos.

En tercer lugar, "el sujeto político no emerge de técnicas existentes del ejercicio del poder, particularmente técnicas legales, sino más bien de la resistencia contra dichas técnicas. El Príncipe no es un sujeto político. Es un gobernante" (Samaddar, 2014, p. 15). Este aspecto es importante porque ilustra, al sujeto político desde una perspectiva de resistencia a través de un análisis integral de las situaciones y el planteamiento de opciones con mejores condiciones de justicia, equidad e igualdad.

Seguidamente, como cuarta instancia:

Un conjunto de prácticas se vuelve significativo en la configuración del sujeto político. La innovación de un nuevo grupo de prácticas indica la emergencia de un nuevo sujeto en política que deviene así su nuevo autor. Estas prácticas son tanto discursivas como institucionales. (Samaddar, 2014, p. 15)

Finalmente, "estas prácticas son esencialmente colectivas, esto es, relacionales (conflictivas, por un lado, dialógicas por otro), y debido a esto, la emergencia del sujeto político es solo posible de forma colectiva" (Samaddar, 2014, p. 15).

Como se puede evidenciar en los capítulos siguientes, la colectividad es tan significativa como las intervenciones propias del Estado a través de su institucionalidad, surgen nuevas propuestas de articulación y trabajo grupal que logran ahondar en nuevos escenarios de discusión y aprendizaje. 


\section{Función del Mercado en el Sistema de Protección Social}

Avanzando en la conceptualización de las esferas principales de los Estados, se aborda la definición de Mercado, pensándolo como escenario fundamental para la construcción y el funcionamiento de este, la planificación de las políticas públicas y la viabilidad del quehacer del Sistema de Protección Social. Teniendo en cuenta esto, se puede decir que el Mercado es una institución social mediante la cual se entabla una relación comercial.

Puntualmente para los Estados, es el mecanismo mediante el cual se logra obtener los recursos económicos propios para la sostenibilidad del territorio, pero además es el medio mediante el cual los Estados entre sí establecen relaciones de poder, dominio y estructuran la forma en la que la sociedad debe establecerse.

Lo anterior fue expuesto por Guerrero (2006), quien manifestó que hablar del mercado laboral es hablar de la principal fuente de ingresos de las personas, "la composición y la dinámica del mercado de trabajo determinan los grupos objetivo que deben ser atendidos por los diferentes componentes del sistema de la protección social” (p. 14). Aunque el mercado en su forma laboral es la principal fuente de ingresos para las personas y finalmente para el Estado, se convierte aun en un reto, pues la vinculación de los ciudadanos a escenarios laborales dignos en donde las empresas ya sean públicas o privadas estén dispuestas a cumplir con los mandatos legales, pero además, a brindar condiciones estables y apropiadas para el mejoramiento de la calidad de vida de las personas, es casi imposible. 


\section{CAPÍTULO II. MARCO JURÍDICO}

\section{EL CUIDADO COMO DERECHO FUNDAMENTAL}

Pese a que el cuidado empezó a ser tema de discusión pública en Europa en los años setenta, a través de movimientos feministas liberales, los cuales exigieron el reconocimiento social del cuidado doméstico como parte fundamental de la existencia humana y promulgaban la desigualdad desenfrenada entre hombres y mujeres, frente al rol en lo que se denominó el ámbito privado. En América Latina, es hasta inicios del presente siglo a través de los consensos Regionales, en donde progresivamente se han establecido acuerdos en las agendas públicas, enfocados en lograr la equidad de género, la erradicación de toda práctica discriminatoria, la exclusión social y la dignificación del cuidado.

Es por ello que el presente capitulo pretende describir esas aproximaciones jurídicas y los avances hasta hoy implementados por el Estado colombiano, en su reto por reconocer el ejercicio del cuidado como principio fundamental de la economía nacional y la necesidad de reestructurar el Sistema de Protección Social, a la luz de los cambios demográficos y las asimetrías familiares y de género que aún persisten en la sociedad.

\subsection{Contexto Internacional}

América Latina dio inicio a este proceso de reconocimiento del cuidado a partir de del Consenso de Quito desarrollado en el año 2007, en donde se establecieron por primera vez deliberaciones entre los países miembros, dirigidos a la dignificación del cuidado y la distribución de responsabilidades de los diferentes actores en ello. Estas reflexiones se 
concentraron principalmente en tres aspectos. Por un lado, verificar la corresponsabilidad existente entre los hombres y las mujeres, en la realización compartida de las actividades domésticas y familiares así como, empezar por adoptar estrategias y medidas legislativas e institucionales que les permitiese a las mujeres participar en la esfera política en condiciones igualitarias y reconocer que ese trabajo no remunerado aporta significativamente al bienestar de las familias y finalmente, al desarrollo económico de los países.

En segunda instancia, se destaca la preocupación por la crisis que a traviesan los Sistemas de Protección Social en la región, toda vez que se requiere pensar los Sistemas Públicos desde la integralidad para el acceso oportuno a la seguridad social y la garantía de coberturas universales, en donde las políticas públicas sean capaces de equilibrar responsabilidades entre hombres y mujeres supere los estereotipos de género culturalmente establecidos e iguale las condiciones y los derechos laborales del trabajo doméstico al de los demás trabajos remunerados, erradicando entonces, cualquier forma de explotación y desigualdad social.

Finalmente, se promueve la urgencia de establecer instrumentos de medición constante del trabajo no remunerado que realizan tanto las mujeres como los hombres, reconociendo su valor e incorporando sus resultados al sistema de cuentas nacionales, generando con ello un compromiso Estatal en "la reproducción social, el cuidado y el bienestar de la población como objetivo fundamental de la economía y una responsabilidad pública indelegable” (Consejo Nacional para la Igualdad de Género [CNIG], 2016, p. 19).

Surge entonces un segundo encuentro regional, en el cual los Estados miembros retoman en el Consenso de Brasilia realizado en el año 2010, las reflexiones ya establecidas y dispone de nuevos apartados, esta vez convocando a las naciones a encaminar sus esfuerzos 
presupuestales, jurídicos y administrativos ahora, promoviendo y reconociendo el cuidado como un Derecho.

Teniendo en cuenta esto, se exige promover autonomías económicas y financieras para las mujeres que ejercen dicha labor, desde la asistencia técnica garantizada y el fomento de capacidades empresariales, asociativas y comunitarias con seguridad presupuestal. Igualmente, se hace un llamado a incrementar la inversión en seguridad social, con el propósito de cubrir integralmente las necesidades que enfrentan las mujeres cuidadoras, y que están íntimamente relacionadas con situaciones de enfermedad, discapacidad, desempleo y responsabilidad con la infancia y la vejez.

Como último espacio Regional, los Estados de América Latina y el Caribe participaron en la Duodécima Conferencia Regional sobre la Mujer, la cual se denominó Consenso de Santo Domingo, desarrollado en el año 2013, cuya finalidad fue reflexionar sobre los avances en la implementación de los acuerdos ya establecidos e incorporar nuevos elementos como marco del reconocimiento al Cuidado, los cuales se enfocan en la formación profesional de las mujeres y su participación en la investigación y la producción de conocimiento, así como el reconocimiento a la diversidad cultural que es propia de América Latina.

Lo anterior, dado a que las mujeres cuidadoras de la Región presentan condiciones específicas de vida, derivadas de los entornos urbanos y rurales, así como la pertenencia a grupos étnicos (indígenas y afrodescendientes). Así mismo, los ponentes determinaron que los Estados también deben implementar acciones de regulación y supervisión, capaces de visibilizar el impacto de las nuevas estrategias en la calidad de vida de las mujeres, pero 
también es fundamental contar con la capacidad jurídica que proteja sus derechos ante las prácticas laborales universales y no convencionales como por ejemplo, los teletrabajos.

Ahora bien, a pesar de los avances regionales anteriormente descritos, definir el cuidado implica para los Estados una disyuntiva permanente, puesto que se debate frecuentemente entre elementos de justicia social, inversión social y obligación familiar, lo cual permite que cada uno de ellos dentro de su soberanía determine el cauce de sus políticas sociales y el impacto de las mismas a largo plazo. Por otro lado, si se sigue concibiendo al cuidado como una obligación netamente familiar, el Estado seguirá asumiendo un rol subsidiario especialmente con las personas menos favorecidas, pero esto implica que las brechas de pobreza y exclusión sigan creciendo.

\subsection{Contexto Nacional}

Para ilustrar las voluntades sociopolíticas que debe enfrentar el país frente al tema del Cuidado y el cumplimiento de los acuerdos regionales, es fundamental empezar por comprender los cambios y las trasformaciones sociodemográficas por los que atraviesa la población colombiana. En primer lugar, Fedesarrollo y la Fundación Saldarriaga (2015) indicaron que Colombia cuenta con cinco millones de personas que están transitando de la etapa del envejecimiento a la vejez, lo cual evidencia un fenómeno social particularmente

creciente y pone en la mesa pública los logros y las dificultades del Sistema de Protección Social.

De la misma forma, el Departamento Administrativo Nacional de Estadística [DANE] (2010) aseguró que 858 mil personas presentan algún tipo de discapacidad y de acuerdo al Fondo de las Naciones Unidas para la Infancia [UNICEF] (2015), hay 15 millones de niños, 
niñas y adolescentes que requieren de una persona como mínimo, que ejerza el cuidado y brinde herramientas de desarrollo y protección. Por tanto, se estima que en el país alrededor de veintiún millones de personas están expuestas a asumir el rol de cuidador. Esto representa que más de la mitad de la población Colombiana está o estará ejerciendo el cuidado no remunerado como actividad principal, es decir, no es un asunto menor de Estado y por tanto, se deben tomar medidas urgentes para garantizarles a estas personas una calidad de vida digna y lejana de todo acto de desigualdad, discriminación y exclusión social.

A continuación, se describen las ponencias legislativas promulgadas por la Nación cuyo objetivo se centra en bridar herramientas de protección a las personas que se dedican al cuidado como actividad no remunerada.

Como primera iniciativa, se encuentra el Proyecto de Ley 033 de 2009, el cual se destaca por ser la única propuesta del Senado de la República de Colombia, en cuanto al reconocimiento y exaltación de las personas que ejercen el cuidado familiar para individuos en estado de dependencia. Su ponente es la senadora Yolanda Pinto Afanador del Partido Liberal, quien en el año 2009 recopiló la deuda que tiene el Estado frente a la labor desempeñada por mujeres y hombres, quienes se enfrentan diariamente a condiciones de exclusión y desigualdad social.

En dicha ponencia, la autora propuso asignar la figura jurídica al cuidador familiar en casa, refiriéndose a personas que están a cargo de familiares que por su condición de discapacidad dependen de ellos para realizar las actividades esenciales de la vida diaria, con cuatro propósitos particulares:

a. Obtener beneficios pensionales a través del fondo de solidaridad pensional en la subcuenta de solidaridad, pues son personas que presentan dificultades permanentes para 
vincularse laboralmente y por ende, para iniciar o continuar con las cotizaciones correspondientes al sistema.

b. Acceder prioritariamente a todos aquellos planes de primera necesidad como alimentación, vivienda y educación.

c. Recibir por parte del Sistema de Salud apoyo a nivel instrumental, emocional y social que le permita al cuidador y a la persona dependiente enfrentar con mayores habilidades su realidad.

d. Ser capacitado y certificado en técnicas de cuidado, primeros auxilios y manejo de medicamentos.

Para lograr estos cuatro objetivos, la senadora proponía que fueran las Secretarías de Salud de cada ciudad, municipio y departamento quienes estuvieran en la obligación de implementar un registro de identificación, en el cual se pudieran establecer cuántos cuidadores son y en dónde se encuentran en aras de establecer los beneficiarios de la presente ley.

Sin embargo, la iniciativa fue archivada ya que el Ministerio de Hacienda y Crédito Público emite un concepto técnico y jurídico, en donde determina su inviabilidad presupuestal, teniendo en cuenta que existe afectación de la Subcuenta de Solidaridad del Fosyga por recursos que ascienden a $\$ 1.16$ billones anuales.

En segunda instancia, se encuentra la Ley 1413 de 2010 promovida por el Senado de la República, la cual obedece a uno de los acuerdos regionales y regula en Colombia la inclusión de la economía del cuidado en el sistema de cuentas nacionales, su objetivo es "medir la contribución de la mujer al desarrollo económico y social del país y al mismo tiempo, ser la 
herramienta base para la definición e implementación de políticas públicas” (Ley 1413, 2010, Art. 1).

Su intención es incluir la economía del cuidado en la técnica estadística que utiliza el país, a través del Departamento Administrativo Nacional de Estadísticas - DANE -, para conocer una representación cuantificada de esa contribución al desarrollo económico y social. De igual manera, se reconoce por primera vez en Colombia, las tareas que culturalmente fueron adscritas al hogar.

En ese mismo orden de ideas, el "Departamento Administrativo Nacional de Estadística DANE- es la autoridad responsable de coordinar el cumplimiento de lo dispuesto en la presente ley" (Ley 1413, 2010, Art. 4), es quien debe establecer los mecanismos y realizar las gestiones necesarias para planear, diseñar, aplicar y actualizar una Encuesta de Uso del Tiempo.

[En cuanto al] Seguimiento, Vigilancia y Control, la Consejería Presidencial para la Equidad de Género tiene la función de coordinar una mesa de trabajo con la participación de los entes de control, la academia y las organizaciones sociales con el objeto de hacer seguimiento y contribuir al proceso de implementación de la Encuesta de Uso de Tiempo. (Ley 1413, 2010, Art. 6)

Para finalizar, se encuentra el Decreto 2490 de 2013, mediante el cual se reglamenta en Colombia la Ley 1413 y se crea además, la Comisión Intersectorial, cuyo objeto es definir la forma de inclusión de información sobre trabajo de hogar no remunerado en el Sistema de Cuentas Nacionales. Su función principal está enmarcada en la emisión "de conceptos vinculantes y recomendaciones sobre los requerimientos de estadística básica necesarios para la actualización continua de la cuenta satélite de trabajo no remunerado" (Decreto 2490, 2013, Art. 4 numeral 2). Por otro lado, sus integrantes corresponden al:

Ministro de Salud y Protección Social, el Ministro de Trabajo, el director del Departamento Nacional de Planeación, el director del Departamento Administrativo 
de la Presidencia de la República, el Director del DANE quien la preside y el director del Departamento Administrativo para la Prosperidad Social. (Decreto 2490, 2013, Art. 3)

Para el año 2016 y luego de comenzar con el proceso, la comisión logra adoptar otros conceptos fundamentales en el ejercicio del cuidado que actualizan, amplían y profundizan la base teórica de la Economía del Cuidado en Colombia (economía del cuidado, cuidado, cuidado directo e indirecto, servicios de cuidado, trabajo de cuidado y cuidado no remunerado, trabajo doméstico, persona que cuida y persona sujeto de cuidado).

Su relevancia radica, por un lado, en el reconocimiento de todos los roles que se derivan del cuidado y en segunda instancia, porque su construcción conceptual tiene una base significativa de:

La Organización Internacional del Trabajo (OIT), la Comisión Económica para América Latina y el Caribe (CEPAL) y expertas internacionales que han sido consultoras en el tema de Economía del cuidado para Colombia como Valeria Esquivel, Soledad Salvador y Karina Batthyány. (DANE, 2016, p. 7)

\subsection{Contexto Distrital}

Resulta pertinente mencionar que Bogotá, al ser la capital del país, presenta una transformación poblacional más rápida y con ello, el reto administrativo y político está en encaminar las acciones gubernamentales en pro de atender de manera efectiva y oportuna las diversas necesidades de su población y articular esfuerzos para albergar en condiciones dignas a sus nuevos ocupantes.

En ese escenario, la ciudad ha realizado cambios progresivos en los Planes de Desarrollo Distrital para fortalecer sus proyectos y programas, e intentar dar solución efectiva a las problemáticas sociales especialmente, la discapacidad y el cuidado tal y como se evidencia en las siguientes ponencias: 
El avance legislativo más importante para los Bogotanos tiene que ver con el Decreto 470 de 2007, mediante el cual se adopta la Política Pública Distrital de Discapacidad - PPDD, en donde intiman a las administraciones venideras a promover de manera permanente la inclusión social, desde el reconocimiento y la garantía de los derechos de las personas con discapacidad y sus familias. Su marco conceptual se construye a partir de la mirada integradora y holística del ser humano, permitiéndole a la población vivir en condiciones de dignidad desde todas las dimensiones así como, una vida libre de violencias y discriminaciones. Para ello, el mandato plantea cuatro propósitos esenciales, entre los que se encuentran:

Inicialmente, el desarrollo de programas de protección económica que permitan la generación de apoyos para personas con discapacidad y/o sus familias, así como facilitar la creación de tarifas diferenciales o acciones afirmativas económicas en el transporte y:

Formular e incentivar [...] programas que promuevan la inclusión laboral de las personas con discapacidad, por medio de la regulación normativa que comprometa a la empresa privada y pública desde la perspectiva de responsabilidad social, para favorecer la vinculación de esta población. (Decreto 470, 2007, Art. 12 literal c)

En segundo lugar, implementar planes y programas integrales de empleo que garanticen la inclusión laboral de las familias de las personas con discapacidad. Como tercer aspecto se encuentra la necesidad de impulsar y reglamentar todo tipo de "acuerdos, normas y leyes relacionadas con la garantía de un salario o pensión para aquellas personas que por presentar una discapacidad severa o múltiple no pueden desarrollar alguna actividad productiva" (Decreto 470, 2007, Art. 12 literal r). 
[Finalmente] propiciar y fomentar la creación de redes de apoyo institucionales y sociales por medio de la creación de organizaciones, empresas productivas, talleres protegidos, cooperativas y asociaciones de personas con discapacidad que busquen nuevas alternativas de producción de bienes y servicios, acordes a las necesidades del país [...]. (Decreto 470, 2007, Art. 12 literal t)

Ahora bien, existe un reconocimiento fundamental en la presente disposición y está relacionado con el rol de la familia, las cuidadoras y cuidadores en el diario vivir y el bienestar de las personas con discapacidad, pues en general son estos actores los que disputan el cumplimiento de la norma y enfrentan las condiciones de exclusión social, económica, cultural y política.

Por tanto, supone dos ejes transversales, por un lado, la urgencia que tiene el Distrito de establecer estrategias que promuevan la condición de Bienestar en toda la familia, garantizando la preservación del mínimo vital y la provisión de seguridad social. Por otro lado, la promulgación del enfoque de Ciudadanía, en donde reconoce la autonomía de las personas con discapacidad, sus familias, cuidadoras y cuidadores, al mismo tiempo que sus derechos políticos, civiles, económicos y sociales.

Por último, suscita la participación como un derecho fundamental y expresión de ciudadanía, en donde las personas con discapacidad, sus familias, cuidadoras, cuidadores y diferentes actores sociales y políticos interactúan permanentemente, en pro de la trasformación social y la búsqueda de una ciudad incluyente y corresponsable con el bienestar de la población.

En ese sentido, el Consejo de Bogotá a través del Acuerdo 505 de 2012 estableció el Sistema Distrital de Atención Integral de Personas en condición de discapacidad en el Distrito 
Capital, una de la disposiciones con mayor receptividad por parte de la ciudadanía, cuyo objetivo está dirigido a aunar esfuerzos y recursos en el Distrito, que permitan aumentar la cobertura, descentralizar y organizar la oferta de programas y servicios institucionales e igualmente, promover la participación activa de las personas con discapacidad, sus familias, sus cuidadoras y cuidadores.

Cabe señalar que las instancias del Sistema Distrital de Discapacidad en el Distrito Capital, según el Acuerdo, corresponden al Consejo Distrital de Discapacidad y al Consejo Local de Discapacidad, quienes están liderando el proceso de articulación de la Política Pública entre la institucionalidad y la comunidad. Su carácter obedece a la "instancia consultiva, asesora y gestora, direccionada a la coordinación, planificación, concertación, adopción y evaluación de políticas, planes, programas y proyectos relacionados con la discapacidad en el Distrito Capital” (Acuerdo 505, 2012, Art. 4).

Aunque su objetivo es participar y asesorar el proceso para la formulación, implementación, seguimiento y evaluación de la Política Pública Distrital de Discapacidad debe "propender porque se respeten y difundan los derechos y deberes de las personas con discapacidad, sus familias, sus cuidadoras y cuidadores, teniendo en cuenta su condición de género, clase social, ciclo vital, diversidad poblacional u orientación sexual" (Acuerdo 505, 2012, Art. 6 numeral 11).

En ese orden de ideas, el Acuerdo 505 además de respaldar el proceso de gestión y construcción de la Política Pública Distrital para Personas con Discapacidad, ha permitido la participación formal en los diferentes escenarios de discusión política de las familias, cuidadoras y cuidadores, lo cual es fundamental para el ejercicio que se desarrolla en tanto, 
son estos últimos quienes deben velar continuamente por la garantía de derechos de las personas con discapacidad y su acceso a los diferentes bienes y servicios del Estado.

En conclusión, esta iniciativa ha facultado a las cuidadoras y cuidadores para que sean representantes no solo de la discapacidad que presenta su familiar o conocido, sino de la realidad social, familiar y económica que deben enfrentar junto con ellos en la cotidianidad. Es decir, le permite al Consejo ya sea Distrital o Local tener una perspectiva holística de la discapacidad.

Finalmente y como avance legislativo, en el año 2015, el Consejo Distrital promovió el Proyecto de Acuerdo 253 de 2015, cuyo propósito según sus ponentes era reconocer la labor que realizan los cuidadores y las familias de las personas con discapacidad, en la construcción de mejores formas de vida para sus familiares y las circunstancias permanentes de discriminación y desigualdad social a la que se ven enfrentados. Dicho reconocimiento está enfocado en la construcción de un protocolo de atención, que le permita a las distintas entidades atender de manera integral las necesidades de los (las) cuidadores(as) de personas con discapacidad, no solo desde el enfoque psicosocial sino asumiendo el cuidado desde el derecho a la protección y bienestar de dicha población.

Así mismo, busca visibilizar a las personas cuidadoras a través de una caracterización sociofamiliar y económica de carácter formal y estandarizado, la cual le permita a la ciudad conocer la ubicación exacta de esta población, sus necesidades laborales, la cuantificación y valoración de la labor del cuidado, así como un proceso de transformación de imaginarios sociales y culturales en donde existan redistribuciones de los roles en la familia. Este instrumento de caracterización estaría a cargo de las Secretarías de Salud e Integración social, las cuales tendrían la obligación de identificar también las habilidades, capacidades y 
competencias de las cuidadoras y cuidadores; generar un programa de atención psicosocial e implementar una Ruta Distrital de Atención Integral para las cuidadoras y cuidadores de las personas con discapacidad que les posibilite el acceso oportuno a sus derechos y la participación en los diferentes escenarios institucionales. Sin embargo, fue una propuesta que no tuvo la voluntad política requerida para entrar en funcionamiento y mejorar la calidad de vida de las personas cuidadoras. 


\section{MARCO METODOLÓGICO}

\subsection{Objetivo general}

Determinar el rol social y político en el Sistema de Protección Social de mujeres cuidadoras de niños con discapacidad localidad de Bosa, Bogotá D.C., Colombia, 2016, en el contexto de la pobreza, inequidad y discriminación de género.

\subsection{Objetivos específicos}

I. Caracterizar las condiciones sociales, políticas, económicas, familiares, comunitarias e institucionales de las mujeres cuidadoras de niños con discapacidad de la localidad de Bosa.

II. Identificar y describir los roles sociales y políticos desarrollados por las mujeres cuidadoras de niños con discapacidad en el contexto de la institucionalidad local.

III. Explicar el proceso de construcción de los roles políticos y sociales ejercidos por las mujeres cuidadoras de NNA en condición de discapacidad en la localidad de Bosa en el contexto de la pobreza, inequidad y discriminación de género.

El presente proyecto se plantea como un estudio investigativo mixto o combinado, el cual se ha convertido para la investigación social en una necesidad a priori, en la medida en que abordar los fenómenos socioculturales y las diferentes problemáticas implica pensar más allá de un estudio investigativo clásico (cualitativo - cuantitativo), puesto que “ representa el más alto grado de integración o combinación entre ellos, agrega complejidad al diseño de estudio 
y contempla todas las ventajas de cada enfoque” (Hernández, Fernández, \& Baptista, 2003, p. 12); igualmente, es importante mencionar que cada paradigma en su concepción carece de elementos propios que no permite responder desde una visión integradora, suficiente y holística a la necesidad evidenciada.

Ahora, los estudios investigativos clásicos privan de un componente fundamental al investigador, como lo es la complementariedad tanto a la hora de determinar el diseño investigativo como al momento de obtener la información, análisis y construcción de una visión intersubjetiva, que facilite la comprensión de la realidad y permita descubrir los matices intrínsecos en la misma (Hernández, Fernández, \& Baptista, 2014)

En concordancia con lo anterior, los mismos autores señalaron bondades importantes a la hora de implementar un diseño mixto dado a que están relacionadas con lo siguiente.

a. Una perspectiva de la realidad mucho más amplia y profunda: es la oportunidad de analizar y comprender las vivencias sociales desde los números, variables, graficas, funciones y modelos analíticos así como desde las narrativas, las experiencias y los símbolos.

b. Creatividad y versatilidad en cuanto a la implementación de técnicas e instrumentos: logra vincular y entrelazar diferentes técnicas e instrumentos, a partir de la necesidad del investigador y de la accesibilidad a los sujetos y entornos involucrados, es una oportunidad para tener mayor intromisión en todos los aspectos que influyen en las dinámicas sociales. 
c. Mayor calidad del dato: evidencian una "fotografía" más compacta de la realidad de los sujetos de investigación, en la medida en que cada resultado es evaluado desde la complementariedad y rigurosidad.

\section{d. Mayor solidez y rigurosidad tanto en la obtención de información como en el}

análisis: es una oportunidad que tiene el investigador para abstraer de cada método un resultado que evidencia transparencia en el proceso de la investigación y le da una base científica dado a que cuenta con múltiples elementos de sustentación, claridad y consolidación.

Teniendo en cuenta estas características, la presente investigación intenta acoger cada uno sus elementos y responder de manera trasversal a las exigencias establecidas, por tanto, el estudio se basa inicialmente en el método mixto, el cual Johnson y Onwuegbuzie como se citó en Pereira (2011) definieron como la existencia de fases de trabajo establecidas, en donde el investigador tiene la potestad de aplicar el método cuantitativo en una fase de la investigación y el cualitativo en otra, tomando en cuenta tanto los objetivos planteados como la necesidad identificada.

En un segundo momento, se eligió el estatus dominante Secuencial Cuan $\rightarrow$ CUAL, dado que el proceso de ejecución se realizó de manera ordenada y consecutiva, utilizando el método secundario después de lograr la recolección de los datos primarios, es decir, luego de la aplicación de la encuesta. Empero, el método cualitativo fue priorizado tanto para el diseño como para el análisis de la información obtenida.

El proyecto, además, se enmarca en el tipo de investigación explicativa, la cual facilitó la integración de los datos obtenidos (tanto cuantitativos como cualitativos), generando el 
cumplimiento del propósito principal de evidenciar la condición de vida actual de las mujeres cuidadoras de niños con discapacidad, el proceso de construcción del sujeto sociopolítico y la incidencia del Sistema de Protección Social, desde las experiencias particulares, la concepción grupal y la demostración de situaciones internas y externas en la dinámica del fenómeno social.

Vale destacar que su base teórica obedece al paradigma interpretativo con carácter cualitativo, el cual, según Curtis citado por Ricoy (2006) "profundiza en los diferentes motivos de los hechos, no busca la generalización en los resultados, toda vez que la realidad es dinámica e interactiva y tienen en cuenta el comportamiento de los otros actuando consecuentemente desde una perspectiva holística” (p. 16); de igual manera afirmó:

El sujeto es un individuo comunicativo que comparte significados entre ellos (incluido el investigador) por lo cual, se establece una comunicación bidireccional pero, son los propios individuos los encargados de construir acciones interpretando y valorando la realidad en su conjunto de modo analítico-descriptivo. (p. 16)

De otro lado, Ricoy (2006) concluyó que "las investigaciones que comparten la doctrina del paradigma interpretativo están ligadas fundamentalmente a un escenario educativo concreto, contribuyendo también, a comprender, conocer y actuar frente a otras situaciones" (p. 17). Hay que mencionar, además, otros planteamientos que refuerzan el valor científico del paradigma entre los que se encuentran:

Cabe resaltar la postura de Monje (2011), quien aseguró que el enfoque cualitativo parte del supuesto que los actores sociales no son únicamente objetos de estudio como si fueran cosas herméticas, sino que por el contrario, tienen la capacidad de reflexionar sobre su situación, hablar de ella desde sus vivencias y tomar decisiones como seres libres y 
autónomos. Este enfoque interpreta desde los significados y da prioridad a la comprensión de los fenómenos sociales.

Por su parte, Hernández et al. (2014) indicaron que el proceso de indagación desde el enfoque cualitativo es más flexible, se fundamenta en una perspectiva interpretativa, su propósito consiste en reconstruir la realidad desde la mirada de los actores y es holístico, considera el "todo" sin reducirlo al estudio de sus partes.

Por último, Ragin citado por Rodríguez et al. (2011) aseveró que la finalidad del enfoque cualitativo incluye dar voz, interpretar la importancia histórica y cultural así como hacer progresar la teoría a partir de la práctica es decir, todo conocimiento teórico parte de lo evidenciado en la realidad. Todas estas afirmaciones conllevan a la construcción y desarrollo del siguiente diagrama metodológico (Pereira, 2011), en pro de cumplir con los objetivos de la investigación. 


\section{Diseño Mixto}

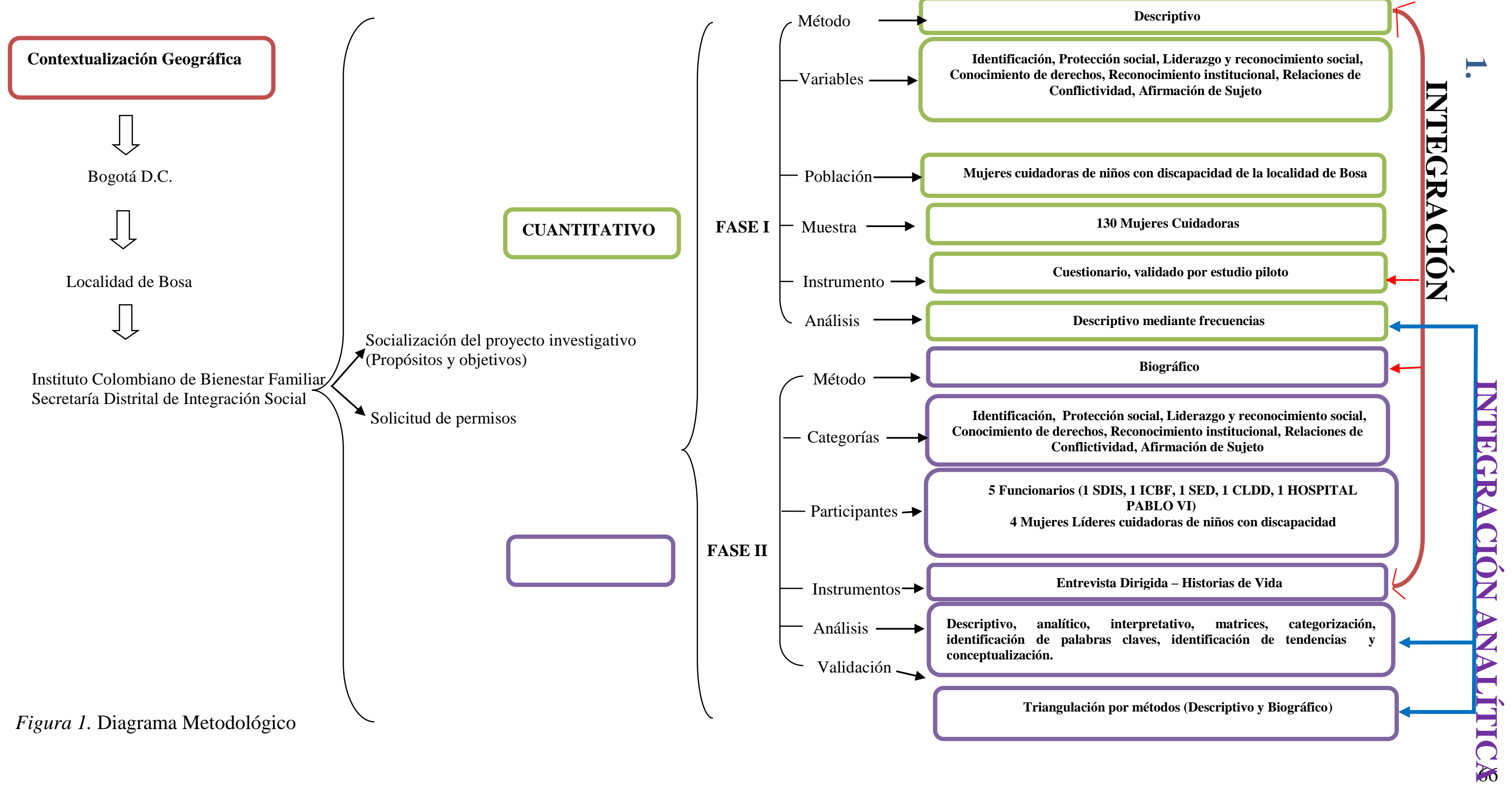




\subsection{Fase I: Enfoque cuantitativo, Método descriptivo}

La fase I conllevó a la implementación del método descriptivo, tomando en cuenta que la necesidad inicial de la presente investigación consistía en determinar las características sociodemográficas de las mujeres cuidadoras de niños con discapacidad en la localidad de Bosa, en aras de evidenciar el contexto social, económico, político, familiar y cultural en el que se encuentran inmersas, así como la calidad de vida que presentan sus oportunidades y problemáticas. De acuerdo con ello, Hernández et al. (2014) mencionaron que dicho método es el único que le permite al investigador “especificar las propiedades, las características y los perfiles de personas, grupos, comunidades, procesos u objetos"; no obstante, es el momento en el cual el investigador debe, según Monje (2011), con base en la información obtenida, ordenar los rasgos, atributos y características de la realidad tal como ocurren, teniendo la habilidad de explicar más adelante los mismos.

\subsubsection{Variables}

La capacidad de socializar los resultados depende además de la clasificación de variables y la definición de las mismas, que para el presente caso corresponden a lo siguiente.

A. Identificación: en este conjunto de variables se describen las características sociodemográficas de la población objeto de estudio, permiten establecer generalidades y al mismo tiempo particularidades en su interacción con el contexto social de la localidad, entre ellas se encuentran:

- Edad. Años de vida cumplidos hasta el momento del diligenciamiento del cuestionario. 
- Etnia. "Grupo humano que comparte y reconoce como propias ciertas características culturales específicas, que determinan su identidad frente a otros colectivos" (CANDANE, 2007 como se citó en Asociación Afromiel, 2014, p. 8).

Afrocolombiana. Persona que presenta una ascendencia africana reconocida y que poseen algunos rasgos culturales que les da singularidad como grupo humano, comparten una tradición y conservan costumbres propias que revelan una identidad que la distinguen de otros grupos, independientemente de que vivan en el campo o en la ciudad (CANDANE, 2007 como se citó en Asociación Afromiel, 2014, p. 8).

- Indígena. "Persona de origen amerindio, con características culturales que reconocen como propias del grupo y que le otorgan singularidad y revelan una identidad que la distingue de otros grupos, independientemente de que vivan en el campo o en la ciudad" (CANDANE, 2007 como se citó en Asociación Afromiel, 2014, p. 8).

- Mestiza. "Persona nacida de la mezcla indígena y blanco(a). Forman el colectivo mayoritario del país" (CANDANE, 2007 como se citó en Asociación Afromiel, 2014, p. 9).

- Estado civil. Situación jurídica que define si la mujer comparte algún tipo de vínculo formal con una persona del otro sexo o del mismo.

- Soltera. "Persona que nunca ha contraído matrimonio ni ha vivido en unión libre" (CANDANE, 2007 como se citó en Asociación Afromiel, 2014, p. 9)

- Casada. "Persona que ha contraído matrimonio según la ley civil (ante un Juez o Notario o según los ritos religiosos de algún credo" (católico, bautista, judío, etc.) (CANDANE, 2007 como se citó en Asociación Afromiel, 2014, p. 9).

- Separada. "Persona cuya unión (casada o en unión libre) ha sido disuelta por vía legal o de hecho y no se ha vuelto a casar, ni vive en unión libre" (CANDANE, 2007 como se citó 
en Asociación Afromiel, 2014, p. 8).

- Unión libre. "Persona que vive en unión marital y ha constituido una familia, sin que exista vínculo matrimonial civil o religioso" (CANDANE, 2007 como se citó en Asociación Afromiel, 2014, p. 8).

- Viuda. "Persona que estuvo casada o en unión libre y no ha vuelto a casarse ni viven en unión libre después de la muerte de su último cónyuge" (CANDANE, 2007 como se citó en Asociación Afromiel, 2014, p. 9).

- Estrato socioeconómico. Es la clasificación que se le da a los sectores barriales en aras de identificar sus niveles de vulnerabilidad.

- Tipología familiar. Se entiende como la característica que presenta la familia a partir de la composición de sus integrantes.

- Parentesco. Es el lazo consanguíneo o afectivo entre la mujer cuidadora y el niño con discapacidad.

- Personas a cargo. Número de familiares en condición de discapacidad a quien la mujer cuidadora debe brindarle cuidado y protección.

- Conflicto armado interno. Hace referencia si la mujer cuidadora fue o no víctima de los hechos reconocidos por el Estado como violación a los derechos humanos, en el marco del conflicto armado interno que vive el país, entre los que se encuentran: homicidio, desplazamiento forzado, abuso sexual, tortura, despojo de tierras, desaparición forzada.

- Nivel educativo. "Se refiere al grado de escolaridad más alto al cual ha llegado la persona, de acuerdo con los niveles del sistema educativo formal: preescolar, básica en sus niveles de primaria, secundaria, media y superior" (CANDANE, 2007 se citó en Asociación Afromiel, 2014, p. 9). 
- Ocupación. La actividad que desarrolla la mujer cuidadora cotidianamente.

- Tenencia de la vivienda. "Se refiere a la forma de posesión del espacio de la vivienda que ocupa la familia” (CANDANE, 2007 se citó en Asociación Afromiel, 2014, p. 9).

- Acceso a servicios públicos. La existencia de agua potable, alcantarillado, luz, gas, en el hogar en el que habita la mujer cuidadora.

- Protección social: cuyo objetivo se enfoca en determinar las posibilidades que han tenido las mujeres para ingresar al campo laboral, el tipo de contrato ofrecido, las principales dificultades para vincularse laboralmente. Por otro lado, verificar si desde el sistema de salud se han presentado barreras de acceso, la presencia de enfermedades crónicas y el acceso a los diferentes programas ofertados por las instituciones del gobierno.

- Liderazgo y reconocimiento social: dirigido principalmente a establecer si las mujeres cuidadoras se sienten reconocidas como líderes en sus contextos familiares, grupales, comunitarios e institucionales y si desde su experiencia reconocen que tienen las habilidades requeridas para liderar grupos y participar en diferentes espacios.

- Conocimiento de derechos - normatividad y organización: identificar qué tanto las mujeres cuidadoras conocen las diferentes políticas públicas dirigidas a la mujer, la discapacidad y la infancia, además de la percepción que tienen como ciudadanas frente al reconocimiento y garantía de derechos por parte del Estado y gobierno y finalmente, intenta determinar cuáles son las temáticas trascendentales en las cuales las instituciones deben concentrarse para apoyar su proceso de cuidado.

- Reconocimiento institucional: está dirigido a determinar en qué medida conocen las mujeres cuidadoras las funciones que cumplen las instituciones de carácter local, las rutas y protocolos de atención permite también, determinar cuáles han sido los mecanismos jurídicos utilizados 
para garantizar el acceso prioritario a diferentes servicios institucionales y de igual manera, identificar a nivel general qué institución presenta mayores barreras de acceso. Relaciones de conflictividad: hace referencia a todas aquellas situaciones complejas, violentas y discriminatorias que las mujeres cuidadoras han tenido vivir a nivel familiar, emocional, comunitario por ejercer el cuidado de sus hijos en condición de discapacidad.

- Afirmación de sujeto: esta variable está dirigida a determinar la percepción que tienen las mujeres cuidadoras frente a su labor del cuidado, la importancia de esta para la comunidad y especialmente para los niños y adolescentes con discapacidad, y las garantías o particularidades que ellas reconocen dentro de la localidad de Bosa que aporta o no a mejorar las condiciones de vida de sus familias.

\subsubsection{Población}

De acuerdo con el reporte de la Secretaría Distrital de Integración Social, quien tiene a cargo la territorialización de la política pública de discapacidad en la ciudad; Bosa actualmente cuenta con 2.900 mujeres cuidadoras de personas con discapacidad. Sin embargo, ni la ciudad ni el país en general cuentan con estadísticas confiables que permitan determinar el total, tanto de niños en condición de discapacidad como de las personas que se dedican al ejercicio del cuidado.

\subsubsection{Muestra}

Ahora bien, en el caso concreto de esta investigación se determinó la importancia de seleccionar la muestra no probabilística desde la Conveniencia como procedimiento de elección de los sujetos participantes, dados los objetivos planteados y el interés de la investigadora por comprender las 
condiciones de vida de las mujeres cuidadoras, pero también, el proceso de construcción de sujetos sociopolíticos en el contexto comunitario e institucional.

Según Hernández et al. (2014), dicho procedimiento "es útil cuando no se requiere una representatividad de elementos de una población, sino una elección de casos con ciertas características especificadas previamente en el planteamiento del problema”. Empero, aunque la investigación tiene un carácter flexible, busca lograr una aproximación a la realidad de la población con el fin de adquirir rigurosidad y confiabilidad en los resultados finales, motivo por el cual Cuesta y Herrero (s.f.) sustentaron que tal muestreo se caracteriza por el esfuerzo intencional que realiza el investigador para obtener mayor especificidad en las características.

Por lo anterior, se seleccionaron 130 mujeres cuidadoras de niños en condición de discapacidad, quienes participaban en espacios institucionales como el Consejo Local de Discapacidad, Instituto Colombiano de Bienestar Familiar, Subdirección Local de Integración Social, Hospital Pablo VI, y las cuales cumplieron con los requisitos de representación en cuanto a la etnia, parentesco con el niño con discapacidad, estado civil, edad, población víctima del conflicto armado, liderazgo, reconocimiento de derechos y ocupación.

\subsubsection{Instrumento}

Acorde con lo expuesto, el estudio investigativo partió de la necesidad de implementar la Encuesta como técnica base del enfoque cuantitativo, debido a su propósito de "determinar rasgos concretos de las personas así como, proponer o establecer relaciones entre las características evidenciadas tanto de los sujetos como de los lugares, situaciones o hechos" (García, 2002, p. 41).

De acuerdo con el mismo autor, "la encuesta es una actividad consiente y planeada", en la cual el investigador logra conseguir información demográfica y establecer las opiniones o 
conocimientos de los sujetos frente a un asunto en particular. Dicha información, entonces, debe obedecer a "exponer los hechos o acontecimientos desde una naturaleza objetiva en donde el encuestado es el principal protagonista” (López \& Fachelli, 2015, p. 16). Su carácter Descriptivo permite identificar los rasgos más comunes en la población y detallar posibles fenómenos o situaciones inmersas en la realidad.

Por ello, el Cuestionario es el instrumento más idóneo para lograr la caracterización sociodemográfica de las mujeres cuidadoras de niños con discapacidad en la localidad de Bosa, pues al ser "un sistema de preguntas ordenadas con coherencia, con sentido lógico y psicológico, expresado con lenguaje sencillo y claro" (García, 2002, p. 41), permite la recolección de datos a partir de las fuentes primarias, vinculando directamente el propósito de la investigación y el planteamiento del problema con la información obtenida.

Para el caso particular de esta investigación, se realizó una prueba piloto con tres mujeres cuidadoras, las cuales manifestaron desconocimiento de términos, poco entendimiento en algunas preguntas, repetición de información e hicieron observaciones importantes de temas no incluidos. Con ello, la investigadora efectuó las correcciones pertinentes del instrumento y pudo determinar también un tiempo aproximado de respuesta.

A la hora de la aplicación formal se contó con un espacio comunitario ubicado dentro de la localidad, en donde se convocó a través de contacto telefónico a cada una de las mujeres cuidadoras seleccionadas y se socializaron los propósitos y la finalidad de la investigación, así como la declaración de consentimiento informado, permitiéndole a las personas expresar sus inquietudes y decidir voluntariamente su participación en ella.

Con el objetivo de propiciar un escenario ameno para las mujeres cuidadoras y sus hijos en condición de discapacidad, se dividió el total de participantes en cuatro (4) subgrupos de 33 
personas cada uno y se dispuso de dos días para la aplicación del cuestionario. Luego del diligenciamiento, la investigadora se percató en primera instancia de revisar cada instrumento, con el ánimo de verificar que todas las preguntas hayan sido contestadas por las cuidadoras y en un segundo momento, validar que el consentimiento informado estuviese en esfero y portara las firmas correspondientes.

Finalmente, a través de una matriz de datos (ver Figura 2) se estableció en un espacio específico cada una de las variables de investigación, las cuales Hernández et al. (2014) definieron como "propiedades medidas y que forman parte de las hipótesis o que se pretenden describir" (p. 12). Allí mismo, se presentaron las variables de la matriz de datos que corresponden según los mismos autores a columnas constituidas por ítems que para este caso son las preguntas, se enumeró del número 1 al 130 en representación de cada una de las mujeres cuidadoras y las opciones de respuestas fueron codificadas con el abecedario. Entre tanto, a cada respuesta emitida por los sujetos de investigación se le otorgó el valor numérico 1, lo que al final generó la frecuencia de respuesta, además se verificó con atención, la adecuada sistematización de la información recolectada. 


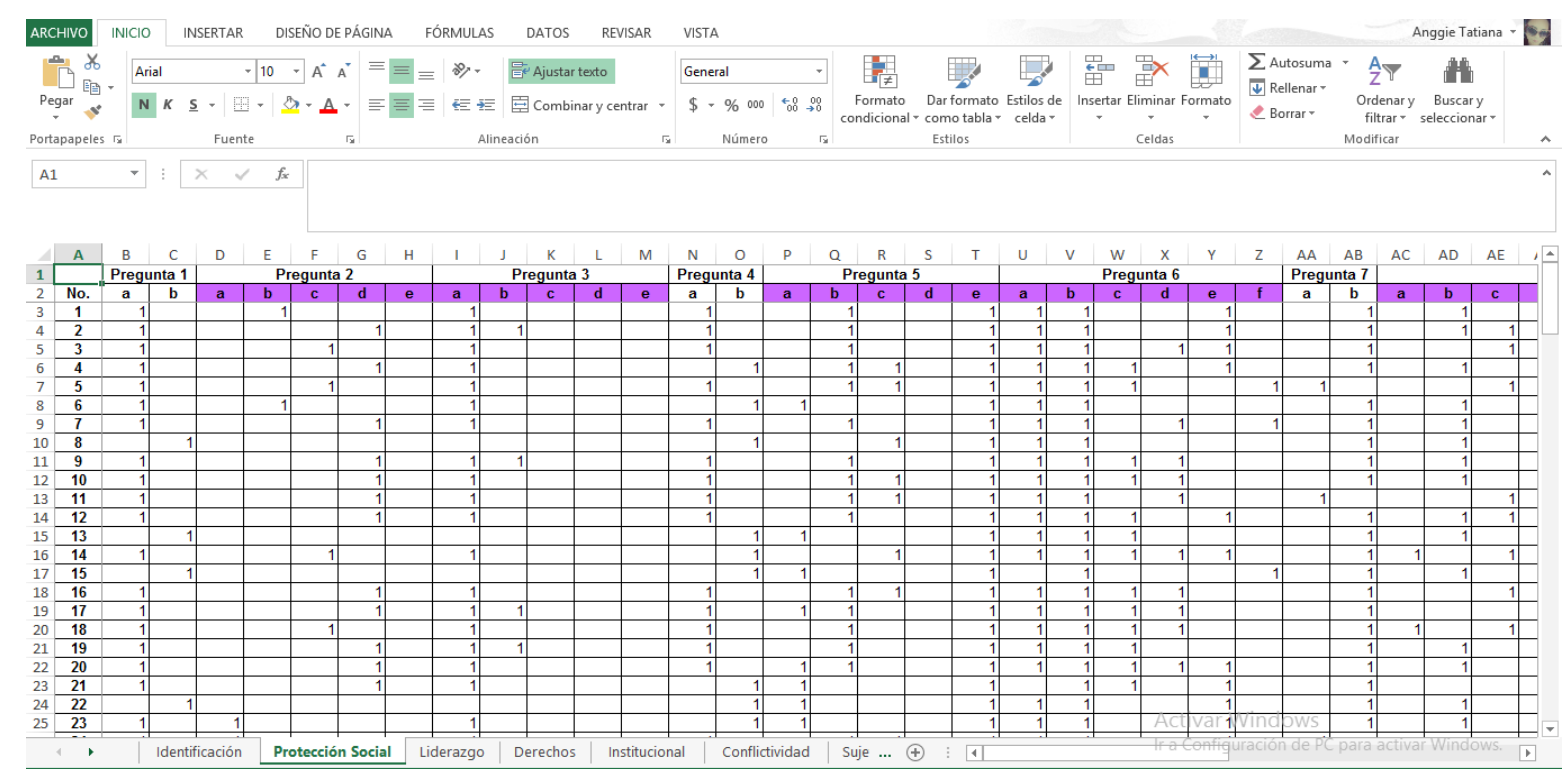

Figura 2. Matriz de datos

\subsubsection{Análisis}

El tipo de análisis seleccionado para esta fase metodológica corresponde al Descriptivo mediante frecuencias, puesto que según Monje (2011) “es la forma adecuada de organizar, resumir los datos recolectados e indicar el número de veces que se repite cada valor” (p. 71). Permite, además, desde el resultado ilustrar un fenómeno, compararlo con otros y correlacionarlos.

Para lograr lo anterior, en la investigación se implementó de manera rigurosa una distribución de frecuencias, la cual se conceptúa como "un conjunto de puntuaciones respecto de una variable ordenada en sus respectivas categorías" (Hernández et al, 2014, p. 132), y se representan a través de tablas, cuadros o gráficas que para el caso resultaron 75 .

\subsection{Fase II: Enfoque cualitativo, Método biográfico}

La Fase II utilizó el método biográfico como base principal del enfoque cualitativo debido a su carácter dialógico, en donde el investigador logra captar la realidad de los sujetos a través de la 
reconstrucción oral e histórica (relato de experiencias, vivencias y sentimientos) y le permite, además, confrontar de primera mano la teoría con la realidad. Es decir, es "una concepción que proporciona una lectura de lo social desde la reconstrucción del lenguaje" (Puyana y Barreto, 1994, p. 185).

Para estas autoras, "el recuento de vida" a través de cualquiera de sus fuentes - biografías, relatos de vida, autobiografía, diario e historias de vida - se convierte en un medio para que cada hombre o mujer logre ser dueño y consciente de su realidad, lo que llamaría Ferrarotti como se citó en Mallimaci y Giménez (2006): “La apropiación de lo que vive en una relación de igualdad con el investigador" (p. 81).

De acuerdo con este mismo autor citado por Rodríguez et al. (2011) debe instaurarse entre los sujetos de investigación y los investigadores "una relación significativa, una auténtica interacción, que en tanto, involucre de manera natural a las personas, reclame al investigador permanecer en la causa y al final, derribar el muro defensivo" (p. 97). Esto en contraposición a la crítica constante que recibe dicho método por "falta" de rigurosidad científica, en la medida en que no existe una distancia entre el sujeto y el investigador que le permita a este último tener una visión objetiva de la realidad. No obstante, para las Ciencias Sociales lo biográfico ha sido el escenario mediante el cual, es posible "captar los mecanismos que subyacen a los procesos que utilizan los individuos para dar sentido y significación a sus propias vidas así como, mostrar un análisis descriptivo, interpretativo, y necesariamente sistemático y crítico" (Sanz, 2005, p. 102).

Igualmente, Monje (2011) aseguró que en la biografía "se encuentran puntos de inflexión o hitos que permiten entender con mayor profundidad los contextos en los que se inscribe esa vida reconstruyendo, el contexto de una época o de una comunidad desde la perspectiva interpretativa" (p. 62). Considerando lo anterior, el presente estudio investigativo acude al siguiente instrumento: 


\subsubsection{Historia de Vida}

Teniendo en cuenta que es el instrumento más idóneo para identificar, describir y explicar tanto el proceso de construcción del sujeto político de las mujeres cuidadoras, como cada uno de los roles que desarrollan en sus contextos comunitarios e institucionales. Según Puyana y Barrera (1994), esta fuente "es una estrategia de la investigación, encaminada a generar versiones alternativas de la historia social, a partir de la reconstrucción de las experiencias personales y permite traducir la cotidianidad en palabras, gestos, símbolos, anécdotas y relatos” (p. 185).

Por su parte, para Chárriez (2012), dicho instrumento se define como "la forma en que una persona narra de manera profunda las experiencias de vida en función de la interpretación que ésta le haya dado a su vida y el significado que se tenga de una interacción social"'(p. 53). En la postura de Jones (1983) citado por Chárriez (2012):

Las historias de vida ofrecen un marco interpretativo a través del cual el sentido de la experiencia humana se revela en relatos personales de modo que da prioridad a las explicaciones individuales de las acciones más que a los métodos que filtran y ordenan las respuestas en categorías conceptuales predeterminadas. (p. 52)

\section{Categorías}

Teniendo en cuenta lo expuesto, el instrumento tuvo las siguientes categorías.

A. Identificación: en esta variable se describen desde la narrativa de las mujeres cuidadoras sus características sociodemográficas.

B. Protección social: cuyo objetivo se enfoca en determinar las posibilidades que han tenido las mujeres para ingresar al campo laboral, el tipo de contrato ofrecido, las principales dificultades para vincularse laboralmente. Por otro lado, verificar si desde el sistema de salud se han presentado barreras de acceso, la presencia de enfermedades crónicas y el 
acceso a los diferentes programas ofertados por las instituciones del gobierno.

C. Liderazgo y Reconocimiento Social: dirigido principalmente a establecer si las mujeres cuidadoras se sienten reconocidas como líderes en sus contextos familiares, grupales, comunitarios e institucionales y si desde su experiencia reconocen que tienen las habilidades requeridas para liderar grupos y participar en diferentes espacios.

D. Conocimiento de derechos - normatividad y organización: identificar qué tanto las mujeres cuidadoras conocen las diferentes políticas públicas dirigidas a la mujer, la discapacidad y la infancia, además de la percepción que tienen como ciudadanas frente al reconocimiento y garantía de derechos por parte del Estado y gobierno; finalmente, intenta determinar cuáles son las temáticas trascendentales en las cuales las instituciones deben concentrarse para apoyar su proceso de cuidado.

E. Reconocimiento institucional: está dirigido a determinar en qué medida conocen las mujeres cuidadoras las funciones que cumplen las instituciones de carácter local, las rutas y protocolos de atención, permite también determinar cuáles han sido los mecanismos jurídicos empleados para garantizar el acceso prioritario a diferentes servicios institucionales y de igual modo, identificar a nivel general qué institución presenta mayores barreras de acceso.

F. Relaciones de conflictividad: hace referencia a todas aquellas situaciones complejas, violentas y discriminatorias que las mujeres cuidadoras han tenido vivir a nivel familiar, emocional, comunitario por ejercer el cuidado de sus hijos en condición de discapacidad

G. Afirmación de sujeto: esta categoría está dirigida a determinar la percepción que tienen las mujeres cuidadoras frente a su labor del cuidado, la importancia de esta para la comunidad y especialmente para los niños y adolescentes con discapacidad, y las garantías 
o particularidades que ellas reconocen dentro de la localidad de Bosa que aporta o no a mejorar las condiciones de vida de sus familias.

\section{Participantes}

En cuanto a la aplicación de las historias de vida, la investigadora intencionalmente seleccionó un total de cuatro (4) mujeres cuidadoras, quienes participan de manera permanente tanto en el Consejo Local de Discapacidad como en diferentes escenarios locales e inclusive Distritales. Así mismo, se realizó una observación rigurosa en los diferentes espacios de encuentro local, en aras de identificar mujeres cuidadoras que recién inician un proceso de empoderamiento y liderazgo para evidenciar al final diferencias y similitudes.

Como la voluntad es un elemento fundamental en el desarrollo de los instrumentos biográficos, se determinó dicho número de participantes con el fin de contar con relatos más completos e íntegros; sin embargo, es importante manifestar que la poca disponibilidad de tiempo de las cuidadoras es un elemento que se debe tener en cuenta, pues muchas de ellas deben asistir permanentemente junto con sus hijos a procesos médicos o terapéuticos que llevan mucho tiempo esperando por parte de las EPS o que de ellos depende la estabilidad en la condición de salud de los niños.

Ahora bien, esta investigación también tuvo el interés de conocer de primera mano la concepción que tienen los funcionarios de las diferentes instituciones con presencia local, acerca de las condiciones de vida que enfrentan las mujeres cuidadoras y el desarrollo de su rol sociopolítico en la cotidianidad comunitaria, a través de un instrumento que tuviese la capacidad de abarcar desde la oralidad aspectos más claros y profundos. Teniendo en cuenta lo anterior, se eligió un segundo instrumento cualitativo: 


\subsubsection{Entrevista dirigida}

Debido a su pertinencia con la metodología seleccionada, Canales citado por Díaz, Torruco, Martínez y Varela (2013) manifestó que "la entrevista es una comunicación interpersonal que se establece entre el investigador y el sujeto de estudio, a fin de obtener respuestas verbales a las interrogantes planteadas sobre el problema propuesto" (p. 163); aseguró que para lograr esa relación bidireccional "el entrevistador debe mantener una actitud activa durante el desarrollo de la entrevista" (p. 164), toda vez que la interpretación sigue siendo la característica principal de la investigación.

La entrevista es muy ventajosa principalmente en los estudios descriptivos y en las fases de exploración pues, se caracteriza por obtener información relevante en relación con un tema determinado, es más precisa, se consiguen significados que los informantes atribuyen a los temas en cuestión y permite comprender desde el discurso del entrevistado la realidad y sus dinámicas. (Díaz et al., 2013, p. 163)

Conviene subrayar, entonces, la tipología semiestructurada ya que dichos autores infieren lo siguiente:

Presentan un grado mayor de flexibilidad que las estructuradas, debido a que parten de preguntas planeadas, que pueden ajustarse a los entrevistados. Su ventaja es la posibilidad de adaptarse a los sujetos con enormes posibilidades para motivar al interlocutor, aclarar términos, identificar ambigüedades y reducir formalismos. (Díaz et al., 2013, p. 163)

\section{Categorías}

A continuación, se relacionan las siete categorías principales cuya finalidad era lograr establecer la concepción que tienen las instituciones acerca de las condiciones de vida de las mujeres cuidadoras y su rol sociopolítico en la localidad. 
A. Identificación: en esta variable se describen las características sociodemográficas que identifican las instituciones de la población objeto de estudio y que permiten establecer generalidades, y al mismo tiempo, particularidades en su interacción con el contexto social de la localidad.

B. Protección social: cuyo objetivo es determinar desde la institucionalidad local, las posibilidades que han tenido las mujeres para ingresar al campo laboral, las oportunidades que ellos han aperturado para el acceso de las mujeres cuidadoras al emprendimiento y la educación, el tipo de contrato ofrecido, las principales dificultades para vincularse laboralmente. Por otro lado, verificar cuál ha sido la entidad que presenta mayores barreras de acceso, la presencia de enfermedades crónicas y el acceso a los diferentes programas ofertados por las instituciones del gobierno.

C. Liderazgo y reconocimiento social: dirigido principalmente a establecer si las instituciones reconocen como líderes a las mujeres cuidadoras en sus contextos familiares, grupales, comunitarios e institucionales y si desde su experiencia identifican habilidades que les han facilitado el acceso a los diferentes servicios.

D. Conocimiento de derechos - normatividad y organización: identificar desde el proceso de intervención de las instituciones qué tanto las mujeres cuidadoras conocen las diferentes políticas públicas dirigidas a la mujer, la discapacidad y la infancia, además de su percepción frente al reconocimiento y garantía de derechos por parte del Estado y gobierno; finalmente, intenta determinar cuáles son las habilidades y dificultades que presenta el talento humano que interactúa permanentemente con las mujeres cuidadoras.

E. Reconocimiento institucional: está dirigido a identificar las propuestas desde la institucionalidad que conlleven a mejorar progresivamente las condiciones de vida de las 
mujeres cuidadoras y determinar los retos que tiene el Sistema de Protección Social a la luz de las políticas públicas y el accionar del Estado.

F. Relaciones de conflictividad: hace referencia a todas aquellas situaciones complejas, violentas y discriminatorias que evidencian las instituciones en la cotidianidad de las mujeres cuidadoras a nivel familiar, emocional y comunitario.

G. Afirmación de sujeto: esta categoría está dirigida a determinar la percepción que tienen las instituciones frente a su labor que desempeñan las mujeres cuidadoras, la influencia de ellas para la comunidad y especialmente para los niños y adolescentes con discapacidad, y las garantías o particularidades que ellas reconocen dentro de la localidad de Bosa que aporta o no a mejorar las condiciones de vida de sus familias.

\section{Participantes}

Partiendo de la misma premisa de las historias de vida, en la entrevista se contó con una representación de las instituciones con presencia local, buscando inicialmente recopilar aportes vivenciales desde su experiencia e intervención con las mujeres cuidadoras y los niños con discapacidad y en un segundo plano, se pretendía dar cuenta de las acciones realizadas por el Sistema de Protección Social colombiano.

En vista de lo anterior, se aplicaron cinco entrevistas dirigidas a un funcionario de las siguientes instituciones locales: Subdirección local de Integración Social Proyecto 721), Dirección Local de Educación (Inclusión Escolar), Consejo Local de Discapacidad, Hospital Pablo VI (Salud Pública) e Instituto Colombiano de Bienestar Familiar (Hogar Gestor). 


\section{CAPÍTULO IV. LA REALIDAD DE LAS MUJERES CUIDADORAS DE LA LOCALIDAD DE BOSA Y LA CONSTRUCCIÓN DE SUS ROLES SOCIALES Y POLÍTICOS}

En el presente capítulo, la investigadora logra evidenciar desde la metodología implementada, la situación de vida actual de las mujeres cuidadoras de la localidad séptima del Distrito Capital, así como el proceso de construcción de los roles sociales y políticos en el ejercicio del cuidado, desde la perspectiva personal e institucional. Es por ello que en aras de dar a conocer los resultados obtenidos y los propósitos alcanzados dentro del estudio, este apartado ilustra, inicialmente, el desarrollo del proceso cuantitativo, la aplicación y tabulación del instrumento, así como las variables utilizadas. Lo anterior con el fin de demostrar la situación de vida actual de las mujeres cuidadoras en su contexto cotidiano.

En segunda instancia, se describen, por medio del análisis de las cinco entrevistas realizadas y desde la mirada de las diferentes instituciones locales, los roles sociales y políticos ejercidos por las mujeres cuidadoras en su comunidad, sus avances y limitaciones. Finalmente y a partir de cuatro historias de vida, se explica el proceso de construcción sociopolítico de las mujeres cuidadoras, desde el tránsito por sus diferentes ciclos vitales, evidenciando las influencias económicas, familiares y culturales.

\subsection{Caracterización socioeconómica, política, familiar y comunitaria}

Inicialmente, este proceso de caracterización emerge a partir de la construcción del Artículo Científico denominado "El Rol social de las mujeres cuidadoras de niños, niñas y adolescentes en condición de discapacidad de la localidad de Bosa, desde el marco de la Protección Social”, el cual fue financiado por de la Universidad Santo Tomas, Sede Bogotá, a través de la Unidad de 
Investigación. En dicho artículo, se seleccionaron de acuerdo a la Metodología, 130 mujeres cuidadoras de la localidad, con el propósito de identificar el ejercicio sociopolítico de esta población y su relación con la Protección Social, logrando:

a. Diseñar el instrumento de recolección de datos a partir de la construcción de siete (7) variables que permitirían recolectar la información requerida.

b. Diseñar el formato de consentimiento informado.

c. Implementar una prueba piloto, en donde se verificó la existencia de preguntas repetidas o con la misma finalidad, falta de comprensión en algunas preguntas y confusión en la redacción.

d. Realizar los ajustes pertinentes al instrumento.

e. Socializar los propósitos de la investigación, así como el contenido del consentimiento informado a la muestra poblacional.

f. Aplicar el instrumento oficial a las 130 mujeres cuidadoras seleccionadas para la investigación.

g. Verificar el diligenciamiento de las encuestas.

h. Tabular cada una de las 130 encuestas implementadas.

i. Elaborar el análisis y las conclusiones correspondientes.

Teniendo en cuenta lo anterior, a continuación se describen las condiciones de vida identificadas en el grupo de mujeres cuidadoras, a partir de cada una de las variables: 


\subsubsection{Identificación}

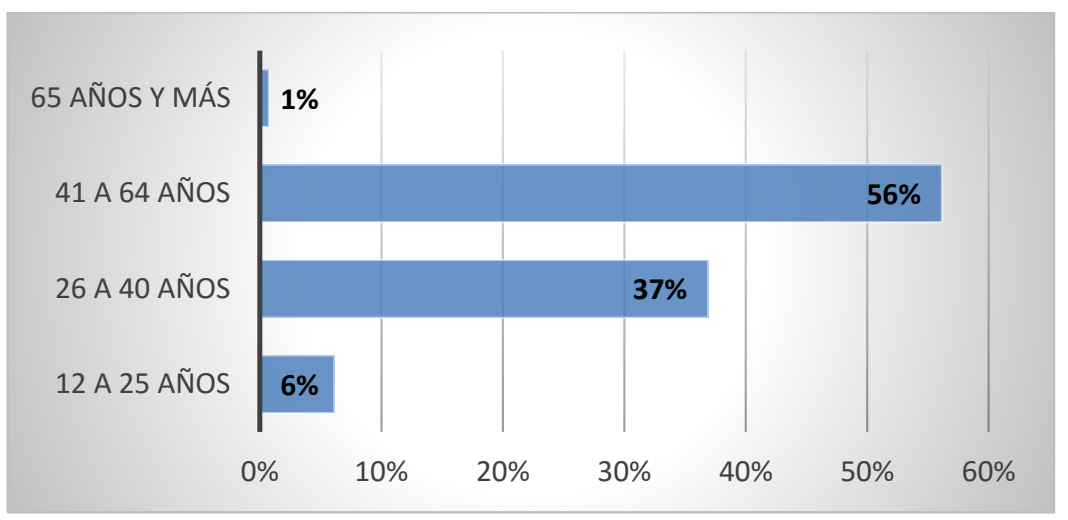

Figura 3. Edad

De acuerdo con los resultados obtenidos, se puede evidenciar, en principio, la responsabilidad del cuidado atribuida a las mujeres que se encuentran transitando de la vida adulta a la ancianidad, lo que podría significar esfuerzos físicos y emocionales con mayores repercusiones para su estado de salud e imposibilidades para continuar con el ejercicio del cuidado y protección de sus familiares.

Igualmente, existe una representación significativa de las mujeres que se encuentran en el ciclo vital de Adulto Joven y maduro, cuya situación podría verse reflejada también, en la baja cobertura laboral para ellas, la falta de acceso a condiciones dignas de empleo y con ello, la no cotización a los sistemas pensionales o la intermitencia en dicho proceso. Por su parte, las mujeres cuidadoras en ciclo vital de la juventud también dejan ver las dificultades que podrían presentar en cuanto a la culminación de estudios básicos, medios y superiores, y por tanto, la falta de herramientas académicas para mejorar la calidad de vida de sus familias y al mismo tiempo, su "inactividad laboral" en términos económicos. 


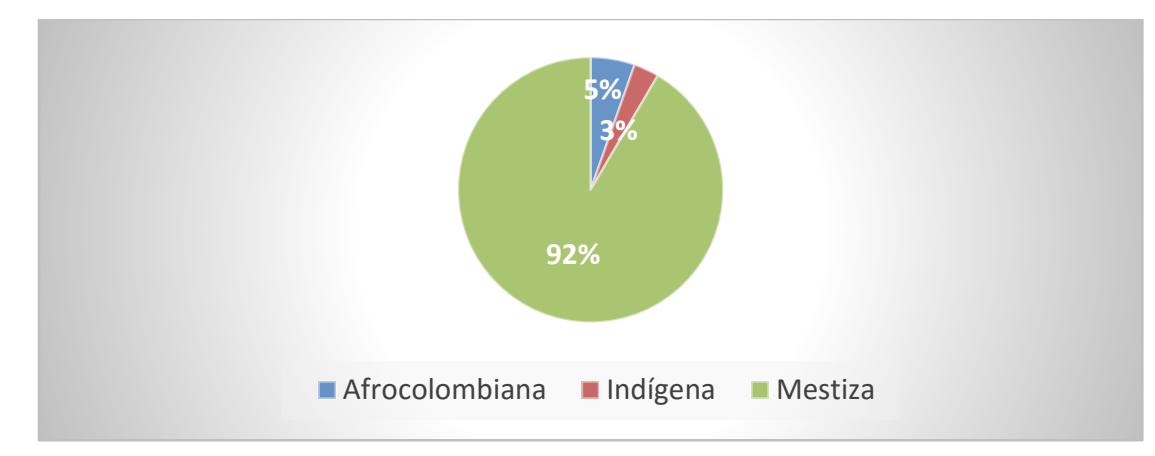

\section{Figura 4. Etnia}

En cuanto a la pertenencia étnica, existe correlación con el estudio desarrollado por la Secretaría Distrital de Planeación (2009), en donde visualiza una población mayoritariamente mestiza, pero con predominancia de la población afrocolombiana frente a las comunidades indígenas.

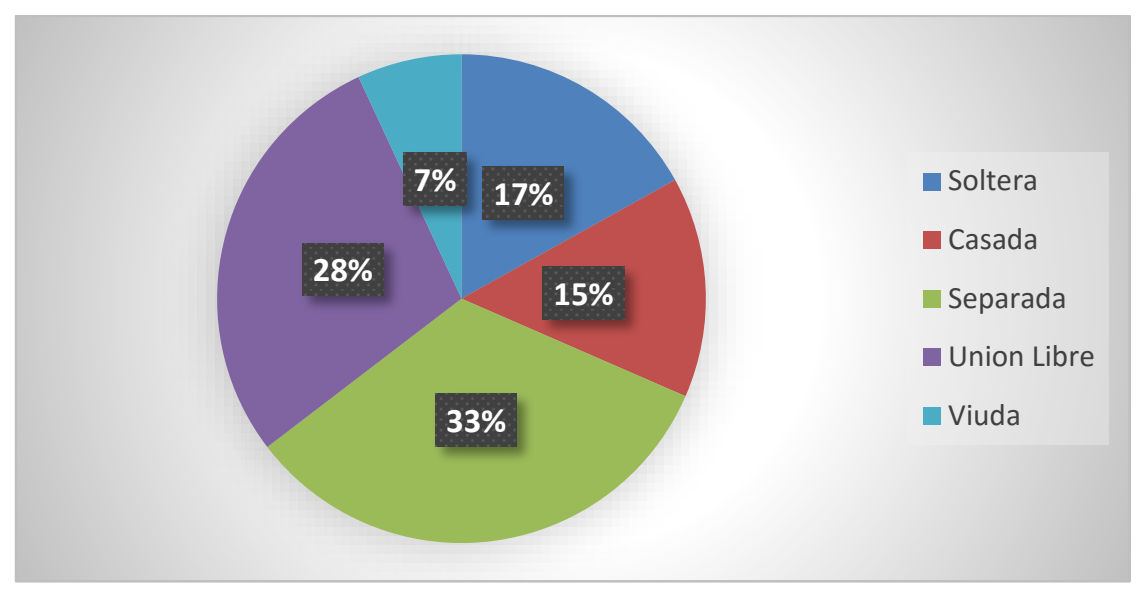

\section{Figura 5. Estado civil}

En el escenario del estado civil de las mujeres cuidadoras para el año 2016, se observa que el $33 \%$ de ellas son separadas, situación que afecta directamente la calidad de vida de las mujeres y sus familias, puesto que son ellas quienes asumen el rol protector y proveedor del hogar, sin tener garantías mínimas de acceso a ofertas laborales dignas y adecuadas a sus particularidades. De igual forma, se promueven trasformaciones significativas en las actividades propias de cada integrante del hogar, toda vez que los adolescentes se ven obligados a desertar de la escuela para convertirse en apoyo económico para su progenitora. 


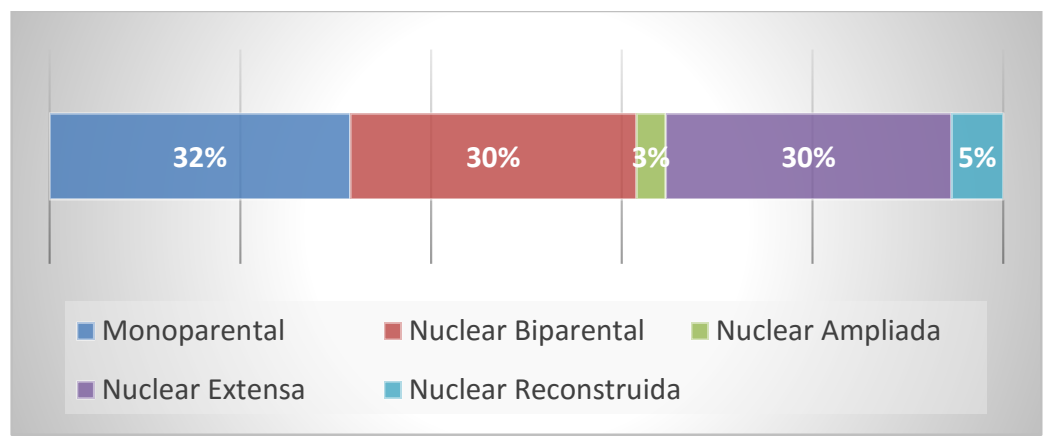

Figura 6. Tipología Familiar

Ahora bien, se encontró que la tipología familiar predominante es la familia monoparental. Sin embargo, existe presencia importante de abuelos en los hogares (familia extensa), lo cual puede generar un apoyo fundamental, en la medida en que son ellos los encargados del cuidado de los niños, pero a su vez, existe alta probabilidad que las personas mayores sean también sujetos de especial cuidado por parte de las mujeres. Es decir, existirían múltiples cuidados por ejercer.

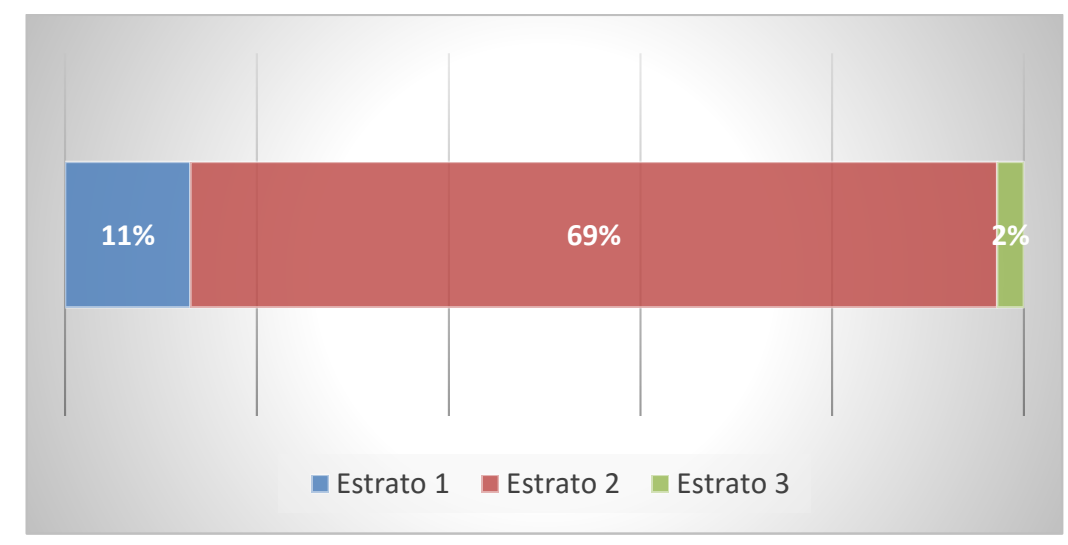

Figura 7. Estrato Socioeconómico

De forma coherente con la caracterización dada a las Unidades de Planeamiento Zonal de la localidad, las mujeres cuidadoras pertenecen en un $69 \%$ al estrato socioeconómico 2. No obstante, el $11 \%$ de ellas se encuentran en el estrato socioeconómico 1, ilustrando condiciones generales de vulnerabilidad socioeconómica acentuada y pobreza. 


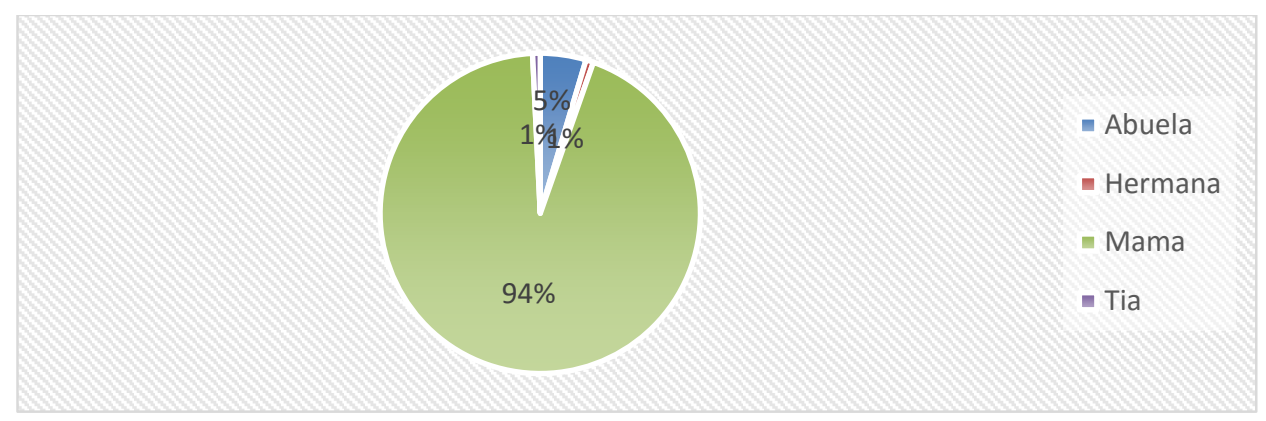

Figura 8. Parentesco de las Mujeres

La Figura 8, por su parte, confirma que quienes ejercen el cuidado de los niños con discapacidad en la localidad de Bosa corresponde en un $94 \%$ a las progenitoras, empero, aparecen en segundo lugar las abuelas con un $5 \%$ y con un mínimo porcentaje $(1 \%)$ se encuentran las hermanas o las tías.

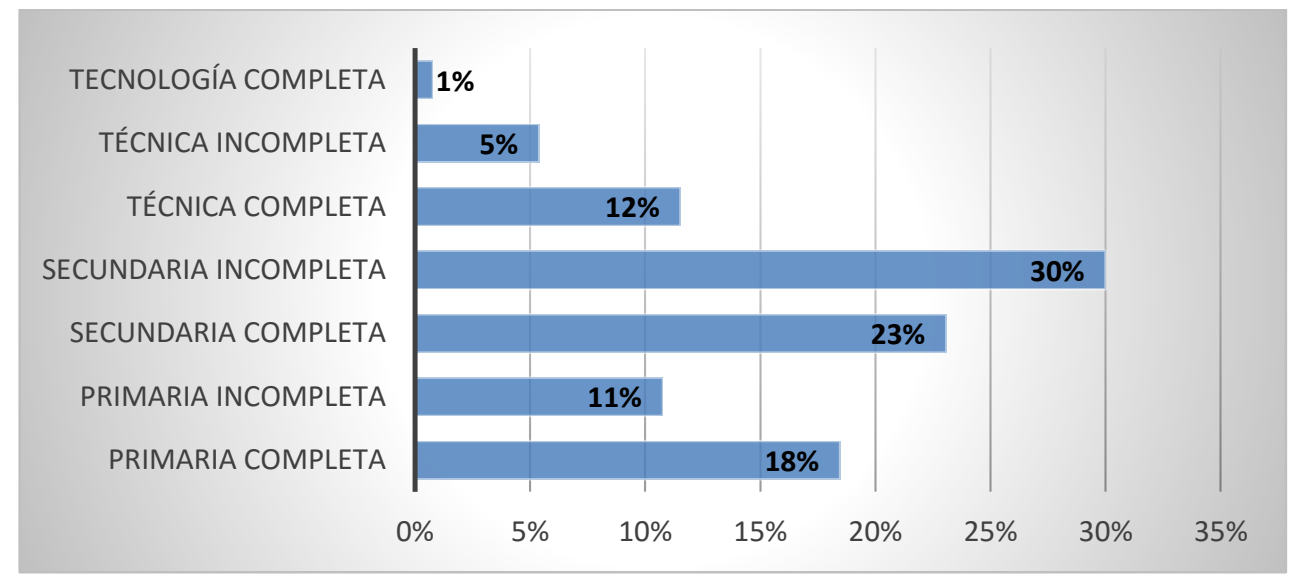

Figura 9. Grado de Escolaridad

Se evidencia que el grado escolar de las mujeres cuidadoras de niños con discapacidad en la localidad de Bosa está enmarcado principalmente por la secundaria incompleta, lo cual se convierte en una barrera de acceso al momento de solicitar un empleo formal, tomando en cuenta que los requisitos exigidos por las empresas no se adecúan a las condiciones académicas de ellas, motivo por el cual el ámbito informal es cada vez más, la única opción para estas familias. 


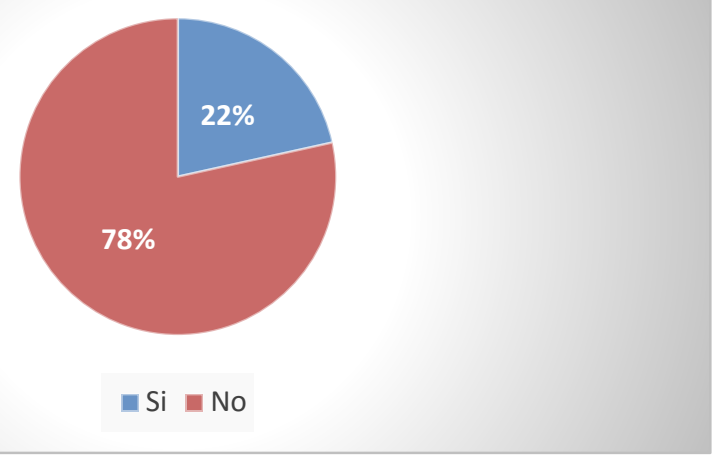

Figura 10. Víctimas del Conflicto Armado Interno

De acuerdo con el resultado, el $22 \%$ de las mujeres aseguró haber vivido algún hecho victimizante reconocido por la Ley 1448. Lo cual demuestra una condición de vulnerabilidad adicional, pues abandonaron sus territorios de origen y se enfrentan a una ciudad hostil y compleja.

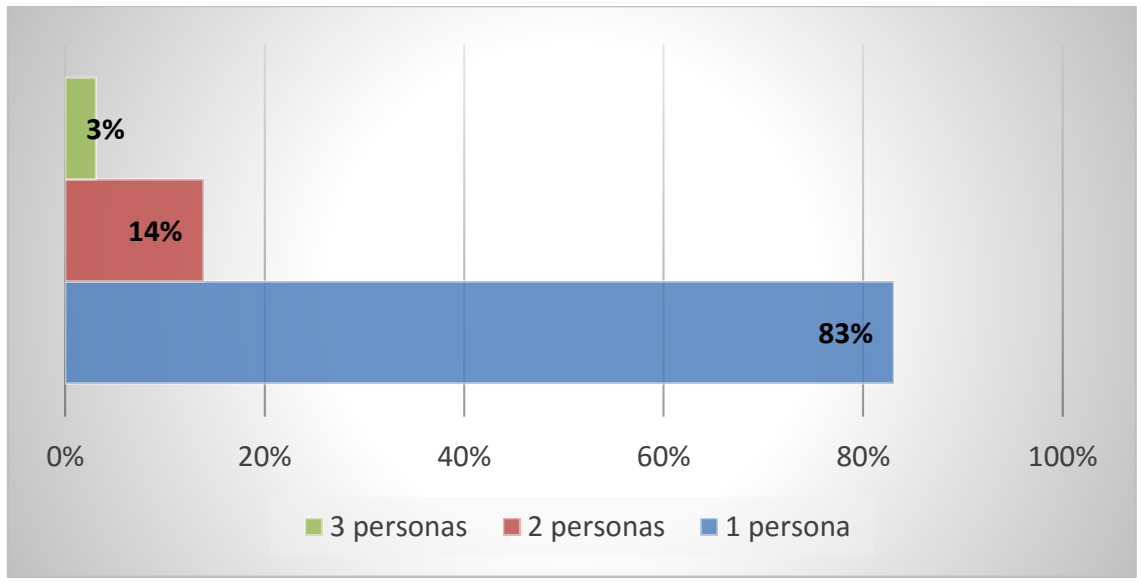

Figura 11. Personas con Discapacidad a Cargo

En concordancia con la Figura 11 y a pesar de que el $83 \%$ de las mujeres indicaron cuidar a una sola persona con discapacidad, el $17 \%$ de ellas no solo deben cuidar a una persona y estar presente en el proceso de formación de sus demás hijos, sino por el contrario, se enfrentan al cuidado permanente de más de dos personas que requieren el apoyo incondicional de ellas, presentando así una situación crítica en términos de protección social, dado que sus posibilidades de bienestar son completamente limitadas. 


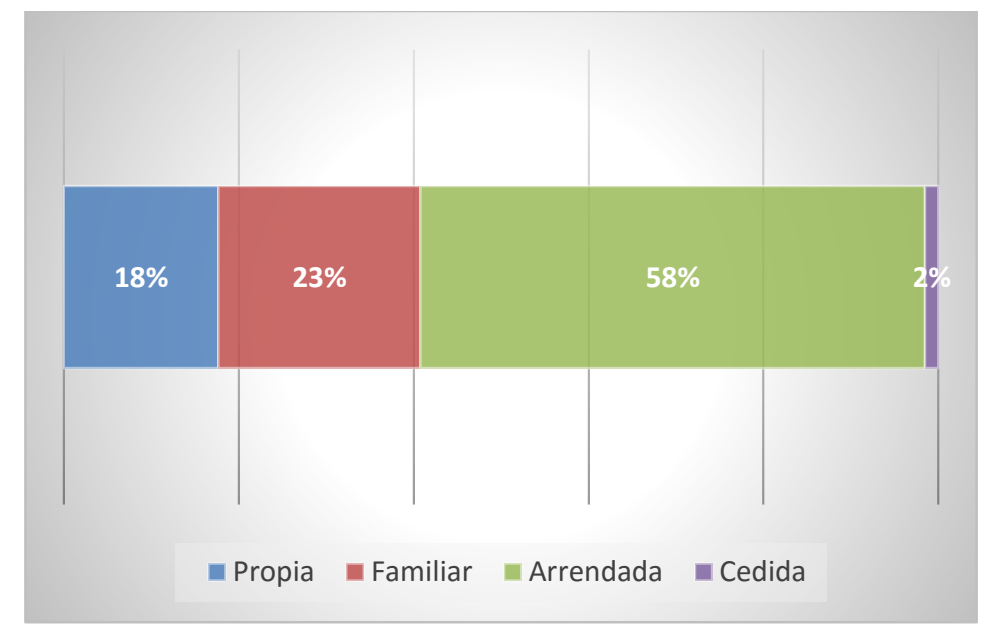

Figura 12. Tenencia de la Vivienda

Teniendo en cuenta el resultado, se logra evidenciar que la mayoría de las mujeres cuidadoras presentan una condición de fragilidad social importante, puesto que están expuestas a ser desalojadas permanentemente de sus hogares al no obtener los recursos económicos suficientes para el pago del arriendo y los servicios públicos.

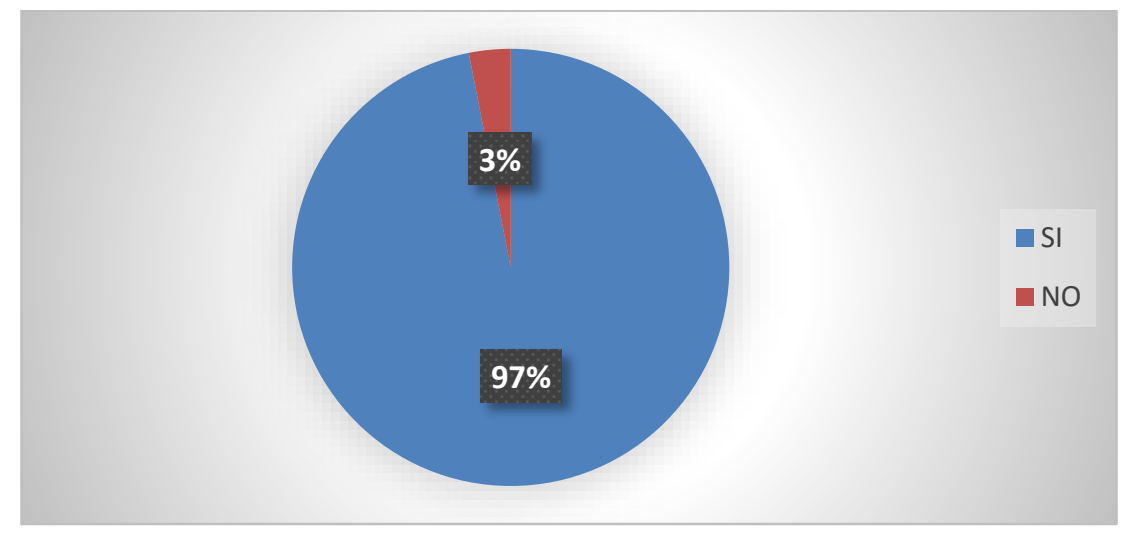

Figura 13. Acceso a Servicios Públicos

Ahora bien, la población de mujeres cuidadoras, según la Figura 13, cuenta en su mayoría con el acceso a servicios públicos, aunque el $3 \%$ de ellas aun presentan dificultades para gozar de este derecho. Si bien es un porcentaje mínimo, es preocupante que en la actualidad existan familias en el Distrito que no logren acceder a un servicio primario que brindaría calidad de vida a sus integrantes. 


\subsubsection{Protección Social}

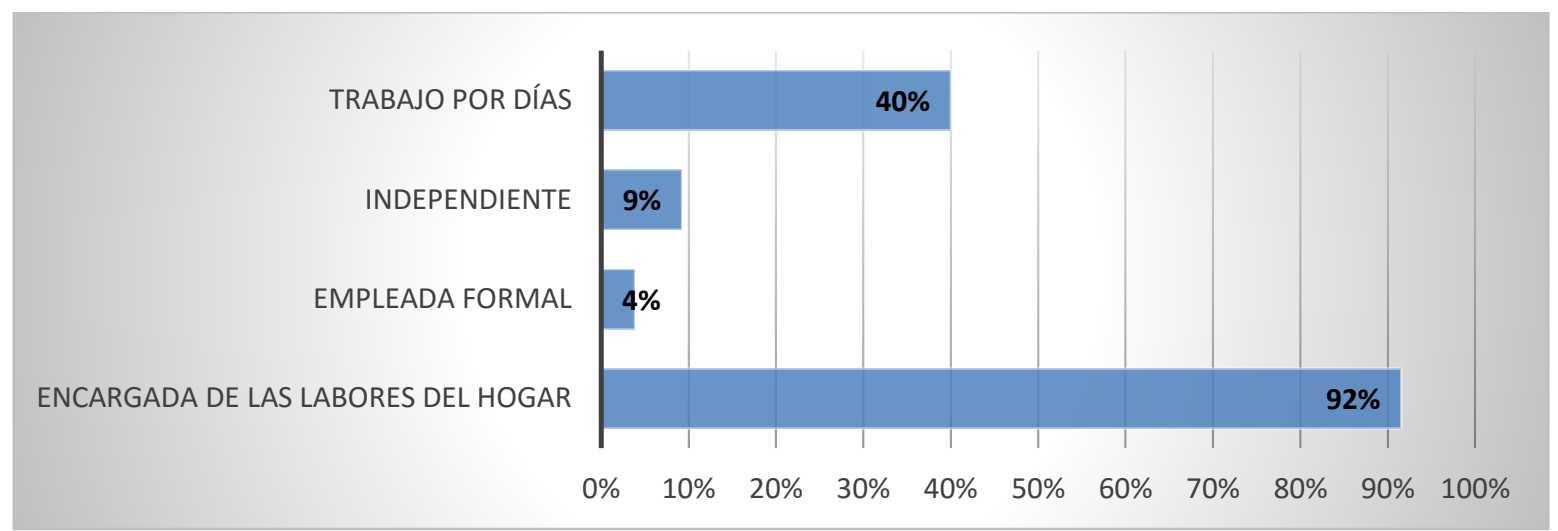

Figura 14. Ocupación de las mujeres cuidadoras además del Cuidado

En la presente ilustración se observan las múltiples tareas que deben cumplir las mujeres en sus hogares, debido a que al mismo tiempo que cuidan, deben encargarse de las labores físicas del hogar tales como cocinar, organizar y atender a sus demás familiares y acudir al lugar en donde reciben una remuneración por lo realizado, siendo en su mayoría oficios domésticos por días.

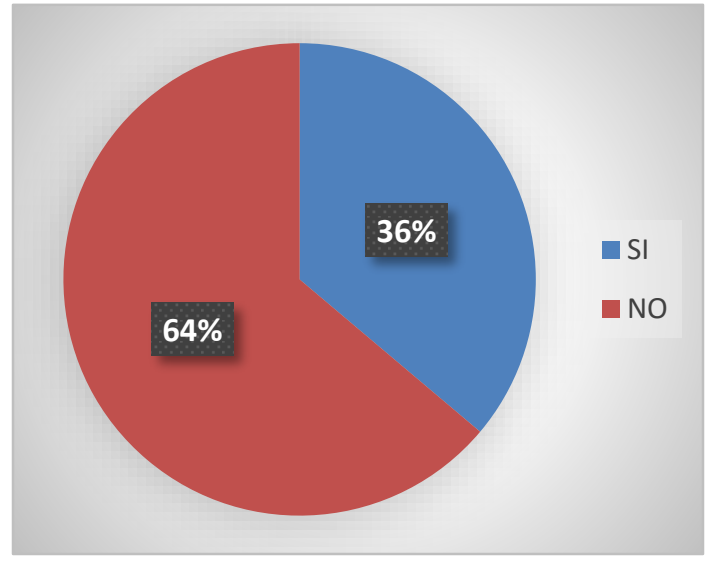

Figura 15. Vinculación Laboral

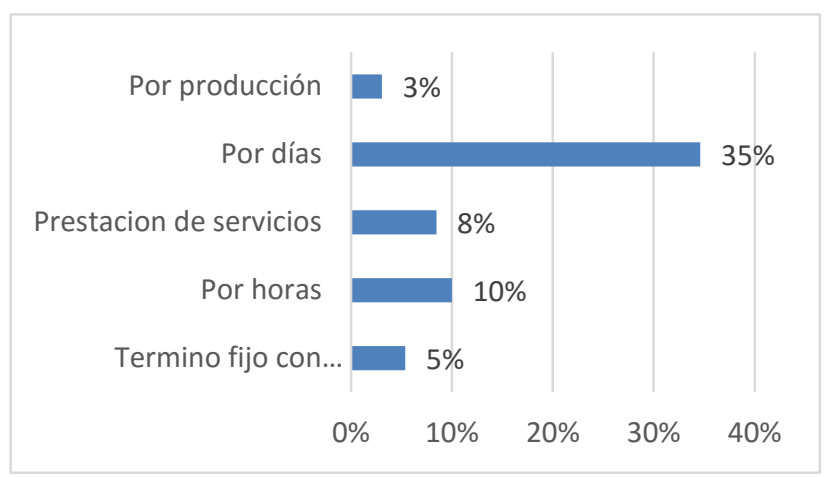

Figura 16. Tipo de Contrato

Frente a las oportunidades laborales, se evidencia la complejidad económica en los hogares de las mujeres cuidadoras, en primera instancia, porque la mayoría de ellas no cuenta con ningún tipo de trabajo remunerado en la actualidad y por ende, la satisfacción de necesidades básicas es cada 
vez menor y el riesgo de situaciones como la desnutrición y la deserción escolar en los menores de edad empiezan a surgir como consecuencia de ello.

En segundo lugar, se identifica que pese a que el $35 \%$ de mujeres cuenta con ingreso económico producto de la labor desempeñada, el tipo de contrato con el que cuentan generalmente es por días, quiere decir que no tienen estabilidad de ingreso económico y sus condiciones de seguridad social son inexistentes, pues si bien existen legislaciones nuevas al respecto, los hogares en los cuales laboran las mujeres cuidadoras no tienen tampoco condiciones económicas para garantizarles afiliaciones (Salud, Pensión y ARL) y pagos extras.

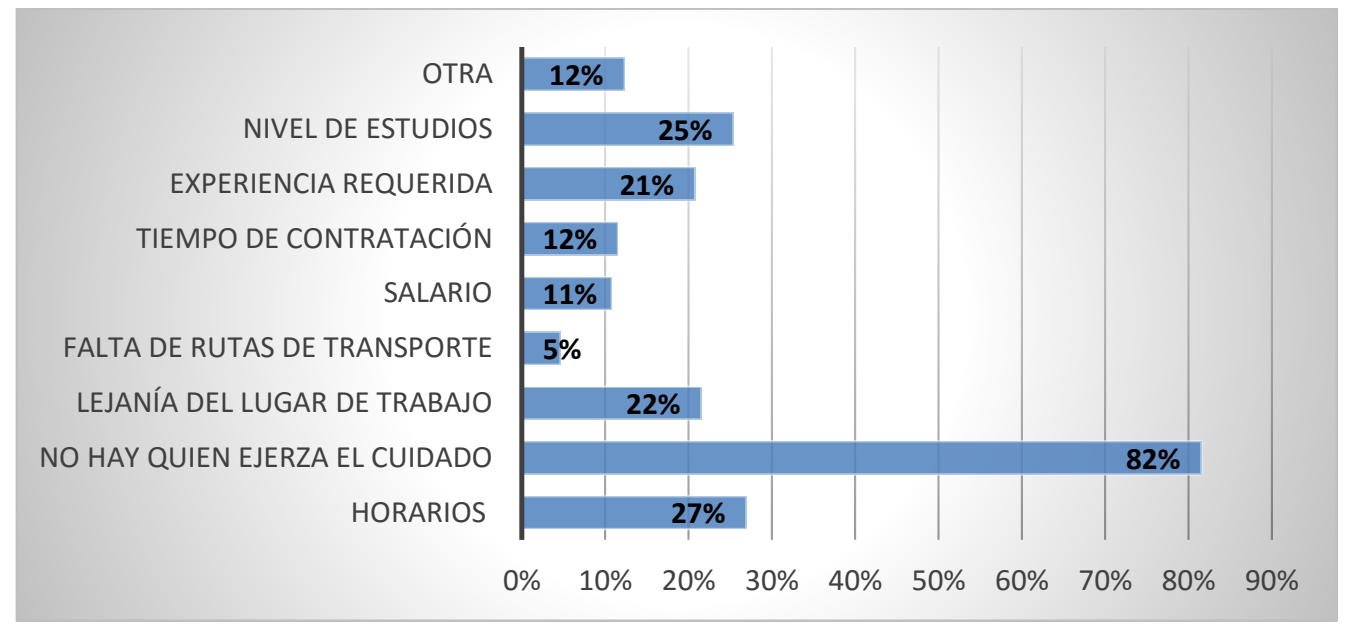

Figura 17. Dificultades para el Acceso Laboral

En esta ilustración se pueden ver las principales dificultades o barreras de acceso que encuentran las mujeres al momento de vincularse laboralmente. Pese a que existen familias solidarias en donde todos los integrantes buscan apoyar el cuidado del niño con discapacidad, las mujeres no logran conseguir con facilidad personas externas que estén dispuestas a cuidar y proteger a sus hijos. Es el caso de los hogares comunitarios o jardines infantiles públicos/privados en donde no aceptan con facilidad a los niños. Igualmente, las situaciones que enfrentan todos los colombianos a la hora de conseguir trabajo siguen siendo muy latentes como la falta de experiencia y el nivel educativo. 


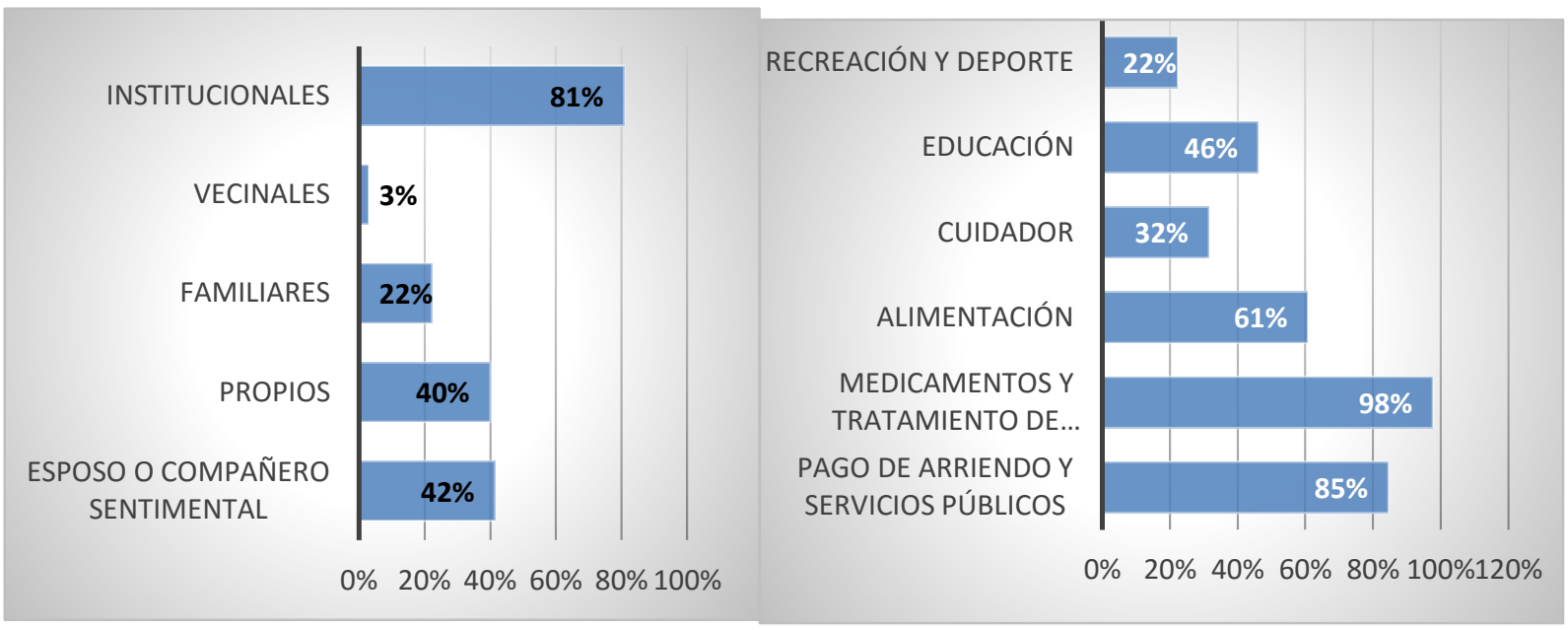

Figura 19. Provisión de ingresos en el hogar

Figura 18. Gastos del hogar

En esta apartado se puede observar que los recursos económicos que perciben las mujeres cuidadoras mensualmente corresponden en su gran mayoría a los apoyos económicos entregados por las instituciones de asistencia social, quiere decir que la fragilidad socioeconómica de esta población es permanente, ya que dependen de criterios y voluntades administrativas que cambian drásticamente e influyen en la calidad de vida de las familias.

En ese orden de ideas, se ilustra cómo las mujeres deben designar la mayor parte del ingreso familiar para cubrir la compra de medicamentos y acceder a los tratamientos especializados que deberían ser cubiertos de manera oportuna por el Sistema de Salud. En conclusión, son dineros que aunque están destinados para cubrir todas las necesidades del hogar y contribuir al bienestar de la familia, se están invirtiendo principalmente en cobijar las responsabilidades propias del sector salud y de esta manera, la condición de vulnerabilidad se vuelve cada vez más acentuada. 


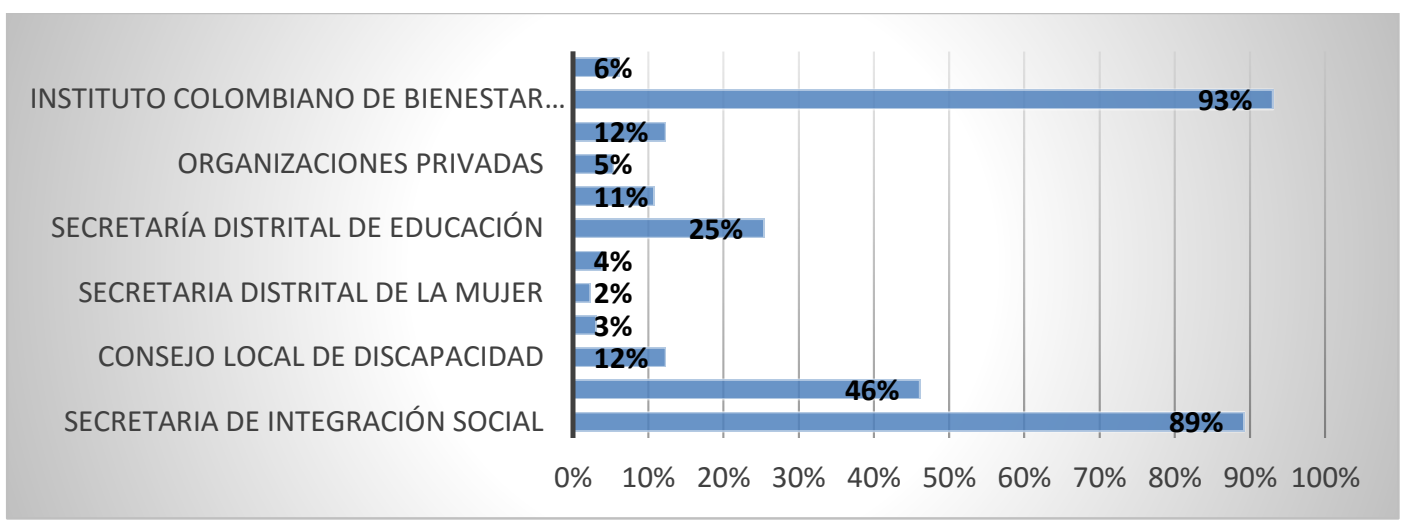

Figura 20. Acceso a las Instituciones

De acuerdo con el resultado obtenido, se observa que las principales entidades en las cuales las mujeres cuidadoras pueden participar son principalmente las destinadas a la Asistencia Social, lo cual promueve las prácticas desarticuladas y la dependencia a los servicios, puesto que escenarios productivos, laborales y de emprendimiento no cuentan con la capacidad de oferta y sus promulgaciones son limitadas.

\section{Sistema General de Pensiones}

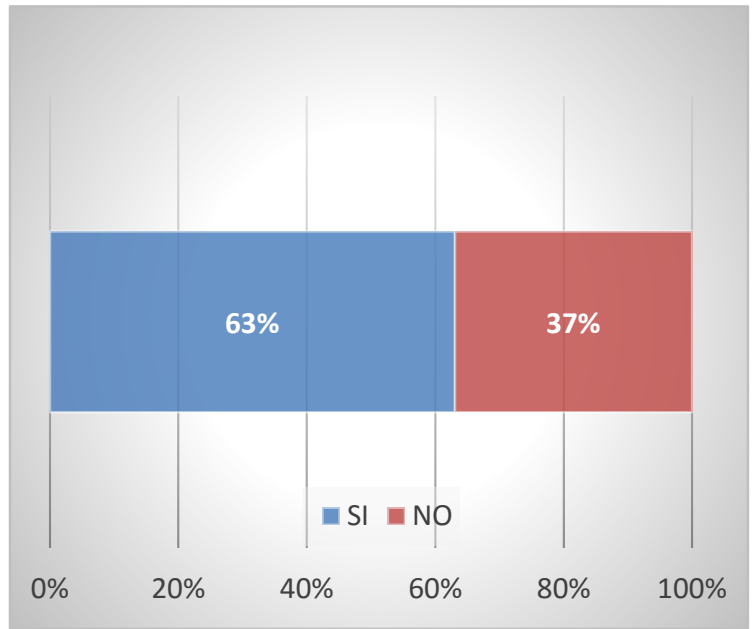

Figura 22. Afiliación

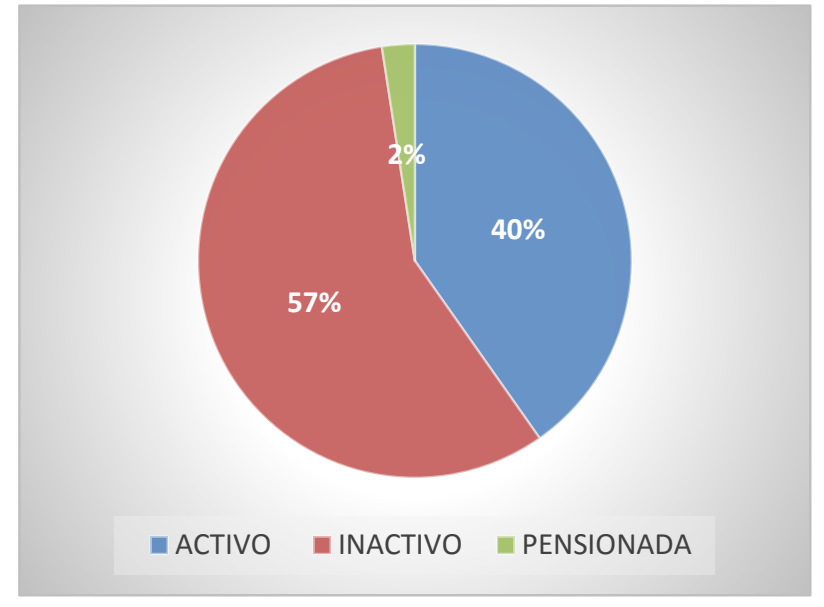

Figura 21. Estado Actual 


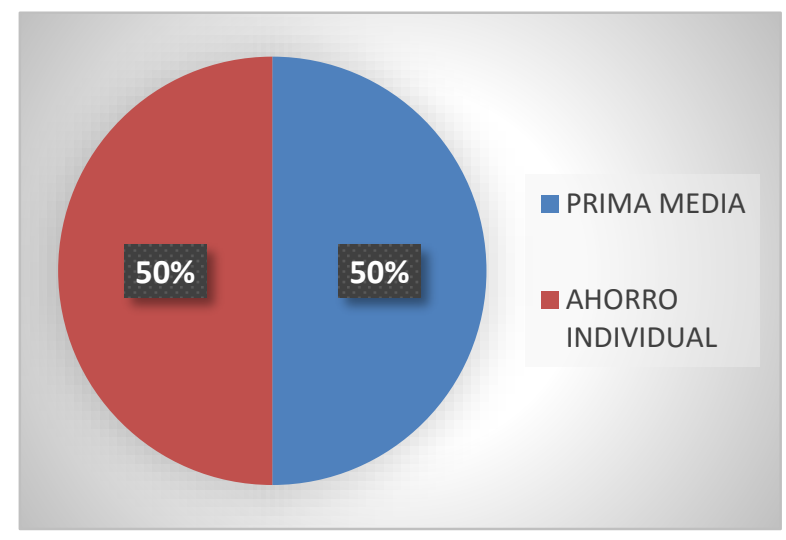

Figura 23. Régimen de Cotización

En aproximación a la condición laboral de las mujeres cuidadoras, se evidenció que el 63 \% de las mujeres cuidadoras logró afiliarse al sistema pensional durante su etapa productiva o la posibilidad de ingreso al mercado laboral; no obstante, la mayor parte de ellas actualmente se encuentran inactivas, quiere decir que pese a estar afiliadas al sistema no lograrían pensionarse por el número mínimo de semanas cotizadas. Igualmente, se destacó la igualdad de afiliación tanto en el Régimen de Prima Media como de Ahorro Individual como administradoras de pensiones.

\section{Sistema General de Salud}

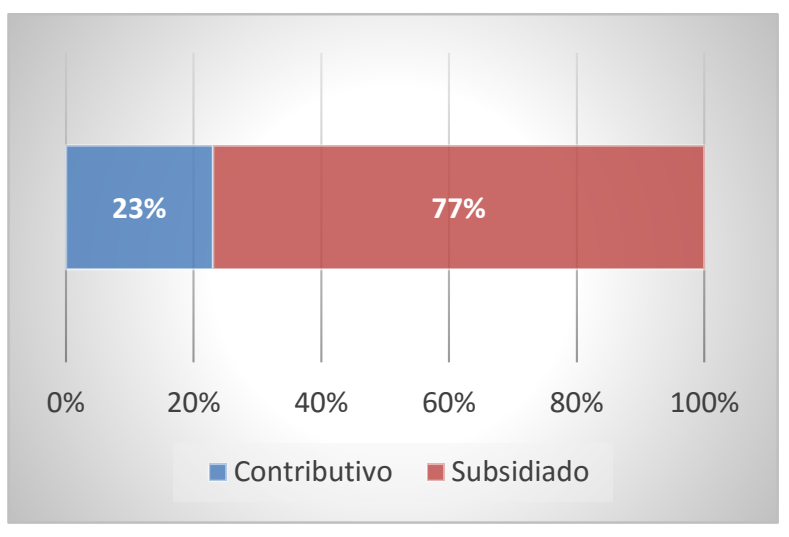

Figura 25. Afiliación

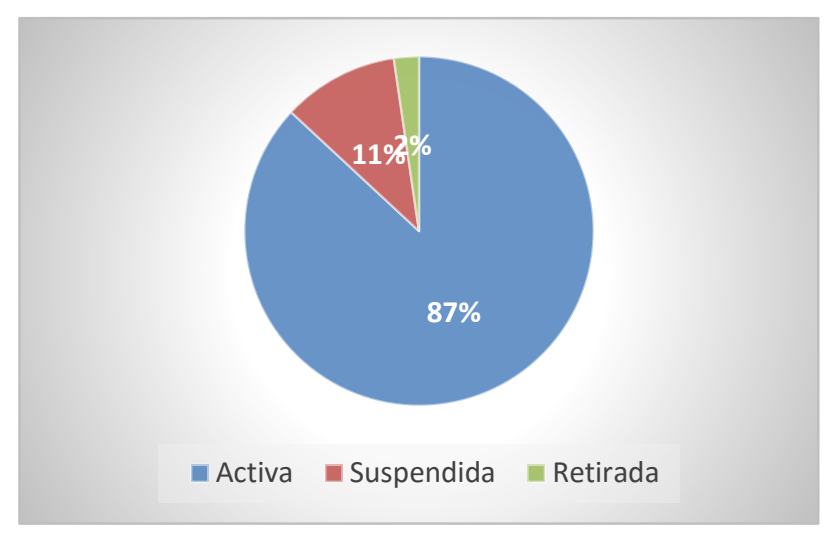

Figura 24. Estado Actual

Al mismo tiempo, las figuras reflejan que actualmente el $77 \%$ de mujeres cuidadoras de niños con discapacidad se encuentran activas en el régimen de salud subsidiada, es decir que es el Estado el responsable de atender y brindar todo tipo de procedimiento que promueva la salud y prevenga 
las enfermedades. No obstante, existe un porcentaje importante de cuidadoras que actualmente no cuentan con el derecho a la salud y por tanto, su calidad de vida y la de su familia se ve permanente amenazada, más aun cuando se tiene una persona con discapacidad la cual requiere de todo tipo de medicamentos y procedimientos para conservar la vida.

\subsubsection{Liderazgo}

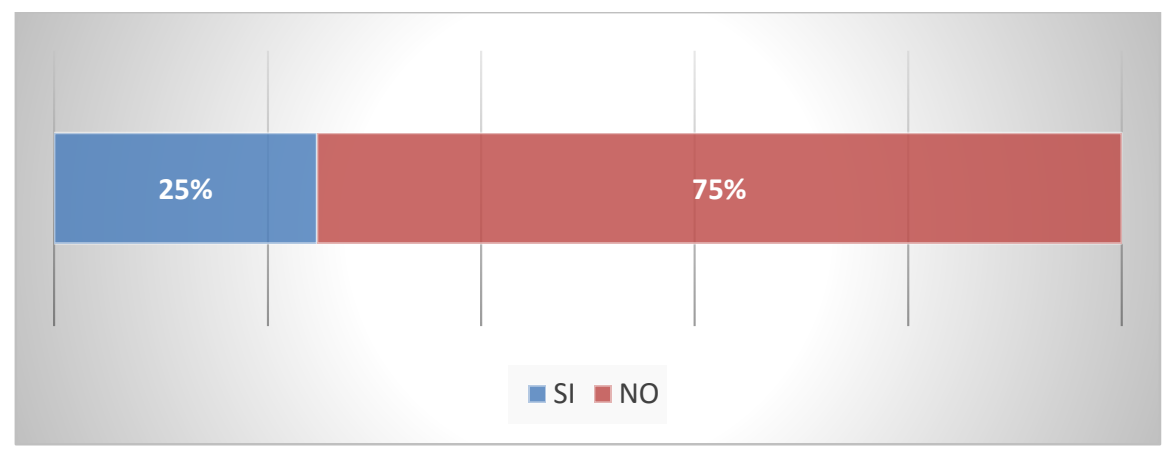

Figura 26. Percepción de Reconocimiento de las Cuidadoras

Teniendo en cuenta el resultado obtenido, la mayor parte de las mujeres cuidadoras de Bosa no se sienten reconocidas o valoradas por la comunidad y las instituciones locales por el ejercicio de cuidado y protección que desarrollan permanentemente. Este tema está relacionado con la discriminación que enfrentan las poblaciones más vulnerables, toda vez que no se logra identificar desde el ámbito social los retos y las limitaciones que enfrentan estas mujeres en su cotidianidad.

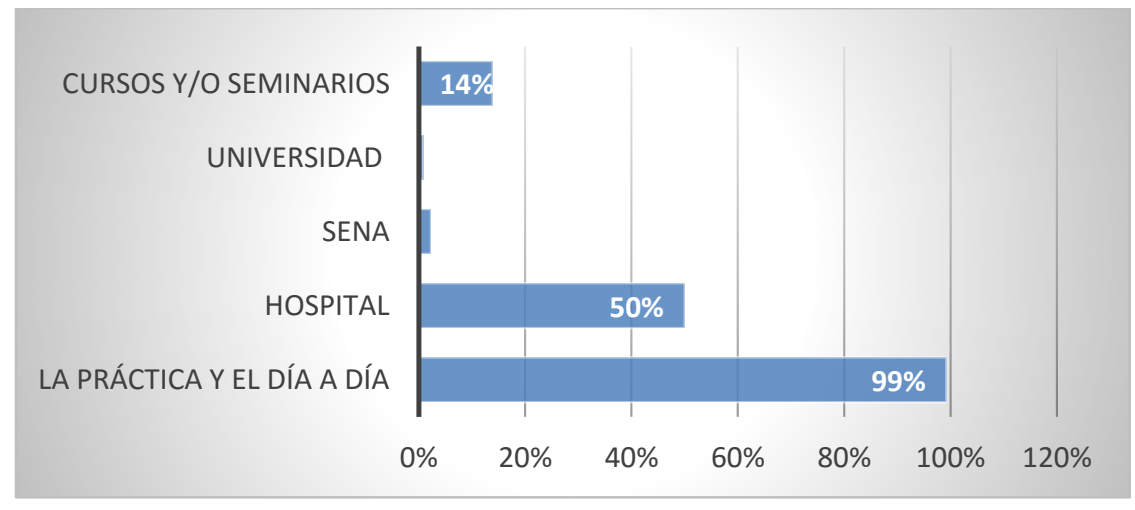

Figura 27. Conocimiento de Cuidado 
La población de mujeres cuidadoras de niños con discapacidad de la localidad de Bosa afirma haber adquirido el conocimiento de esta actividad en la práctica y la cotidianidad; sin embargo, se evidencia un apoyo significativo del hospital de la localidad, quien también brindó herramientas adecuadas para mejorar las prácticas y ejercer con calidad el cuidado.

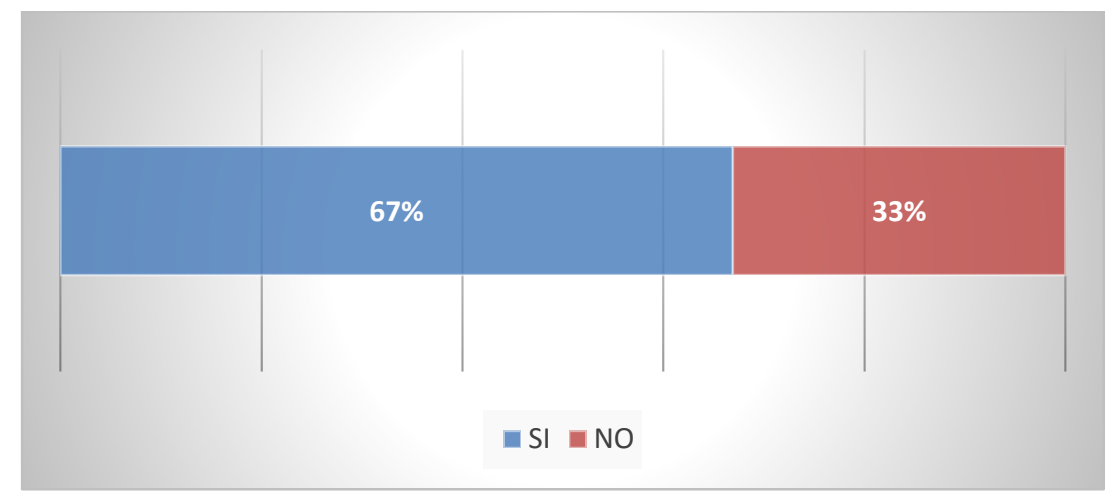

\section{Figura 28. Apoyo Comunitario}

De acuerdo con lo manifestado por las mujeres cuidadoras, el $67 \%$ de ellas están interesadas en multiplicar sus saberes y apoyar a otras mujeres para que puedan adquirir nuevos conocimientos y herramientas que mejoren la calidad de vida de sus hijos en condición de discapacidad; pero el $33 \%$ de ellas no tienen ninguna motivación para hacerlo. Aquí se evidencia que la comunidad de cuidadores no comparte los mismos criterios de apoyo social que puedan lograr la promoción de nuevas y mejores prácticas. 


\subsubsection{Conflictividad}

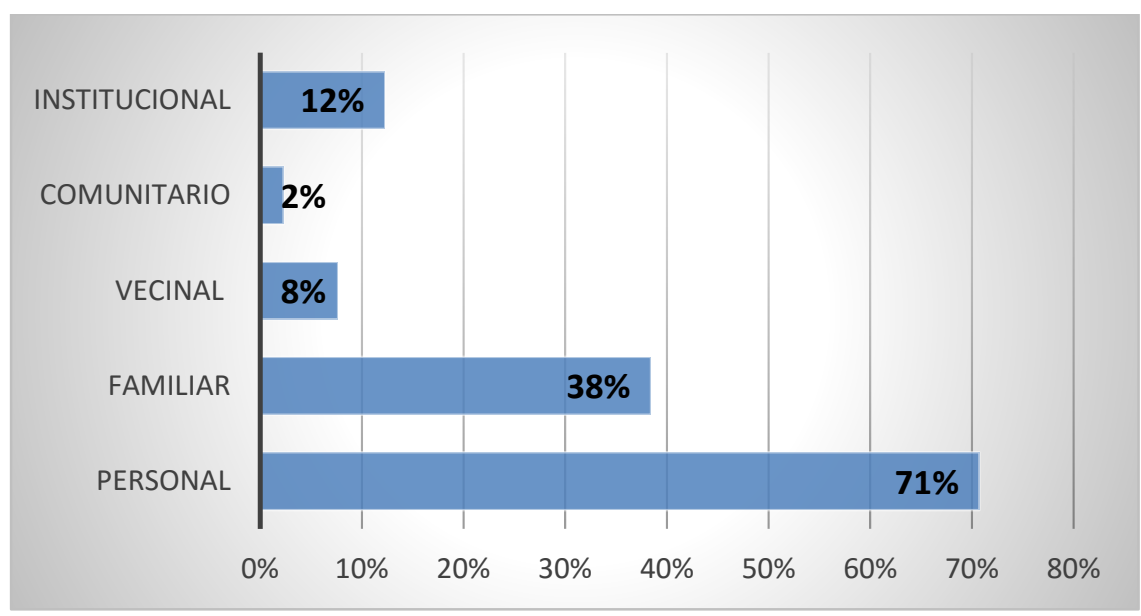

Figura 29. Conflictos por el ejercicio del Cuidado

Tomando en cuenta lo manifestado por las mujeres encuestadas, el $71 \%$ de ellas reconoce que el ejercicio del cuidado le ha generado conflictos personales, pues como se mencionaba, existen sentimientos de soledad y culpa que generan problemas emocionales para las cuidadoras y que no tienen ningún tipo de apoyo psicológico para ello. Así mismo, el $38 \%$ de ellas evidencian conflictos al interior de sus familias, dado que allí se observan situaciones dramáticas para toda la familia como las separaciones y los abandonos recurrentes.

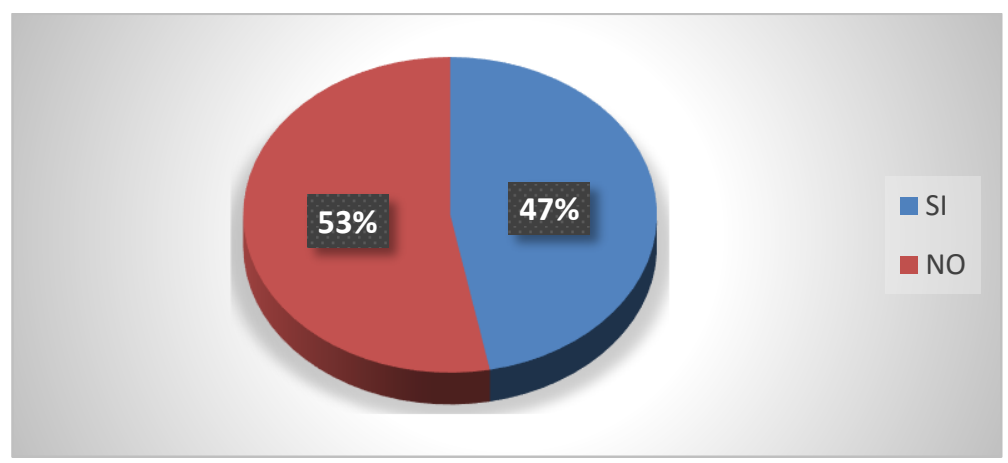

Figura 30. Abandono Familiar

Culturalmente, los hombres han sido formados para tener el control frente a sus realidades, sin embargo, la discapacidad al ser biológica y aun mitológica se vuelve confrontativa y la mayoría 
de ellos, tal como lo afirma el $47 \%$ de las mujeres, deciden no participar del proceso de rehabilitación y formación de sus hijos, pese a la obligación legal que les acoge.

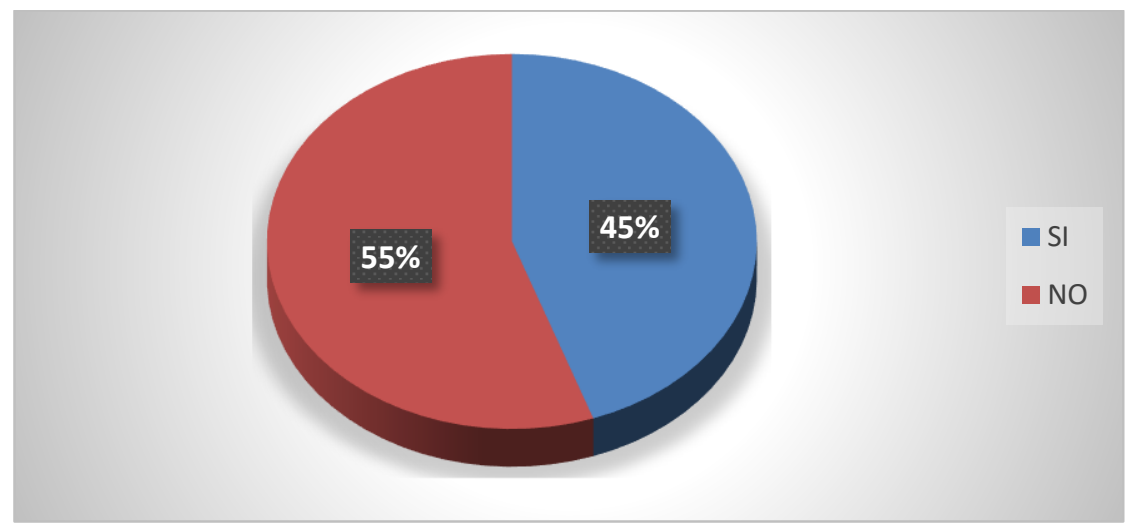

Figura 31. Violencia Intrafamiliar

Según la Secretaría De Cultura, Recreación y Deporte, Dirección de Planeación Proyectos Estratégicos y la Subdirección Análisis Sectorial, Poblacional y Local (2016), la localidad de Bosa ocupa el tercer puesto a nivel distrital en violencia intrafamiliar por hechos de violencia de pareja, como lo asegura el $45 \%$ de cuidadoras, quienes indican haber sufrido en algún momento de su vida violencia múltiple al interior de sus hogares. Situación que promueve la desigualdad de género y la desintegración familiar.

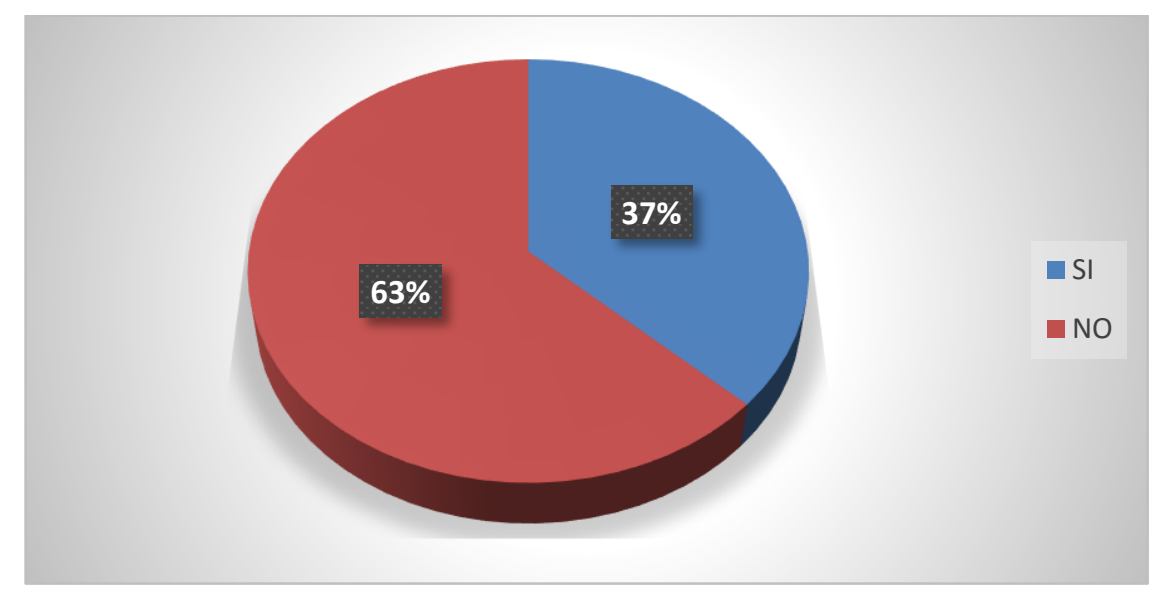

Figura 32. Ejercicio de la mendicidad 
Aunque la mayor parte de las mujeres cuidadoras manifestó no haber tenido que recurrir a la mendicidad para satisfacer las necesidades básicas de su hogar, existe un porcentaje representativo y preocupante que reconoce haber ejercido la mendicidad como única opción para conseguir el alimento para su familia y el acceso a citas médicas o terapias de rehabilitación.

\subsubsection{Derechos}

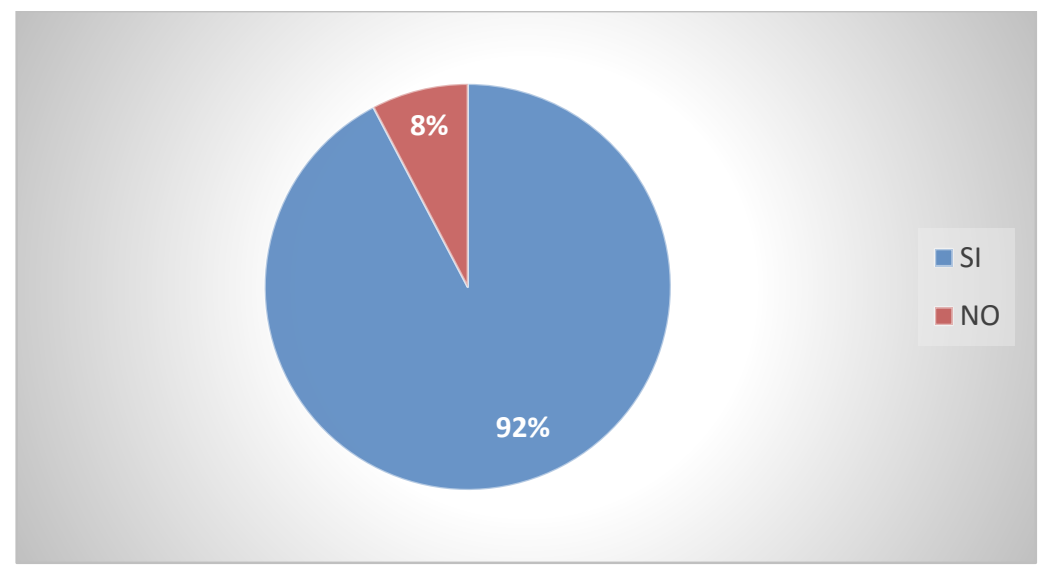

Figura 33. Percepción de Estado

Es de señalar que el $92 \%$ de las mujeres cuidadoras de la localidad de Bosa percibe al Estado como un Aparato de Poder excluyente en su ejercicio diario, pues las condiciones socioeconómicas y laborales que ofrece para ellas, cada vez son más precarias y no están adaptadas a sus necesidades. Igualmente, desconoce la condición de salud de sus hijos, la inexistencia de redes de apoyo y la falta de garantías en el sistema de salud. 


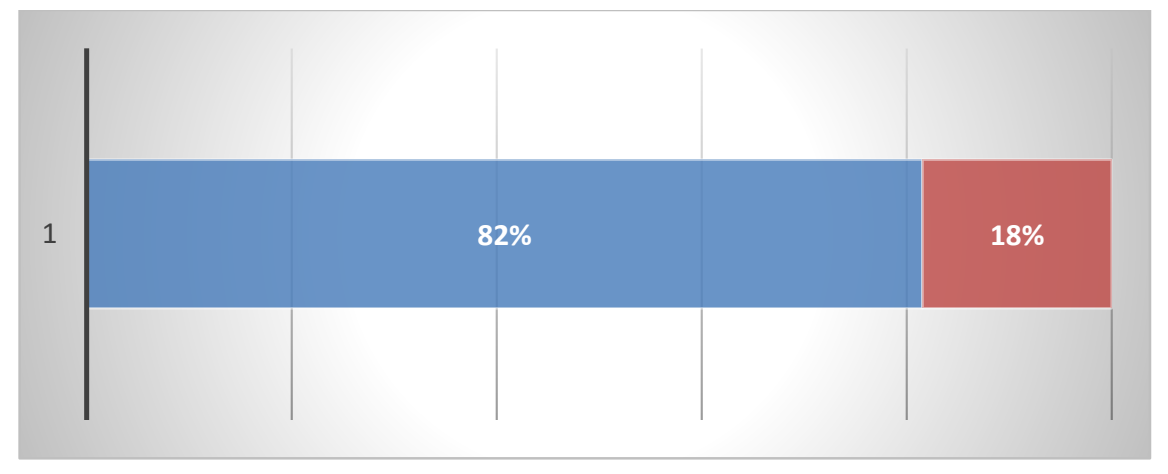

Figura 34. Percepción de género

De acuerdo con la encuesta aplicada, el $82 \%$ de las cuidadoras indicó sentirse más vulnerable por el hecho de ser mujeres tanto en las esferas públicas como privadas, sabiendo que culturalmente no cuentan con las mismas oportunidades que los hombres en cuanto al acceso al trabajo y la educación. Así como les han sido asignadas funciones que aunque son complejas y demandantes no cuentan con ningún tipo de remuneración económica, tales como el oficio doméstico, la crianza y el cuidado.

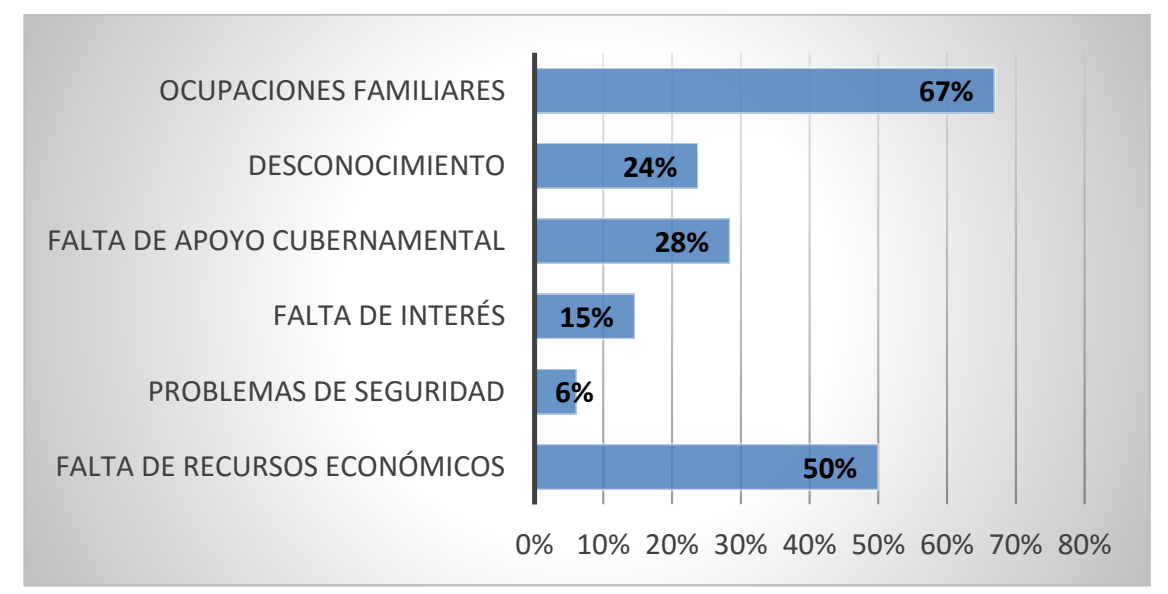

Figura 35. Dificultades de Asociación Comunitaria

Según las participantes, la principal dificultad que enfrentan al momento de gestar una organización de apoyo comunitario para los cuidadores y los niños con discapacidad obedece a la carencia de redes de apoyo para el cumplimiento de sus obligaciones familiares y de cuidado. Del 
mismo modo, la falta de recursos económicos y el desconocimiento técnico les impide iniciar con dichas proyectos, puesto que socialmente existen más fundaciones u organizaciones que entran a licitar por recursos públicos.

Reconocimiento de Políticas Públicas

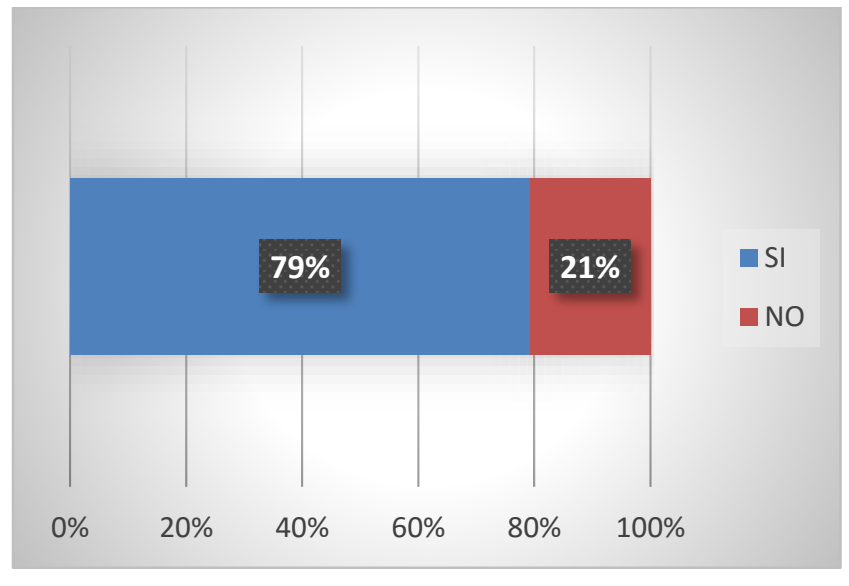

Figura 36. Discapacidad

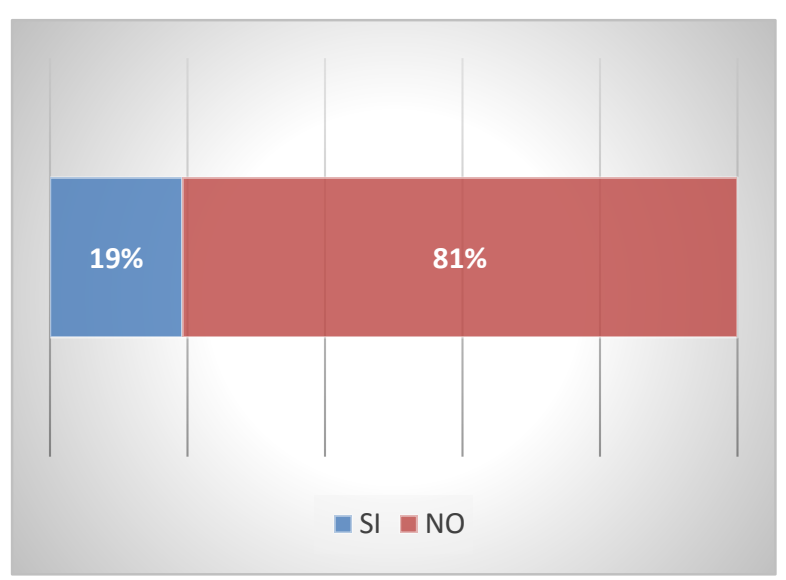

Figura 37. Mujer y Género

En lo que refiere al reconocimiento y apropiación que tienen las mujeres cuidadoras frente a estas dos políticas, se logra evidenciar que a pesar de tener un conocimiento mucho más amplio y vigente de los principios que plantea la política pública de discapacidad, las mujeres desconocen ampliamente la existencia de una política inclusiva y diferencial para ellas. Esto representa que las mujeres, pese a tener una vida políticamente más activa, siguen velando por el bienestar de los demás por encima de sus propios intereses.

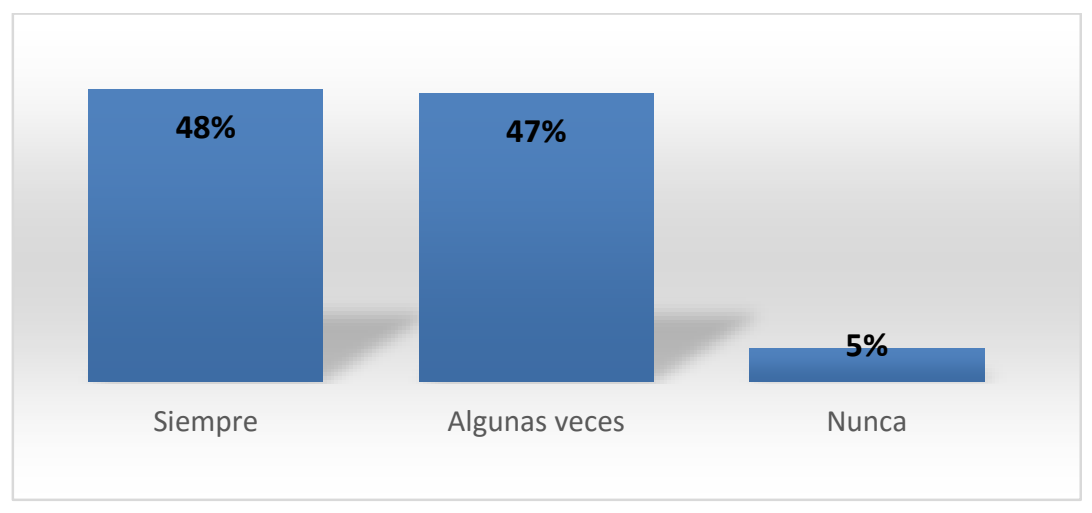

Figura 38. Acceso a bienes y servicios del Estado 
Frente al acceso a bienes y servicios se evidencia que el Estado sigue siendo transversal al bienestar de estas familias, ya que si bien una representación significativa de mujeres indica que es ocasional, no desconoce por completo la labor que realiza el mismo desde la institucionalidad.

\subsubsection{Reconocimiento Institucional}

Barreras de acceso a servicios y mecanismos de exigencia de derechos

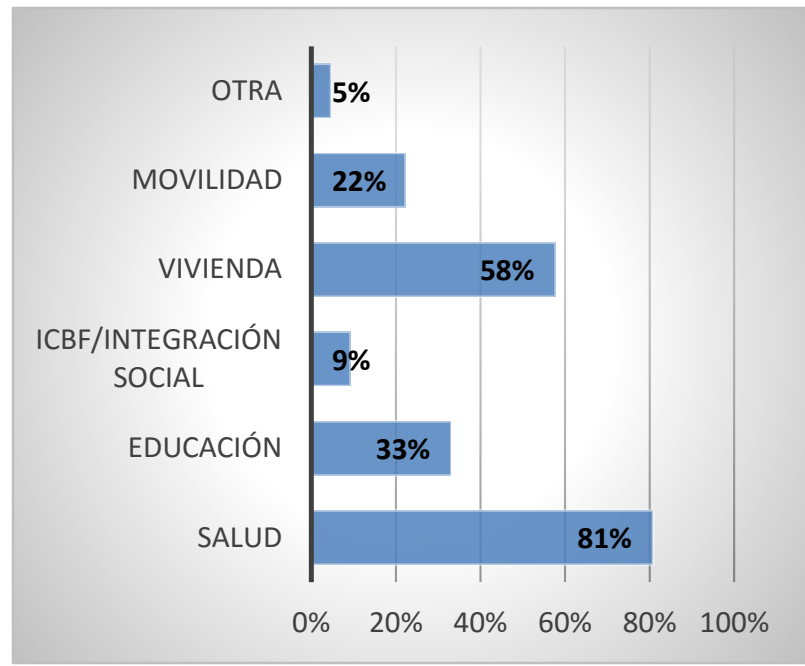

Figura 40. Barreras Institucionales

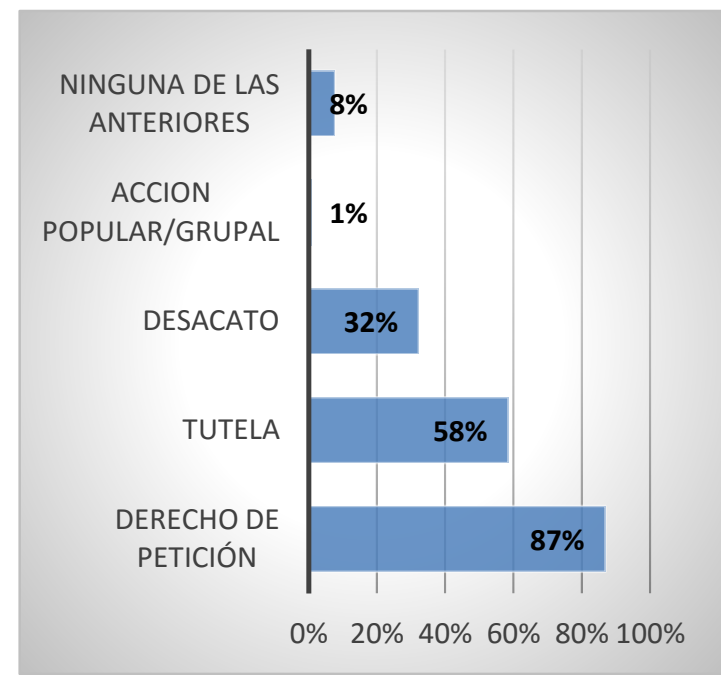

Figura 39. Mecanismos de Protección

Para las mujeres cuidadoras no solo existe una sola entidad a nivel local, cuya operatividad genere dificultades de acceso. Sin embargo, es preocupante que los sistemas de salud y educación como rectores de derechos sean reconocidos por esta población, debido a su falta de garantías y la dificultad en cuanto a rutas y lineamientos de acceso. Bajo ese mismo parámetro, se observa la necesidad que tienen las mujeres cuidadoras de acudir a los mecanismos de protección colombianos, tales como el derecho de petición y la acción de tutela como único medio para lograr la garantía de derechos para sus hijos. 
De igual forma, se evidencia que el desacato se convierte para las cuidadoras, en una figura sumamente importante, pues ilustra la decadencia de los mecanismos de protección y la omisión de las entidades frente a los requerimientos.

\subsubsection{Sujeto}

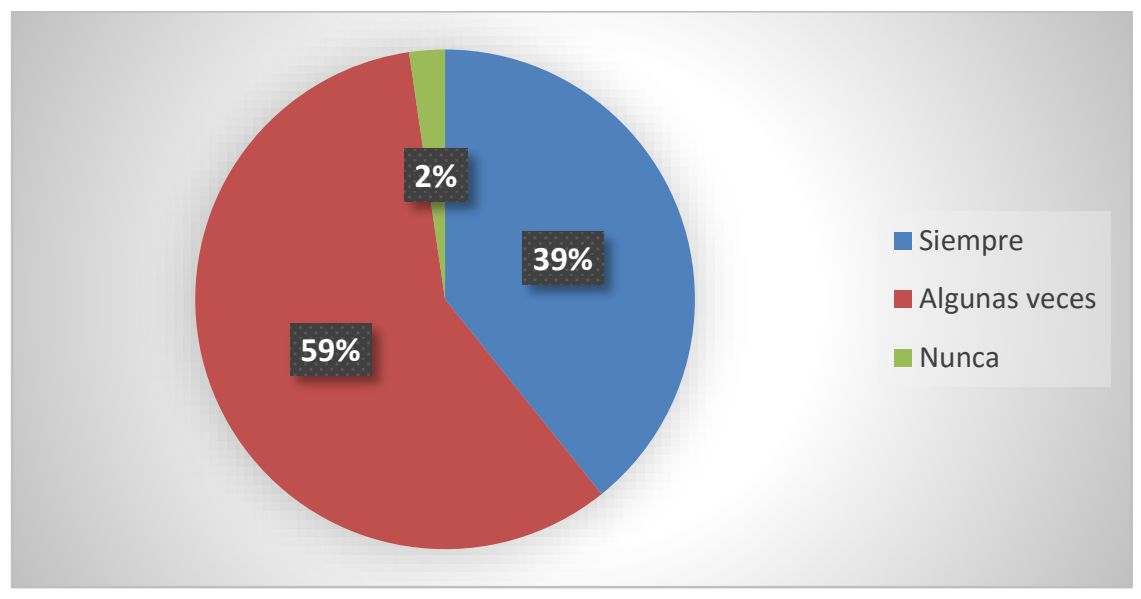

Figura 41. Estabilidad Emocional

De acuerdo con la realidad social y cultural en la que viven las mujeres cuidadoras, se logra observar que a pesar de los avances adquiridos frente al reconocimiento de la discapacidad, para la mayor parte de las encuestadas, su rol como progenitoras, protectoras y cuidadoras las sigue confrontando, de manera tal que su estado de tranquilidad y estabilidad emocional se ve afectado negativamente. Aquí se evidencia, entonces, que la discapacidad y el cuidado siguen siendo un tema exclusivo del ámbito privado y con responsabilidades propias de género, lo cual perpetúa la desigualdad y la exclusión social. 


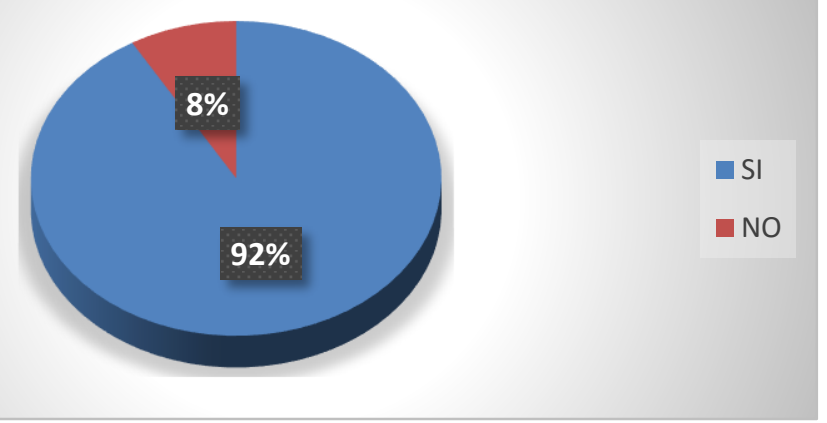

Figura 42. Percepción del Cuidado

Para la mayor parte de las mujeres encuestadas, la labor de cuidado es fundamental para la comunidad, pues son ellas las encargadas de generar calidad de vida en un Estado que según ellas no ofrece garantías para las personas en condición de discapacidad. No obstante, el $8 \%$ de las encuestadas también infieren que su labor no es importante y esto puede ser la consecuencia de la falta de interés gubernamental que desmotiva los intereses de las comunidades.

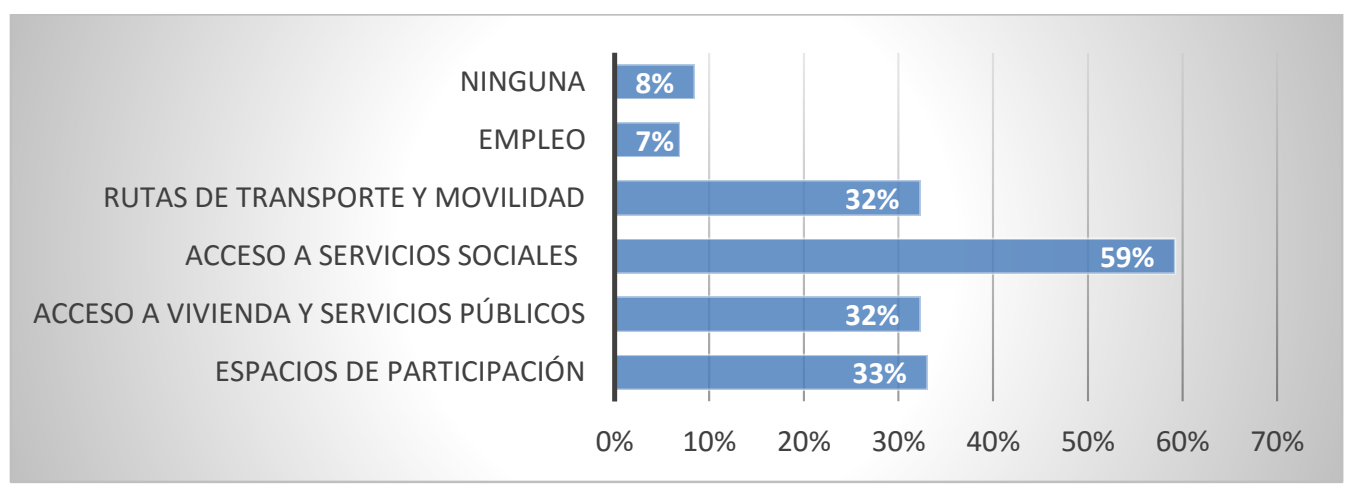

Figura 43. Garantías Locales

Concluyendo, para las mujeres cuidadoras existe una apropiación sobre su territorio que les permite sentirse parte de una comunidad, ya que reconocen que allí han logrado acceder a todo tipo de programas de asistencia social y a espacios de participación política en donde han podido apropiarse de su ser y su realidad para mejorar el bienestar de toda una comunidad. 


\subsection{Descripción de roles sociales y políticos}

Una vez realizado el proceso de caracterización de las condiciones generales de las mujeres cuidadoras, la investigadora logró a través de la puesta en marcha de la Fase II de la metodología seleccionada, identificar y describir los roles sociales y políticos desarrollados por las mujeres cuidadoras de niños con discapacidad, en el contexto de la institucionalidad local, a partir de cinco entrevistas semiestructuradas, las cuales fueron diseñadas y aplicadas a un profesional del Instituto Colombiano de Bienestar Familiar, Secretaría de Integración social, Secretaría Distrital de Educación, Hospital Pablo VI y Consejo Local de Discapacidad, cuya misionalidad se enfoca en la atención y acompañamiento de las personas en condición de discapacidad y sus familias en la localidad de Bosa.

Allí se seleccionaron siete categorías de análisis y se desarrollaron dos fases dentro de dicho proceso; en primer lugar, se tomó de manera individual cada una de las entrevistas en aras de realizar un estudio a profundidad sobre los aspectos relevantes del rol social y político ejercido por las mujeres cuidadoras; y en segunda instancia, se tomaron puntos de consensos entre cada una de ellas para llegar al análisis final.

Teniendo en cuenta lo anterior, a continuación, se ilustra por medio de una síntesis los elementos principales en el ejercicio sociopolítico de las mujeres cuidadoras y la descripción de cada uno de ellos: 
Tabla 1. El Rol Sociopolítico desde el Contexto Local. Síntesis

\begin{tabular}{|c|c|}
\hline CATEGORÍAS & ANÁLISIS \\
\hline \multirow[t]{9}{*}{$\begin{array}{l}\text { IDENTIFICA- } \\
\text { CIÓN }\end{array}$} & $\begin{array}{l}\text { i. Las mujeres cuidadoras hacen parte de familias monoparentales o extensas ya que son } \\
\text { abandonadas por su pareja. }\end{array}$ \\
\hline & ii. Las mujeres cuidadoras no cuentan con redes de apoyo efectivas. \\
\hline & $\begin{array}{l}\text { iii. Algunas mujeres cuidadoras migraron a la Ciudad de Bogotá a causa del Conflicto Ar- } \\
\text { mado. }\end{array}$ \\
\hline & iv. Las mujeres cuidadoras presentan condiciones de pobreza acentuadas. \\
\hline & v. La mayoría de las mujeres cuidadoras presentan bajo nivel educativo. \\
\hline & $\begin{array}{l}\text { vi. En algunos casos las mujeres cuidadoras tienen más de un hijo o familiar en condición } \\
\text { de discapacidad. }\end{array}$ \\
\hline & vii. Las mujeres cuidadoras se convierten en sobreprotectoras de sus hijos. \\
\hline & $\begin{array}{l}\text { viii. Se evidencia que las mujeres cuidadoras establecen formas de comunicación alternas } \\
\text { con sus hijos, logrando identificar sus necesidades. }\end{array}$ \\
\hline & $\begin{array}{l}\text { ix. Algunas mujeres deciden abandonar su hijo con discapacidad y son los abuelos quienes } \\
\text { a pesar de su edad, asumen el procedo de cuidadores. }\end{array}$ \\
\hline \multirow[t]{5}{*}{ LIDERAZGO } & $\begin{array}{l}\text { i. Las mujeres cuidadoras se han abierto campo en todos los espacios de participación tanto } \\
\text { a nivel local como distrital. }\end{array}$ \\
\hline & $\begin{array}{l}\text { ii. Desde la cotidianidad y falta de respuesta de las instituciones como Salud, las mujeres } \\
\text { cuidadoras empiezan a dar respuesta desde sus propios medios a la necesidad de sus hijos } \\
\text { como la rehabilitación, los mecanismos de protección y la educación. }\end{array}$ \\
\hline & $\begin{array}{l}\text { iii. Las mujeres cuidadoras han construido verdaderas redes de apoyo comunitarias como } \\
\text { mecanismo de exigencia de derechos. }\end{array}$ \\
\hline & $\begin{array}{l}\text { iv. Las mujeres cuidadoras se convierten en veedoras críticas de los programas de atención } \\
\text { para los niños con discapacidad. }\end{array}$ \\
\hline & $\begin{array}{l}\text { v. Aunque progresivamente los hombres también han empezado asumir el rol de cuidador } \\
\text { de manera empoderada, las mujeres por tradición cultural siguen siendo las encargadas de } \\
\text { ello. }\end{array}$ \\
\hline \multirow[t]{4}{*}{$\begin{array}{l}\text { PROTECCIÓN } \\
\text { SOCIAL }\end{array}$} & $\begin{array}{l}\text { i. Los programas de asistencia social tienen como objetivo el fortalecimiento de habilida- } \\
\text { des sociales, comunitarias y el restablecimiento de derechos, a través de proyectos específi- } \\
\text { cos desde cada área. }\end{array}$ \\
\hline & ii. La cobertura de los proyectos es significativa e impacta a la comunidad local y distrital. \\
\hline & $\begin{array}{l}\text { iii. La condición laboral del talento humano que trabaja con las mujeres cuidadoras es pre- } \\
\text { caria, pues no cuentan con contratos de trabajo prolongados y por tanto existe mucha rota- } \\
\text { ción en las entidades. }\end{array}$ \\
\hline & $\begin{array}{c}\text { iv. La condición económica de las mujeres cuidadoras es deficiente pues, por su ejercicio } \\
\text { no logran vincularse a un trabajo formal que le brinde las prestaciones de ley, no cuentan } \\
\text { con el apoyo de los progenitores de sus hijos y las necesidades de los hogares van incre- } \\
\text { mentando en la medida en que los hijos van creciendo. }\end{array}$ \\
\hline
\end{tabular}


v. Las ofertas laborales a las que tienen acceso las mujeres cuidadoras son trabajos informales, esporádicos y mal remunerados tales como ventas ambulantes, oficios varios, promoción de catálogos de belleza, auxiliares de cocina, costuras, cuidado de otros niños o personas.

vi. El Estado no promueve acciones significativas para que las mujeres cuidadoras tengan algún tipo de seguridad económica en la vejez.

vii. Las mujeres cuidadoras están expuestas a todos los riesgos que puedan emerger tanto por su ejercicio de cuidado como en las formas laborales que encuentran.

viii. El Sistema de Salud colombiano es quien paradójicamente le interpone más barreras a estas mujeres pues su ejercicio es demasiado discreto.

ix. Colombia no tiene estructuralmente definido estrategias de abordaje tanto para la discapacidad como para la vejez.

RECONOCIMIENTO INSTITUCIONAL i. El Estado debe seguir construyéndose a partir de la identificación de las necesidades de su población en mayores niveles de exclusión y pobreza tanto del área rural como urbano.

ii. Las instituciones avanzan en el planteamiento de estrategias de abordaje desde el ámbito comunitario.

iii. No hay disposición política para que la calidad de vida de las personas con discapacidad y sus familias mejore.

iv. El SPS es aún muy joven y debe encaminarse en las verdaderas necesidades de la ciudadanía.

v. La discapacidad mental psicosocial no ha logrado articularse interinstitucionalmente.

vi. El Estado debe brindar herramientas para que las mujeres cuidadoras logren ser autónomas y no dependan de la asistencia social.

CONFLICTIVI- i. En las instituciones se debe mejorar los procesos de selección del talento humano, dado DAD que para algunos el trabajo con personas con discapacidad y sus familias son poco importante.

ii. La institucionalidad no tiene los mecanismos necesarios para divulgar de manera oportuna y masiva información de interés para las mujeres cuidadoras.

iii. Fenómenos como la desviación de recursos y la corrupción afecta directamente los programas de asistencia social en el país.

iv. Las mujeres cuidadoras no logran unificar criterios entre ellas y por tanto, no hay solidaridad ni unión lo que ha dificultado la aprobación de diferentes iniciativas.

v. Las mujeres cuidadoras al no tener ningún de tipo de apoyo, descuidan por completo sus hogares y se evidencian fenómenos como el abandono y el consumo de SPA.

vi. Los programas con mayor presupuesto se enmarcan únicamente en la infancia y se descuida la etapa de la juventud y la adultez. 
i. Las mujeres cuidadoras y sus hijos deben ser atendidos de manera integral y articulada por todas las entidades del Gobierno ya sea Local, Distrital o Nacional.

ii. Los cambios de administración afectan considerablemente los programas de asistencia social dirigidos a la discapacidad y a sus cuidadores.

iii. Las mujeres cuidadoras asisten todo el tiempo a la institucionalidad porque no cuentan con ningún tipo de apoyo o garantía para el bienestar de su familia.

iv. La condición de pobreza en la que viven las mujeres cuidadoras dependen de una falla estructural del Estado dado a que la discapacidad no es importante y menos el cuidado.

v. Aunque la Salud y la Educación son un derecho universal, estos no se materializan.

vi. Los programas de atención deben ser dirigidos a todos los estratos socioeconómicos, pues la discapacidad desconoce estratos.

vii. Algunas mujeres cuidadoras desarrollan dependencia al Estado y no se interesan por acceder a programas de formación o emprendimiento.

SUJETO i. La mayoría de las entidades locales identifican la necesidad que tiene el talento humano de cualificarse en temas propios de la discapacidad y su política pública.

ii. Las mujeres cuidadoras, luego de recibir el diagnostico de su hijo, comienzan a transformar toda su realidad en función de ellos y su máximo interés es defender sus derechos por encima de los de ellas mismas.

iii. Las mujeres cuidadoras están expuestas permanentemente a factores de exclusión socioeconómica, puesto que no cuentan con una política pública o alguna jurisprudencia que garantice sus derechos.

iv. Las mujeres antes de empezar a ejercer un rol político, inician en ello por temas de supervivencia y debido a la necesidad que las apremia.

v. Las mujeres son fundamentales en el desarrollo de un Estado.

vi. El gobierno ha venido realizando un ejercicio importante en la atención de las mujeres cuidadoras; no obstante, algunas de ellas lo responsabilizan de su situación y no están interesadas en establecer una relación de corresponsabilidad.

vii. Las mujeres cuidadoras se enfrentan a problemas con sus demás hijos por el descuido en el que terminan.

viii. Las instituciones en las últimas administraciones han empezado por implementar programas de liderazgo y empoderamiento.

De acuerdo con lo analizado en las cinco entrevistas, cuyos protagonistas fueron funcionarios

de las entidades locales que brindan apoyo y acompañamiento a los niños con discapacidad y sus

familias en la Localidad Séptima del Distrito, las mujeres que ejercen el cuidado allí se identifican

por pertenecer a familias monoparentales o extensas, ya que sufren el abandono permanente de sus 
parejas sentimentales, o en algunos casos son las mujeres quienes abandonan el hogar, es entonces cuando los abuelos se encargan de ejercer el cuidado y la protección de los niños con discapacidad; aunado a ello, carecen de redes de apoyo efectivas tanto a nivel social como familiar que les permitan mejorar su calidad de vida, lo cual perpetua los ciclos de pobreza extrema en estas personas y sus familias.

Asimismo, Bosa presenta, según los entrevistados, una particularidad, puesto que las mujeres cuidadoras tienen en su familia a más de un integrante en condición de discapacidad, lo que les impide continuar con su proyecto de vida en el marco del acceso a la educación básica y superior, por tanto, son personas que presentan bajos niveles de formación. No obstante, estas mujeres han adquirido habilidades de cuidado importantes que facilitan la construcción de canales de comunicación no convencionales y la identificación de necesidades básicas, convirtiéndose en sobreprotectoras de sus hijos.

Ahora bien, teniendo en cuenta las condiciones sociopolíticas del país, se evidencia que algunas mujeres cuidadoras llegaron a la ciudad de Bogotá por causa del Conflicto Armado Interno, generando un desarraigo cultural y la perdida de tradiciones propias de los territorios. Adicionalmente, su proceso de reparación administrativa ha sido lento y su acceso a la justicia restaurativa ha sido limitado. Pese a las limitaciones que enfrentan las mujeres cuidadoras en su cotidianidad, las entidades consideran que la falta de respuestas oportunas por parte del Estado ante sus necesidades, les ha permitido a este grupo poblacional recurrir a mecanismos de protección (conocidos progresivamente) con recursos propios, para que sus hijos puedan acceder a espacios de rehabilitación y educación.

En ese orden de ideas, las cuidadoras han construido verdaderas redes de apoyo comunitario desde la necesidad de visibilizar la desprotección y la desigualdad en la que se encuentran y su 
objetivo principal obedece tanto a su inmersión en espacios de participación local y distrital, como a la promulgación abierta de las condiciones socioeconómicas y familiares que presentan. En consecuencia de esto, las mujeres cuidadoras se convierten en veedoras críticas de los programas y proyectos dirigidos a la atención de los niños en condición de discapacidad.

Además, la institucionalidad reconoce que Colombia es un país que sigue manteniendo tradiciones culturales arraigadas al rol cuidador obligatorio de las mujeres; empero, identifican que los hombres progresivamente han asumido una postura más corresponsable con el ejercicio del cuidado y la protección de los niños especialmente, cuando presentan una discapacidad o enfermedad de alto costo, siendo un apoyo fundamental para sus hijos y familias en general.

Por otro lado, los funcionarios concluyen que frente al Sistema de Protección Social colombiano, las mujeres cuidadoras, por su mismo ejercicio, no pueden acceder a un trabajo formal con un salario fijo y las prestaciones de ley correspondientes, debido a que las empresas requieren de disponibilidad de tiempo y cumplimiento de metas. Motivo por el cual las ofertas laborales a las que tienen acceso las mujeres cuidadoras se enmarcan en la informalidad (ventas ambulantes, aseo en casas de familia, promoción de catálogos de belleza, auxiliares de cocina, costura y cuidado de otros niños o personas mayores) y en la explotación económica.

Teniendo presente lo anterior, los entrevistados coinciden en que las mujeres cuidadoras están más expuestas a toda clase de riesgos ya sea por su labor del cuidado o por las actividades remuneradas que desempeñan, paradójicamente, consideran que el Sistema de Salud es uno de ellos, en tanto no les garantiza intervenciones mínimas que mejoren la calidad de vida de sus hijos o de ellas mismas; no cuentan con acciones significativas por parte del Estado que respondan a su seguridad económica actual, pero tampoco en la etapa de la vejez. Colombia tiene dificultades estructurales muy importantes frente al abordaje institucional de la discapacidad y la vejez. 
Hay que mencionar la trascendencia que tienen los proyectos y programas de asistencia social, pues los entrevistados infieren que el objetivo de los mismos se enmarca en el fortalecimiento de habilidades sociales y el restablecimiento de derechos, su cobertura a nivel local es significativa e impactan positivamente a la comunidad. Empero, la condición laboral del talento humano que trabaja con las mujeres cuidadoras y los niños con discapacidad es precaria, dado que según los participantes, los contratos son de pocos meses y existe rotación masiva del personal, lo cual impide la continuidad en los proceso de acompañamiento.

El siguiente aspecto identificado por las entidades locales corresponde a la falta de disposición política, para que la calidad de vida de las personas con discapacidad y sus cuidadoras mejore, toda vez que manifiestan que el Estado debe construirse a partir de la identificación de las necesidades de su población con mayores niveles de exclusión y pobreza tanto del área rural como urbano, logrando con ello brindar mejores herramientas para que los más necesitados logren ser autónomos y no dependen permanentemente de la asistencia social.

Particularmente, los entrevistados refieren que la discapacidad mental psicosocial no ha logrado articularse interinstitucionalmente y por ende, no se atiende de manera integral. A nivel de derechos, los funcionarios expresan que la atención a los niños con discapacidad y sus cuidadores debe ser de manera integral y articulada por todas las entidades del gobierno, ya sea de carácter local, distrital o nacional, ya que la centralización de recursos e intervenciones desconoce la corresponsabilidad de los diferentes sectores y sobre todo, estigmatiza la discapacidad como algo minoritario y sin importancia. Es por ello que los funcionarios manifiestan la importancia de extender la cobertura de los programas de atención a todos los estratos socioeconómicos, puesto que la discapacidad y sus consecuencias sociofamiliares se presentan en todas las sociedades. 
Aunado a lo anterior, las entidades identifican que los sistemas de Salud y Educación, aunque son derechos universales, no se materializan en la cotidianidad de las comunidades y exponen a las cuidadoras a asumir responsabilidades ajenas a sus recursos, generando dependencia a los servicios sociales como forma de garantía de sus derechos y en algunos casos, los entrevistados observan que la dependencia severa ocasiona falta de interés para acceder a programas de formación y/o emprendimiento.

Simultáneamente, los funcionarios evidencian que las mujeres cuidadoras se enfrentan a problemas familiares relevantes, sobre todo con sus demás hijos, puesto que se genera un descuido a las necesidades de estos y estos convergen en problemas de comportamiento, riesgo de violencias e inicio en consumo de alcohol o sustancias psicoactivas.

Con respecto a lo anterior, las entidades también analizan cinco aspectos fundamentales en la presentación de los servicios y que influye negativamente en la cotidianidad de las mujeres cuidadoras; inicialmente, plantean la necesidad que tienen las instituciones de mejorar sus procesos de selección del talento humano, debido a que existen profesionales que no tienen la vocación ni las aptitudes para la intervención con personas con discapacidad y sus familias. En segunda instancia, las entidades no cuentan con los mecanismos de divulgación requeridos para informar de manera oportuna y efectiva a la población acerca de actividades a desarrollar y todo tipo de información de interés.

Así mismo, existen fenómenos recurrentes como la desviación de recursos y la corrupción que afectan directamente los programas de asistencia social en el país, sumado a los cambios recurrentes de administraciones los cuales, no permiten la continuidad de los servicios o transforman los enfoques de atención. Como cuarto aspecto, los profesionales indican que los programas con mayores presupuestos se concentran en la infancia (0 a 18 años), descuidando así, 
la atención de las personas con discapacidad que se encuentran en ciclo vital de la juventud y/o la adultez, situación que perpetua su condición de fragilidad y vulnerabilidad socioeconómica.

Finalmente, se perciben relaciones sociales conflictivas entre el grupo de mujeres cuidadoras, pues no logran unificar esfuerzos y conocimientos para promover acciones puntuales ante el gobierno local y distrital que garantice la satisfacción de sus necesidades y su incursión en escenarios sociopolíticos decisivos para la comunidad en general.

\subsection{Construcción del sujeto sociopolítico}

En cumplimiento del tercer objetivo planteado en el presente estudio, la investigadora logró explicar cómo ha sido el proceso de construcción de las mujeres cuidadoras de niños con discapacidad como sujetos sociopolíticos, en el marco de la pobreza, inequidad y discriminación de género, a partir del análisis de cuatro historias de vida, en las cuales se abordaron las diferentes etapas del ciclo vital y los contextos familiares, culturales y comunitarios.

Para ello, se tomaron siete categorías de análisis y de manera individual se realizó un estudio holístico sobre los aspectos relevantes que conllevaron a la construcción sociopolítica de las mujeres; igualmente, se tomaron los puntos de consenso y los aspectos sociofamiliares, económicos, políticos y culturales más reiterativos en las cuatro historias de vida, para llegar al análisis final y evidenciar la realidad de las mujeres cuidadoras. Tal como se describe a continuación:

Tabla 2. El Ser. Sintesis

CATEGORÍAS

ANÁLISIS 


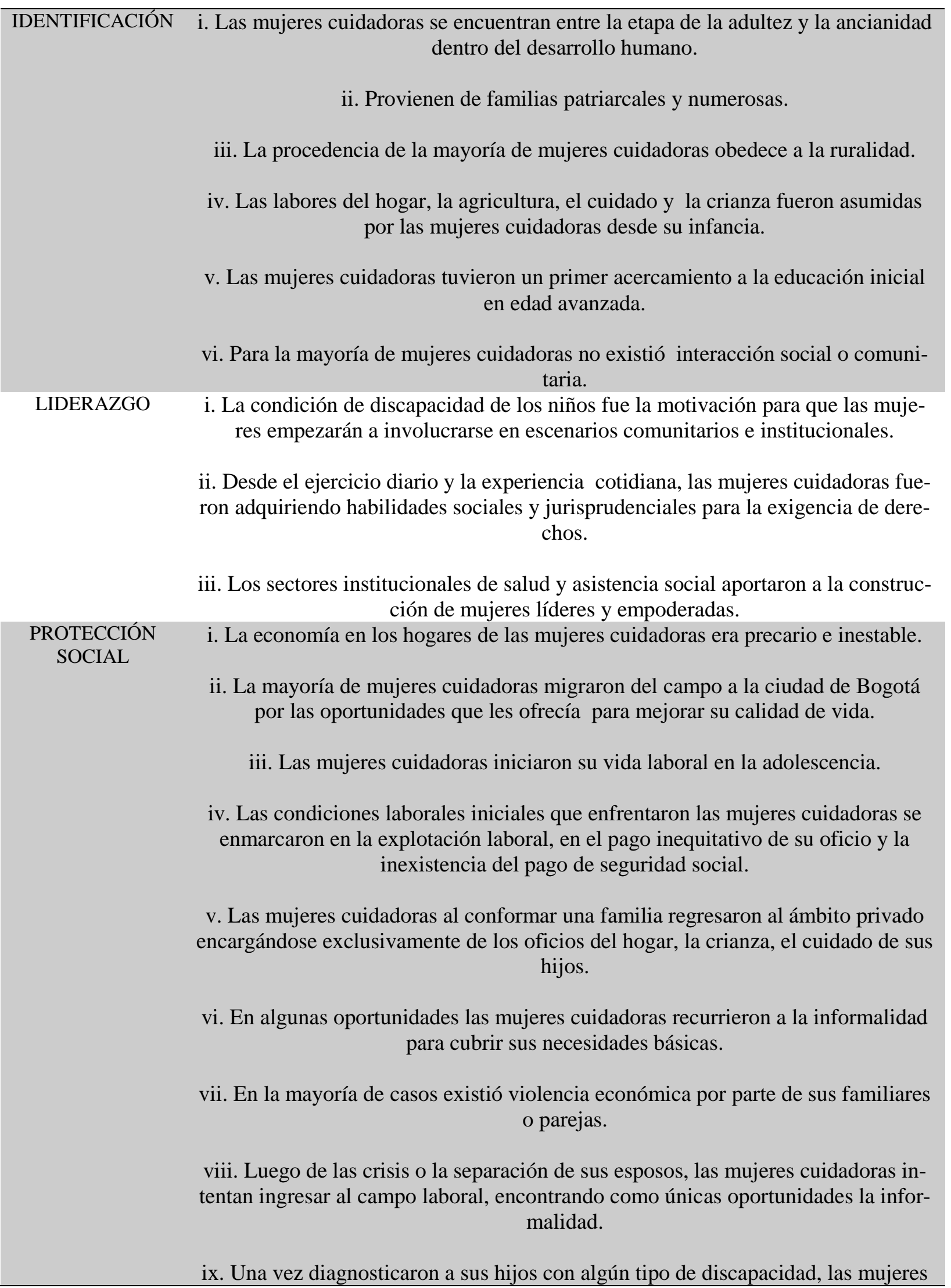




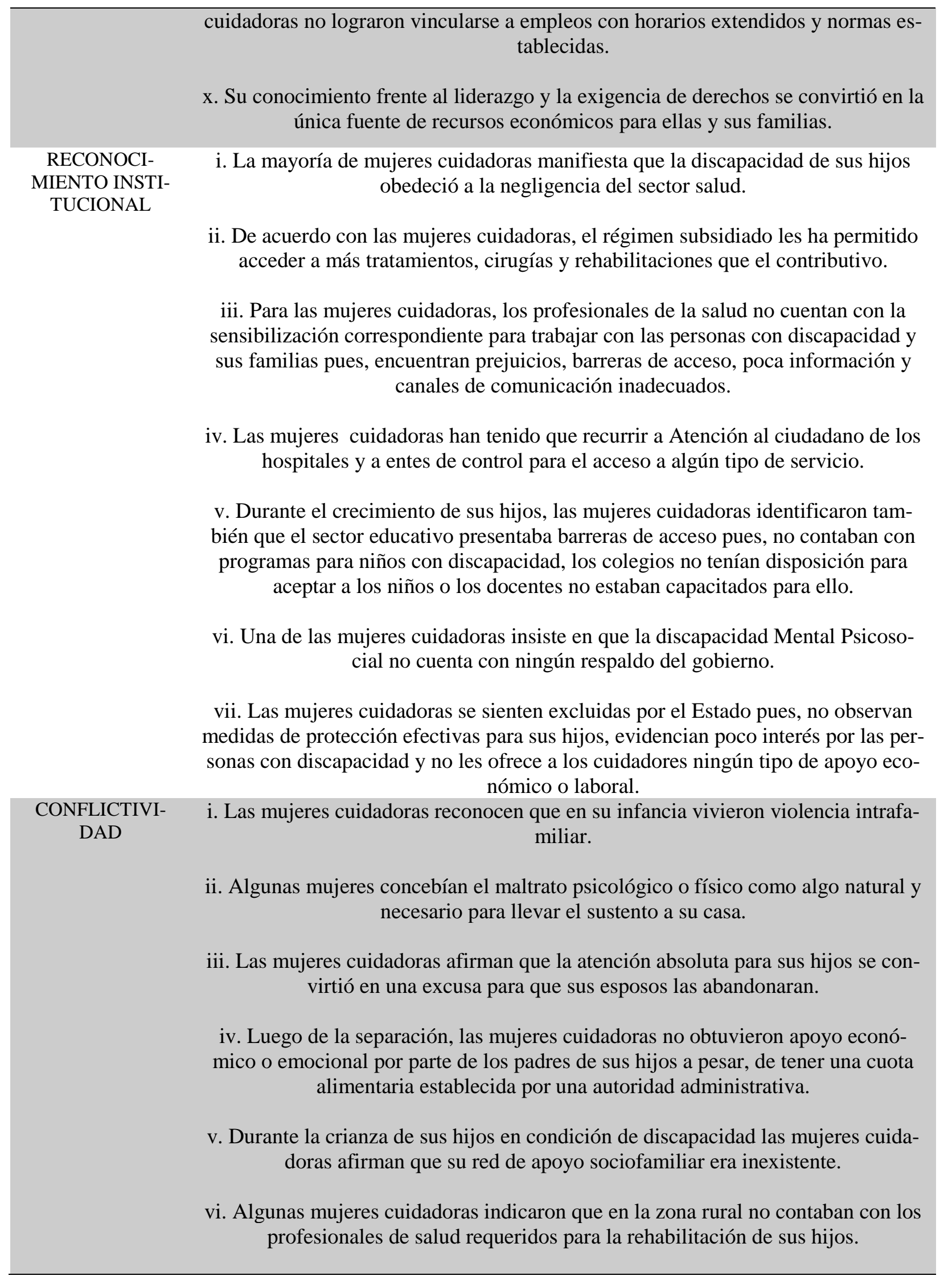




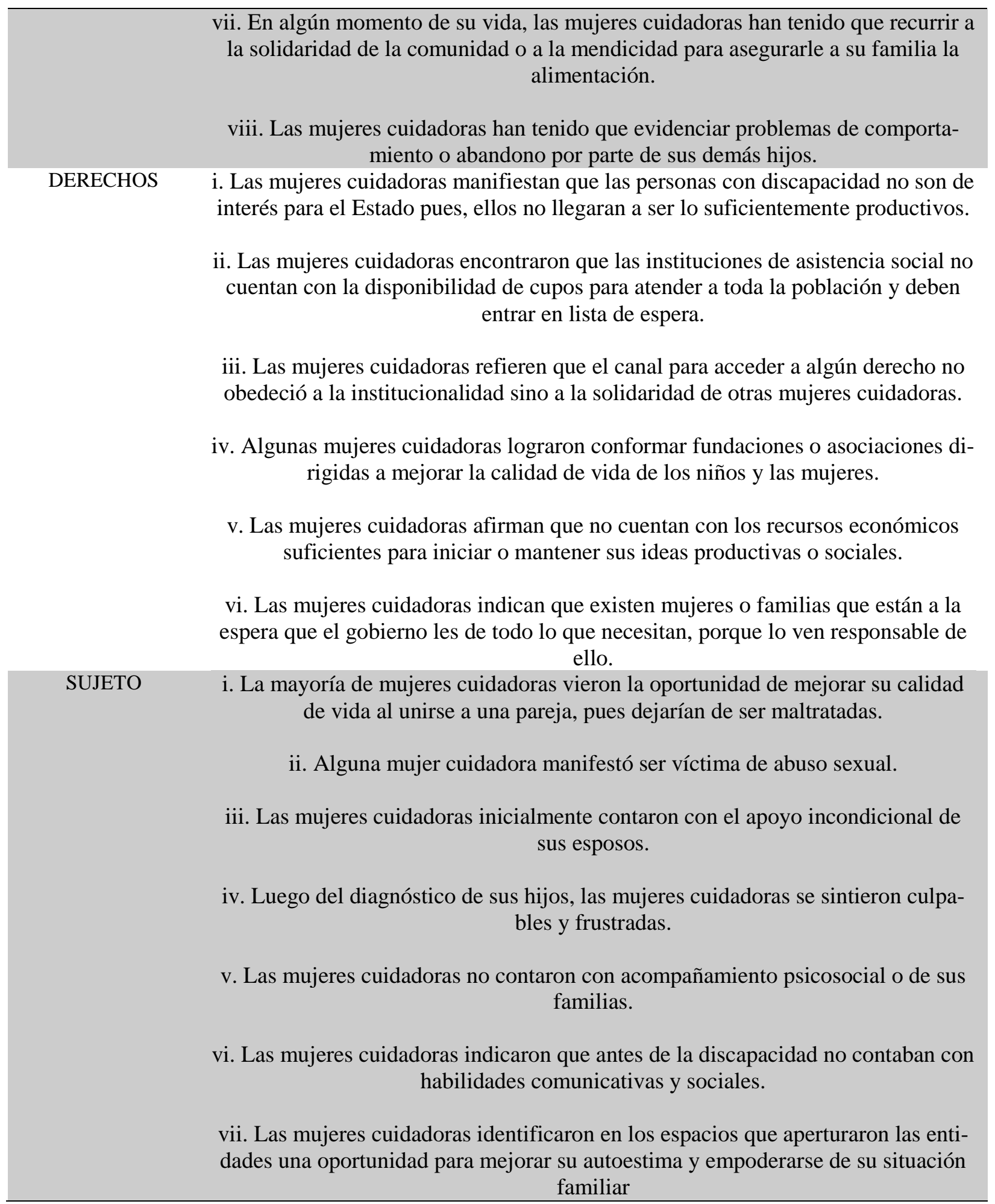

A partir de lo descrito en la síntesis, se identifica que las mujeres cuidadoras están en la etapa de la adultez y la ancianidad dentro del desarrollo humano, provienen de familias patriarcales y 
numerosas, dado que nacieron y vivieron sus primeros años en la zona rural del país; por tanto, desde su niñez aprendieron y desarrollaron actividades propias del hogar como el aseo, la organización, la preparación de alimentos para los empleados y la familia, el cuidado y la protección de hermanos o familiares menores, así como labores de agricultura.

Es por ello que las mujeres cuidadoras relacionan su crianza tradicional con la imposibilidad de participar en escenarios sociales o comunitarios por la dinámica de la jefatura de hogar; de igual manera, el acceso a la educación inicial se produjo en edades avanzadas y estaban completamente ligadas a las voluntades sociofamiliares. Ahora bien, frente al sistema de la protección social, se evidencia que las mujeres cuidadoras provienen de hogares cuya economía fueron predominantemente precarias e inestables, motivo por el cual debieron emplearse desde su adolescencia en trabajos mal remunerados, con múltiples actividades a realizar y no contaron con garantías de acceso al sistema general de seguridad social.

Teniendo en cuenta lo anterior, las participantes se vieron obligadas a migrar a la ciudad de Bogotá, en aras de mejorar su calidad de vida pues, en sus municipios no contaron con el acceso laboral, médico y económico requerido; situación que generó desarraigo cultural en sus hijos, desaparición de tradiciones, fragilidad en sus redes familiares y confrontaciones emocionales, toda vez que no conocían la ciudad, debieron aprender a movilizarse, ubicarse y a encontrar otro tipo de redes de apoyo.

Al conformar una familia, las mujeres cuidadoras dejan el ámbito laboral para dedicar su tiempo nuevamente al ámbito privado, encargándose de los oficios propios del hogar, la atención a sus esposos y la crianza y cuidado de sus hijos. Sin embargo, la mayoría de ellas manifestaron haber sido víctimas de violencia económica por parte de sus parejas o familiares. Al mismo tiempo, las 
mujeres cuidadoras afirman que una vez separadas de sus esposos o parejas sentimentales, intentaron vincularse al ámbito laboral para continuar con la satisfacción de necesidades de sus hogares; no obstante, la única opción que tuvieron para hacerlo fue la informalidad.

En ese sentido, se concluye que luego de conocerse el diagnóstico médico de sus hijos y una vez iniciaron con el trámite de atención en salud correspondiente, las dificultades de vinculación laboral se empeoraron en la medida en que ellas, no tienen oportunidad de cumplir horarios y requieren de permisos constantes. Es entonces cuando su conocimiento, liderazgo y empoderamiento se convierten en la fuente de recursos económicos principales para estos hogares.

Por otra parte, se evidencian los factores que influyen en el reconocimiento de las participantes hacía el ejercicio de la institucionalidad, iniciando con la presunta negligencia del sector salud frente al nacimiento, diagnóstico y tratamiento oportuno para sus hijos, ya que la mayoría de ellas señala malos procedimientos, falta de garantías y corresponsabilidad con los niños y sus familias. Algunas participantes aseguraron que de no haber sido por la equivocación médica, sus hijos no presentarían ningún tipo de discapacidad, podrían hacer parte productiva para sus hogares y ellas tendrían una vida familiar y económica mejor.

Aunado a esto, se encuentra la falta de sensibilidad y ética profesional de los empleados de dicho sector, en las intervenciones que reciben tanto los niños con discapacidad como sus cuidadores, puesto que las mujeres cuidadoras encuentran a diario, prejuicios, barreras de acceso, poca información y amenazas. De igual forma, identifican al sector educativo como un limitante para sus hijos, en el entendido de no contar con currículos académicos, formación del talento humano, estructuras físicas y garantías para el ingreso de niños con discapacidad a la educación inicial y básica. 
Frente a las entidades de asistencia social, las participantes infieren la inexistencia de cupos de ingreso para toda la población, es decir, la cobertura de los servicios es insuficiente para la demanda de las localidades y deben obligatoriamente entrar en una lista de espera que vulnera sus derechos y los derechos de sus hijos. Esto ha obligado a las mujeres cuidadoras a recurrir permanentemente a las áreas de atención al ciudadano y a los diferentes entes de control, con el fin de lograr su participación en algún servicio de manera oportuna.

Esto, en efecto, a las mujeres cuidadoras les hace concebir al Estado, desde una postura excluyente en tanto no observan, medidas de protección para sus hijos, existe poco interés por las personas con discapacidad dado a que en su etapa adulta no lograran ser productivos para el sistema económico y a sus cuidadores no les brinda ningún tipo de apoyo económico o laboral que mejoren sus condiciones de vida. Pese a las falencias identificadas, es importante referir que las mujeres cuidadoras reconocen también al régimen subsidiado de salud, como una fuente trascendental en la vida de sus hijos y familias ya que allí accedieron a todo tipo de tratamientos médicos, cirugías y consultas especializadas a diferencia de lo que algunas de ellas encontraron en el Régimen Contributivo.

Con respecto a la categoría de derechos, las mujeres sujetas de investigación, afirman que su acceso a algún servicio no ha obedecido en su mayoría al trabajo de la institucionalidad; por el contrario, relacionan su vinculación, a la solidaridad de otras mujeres cuidadoras quienes desde su experiencia les han orientado y acompañado en todos los procesos que han requerido. Por ello, han logrado unificar criterios y construyendo verdaderas redes comunitarias de apoyo, a partir de la creación de fundaciones, organizaciones, asociaciones y demás, que han tenido como objetivo el mejoramiento de la calidad de vida tanto de los niños con discapacidad como la de sus familias. 
Sin embargo, las mujeres reconocen que existen dos factores claves en la creación y sostenimiento de dichas iniciativas. Inicialmente, no cuentan con los recursos económicos suficientes para empezar a desarrollar sus ideas, en tanto no tienen algún ingreso fijo que las respalde y por desconocimiento técnico, no logran acceder a las convocatorias locales que realizan las entidades de este nivel y que promueven la financiación de estas iniciativas.

En un segundo momento, identifican la existencia de mujeres o cuidadores en general, que están a la espera de la garantía plena de sus derechos por parte del Estado pues, lo responsabilizan de su situación sociofamiliar y económica, entonces es allí en donde se observan familias que no tienen disposición para incorporarse a escenarios laborales o productivos, no participan en espacios de discusión comunitaria y política y no promueven opciones de cambio.

El siguiente aspecto tiene relación con la afirmación de sujeto, aquí las mujeres cuidadoras evaluaron todas las situaciones que les generaron una postura frente a su realidad, la discapacidad y a su labor sociopolítica. En un primer momento, la mayoría de ellas vieron la oportunidad de mejorar su calidad de vida al unirse a una pareja, puesto que de esta forma dejarían de responsabilizarse de las labores asignadas por sus familias que las agobiaban constantemente (trabajo agrícola, cuidado y protección de familiares, así como actividades propias del hogar).

Empero, en ese proceso de convivencia fueron víctimas de abusos sexuales, maltrato físico y psicológico, situaciones que para ellas tenían un orden natural, pues su crianza obedeció a estas prácticas y en algunos casos lo veían necesario para disfrutar de una condición de vida aceptable y para mantener los vínculos familiares.

Así mismo, la discapacidad, según ellas, era una condición asociada a lo inaceptable, lo mal hecho y lo mal obrado, es por ello que cuando sus esposos y familiares conocieron el diagnóstico de sus hijos, aparentemente contaron con un apoyo solidario y corresponsable, pero luego se 
convirtió en un motivo para ser abandonadas por sus parejas y desligadas de los núcleos familiares extensos. Desde su inicio, ellas no contaron con un acompañamiento biopsicosocial que les permitiera aceptar la discapacidad, su origen y consecuencias, razón motivo por la cual la aprobación de la enfermedad y lo que ello conlleva es algo que con los años no han podido superar por completo, aun se sienten culpables de la situación médica de sus hijos y de las condiciones económicas de sus hogares.

En algunas oportunidades, la falta de redes de apoyo familiar conllevó a que las mujeres recurrieran a la solidaridad de sus comunidades e inclusive a la mendicidad para llevar satisfacer las necesidades básicas de su hogar. En la actualidad, algunas refieren tener en sus hogares conflictos intrafamiliares asociados a problemas de comportamiento, abandono del hogar de otros hijos e inclusive consumo de Sustancias Psicoactivas. Empero, ha sido la discapacidad la oportunidad que han tenido estas mujeres para desarrollar sus habilidades sociales, políticas y comunitarias, así como participar en los espacios consultivos y decisorios de la localidad, aprender y trasmitir sus saberes desde las iniciativas institucionales en temas como liderazgo, toma de decisiones, empoderamiento y resiliencia.

Finalmente, se identifica un marco fundamental en el proceso de exigencia de derechos y acceso a la institucionalidad de los niños con discapacidad y sus cuidadoras, relacionado con las habilidades jurídicas adquiridas desde la experiencia cotidiana, la negación de servicios y utilizada entonces, para mejorar la condición de vida de otras familias y además como un mecanismo económico propio para solventar sus necesidades. 


\section{CAPÍTULO V. DISCUSIÓN}

Tras describir y analizar los resultados obtenidos en la metodología implementada en la presente investigación, frente al rol social y político ejercido por las mujeres cuidadoras de niños con discapacidad de la localidad de Bosa, se procede ahora realizar un cuestionamiento centrado en dos líneas principales.

Por un lado, visualizar desde el campo académico, las circunstancias que rodean el ejercicio del cuidado, en un Estado que pareciera ser, no tiene interés político de mejorar las condiciones de vida de las comunidades con necesidades más apremiantes e igualmente, evidenciar la urgencia de reestructurar el Sistema de Protección Social Colombiano a la luz de las condiciones de pobreza, inequidad socioeconómica y discriminación de género que enfrentan cotidianamente las mujeres. En segunda instancia, demostrar que pese al esfuerzo comunitario realizado por las mujeres

cuidadoras y su trasformación progresiva en sujetos políticos capaces de movilizar las disposiciones gubernamentales, existen voluntades supremas que violentan cada vez más sus derechos.

\subsection{Realidad Social}

De acuerdo al análisis teórico y jurídico realizado, el cuidado sigue siendo para Colombia, una “función" exclusiva del ámbito privado y con responsabilidad asignada a las mujeres, en donde la obligación del Estado, se centra en subsidiar parte de este procedimiento desde iniciativas generalizadas, como por ejemplo la creación de jardines infantiles para la primera infancia. No obstante, el cuidado como un derecho fundamental no ha sido un tema a tratar en la agenda pública del país, ya que las prácticas culturales y económicas, desiguales y excluyentes se continúan promoviendo; a la mujer el Estado la responsabiliza de cumplir a cabalidad su función productiva 
y reproductiva, y la sociedad por su parte, legitima las múltiples violencias hacía ellas y el descargo de responsabilidad de los hombres.

Por tanto, los esfuerzos institucionales, jurídicos, técnicos y presupuestales no son los que se requieren tal y como lo demuestran los siguientes hallazgos. En principio, se evidencia que la mayoría de las mujeres que desempeñan la labor del cuidado en la localidad de Bosa, se encuentran en el ciclo vital del envejecimiento y la vejez (41 años a 64 años), es decir que son mujeres que también empiezan a ser sujetos de cuidado, dadas las condiciones médicas, laborales y patológicas que van presentando.

Allí se enfrentan a dos condiciones estructurales que continúan promoviendo su vulnerabilidad y que demuestran un Sistema de protección Social ineficiente; la primera está relacionada a vivir la vejez sin ningún tipo de garantía socioeconómica, pues la única forma de vinculación laboral a la que han tenido acceso desde el momento en que empezaron a cuidar de sus hijos ha sido el trabajo informal, siendo representativo el trabajo doméstico el cual, ejercen uno o dos días por semana y del que no obtienen ningún tipo de aseguramiento.

Con ello, el Mercado como agente principal se convierte también en promotor de las prácticas desiguales, ya que los modelos laborales no se ajustan a la realidad de las personas que desarrollan el cuidado como actividad no remunerada. Adicionalmente, las probabilidades de acceder a una pensión son mínimas, tomando en cuenta que no lograron cotizar las semanas requeridas para ello y no tuvieron tampoco oportunidad de ahorrar para el futuro.

Ahora, se deduce que al ser parte de hogares mayormente monoparentales o extensos con una o más persona requirente de cuidado, no cuentan con ningún tipo de apoyo económico por parte de los progenitores o hermanos (en los casos en que los padres están bajo el cuidado de la mujer); 
por ende, deben ser ellas las únicas encargadas de satisfacer las necesidades básicas de toda la familia. Al indagar por la fijación de cuota alimentaria, se identificó que más del $50 \%$ de las mujeres iniciaron un proceso de restablecimiento de derechos no obstante, el demandado no da cumplimiento con lo pactado y las autoridades administrativas tampoco realizan un seguimiento.

Finalmente, se estableció que los programas de asistencia social, de los cuales, dependen la mayoría de mujeres cuidadoras, están expuestos a las voluntades e intereses de la administración entrante y por tanto, sufren modificaciones trascendentales que ponen en riesgo su continuidad. Es importante mencionar que pese a que existen políticas públicas poblacionales definidas, existen autonomías para su interpretación e implementación, lo cual debería ser un tema de debate público, puesto que de ellas depende el reconocimiento de la ciudadanía y los derechos humanos.

El siguiente aspecto está relacionado con la falta de redes de apoyo efectivas que puedan ejercer el cuidado en doble vía, tanto para la persona mayor (cuidadora) como para la persona con discapacidad. Lo anterior, teniendo en cuenta que el Estado no cuenta con una política pública integral de cuidado que le permita a las mujeres llegar a la etapa de la vejez sin dilemas y a las personas con discapacidad de gozar de espacios formales en todo el transcurso de su vida, en los cuales puedan recibir todo tipo de asistencia y protección.

Se considera ahora que al perder la capacidad laboral, las mujeres cuidadoras se ven expuestas, a más situaciones de violencia en sus hogares y en el ámbito comunitario, pues por las dinámicas familiares disfuncionales en las que vivieron por mucho tiempo, no cuentan con recursos económicos provenientes de sus hijos, pierden el reconocimiento de sus habilidades y capacidades sociales, se les perpetúa el ejercicio del cuidado como algo obligatorio (cuidado de nietos) y existe el riesgo de ser abandonadas o desalojadas del lugar donde residen. 
También, los derechos de los niños con discapacidad se ven expuestos, en la medida en que las mujeres disminuyen sus capacidades de liderazgo y exigencia de derechos. Su participación en espacios locales empieza a disminuir y en un punto, las gestiones ante los sistemas de salud, por ejemplo, cesarán y la vida de las personas con discapacidad empieza a estar amenazada. Es pertinente recordar que las mujeres son quienes realizan todo tipo de trámite y diligencia ante las EPS, recorriendo largas distancias o asistiendo a horas no convencionales (madrugada) que con la edad y la enfermedad se vuelven muy dispendiosas.

Habría que mencionar también a las mujeres cuidadoras que se encuentran en etapas biológicas distintas a la vejez, puesto que ellas también enfrentan las mismas condiciones familiares y laborales; sin embargo, aquí se evidencia la falta de garantías del Estado frente a la promoción de proyectos de vida activos y productivos que les permita pensar en la vejez de una forma autónoma y con mayores garantías. Por ejemplo, el nivel educativo es, para ellas, la barrera de acceso más frecuente al momento de vincularse al sector laboral, ya que solo un porcentaje mínimo logró culminar sus estudios de bachiller. Combinar la función de cuidadora y mujer no es una tarea sencilla y más cuando se tiene una condición específica en su hogar como la discapacidad o la vejez.

De tal modo, procesos productivos o de emprendimiento surgen en el diario vivir como una “opción” más sensata para ellas; no obstante, la falta de garantías técnicas, presupuestales y de alianzas público- privadas, terminan siendo los principales factores en la deserción, pues al momento de empezar sus iniciativas reconocen que en un mercado desigual sus oportunidades son limitadas.

Entonces, uno de los resultados identificados en las entrevistas realizadas a los funcionarios de instituciones locales demuestra un prejuicio social existente, relacionado con la falta de interés y 
la costumbre de las cuidadoras a la asistencia social; empero, no se demuestra cuáles son las rutas establecidas para que las mujeres puedan acceder al campo educativo y productivo, sin caer luego en el prejuicio social y jurídico de ser malas madres o mujeres, por dedicarse a solventar las necesidades económicas de su casa e intentar al mismo tiempo, estar presentes en el cuidado y crianza de sus hijos.

Resulta necesario mencionar, además, que un porcentaje significativo de ellas (22\%) es víctima del conflicto armado interno, lo que ocasionó su desplazamiento al área urbana, un deterioro del vínculo familiar, un desarraigo cultural y las ha llevado a conocer una ciudad completamente diferente y con riesgos sociales complejos, con los cuales también han tenido que luchar, puesto que vivir en una localidad en donde la pobreza está a la orden del día y en donde, los grupos ilegales organizados, a pesar de que son una amenaza para su vida y la integridad de sus hijos, se convierten para estos últimos en una opción más inmediata para satisfacer necesidades básicas como alimento y techo.

\subsection{Relaciones de Conflictividad}

Tal como se mencionó al comienzo del presente capítulo, el estudio evidencia que las mujeres cuidadoras, debido a su situación de desigualdad social, han desarrollado habilidades y capacidades sociopolíticas que promueven el cumplimiento de los derechos humanos y el ejercicio activo de ciudadanía; sin embargo, es importante comprender que existen factores externos que cotidianamente afectan la labor de estas mujeres en sus contextos comunitarios. Dichas dificultades corresponden a estructuras socioculturales interpuestas por el Estado, el Mercado y la familia que en una triangulación reflejan el patrocinio de las condiciones de pobreza y la ineficiencia del Sistema de Protección Social actual. 
A nivel de la familia, se identifica que el cuidado como rol principal de la mujer es asignado desde los primeros años de vida, está ligado a la concepción de buenas prácticas, enseña lo necesario para enfrentarse al transcurrir de la vida y por tanto, no ejercerlo o desvincularse de él implica su exposición a violencia física y psicológica permanente, tanto de sus progenitores como esposos. Es por ello que para algunas mujeres, las violencias y el maltrato es algo natural que se requiere para tener relaciones familiares estables y vínculos afectivos estrechos.

Lo anterior genera una alarma importante, en la medida en que se tiene el imaginario que por estar en un siglo con posibilidades mucho más liberales y autónomas, las mujeres son violentadas por gusto y decisión, y no por factores culturales marcados y transversales a la vida social. No existe igualdad entre las labores desarrolladas por los hombres y las mujeres en el ámbito privado, pero si existen exigencias sobredimensionadas en las responsabilidades laborales que debe cumplir una mujer. Es por ello que situaciones como el abandono de hogar, los prejuicios y los conflictos intrafamiliares, promueven la necesidad de las mujeres de acudir a la solidaridad de comunidades e instituciones para solventar las necesidades básicas de sus hijos.

Por su parte, el mercado muestra fallas representativas en la realidad de las mujeres cuidadoras, ya que el marco laboral competitivo, el emprendimiento y la productividad están diseñados para las personas que no requieren de ningún tipo de cuidado permanente o que logran conciliar en su vida la carga familiar con la laboral. Es decir que para el mercado una persona en condición de discapacidad no es lo suficientemente atractiva, dado que no logrará ser productivo o no tendrá las mismas capacidades de realización; e igualmente ocurre con las personas que se dedican al cuidado, toda vez que no están en condiciones para cumplir con los horarios y funciones establecidas, razón por la cual las empresas no están en disposición de contratar a una persona que 
tendrá que ausentarse de sus labores en tiempos prolongados, no cumplirá con las metas establecidas y su rendimiento estará directamente ligado con su situación familiar.

Así mismo ocurre con los procesos de emprendimiento y productividad, en los cuales la mayoría de mujeres logra vincularse, realizar todo el proceso de aprendizaje pero al momento de enfrentarse a un mercado informal descontrolado y ventajoso, no logran sostener su idea productiva y terminan desistiendo de la misma. El Estado, por su parte, presenta brechas muy amplias en cuanto a la garantía de los derechos de las mujeres cuidadoras, pues no existen políticas públicas lo suficientemente holísticas y capaces de analizar todas las realidades del territorio, un ejemplo de ello es que la zonas rurales no cuentan con sistemas de salud idóneos, oportunos y efectivos que garanticen calidad de vida; es preocupante que las mujeres identifiquen al sector salud como un responsable de la discapacidad de sus hijos, dada las práctica de malos procedimientos.

Igualmente, la carencia de atención básica en salud de las zonas rurales generan la migración de familias de niños en condición de discapacidad a las principales ciudades del país, ya que en sus municipios de origen, los hospitales y centros de salud no tienen la capacidad técnica y presupuestal para diagnosticar y tratar a los menores de edad.

En consecuencia, se podría pensar que el Estado puede tener responsabilidad en la generación de limitaciones y enfermedades vitalicias para las personas, situación que debe generar debate al interior de las entidades y la rama judicial, en el entendido de realizar veedurías, control y regulación en la prestación de los servicios de salud. Ahora bien, como un resultado relevante se evidencia que las mujeres cuidadoras se sienten excluidas por el Estado, dado que no observan medidas de protección efectivas para sus hijos. Esto en relación a los actuales programas de asistencia social, los cuales se ven obligadas a solicitar pero encuentran que la demanda es superior 
a lo ofertado, generando un tránsito por una lista de espera que puede llevarle años a esta familia para acceder a algún tipo de servicio social.

Adicionalmente, el sector educativo también se convierte en una barrera de acceso para el disfrute de un derecho fundamental, puesto que no existen los lineamientos requeridos para que la educación pública y privada logre brindarles a los niños en condición de discapacidad, la oportunidad de ingreso y un aprendizaje acorde a sus necesidades. Frente a la atención de las mujeres cuidadoras en temas de validación del bachillerato y la promoción de educación técnica y tecnológica, se vienen realizando esfuerzos importantes en cuanto a establecer currículos flexibles, la mayoría de ellos virtuales, en donde esta población pueda culminar una parte de su proyecto de vida.

No obstante, lo que se ha identificado es que las mujeres o no cuentan con acceso a computador e internet en sus hogares o debido al cuidado y la complejidad del diagnóstico de sus hijos, deben estar siempre en función de ellos. La asignación de enfermeras de apoyo es un procedimiento, al cual las cuidadoras deben acceder por medio de desacatos de acción de tutela, debido a que las EPS están pasando por alto lo dispuesto por un juez.

Como último aspecto, en el presente estudio se evidenció que las mujeres cuidadoras han logrado acceder a diferentes bienes y servicios, se han transformado en agentes de cambio y han logrado garantizarle a sus familias algún derecho, no por acciones implementadas desde el sector gubernamental sino por el contrario, a la solidaridad y compromiso de una red de cuidadoras de la localidad, en donde a través de la experiencia se van resignificando sus conocimientos. 


\section{CAPÍtULlOVi. CONCLUSIONES}

1. El proceso de caracterización de las condiciones de vida de las mujeres cuidadoras se convierte en un primer instrumento de análisis para cualquier tipo de estudio o intervención con ellas, pues a partir de allí se logra identificar el contexto, las necesidades, particularidades, limitantes, habilidades, ventajas y desventajas que enfrenta dicha población en su cotidianidad. En la actualidad no existen estudios cuantitativos a nivel local o distrital que permitan establecer el número real de mujeres que se dedican a la labor de cuidado como actividad no remunerada; por tanto, se especula del impacto real de los programas sociales y/o económicos.

2. Ahora, los programas de asistencia social de acuerdo a lo evidenciado en la presente investigación, se han convertido en el único ingreso mensual para las mujeres cuidadoras de niños con discapacidad, lo cual las expone permanentemente a situaciones de desigualdad socioeconómica, en la medida en que dichos programas sufren modificaciones significativas con el ingreso de nuevas administraciones distritales.

3. Si bien los apoyos económicos generados desde la asistencia social son invertidos en las necesidades básicas de la familia, para las mujeres cuidadoras de niños con discapacidad en Bosa, el recurso debe entrar a solventar en gran medida los tratamientos, procedimientos y medicamentos que desde el sistema de salud no se brindan con oportunidad. Esto con el propósito de garantizarle a sus hijos mejor calidad de vida o la preservación de la misma. 
4. Desde el Sistema de Protección Social se logra identificar que el diagnóstico social de las mujeres cuidadoras es desalentador, pues al no tener una política pública como marco de la garantía de sus derechos, se encuentran cada vez más excluidas de entornos laborales y académicos que les permitirían solventar los riesgos de sus hogares sin necesidad de acudir a la asistencia social promovida por el Estado. Ejemplo de ello son los sistemas pensionales y de salud, pues son personas que no logran cotizar para la vejez pero, si requieren de apoyo incondicional del régimen subsidiado en salud. Es decir, que el desbalance será para Colombia mucho más marcado, ya que no se han tomado las medidas económicas requeridas.

5. Por otro lado, es fundamental comprender que las mujeres cuidadoras de niños con discapacidad en Bosa no se sienten reconocidas por parte de las instituciones y del Estado, al momento de desarrollar su actividad como cuidadora y los aportes significativos para la comunidad y sociedad en general. Lo anterior se debe a las múltiples situaciones de desigualdad social que enfrentan y a las condiciones de pobreza, de las cuales intentan salir pero no cuentan con garantías para lograrlo.

6. La discapacidad, la violencia intrafamiliar y la exclusión social han servido como promotores, para que las mujeres cuidadoras hayan logrado formarse empíricamente como sujetos políticos, capaces de exigir el cumplimiento de los derechos, jurisprudencias, planes de gobierno y al mismo tiempo, movilicen alianzas comunitarias en procura de mejorar las condiciones de vida de sus familias.

7. La concepción social de la falta de interés de las personas cuidadoras por acceder a ámbitos laborales y productivos para dejar de depender de los programas sociales, está obligado a cambiar para toda la sociedad, en la medida en que se comprende las condiciones de vida que ellas deben sortear, pero sobre todo cuando se reconocen sus habilidades sociales, 
comunicativas, comunitarias y políticas que transforman ideales y que promueven nuevas y mejores prácticas desde lo cotidiano. 


\section{CAPÍTULO VII. CONSIDERACIONES ÉTICAS}

Esta investigación se desarrolló a la luz de la Resolución 008430 de 1993: "Por la cual se establecen las normas científicas, técnicas y administrativas para la investigación en salud", en la cual prevaleció el respeto a la dignidad y la protección de derechos de las mujeres cuidadoras como sujetos principales de estudio, así como de los funcionarios de las diferentes entidades gubernamentales, quienes participaron de manera voluntaria y aportaron desde su experiencia, elementos fundamentales para la obtención de resultados académicos.

Por lo tanto, se contó con un consentimiento informado y por escrito en donde se explicó la finalidad de la presente investigación, las etapas del proceso, los riesgos existentes, el tiempo de ejecución, el tratamiento confidencial de la información obtenida, así como el derecho a retirarse de la investigación en cualquier etapa del proyecto (ver Anexo 1). Es importante mencionar que la presente investigación fue avalada por el Comité de Ética de la Universidad Santo Tomás en agosto del año 2016. 


\section{REFERENCIAS BIBLIOGRAFICAS}

Alcaldía Mayor de Bogotá Distrito Capital. (2007). Decreto 470 del 12 de octubre de 2007. [Por el cual se adopta la Política Pública de Discapacidad para el Distrito Capital]. Bogotá, D.C., Colombia.

Artigas, C. (2005). Serie 110. Una mirada a la protección social desde los derechos humanos y otros contextos internacionales. Santiago de Chile: Comisión Económica para América Latina y el Caribe.

Asociación Afromiel. (2014). Plan de Etnodesarrollo. Antioquia: Sonson-Antioquia.

Baanante, A. (s.f.). El trabajo domestico (análisis económico desde una perspectiva de género). Obtenido de http://cdd.emakumeak.org/ficheros/0000/0244/publicacion3premio.pdf

Bustos, L. (2009). El lugar de las mujeres pobres: el caso de las beneficiarias de planes sociales. Revista La Aljaba. 13 (13), 1-14.

Cabra, M. (2004). Discapacidad y aspectos sociales: la igualdad de oportunidades, la no discriminación y la accesibilidad universal como ejes de una nueva política a favor de las personas con discapacidad y sus familias. Algunas consideraciones en materia de protección ... Revista del ministerio de trabajo y asuntos sociales. (50), 21-46.

Calduch, R. (1991). El Estado, El Pueblo Y La Nación. Madrid: Editorial Ciencias Sociales.

Cecchini, S., Filgueira, F., Martínez, R., \& Rossel, C. (2015). Instrumentos de protección social Caminos latinoamericanos hacia la universalización. Santiago de Chile: Comisión Económica para América Latina y el Caribe.

Chárriez, M. (2012). Historias de vida: Una metodología de Investigación cualitativa. Revista Grito, 5(1), 50-67. 
Comisión Económica para América Latina y el Caribe [CEPAL]. (2010). Consenso de Brasilia del 16 de julio de 2010. Conferencia Regional sobre la Mujer de América Latina y el Caribe (págs. 1-11). Brasilia: CEPAL.

Comisión Económica para América Latina y el Caribe [CEPAL]. (2013). Consenso de Santo Domingo del 18 de octubre de 2013. XII Conferencia Regional sobre la Mujer de América Latina y el Caribe (págs. 1-17). Santo Domingo: CEPAL.

Concejo de Bogotá Distrito Capital. (2015). Proyecto de Acuerdo 253 del 4 de septiembre de 2015 [Por el cual se establece el protocolo integral por los derechos a la protección y bienestar de los cuidadores y cuidadoras de personas con discapacidad en Bogotá D.C.]. Bogotá, D.C., Colombia.

Congreso de Colombia. (2009). Proyecto de Ley 033 del 23 de julio de 2009. [Por la cual se definen lineamientos para la creación y desarrollo de las áreas de ordenamiento logístico de carga de los niveles nacional y urbano y se dictan otras disposiciones]. Bogotá, D.C., Colombia. Congreso de Colombia. (2010). Ley 1413 del 11 de noviembre de 2010. Diario Oficial No. 47.890. [Por medio de la cual se regula la inclusión de la economía del cuidado en el sistema de cuentas nacionales con el objeto de medir la contribución de la mujer al desarrollo económico y ... ]. Bogotá, D.C., Colombia.

Consejo de Bogotá Distrito Capital. (2012). Acuerdo 505 del 5 de diciembre de 2012. Registro Distrital No. 5022. [Por medio del cual se establece el Sistema Distrital de Atención Integral de Personas en condición de discapacidad en el Distrito Capital y se modifica el Acuerdo 022 de 1999]. Bogotá, D.C., Colombia. 
Consejo Nacional para la Igualdad de Género [CNIG]. (2016). Investigación "Economía del Cuidado, Trabajo Remunerado y No Remunerado” En base al análisis de los resultados de la Encuesta Específica de Uso del Tiempo 2012. Quito: INEC / AECID / CNIG.

Cuesta, M., \& Herrero, F. (s.f.). Introducción al Muestreo. Asturias, España: Departamento de psicología, Universidad de Oviedo.

Departamento Administrativo Nacional de Estadística [DANE]. (2010). Discapacidad en Colombia. Obtenido de Demografía y población: http://www.dane.gov.co/index.php/estadisticas-por-tema/demografia-ypoblacion/discapacidad

Departamento Administrativo Nacional de Estadística [DANE]. (2016). Undécimo informe semestral de gestión Ley 1413 de 2010. Bogotá, D.C.: DANE.

Departamento Nacional de Planeación. (2013). Documento Conpes Social. Política pública nacional de discapacidad e inclusión social. Bogotá, D.C.: Departamento Nacional de Planeación.

Díaz, L., Torruco, U., Martínez, M., \& Varela, M. (2013). Metodología de Investigación en Educación Médica: la entrevista, recurso flexible y dinámico. Departamento de Investigación en Educación Médica. México: Facultad de Medicina. Universidad Nacional Autónoma de México.

Domínguez, M. (2004). Equidad de Género y Diversidad en la Educación Colombiana. Revista Electrónica de Educación y psicología. 1 (2), 1-19.

Fedesarrollo \& Fundación Saldarriaga Concha. (2015). Misión Colombia Envejece: cifras, retos y recomendaciones. Bogotá, D.C.: Editorial Fundación Saldarriaga Concha. 
Fernández, G. (2009). La fomación del sujeto político Aspectos más sobresalientes en Colombia. Medellín: Universidad Nacional de Colombia .

Fondo de las Naciones Unidas para la Infancia [UNICEF]. (2015). Informe anual UNICEF Colombia 2015. Bogotá, D.C.: UNICEF.

Friel, S., \& Marmot, M. (2011). Action on the social determinants of health and health inequities goes global. Annual Review of Public Health. (32), 225-236.

Fucsia. (s.f.). Las colombianas: Mayor nivel educativo, pero menor participación laboral. Obtenido de Actualidad: https://www.fucsia.co/actualidad/personajes/articulo/radiografiaeducacion-mujeres-en-colombia/60998

Fundación para la Promoción de la Mujer. (1997). Roles y Estereotipos. Ciudad de Panamá: Convenio Panameño Alemán Formación Profesional Dual.

García, F. (2002). El cuestionario: Recomendaciones metodológicas para el diseño de cuestionario. . México D.F, México. : División de ciencias exactas y naturales, Universidad de Sonora.

García, R. (1986). Introducción A La Teoría Del Estado. Barcelona: Editorial Teide.

González, N. (2008). Convención de Naciones Unidas sobre los derechos. Anuario Mexicano de Derecho Internacional. (8), 527-540.

Guerrero, R. (2006). El Concepto de la Protección Social. Bogotá, D.C.: Ministerio de Salud y Protección Social.

Guzmán, V. (1997). La equidad de género como tema de debate y políticas públicas. Memoria del foro internacional sobre cuidadanía, género y reforma del Estado (págs. 89-108). México, D.F.: Grupo de Educación Popular con Mujeres. 
Hermida, L., \& Borregón, L. (2010). Cuando las deficiencias se convierten en discapacidad. Revista Prisma Social. (5), 1-32.

Hernández, R., Fernández, C., \& Baptista, P. (2003). Metodología de la investigación. México: McGraw- HIll.

Hernández, R., Fernández, C., \& Baptista, P. (2014). Metodología de la investigación. México D.F: McGraw- HILL Interamericana.

Holzmann, R., \& Jorgensen, S. (2003). Manejo social del riesgo: un nuevo marco conceptual para la protección social y más allá. Facultad Nacional de Salud Pública. 21 (1), 73-106.

Lagarde, M. (2003). Mujeres cuidadoras: entre la obligación y la satisfacción. Vitoria: Emakunde.

Lara, S. (2006). Serie 81. Las metas del Milenio y la igualdad de género. El caso de Colombia. Santiago de Chile: Comisión Económica para América Latina y el Caribe.

López, P., \& Fachelli, S. (2015). La encuesta: Metodología de la Investigación Social Cuantitativa. . Barcelona: Bellaterra (Cerdanyola del Vallès): Dipòsit Digital de Documents, Universitat Autònoma de Barcelona. Capítulo II.3.

Mallimaci, F., \& Giménez, B. (2006). Estrategias de investigación cualitativa: Historias de Vida y Método Biográfico. Barcelona, España.

Maravall, J. (2009). Democracia, desigualdad y populismo en América Latina. En N. Serra, \& J. Vaquer, Democracia en América Latina: la sombra de la desigualdad. Serie América Latina (págs. 11-32). Barcelona: CIDOB Edición.

Martínez, J. (2013). Discapacidad: Evolución de evolución de conceptos. Ciudad Real: Universidad de Castilla - La Mancha.

Ministerio de Salud. (1993). Resolución N 8430. Por la cual se establecen las normas científicas, técnicas y administrativas para la investigación en saluid. Bogotá, Colombia. 
Ministerio de Salud y Protección Social . (2005). Antecedentes de la protección social en colombia. Iniciativa de formación en gerencia social para la protección social . Medellín: Institución Universitaria CES.

Ministerio de Salud y Protección Social. (s.f.). ¿Qué es discapacidad? Obtenido de DisCAPACIDAD:

https://www.minsalud.gov.co/proteccionsocial/Paginas/DisCAPACIDAD.aspx

Monje, C. (2011). Metodología de la investigación Cuantitativa y Cualitativa: Guía Didáctica. Neiva., Colombia: Programa de comunicación social y periodismo, Facultad de ciencias humanas y sociales. Universidad Surcolombiana.

Moreno, M., Náder, A., \& López, C. (2004). Relación entre las características de los cuidadores familiares de pacientes con discapacidad y la percepción de su estado de salud. . Avances En Enfermería. 22 (1), 27-38.

Moreno, M., Rodríguez, M., Gutiérrez, M., Ramírez, L., \& Barrera, O. (2006). ¿Qué significa la discapacidad? Revista Aquicha. 6 (1), 78-91.

Olavarría, M. (2007). Conceptos Básicos en el Análisis de Políticas Públicas. Santiago de Chile: Departamento de Gobierno/Gestión Pública del Instituto de Asuntos Públicos de la Universidad de Chile.

ONU Mujeres. (2015). La declaración y la plataforma de acción de Beijing cumplen 20 años. Nueva York: ONU Mujeres.

Organización de Estados Iberoamericanos [OEI]. (2007). Consenso de Quito del 29 de agosto de 2007. Décima Conferencia Regional sobre la Mujer de América Latina y el Caribe. Quito: OEI. 
Organización Mundial de la Salud [OMS]. (2011). Informe Mundial sobre la Discapacidad. Ginebra: Banco Mundial.

Ortega, J. (2005). Simonedebeauvoir: Su Aportación A La Discusión Sobre El Género. Barcelona: Universidad de Barcelona.

Padilla-Muñoz, A. (2010). Discapacidad: contexto, concepto y modelos. International Law: Revista Colombiana de Derecho Internacional. (16), 381-414.

Pereira, Z. (2011). Los diseños de método mixto en la investigación en educación: Una experiencia concreta. Revista electrónica Educare, Universidad Nacional de Costa Rica. Heredia, Costa Rica.

Pérez, M., \& Bao, R. (2011). Confesiones y reflexiones sobre sexo y género. Elementos Conceptuales Básicos para entender la Equidad de Género. La Habana: Editora Agroecológica.

Presidencia de la República de Colombia. (2013). Decreto 2490 del 13 de noviembre 2013. [Por el cual se crea la Comisión Intersectorial para la inclusión de la información sobre trabajo de hogar no remunerado en el Sistema de Cuentas Nacionales, que ordena la Ley 1413 de 2010]. Bogotá, D.C., Colombia.

Programa de las Naciones Unidas para el Desarrollo [PNUD]. (2015). Objetivos de Desarrollo del Milenio. Informe de 2015. Nueva York: Organización de las Naciones Unidas.

Puyana, Y., \& Barreto, J. (1994). Las Historias de Vida: Recurso en la investigación cualitativa, reflexiones metodológicas. Revista del departamento de antropología Maguaré, 185-196.

Ricoy, C. (2006). Contribución sobre los paradigmas de investigación. . Revista do Centro de Educação, 31(1), 11-22. 
Rodríguez, A., E, C., \& P., L. (2011). Cambios socioculturales vividos por la co-munidad Afrocolombiana, víctima del desplazamiento forzado, residente en el Barrio Lisboa, Suba. Bogotá: Programa de Trabajo Social, Facultad de ciencias humanas y sociales. Corporación Universitaria Minuto de Dios.

Samaddar, R. (2014). La emergencia del sujeto político. Revista Política Común. 6, 1-18.

Sanz, A. (2005). El método biográfico en Investigación social: Potencialidades y limitaciones de las fuentes orales y los documentos personales. Zaragoza, España: Facultad de Sociología, Universidad de Zaragoza.

Secretaría de Cultura, Recreación y Deporte. (2016). Análisis Sectorial, Poblacional y Local Bogotá. Bogotá, D.C.: Dirección de Planeación Proyectos Estratégicos.

Secretaría Distrital de Planeación. (2009). Conociendo la localidad de Bosa: Diagnóstico de los aspectos físicos, demográficos y socioeconómicos. Bogotá, D.C.: Alcaldía Mayor de Bogotá, D.C.

Torrecilla, V. (2016). Apuntes De Teoría Del Estado. Córdoba: El Cid Editor.

Torres-Melo, J., \& Santander, J. (2013). Introducción a las políticas públicas: Conceptos y herramientas desde la relación entre Estado y ciudadanía. Bogotá, D. C.: Instituto de Estudios del Ministerio Público.

Urra, E., Jana, A., \& García, M. (2011). Algunos aspectos esenciales del pensamiento de Jean Watson y su teoría de cuidados transpersonales. Revista Ciencia y EnfermerIa. 17 (3), 1122.

Valenzuela, M., \& Mora, C. (2009). Trabajo doméstico: un largo camino hacia el trabajo decente. Santiago de Chile: Organización Internacional del Trabajo. 


\section{ANEXOS: TRANSCRIPCIÓN DE ENTREVISTAS E HISTORIAS DE VIDA}

Rol Social y Político en el Sistema de Protección Social de mujeres cuidadoras de niños con discapacidad Localidad de Bosa, Bogotá D.C. Colombia, 2016

Trabajo de investigación para optar el título de Magíster en Protección Social

Estudiante: Anggie Tatiana Rodríguez Álvarez

Asesora: Ivonne Andrea Ordóñez Monak

Bogotá, Colombia, 2018 


\section{Contenido}

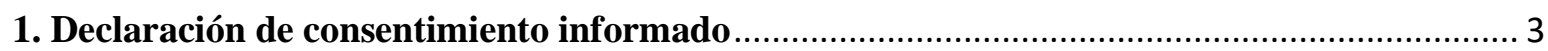

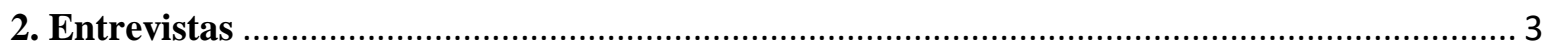

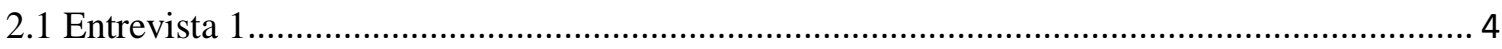

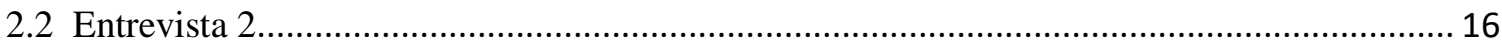

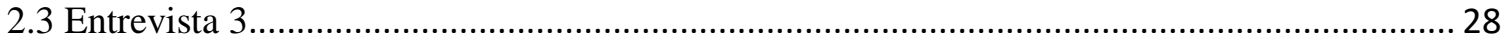

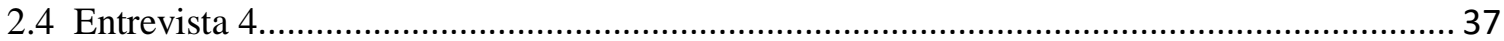

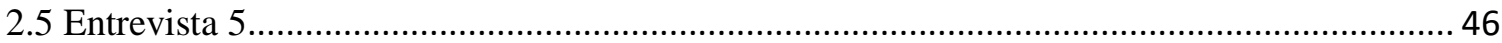

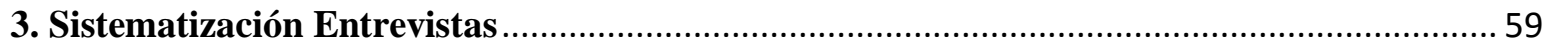

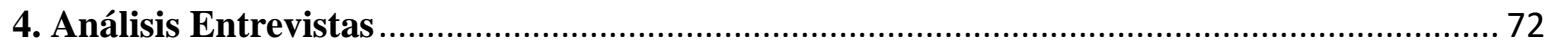

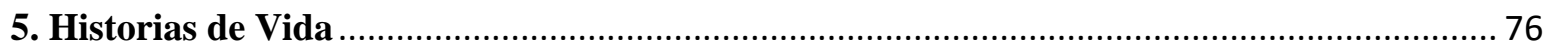

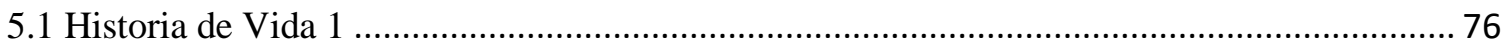

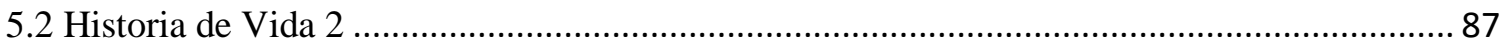

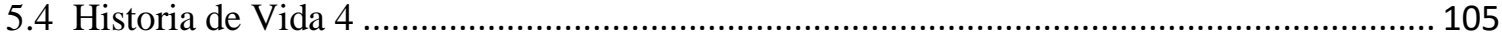

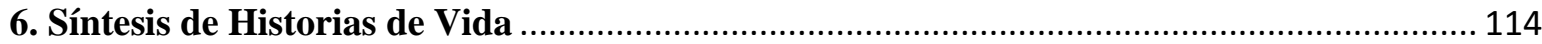

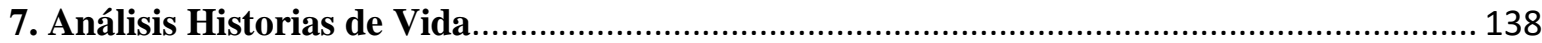




\section{Declaración de consentimiento informado}

Si usted autoriza la participación en este estudio, por favor complete los siguientes datos:

Yo,

identificada con cédula de ciudadanía número: de cuidadora del

Niño, Niña y/o Adolescente autorizo mi participación en el proyecto de investigación "Rol Social y Político de las Mujeres Cuidadoras de Niños, Niñas y Adolescentes en Condición de Discapacidad de la localidad de Bosa año 2016, en el Sistema de Protección Social", y declaro que se me ha leído y explicado detalladamente la información del consentimiento informado, que he comprendido los objetivos para los cuales se aplicará la encuesta; así como los demás aspectos relacionados con el estudio y que tuve la posibilidad de hacer preguntas para aclarar mis dudas.

Declaro que mi participación en este estudio es voluntaria, que colaboraré en lo que pueda y que podré retirarme cuando así lo decida sin ninguna consecuencia. La información que suministre será cierta, sólo me socializaran los resultados finales del proyecto de investigación si así lo solicito, pues los demás datos recolectados serán analizados de manera confidencial, con carácter académico y no serán tenidos en cuenta para continuar o no, recibiendo los beneficios de las diferentes instituciones.

En constancia, firmo a continuación:

Nombre:

Firma:

Fecha:

\section{Testigo 1:}

Nombre:

Relación:

Firma:

Dirección:

Teléfono:

\section{Testigo 2:}

Nombre:

Relación:

Firma:

Dirección:

Teléfono:

Nombre completo del profesional que obtuvo el consentimiento: cédula de ciudadanía número: de

\section{Entrevistas}




\subsection{Entrevista 1}

Funcionario 1, Instituto Colombiano de Bienestar Familiar

Gracias por este espacio, mi nombre es Funcionario 1, Profesional en Trabajo Social y Referente de la modalidad de hogar gestor la cual es una medida de restablecimiento de derechos enfocado en la atención de NNA en condición de discapacidad y sus familias, del Instituto Colombiano de Bienestar Familiar. Llevo 8 años y medio de experiencia dentro de esta institución.

\section{ACCIÓN INSTITUCIONAL}

\section{¿Cuáles son y en qué consisten los programas que promueve su entidad?}

El ICBF se ha preocupado por atender esta población en varias modalidades de restablecimiento de derechos, tiene la modalidad institucional que ya son los niños ubicados como tal una medida con ubicación institucional fuera del núcleo familiar algunos tienen contacto aun con su familia y otros están declarados en Adoptabilidad. La otra modalidad es el externado jornada completa, en donde los niños en condición de discapacidad permanecen con sus familias pero asisten y tienen una atención especializada en un horario de ocho de la mañana a cuatro de la tarde en unos centros aptos para brindar la atención. Y, tenemos la modalidad que garantiza la ubicación familiar de los niños siempre y cuando la familia sea protectora que corresponde al Hogar Gestor que los niños permanecen en su medio familiar todo el tiempo y en donde se brinda un acompañamiento sociofamiliar por parte de la defensoría de familia y un aporte económico de 325. 000 mensuales destinado a garantizar una calidad de vida estable.

\section{Actualmente ¿cuántas personas participan en los programas?, ¿Qué profesionales atienden} dicha población?

Bueno, en la modalidad de hogar gestor actualmente Bogotá cuenta con 510 NNA en condición de discapacidad, frente a la modalidad de ubicación en medio institucional hay 1071 NNA en condición de discapacidad y 531 NNA con discapacidad mental psicosocial para un total de mil seiscientos dos NNA y 520 NNA ubicados en la modalidad de externado jornada completa. En total ICBF - Regional Bogotá atiende a 2.632 NNA en condición de discapacidad bajo las medidas de restablecimiento de derechos que establece la ley 1098 de 2006. 
Dentro de los profesionales que atienden a los NNA y sus familias se encuentran, el Defensor de familia que el defensor de familia es la autoridad administrativa que adopta la medida previa verificación de derechos que realiza él con el equipo técnico interdisciplinario. Es un abogado en derecho administrativo o derecho en familia.

Se encuentra un profesional en nutrición, un profesional en psicología y un profesional en Trabajo Social. Además se cuenta con el apoyo de un técnico que apoya en lo operativo, documental y en el ingreso de las actuaciones a un sistema de información interno. Estos son los profesionales que atienden a los niños y sus familias permanentemente.

\section{¿Considera que los profesionales que brindan atención en dichos programas, cuentan con las habilidades y conocimientos para atender las necesidades de la población?}

Pues yo considero que desde la Regional Bogotá y las coordinaciones de los centros zonales vienen haciendo un gran esfuerzo por adquirir el conocimiento frente al tema de discapacidad pero también frente a la sensibilización de la discapacidad, si, que son dos ejes principales que He evidenciado que los equipos se han esforzado, posiblemente consideraría que falta fortalecer mucho los conocimientos frente a la política pública de discapacidad, nuestro decreto distrital de discapacidad que es un tema que paulatinamente se ha ido abordando, los compañeros vienen participando de los COLDIS lo que le les ha permitido conocer más del proceso y considero que tal vez son temas que nos falta profundizar un poco más.

\section{¿Qué aspectos considera usted, que los profesionales deben fortalecer?}

Como venía diciendo, los equipos están haciendo un esfuerzo para conocer el tema y por brindar las herramientas a las familias, nos falta fortalecer nuestro conocimiento frente a la política pública de discapacidad sin desconocer que se está haciendo un esfuerzo grande para lograr la sensibilización interna frente al tema.

¿Cómo es el proceso de inclusión de las personas a los programas? - cuáles son los criterios de selección y focalización. 
Es importante tener claro que las medidas se adoptan siempre, en el marco de la verificación de derechos que efectué el equipo de la defensoría de familia y el defensor de familia como autoridad administrativa. Es claro que las medidas no se brindan por la discapacidad o por la situación económica de la familia porque ya no está en las manos del ICBF restablecer la situación de salud del NNA o la condición económica de la familia. Es por ello, que todo depende de la verificación de derechos que se realiza inicialmente en donde se establezcan derechos vulnerados, amenazados o inobservados; este es el marco digamos o el argumento base para que un niño ingrese a cualquier modalidad, por ejemplo una vulneración de derechos puede ser cuando evidenciamos que hay una afectación en su calidad de vida, o una afectación en todo el tema de la rehabilitación, esto en el caso del hogar gestor, si?, sin embargo es un tema que se ve muy aunado muy conectado a la atención en salud, entonces pues de una $\mathrm{u}$ otra manera a veces frente a estos incumplimientos se ven afectados los derechos de estos niños y de allí surge la necesidad de empoderar y acompañar a estas familias para que su situación sociofamiliar sea cada vez mejor.

\section{¿Qué estrategias implementa la institución para disminuir el ingreso de personas que no requieren la atención (Riesgo Moral)?}

Bueno, Inicialmente pues realmente en su mayoría hay un alto porcentaje de que las personas se acercan a los centros zonales para la vinculación en las medidas, en general son ellos como representantes legales quienes solicitan la medida, así mismo, nosotros conocemos los casos a través de las diferentes instituciones quienes remiten a la familia para la medida de protección. No obstante, nosotros desde los diferentes espacios interinstitucionales hacemos énfasis que las medidas que tenemos no son para ofertar como programas porque finalmente se basan en una medida legal y es la de restablecimiento de derechos, es decir, les sensibilizamos que no es un programa del cual todas las personas puedan participar ya que todo nosotros actuamos de acuerdo a la verificación de derechos.

Es como si se ofertaran los hogares sustitutos o las instituciones de protección. Hacemos articulación con las instituciones y realizamos lo correspondiente. Las familias podrían decir, que son las que en su mayoría quienes se acercan a solicitar la medida, es importante aclarar que todas las personas pueden hacer la solicitud pero finalmente es el equipo de acuerdo a lo que ordena la ley quien determina el ingreso.

Cómo se egresan, lo que se ha venido trabajando es el fortalecimiento del acompañamiento familiar en las defensorías de familia desde lo social, empoderamiento, redes de apoyo, movilización del 
sistema. Se trabaja con los cuidadores el empoderamiento y la exigencia de derechos en las diferentes entidades. Desde que las familias hayan optado dichas herramientas se realiza una preparación de egreso en donde se establecen. Lo que como institución se ha evidenciado, es que las familias han podido superar su situación inicial es decir, no es que no requieran de la modalidad sino que a través del tiempo han podido realizar las gestiones correspondientes garantizándoles una vida óptima a sus hijos. Durante la vigencia 2015 y 2016 se ha logrado la movilización del 34.8\% de NNA lo que permite la vinculación de otras familias. No desconocemos quizá que haya algunas situaciones por que no tengan vulneración de derechos y es por ello, que desde la defensoría de familia se conceptúa la medida más idónea si es el externado, institución u hogar gestor. Y periódicamente a través de los seguimientos se establece la continuidad del NNA en la modalidad.

\section{¿Considera que la atención a los NNA en condición de discapacidad debe ser centralizada en una sola entidad?}

Yo considero de no se debe centralizar porque cada entidad del Estado tiene una función específica, los NNA en condición de discapacidad como todos sabemos son sujetos de especial protección, lo que implica la corresponsabilidad de sectores como salud, educación, recreación y deporte y demás entidades. Es importante que cada entidad cumpla corresponsablemente con lo que le compete y lo que dentro de su misión está, porque así permite concebir al NNA desde la integralidad del ser humano. Es muy difícil que una sola entidad garantice al NNA en condición de discapacidad lo que se requiere y que proporcione todo. Además porque de una u otra manera es importante que la discapacidad sea sensibilizada y podamos llegar a ese punto que veamos estamos interviniendo con una persona sujeto de derechos. La descentralización de la atención permite mayor corresponsabilidad y nos llama al compromiso y a la atención integral.

¿Finalmente en qué institución local considera usted que debe estar la responsabilidad de diseñar, ejecutar y regular los programas de atención integral a los NNA en condición de discapacidad?

Yo pienso que es importante que todas las entidades se involucren, por ejemplo el hospital pablo VI en Bosa ha sido un muy buen apoyo para ICBF en cuanto a la capacitación de los representantes legales y en la oportunidad de brindar mejores herramientas de cuidado, Bosa particularmente es una localidad que maneja muchos programas para esta población, creo que lo que sucede es que ha faltado mayor conexión entre las entidades que permita la superación de la condición de vulneración a los NNA y sus familias. En ese sentido, todas las entidades con presencia en la localidad deben tener las facultades para diseñar, ejecutar y regular los programas. 
¿Deben ser finalmente los municipios los encargados de ello o deben ser las instituciones de carácter nacional?

Teniendo en cuenta que considero que debe haber una corresponsabilidad en la atención, lo que pienso es que tanto los municipios como las localidades deben fortalecer el tema del diagnóstico, ya que además de conocer el censo poblacional, nos permite conocer desde el enfoque de ciudadanía las verdaderas necesidades de las poblaciones. Pues las necesidades de Usaquén no son las mismas de Bosa. Todo se debe bajar a las localidades, así mismo es importante reflexionar frente al papel de la construcción de ciudadanía, la participación activa de la población ya que, por ponerte un ejemplo yo desde la institución considero que lo que le hace falta a x comunidad es un gimnasio para los NNA pero resulta que todos mis NNA presentan discapacidad absoluta, ves? Allí no aplicaría. Entonces por eso la importancia que las políticas se bajen hasta las comunidades y se adapten a sus necesidades. ¿En qué medida cambian los programas de su entidad destinados a la atención de NNA en condición de discapacidad y sus cuidadores en las nuevas administraciones?

Mira en este tema considero que puntualmente es un fenómeno que se presenta más que todo o con más alto nivel de impacto en las instituciones del Distrito y no en el orden Nacional aunque, no desconozco que por supuesto si existen pues cambios significativos en la misionalidad de los programas. Es una cuestión muy importante en el abordaje de las familias y las personas en condición de discapacidad porque ellos dependen exclusivamente de estos programas y cuando se modifican tienden en su mayoría a disminuir recursos o espacios de participación para esta población. Actualmente las mamitas que se encuentran con nosotros han hecho un llamado al ICBF teniendo en cuenta que Secretaria de Integración Social va a disminuir en más del 50 \% los cupos que tiene ahora.

¿Los programas ofertados responden a un enfoque de derechos? (Diseño, operacionalizacion y evaluación).

El tema de derechos como tal es algo muy complejo para abordar, yo quisiera decir con plena seguridad que todo el proceso de diseño e implementación de los programas obedecen a este enfoque no obstante, la realidad es diferente porque llega un punto en el que de quiebra la base y de alguna manera se queda corto para dar respuesta. Es una cuestión estructural que no le permite a las instituciones dar cumplimiento o intentar garantizar a plenitud todos los derechos de las personas y por supuesto de cubrir sus necesidades pero, existen factores como los recursos y la disponibilidad presupuestal que imposibilitan tener mayor cobertura poblacional y ampliar la oferta institucional. 
Desde el ICBF considero que con las modalidades de atención que tenemos si bien no estamos cubriendo cien por ciento las necesidades de los niños y sus familias, estaos haciendo un esfuerzo por garantizar un mínimo de derechos. Las defensorías de familia desde hace un par de años se evidencian más comprometidos con las intervenciones y están realizando gestiones para dar cumplimiento a un enfoque de derechos partiendo inclusive, de un reconocimiento por la discapacidad y una reflexión frente a las condiciones de estos NNA.

\section{¿Cómo ve la relación entre familia y Estado frente a la situación actual de los niños en condición de discapacidad y sus cuidadoras? (Complementariedad o Sustitución)}

Considero Anggie que es una relación de complementariedad como tú lo mencionas, por sus particularidades sociofamiliares pensar que el Estado está asumiendo la labor de la familia en el tema de la discapacidad y enfermedades de cuidado especial, es hablar desde el desconocimiento. Diría con total convicción que la familia está aportando hasta donde el Estado le ha dado condiciones para intervenir y el Estado está asumiendo lo que no ha podido garantizarle a las familias. Es un proceso en que cada uno abarca desde su influencia, de pronto, en ocasiones uno nota que la Familia es quien tiene toda la responsabilidad de protección de estos chicos y entra uno también a pensar en dónde interfiere el Estado como por ejemplo, en temas de acceso a salud y la oportunidad con la que llega la asistencia médica a las personas.

\section{GÉNERO}

\section{¿Se han incluido a las mujeres cuidadoras dentro de los programas ofertados?}

En el ICBF no se había realizado ningún tipo de trabajo con mujeres cuidadoras específicamente, solo fue a partir del año 2013 a través de una sentencia de la Corte Constitucional en donde nos exigen que se debe realizar un acompañamiento permanente desde el ámbito jurídico y psicosocial a las familias de los NNA que se encontraban en la modalidad de Hogar Gestor y es por ello que surgen, las Unidades de Fortalecimiento Familiar a los NNA en condición de discapacidad y víctimas del conflicto armado interno - UNAFA-. Inicialmente, UNAFA se establece desde la Sede Nacional como una estrategia trasversal operacionalizada por un privado con un control un poco lejano a la intervención de las defensorías de familia, ya desde el año 2013 se constituye como Programa misional dentro de las Regionales a nivel Nacional y se crea como una oportunidad para brindar herramientas de empoderamiento, liderazgo y productividad en las familias, desde allí se realiza todo el trabajo de intervención con las cuidadoras entonces, nosotros realizamos articulación con diferentes 
entidades para ampliar las opciones de vida de estas mujeres, acompañamos desde lo psicosocial y damos procesos de liderazgo a través de talleres y encuentros grupales con ellas para construir redes de apoyo.

¿Cuál considera usted que es la situación actual de las mujeres que se dedican al cuidado de los NNA en condición de discapacidad?

Bueno, te diría que en un $90 \%$ son mujeres cuyas familias son monoparentales y son ellas quienes ejercen la jefatura de hogar, la mayoría fue víctima o aún son víctimas de violencia intrafamiliar ya sea física, económica o psicológica, no cuentan con redes de apoyo que les permita estructurar nuevamente sus proyectos de vida, hay un porcentaje importante de mujeres que también son víctimas de conflicto armado interno, en condiciones de pobreza acentuada, con niveles académicos bajos y con la particularidad que tienen más de un hijo en condiciones de discapacidad o enfermedad de cuidado especial. También se caracterizan porque se dedican a labores informales o a trabajos pesados y con asignaciones salariales precarias.

\section{¿Considera que el ejercicio del cuidado está siendo asumido progresivamente por los hombres o considera que las brechas de género se siguen presentando en la localidad?}

No se puede desconocer que los hombres también están dejando a un lado los estereotipos de género y han asumido progresivamente el cuidado de estos NNA, los que nosotros evidenciamos son más o menos 3 o 4 de 130 mujeres que se dedican al cuidado, también, en ellos lo que yo evidenció es que ejercen un liderazgo positivo, participan en varias entidades de la localidad pero al mismo tiempo se encargan de llevar el sustento económico a las casas desarrollando actividades como construcción y plomeros.

Sin embargo, vemos con preocupación que los hombres no asumen la labor de cuidado sencillamente porque en el proceso de crecimiento de los NNA abandonan los hogares y constituyen otros y además, se desentienden por completo y esto se presenta en las familias relativamente más jóvenes que las otras, no aportan cuotas alimentarias y tampoco generan vínculos afectivos con los niños.

\section{¿Cuáles son las razones por las que las mujeres acuden a los programas de asistencia social?}


No hay que desconocer que habrá mamitas que se acostumbren de alguna manera a vivir de los subsidios y los programas por sus miedos y temores no obstante, lo que pienso es que la mayoría de las mujeres cuidadoras acuden porque no tienen más apoyo, como ya lo mencionaba las condiciones de precariedad en las que viven sus familias son preocupantes y por su puesto el Estado a través de la asistencia social es quien atenúa la condición actual, ahora, Colombia es un Estado que se ha enfocado todo el tiempo en políticas de asistencia social entonces uno no puede llegar a pensar o a convencerse como hay personas que lo hacen, porque las conozco, que dicen "es que no quieren hacer nada, no les gusta buscar trabajo". Si eso es lo que el Estado les ofrece pues ellas están en total derecho de participar y ser beneficiaras de ellos.

\section{ROL SOCIAL Y POLITICO}

¿Evidencia que las mujeres cuidadoras de la Localidad de Bosa han desarrollado habilidades para participar en escenarios de discusión política y social?

Todas las que uno se pueda imaginar, son mujeres que inclusive desde el analfabetismo se han transformado en verdaderas agentes de cambio tanto para sus familias como para la comunidad en general. Es el liderazgo positivo y asertivo lo que las caracteriza, el interés de implementar mecanismos de comunicación y de incentivar las redes de apoyo como opción de exigencia de derechos. De la localidad conozco a una señora de edad avanzada que en este momento participa en el Consejo Distrital de Discapacidad con un empoderamiento impresionante, de pronto es fuerte en su manera de ser pero ella es un ejemplo concreto de las habilidades con las que se están formando las mujeres cuidadoras, tiene conocimiento de lo que está hablando y sus discusiones con las entidades son interesantes en la medida en que ella les hace seguimiento a los resultados y a los impactos, por eso para ella es muy fácil decir eso no se ejecuta por esta y por esta otra razón y lo argumenta, defiende su posición y está comprometida con su labor.

\section{¿Las mujeres desempeñan un ejercicio político en la localidad o solamente se debe a un instinto de supervivencia por ser su referente protector?}

Es un rol protector que les permitió encontrar un espacio en escenarios de discusión social y política, los discursos en sí mismos tu sabes que son frases elaboradas que influyen en un grupo pero, escuchar a estas mujeres es evidenciar desde la experiencia una exigencia permanente por la justicia y la equidad. Considero que la función de ellas tanto en la vida de sus hijos como de sus familias se convierte en una proclamación de derechos y no solamente de cuidado. A nivel Local las mujeres cuidadoras le han permitido al Consejo Local de Discapacidad propender por espacios diferentes y 
que no han tenido buenos resultados y que sin embargo se seguían ejecutando, le dieron la oportunidad al consejo de explorar un ejercicio de articulación directa con las entidades y de la asignación de funciones de liderazgo, control y veeduría a estas mujeres.

El factor comunitario no solamente se ha experimentado desde las redes de interacción primarias, sino como mecanismos efectivos de promulgación y socialización de temas de interés para todos.

\section{¿Cómo cree que ha sido ese proceso de empoderamiento de las mujeres cuidadoras en un contexto de pobreza, desigualdad social y violencia?}

El de cada una ha sido muy diferente creo, sin embargo es la dificultad lo que nos permite evidenciar las potencialidades de estas mujeres porque, a pesar de tantas cosas difíciles ellas han estado dispuestas a vencer sus propios miedos y sus tristezas para darle felicidad y bienestar a sus familias. Ejercer un liderazgo en medio de opresores es casi imposible, pero ellas han superado las barreras para dar un ejemplo a la sociedad Colombiana que se queda siempre pensando en que no hay nada que hacer en temas de conflicto armado interno por ejemplo, la imposibilidad finalmente está en quienes piensan que no hay nada más por ofrecer.

\section{¿Las mujeres cuidadoras logran multiplicar sus saberes con otras mujeres para permitirles a ellas y a sus hijos el acceso a programas y servicios?}

Esto es lo que las caracteriza, son mujeres que reconocen la necesidad y reflexionan sobre todo acerca del derecho a la información, ellas están pendientes siempre no solo de participar o de promulgar actividades sino que por el contrario están como veedoras de los procesos de socialización y convocatorias. No es de contarle a la vecina por contarle sino es una acción que permite el acceso a un servicio o inclusive a la garantía de un derecho reconociendo, que la información que a la institucionalidad le cuesta dar una información oportuna y masiva por lo cual, ellas se convierten en parte fundamental de la comunicación entre sectores de la sociedad local.

\section{¿Las mujeres cuidadoras se ven más expuestas a la exclusión (Social e Institucionalmente) por} ejercer el cuidado?

Definitivamente, considero como mujer inclusive, que el contexto social del país es difícil porque tiene muchos estigmas frente a la participación de las mujeres a la educación y al empleo particularmente, creo que desafortunadamente es un país aun con un machismo importante dentro y fuera de los hogares que generan por supuesto exclusión y desigualdad frente a los hombres y especialmente a la garantía de derechos. En ese orden de ideas, más una mujer que no tiene o tuvo acceso a educación, que se encuentra sola, que no cuenta con redes de apoyo y que aparte deben 
responder por uno o varios hijos que presentan condiciones de discapacidad o de cuidado especial. Ahora, no pueden laborar en las mismas jornadas que los demás y en ocasiones el hecho de que trabajen implica que no sean tenidas en cuenta para ser parte de algún programa de asistencia o sea, es una condición de vida muy complicada que tiene muchos prejuicios también por su rol.

\section{¿Las mujeres aprovechan su rol como cuidadoras de NNA en condición de discapacidad para exigir sus derechos como mujeres o es solamente una exigencia para sus hijos?}

Mira eso es tan difícil que yo lo que identifico es que ellas viven finalmente en función de sus hijos es decir, ellas a veces ni siquiera reconocen sus derechos y no les interesa que sus condiciones de vida personales mejoren si la calidad de vida de sus hijitos sigue igual. Con las mujeres más empoderadas uno evidencia que también empiezan a luchar por sus derechos y a ser tenidas en cuenta pero las mujeres que hasta ahora están en ese proceso les cuesta más porque quizá no han logrado obtener tantos beneficios para los niños, como lo han logrado las señoras que llevan más tiempo en los procesos de inclusión.

\section{¿Son las mujeres cuidadoras de Bosa un grupo reconocido por la comunidad y las instituciones?}

Yo estoy en el área administrativa de la modalidad hace dos años, es decir yo tengo a cargo la parte técnica, jurídica y presupuestal del proceso y no la intervención directa con la familia, lo que yo he evidenciado desde que llegué es que Bosa no logra movilizar la participación de otras familias en la modalidad porqué, porque son mamás que todo el tiempo están interponiendo recursos jurídicos que nos obligan a dar continuidad dentro de la medida de restablecimiento de derechos es decir nosotros por supuesto fallamos porque no estamos realizando un acompañamiento efectivo a estas familias y por tanto no logramos articular con otras entidades para mejorar las condiciones de vida de las familias.

Pero también, es tener siempre que estar muy dispuestos a estar respondiendo institucionalmente a estas mujeres porque no permiten el cierre de los hogares gestores y argumentan muy bien sus condiciones de vulnerabilidad. Y esta situación no sucede con las otras localidades de Bogotá, en las demás se termina la medida y quedo el cupo liberado para otro NNA pero con Bosa si hay esa particularidad. Si son reconocidas por el liderazgo que ejercen.

\section{¿Cuáles son sus debilidades?}


Quizá la desunión que en este momento se evidencia, si las mujeres cuidadoras intentaran crear organización de carácter Distrital estoy segura que sacarían muchas cosas adelante, serían reconocidas a nivel político también pero desafortunadamente, pienso que en ocasiones ellas están enfocadas es en la necesidad inmediata de su hijo y no en la necesidad colectiva de mejorar las condiciones de ellos. No se conocen entre ellas y por tanto no hay un reconocimiento interno frente a la labor que desarrollan.

\section{PROSPECTIVA}

\section{¿Cómo mejorar las condiciones de vida de las mujeres cuidadoras y sus familias sin tener que acudir a los múltiples programas de asistencia Social?}

Definitivamente considero que se deben abrir puertas desde lo laboral, económico y productivo, estas mujeres no están sin empleo porque quieran estar en condición de mendicidad o de dependencia sencillamente, son mujeres que presentan unas características específicas y de difícil manejo que les dificulta tanto ingresar a un empleo digno como crear microempresas o ideas productivas. Es cuestión de que se generen normas que les permita el ingreso a empresas del sector público y privado reconociendo por su puesto sus realidades.

Considero además que si el Gobierno reconociera económicamente la labor de cuidado que ellas realizan, sería la oportunidad perfecta para mejorar las condiciones de vida de estas mamás y la reducción de medidas de asistencia social digamos, reduciría un presupuesto importante en temas de asistencia para pasar a temas de fuerza labor y competitividad.

\section{¿Ha pensado como profesional cómo las mujeres cuidadoras lograrán sobrellevar la vejez, el cuidado de sus hijos e hijas y posibles quebrantos de salud?}

La verdad a mí me afana mucho ese tema, conozco de cerca la realidad de estas familias y me entristece mucho reconocer que el Estado no tiene como garantizar una calidad de vida digna a las personas adultas mayores, es un Estado que no tiene claro tampoco estrategias de acogida para las personas en condición de discapacidad que pierden su familia o que la enfermedad está presente en los cuidadores. 
Son mujeres que se cansan y que sufren pero la salud o la motivación les permiten continuar con su ejercicio, pero cuando llega la vejez o inclusive una limitación medica por más que quieran no van a poder enfrentar solas estas situaciones. Desde mi profesión lo pienso permanentemente y también intento sensibilizar a las defensorías para que evidenciemos estas situaciones tan complejas a tiempo y permitamos de alguna manera que se puedan generar algunas opciones para estas familias desde la movilización y articulación del sistema Nacional de Bienestar Familiar.

\section{¿Hasta dónde, el hecho que las mujeres cuidadoras sigan realizando la labor del cuidado, refleja que el Estado se ha quedado corto en la cobertura de la Protección Social?}

Lo que pienso es que más que corto, el Sistema de la Protección Social se está renovando o adaptando más bien a las realidades propias de sus habitantes, Colombia es un país demasiado diverso tanto en población y territorios como en las mismas problemáticas sociales, considero que hace falta mucho camino por recorrer y sobre todo la movilización del Gobierno a través de sus planes de gobierno para ampliar coberturas. Es decir, es un sistema joven que debe por supuesto enfocarse en mejorar sus acciones y en crecer en favor de la población.

La discapacidad por supuesto es un reto muy grande para la protección social y actualmente no cuenta digamos con las garantías para nuestros NNA y sus familias.

\section{¿En qué institución ve usted más barreras para lograr un trabajo articulado en la localidad?}

Desafortunadamente es Salud, el sistema de salud en este momento es tan lucrativo que sea vuelto un negocio para diferentes personas o grupos que realmente lo están llevando a sus mínimas expresiones de servicio, una discusión que tenemos al interior del ICBF es que con el Hogar Gestor por ejemplo podríamos evidenciar que las familias invierten en temas de educación, alimentación e inclusive ahorro para proyectos productivos lo que genera un bienestar sostenible a lo largo del tiempo para los NNA y sus cuidadores sin embargo, lo que evidenciamos realmente es que son familias que tienen que invertir obligatoriamente el recurso generado en elementos que el sistema de salud no da, me hago entender, mientras una familia que reciba todo de la EPS para la rehabilitación y tratamiento de su hijo puede invertir en otros aspectos, podría asegurar que todas las familias que se encuentran con nosotros gastan el dinero en pañales, terapias, ayudas técnicas e infinidad de elementos que no permiten que los niños gocen de otros beneficios. 
Es lamentable que Colombia no entienda la necesidad que tienen estos chiquitines y en general toda la población, la enfermedad es un estado inherente a la vida y por ende se debe procurar por establecer mecanismos de intervención efectivas desde esta área.

\subsection{Entrevista 2}

Funcionario 2, Secretaria Distrital de Integración Social 
Mi Nombre es Funcionaria 2, soy trabajadora social, tengo un posgrado en educación sexual y familia en la Monserrate, trabajo hace 6 años con la secretaria distrital de la integración social - SDIS- en la Subdirección Local de Bosa, con población con discapacidad, trabajamos con el proyecto 721, atención a niños niñas en condición de discapacidad cerrando brecha, luego se cambia el proyecto con esta alcaldía y se llama proyecto 1113 por una ciudad incluyente y sin barreras.

\section{ACCIÓN INSTITUCIONAL}

\section{¿Cuáles son y en qué consisten los programas que promueve su entidad?}

Uy!, desde la Secretaria de Integración Social se manejan varios proyectos desde los diferentes enfoques de asistencia como por ejemplo habitantes de calle, género, infancia, vejez, juventud ... etc. sin embargo, los programas que manejamos desde la atención a la discapacidad están contemplados, en el ahora llamado proyecto 1113: Por una ciudad incluyente y sin barreras. El objetivo, es pues, fortalecer los procesos de inclusión de las personas con discapacidad, sus familias y cuidadores en los diferentes entornos. Hay varias modalidades dentro del proyecto, está Cuidando nuestras capacidades, que consiste en el acompañamiento psicosocial desde la realización de espacios de participación y un bono económico para las y los cuidadores. Están, los centros crecer que promueven el desarrollo personal y la inclusión social de niños, niñas y adolescentes con discapacidad desde los 6 hasta los 17 años y 11 meses. El servicio realiza un proceso en cuatro áreas para fortalecer la inclusión social que son volver a la escuela, habilidades básicas, habilidades ocupacionales y proyecto de vida.

También está, la atención integral en centros de protección a personas mayores de 18 años con discapacidad que son centros de protección para personas mayores de 18 años con discapacidad y busca garantizar la protección de las personas con discapacidad cognitiva, mental o física en abandono, sin redes familiares o con familia, en situación de vulnerabilidad social o que no puede hacerse cargo de su cuidado. Aquí, es alojamiento, alimentación, vestuario, elementos de aseo personal, dotación para las opciones ocupacionales, transporte y servicios funerarios y acompañamiento psicosocial. Así mismo Anggie, se llevan a cabo procesos de atención dirigidos a potenciar las habilidades y destrezas de los miembros del grupo familiar para involucrarlos en la construcción de su proyecto de vida a partir del marco de la corresponsabilidad.

Requisitos de ingreso

Depende del programa 
En general que exista un NNAJ o adulto con discapacidad certificada a través del DX medico Niveles de SISBEN 1 y 2

Presenten situaciones de vulnerabilidad socioeconómica

Actualmente ¿cuántas personas participan en los programas?, ¿Qué profesionales atienden dicha población?

Un aproximado te podría decir que a nivel de la localidad se atienden entre 7000 personas a 8000 . Las profesiones que desarrollan las intervenciones son psicología, trabajo social, terapia ocupacional, fonoaudiología, fisioterapia y licenciados en educación especial.

\section{¿Considera que los profesionales que brindan atención en dichos programas, cuentan con las habilidades y conocimientos para atender las necesidades de la población?}

Considero que sí, pero sería de mi parte poco sensato desconocer que desafortunadamente hay profesionales a los que no les gusta la intervención con personas en condición de discapacidad y eso pues evidentemente se observa al interior del grupo. Sin embargo, los profesionales que fuimos formados dentro de un contexto social hemos desarrollado con la experiencia habilidades importantes para atender a los ciudadanos pero sobre todo, es ver la discapacidad desde otros escenarios como la potencializacion de habilidades para la vida y la participación social.

En temas de buen trato a las personas, internamente tenemos varios "auditores" por decirlo de alguna manera que están súper pendientes de ello y pues en el momento en que pasamos nuestras cuentas de cobro, pasan acciones de mejora y recomendaciones para que sean cumplidas durante la ejecución del contrato.

Específicamente con los y las cuidador@s la dinámica es diferente porque generalmente logramos tener empatía y el apoyo de ellos, lo que nos permite incluirlos dentro de nuestras intervenciones pero, a veces también pasan de exigir algún servicio a ser groseros y eso indispone a cualquier persona porque finalmente los profesionales seguimos siendo personas.

\section{¿Qué aspectos considera usted, que los profesionales deben fortalecer?}


Considero que la intervención con las familias y el proceso de inclusión de los niños y jóvenes dentro de los espacios de participación social y política, que los vean como seres humanos productivos y con capacidades.

¿Cómo es el proceso de inclusión de las personas a los programas? - cuáles son los criterios de selección y focalización.

El proceso de inclusión primero que todo parte, de la política pública, donde el marco son 3 enfoques fundamentales, el primer enfoque es basado en el sujeto como persona de derechos basado en un marco jurídico, basados en la convención internacional de las personas en condición de discapacidad y para ello se crea el proyecto 721 y como todo proyecto tiene unos criterios de ingreso, esos criterios de ingreso es que vivan en la localidad donde está ubicada la unidad operativa del servicio y los criterios son:

Que viva en la localidad, niños, niñas y adolescentes entre los 6 años a 17 años y once meses, que tenga discapacidad cognitiva, down, autismo, asperger y... ah y que estas discapacidades tengan otra enfermedad de base, pueden ser epilepsia, otra enfermedad de base puede ser un trastorno a nivel psicomotor. Desafortunadamente las personas con discapacidad psicosocial no las atendemos por el difícil manejo que tienen ya que es un espacio cerrado y grupal.

\section{¿Qué estrategias implementa la institución para disminuir el ingreso de personas que no requieren la atención (Riesgo Moral)?}

Bueno eso... hay unos instrumentos para medir de alguna manera la vulnerabilidad de las personas y esos instrumentos son la visita domiciliaria, y la validación que se hace desde el mismo proyecto, cada localidad tiene que hacer un filtro, pasan por la subdirección local, al proyecto cuidando nuestras capacidades, antes se llamaba cuidando nuestras capacidades ahora se llama inclusión comunitaria, porque se trata de incluir a todas aquellas personas que están en los estratos 1,2 y 3 y a veces 4 cuando es pobreza avergonzante, que es una persona que puede vivir en el Nicolás de Federman pero que realmente debe cuotas, no están trabajando y de pronto hay un cuadro de salud mental o hay problemas comportamentales o situación socio- económica critica, o una persona con una enfermedad terminal, entonces esas personas se incluyen porque realmente para nosotros requiere, tiene la necesidad y según los criterios pues ingresaría al proyecto. 
Todas las 20 localidades de Bogotá tienen el proyecto 7-21 que tiene dos modalidades grandes, uno es atención a población mayor con discapacidad y a población menor con discapacidad; esa población mayor, mayores de 18 años tienen derecho a un bono, tienen que tener obviamente el proceso de validación de condiciones, si estuvo en centro crecer de una vez pasa al apoyo del proyecto de inclusión comunitaria, y se mira si realmente amerita el apoyo económico o es para apoyo psicosocial o sea orientación a las familias, manejo de la discapacidad, talleres de empoderamiento para que tengan unidades productivas para que se articulen con otras entidades porque este proyecto tiene algo, se llama inclusión, el solo hecho de ser inclusivo es no a la segregación no a la exclusión social.

Entonces nosotros articulamos todas las entidades de la localidad, y si no aplica para nosotros, la vinculamos a discapacidad múltiple si tiene una discapacidad múltiple y que la secretaria también tiene ese proyecto o se va para otro proyecto de pronto que tenga bienestar o que tenga la secretaria de integración social o el SENA o una ONG, se trata siempre de articular para que este usuario de acuerdo a su necesidad y a esos criterios que tiene cada institución pueda ingresar, pero a ninguno se deja si requiere el servicio, ninguno se deja sin atención y / o si tiene un problema de salud mental nosotros no lo recibimos porque esos son los criterios que no tenga problemas de salud mental como esquizofrenia o trastorno bipolar o problemas conductuales que afectan la vida de él y a de los que lo rodean, porque son, pueden agredir a alguien y pueden poner en riesgo la vida de ellos y la vida de los otros, entonces por esa razón según ese criterio no los recibimos pero si se articula con el hospital o SISBEN o RBC que es el programa de salud mental de la red de hospitales para atender a las personas con discapacidad pero a su vez, con problemas de salud mental y eso se envían a las eps, porque las eps deben ayudar a atender la salud de todo paciente que tenga un cuadro de salud mental, eso no lo recibimos nosotros.

\section{¿Considera que la atención a los NNA en condición de discapacidad debe ser centralizada en una sola entidad?}

No, creo que desde la experiencia cada institución le aporta en algo a las familias y a las personas en condición de discapacidad y al mismo tiempo, ofrecen diferentes servicios que pueden ser de apoyo integral. Como he dicho la discapacidad debe aprenderse a ver desde la inclusión social y es por ello que cada institución debe generar proyectos y programas que los beneficien y que den respuesta a la política pública.

De verdad, si todas las instituciones contáramos con los recursos económicos y administrativos para atender a la población, disminuiríamos las barreras de acceso y la vulneración de derechos. 
¿Finalmente en qué institución local considera usted que debe estar la responsabilidad de diseñar, ejecutar y regular los programas de atención integral a los NNA en condición de discapacidad?

Pues a mí me parece que la labor que desempeña la Secretaria de Integración Social se adecuaría a ese liderazgo local primero, por la experiencia de los territorios y lo segundo porque desde la disponibilidad y existencia de diferentes proyectos podemos articular y mejorar la intervención de la infancia y la adolescencia en condición de discapacidad.

Claro que se necesita del apoyo permanente de las alcaldías locales las cuales, tienen bastante presupuesto y una obligación con las comunidades. Pero en realidad Integración Social podría ser un muy buen líder de política pública.

¿En qué medida cambian los programas de su entidad destinados a la atención de NNA en condición de discapacidad y sus cuidadores en las nuevas administraciones?

Bueno... eh, principalmente en las instituciones distritales se ve evidentemente los cambios en los programas de atención a los niños en condición de discapacidad y sus cuidadores ya sea, por más o menos cobertura o más o menos actividades al interior de las subdirecciones locales . Este quizá es la dificultad que yo evidenció, porque inclusive los profesionales rotan mucho porque no se les da continuidad en sus contratos y esto afecta las intervenciones y el trabajo con las familias.

En esta Alcaldía por ejemplo tenemos que focalizar nuevamente los beneficiarios porque, pasan de 8000 atendidos a 2500 y eso tiene muchas implicaciones y más en una localidad tan vulnerable como la de Bosa.

¿Los programas ofertados responden a un enfoque de derechos? (Diseño, operacionalizacion y evaluación). Desde las intervenciones cotidianas (Desde lo local) ¿se alcanza a expresar la visión de derechos o están dirigidas exclusivamente para el cumplimiento de metas?, ¿Qué tanto opera el enfoque diferencial?

Si, obviamente no en la magnitud que se quisiera pero si desde el diseño hasta la ejecución se trabaja sobre un enfoque de derechos, buscamos atender a las personas desde su integralidad intentado dar respuestas a sus necesidades. Es difícil el tema de lo diferencial porque tendríamos mil proyectos y mil actividades que ejecutar, considero que es más el respeto por la diferencia y garantizar la participación de las minorías dentro de los proyectos. 
El tema de las metas sinceramente creo que no es ajeno a ninguna institución, porque es por ello que nos miden y de alguna manera que aprueban nuestros pagos pero, no dejamos de lado nuestra labor y los derechos que tienen las personas.

\section{GÉNERO}

\section{¿Se han incluido a las mujeres cuidadoras dentro de los programas ofertados?}

Bueno nosotros en este momento dentro de nuestras funciones y dentro de nuestro proyecto está la formación y el empoderamiento de las familias que tienen, que son cuidadoras o s tutores que también tenemos instituciones que tienen convenio con bienestar y tienen niños acá, están un día acá y en la tarde están institucionalizados que son como 4 casos entonces a todos ellos se les da un empoderamiento y dentro de ese empoderamiento, capacitación se llama formación a padres, madres de familia y cuidadores lo desarrolla el equipo sicosocial con todo el equipo, cada área de acuerdo a su especialización empodera a la familia y le muestra que está trabajando con su hijo y nosotros desde sicosocial articulamos con el consejo local de discapacidad frente a todas las novedades en el marco jurídico que las familias deben conocer.

En este momento la fundación país, el ministerio de justicia y especialmente en el ministerio de justicia está actualizando en unos decretos y acuerdos sobre los procesos de interdicción que de acuerdo a la convención internacional de los derechos de las personas en condición de discapacidad ya tienen un viraje diferente entonces el mismo ministerio de justicia está haciendo toda una cantidad de material pedagógico para empoderar a todos los entes y todas las instituciones para cómo garantizarle jurídicamente a las personas en función de discapacidad y garantizarles los derechos según la convención.

\section{¿Cuál considera usted que es la situación actual de las mujeres que se dedican al cuidado de los NNA en condición de discapacidad?}


Son abandonadas, presentan otra unión, maltrato y violencia intrafamiliar, por lo general violencia intrafamiliar y toda cuidadora tiene estas características por estar cuidando a su hijo, no hay trabajo, tienen trabajos inestables, esporádicos, oficios varios, sus trabajos la remuneración es muy precaria, entonces por eso en este momento la ley está tratando en el congreso como esas cuidadoras tienen así sean un salario mínimo, por ser cuidadores que se les va toda la vida cuidando a sus hijos, pero su proyecto de vida como mujeres, como personas que pueden realizarse, a nivel biopsicosocial, a nivel económico, no lo hacen porque se quedan como cuidadores y además las caracteriza como un sentimiento de culpa que casi siempre no se quita, no se retira de sus mentes y sus corazones. Uno todo el tiempo está trabajando con ellas sobre quitar la culpabilidad.

\section{¿Considera que el ejercicio del cuidado está siendo asumido progresivamente por los hombres o considera que las brechas de género se siguen presentando en la localidad?}

$\mathrm{Si}$, se caracteriza, en los centros que yo he trabajado que ha sido mártires y Bosa, hemos evidenciado como equipo psicosocial o sea trabajo social y psicología, que la mayoría son mujeres las que se prestan para el empoderamiento y participan en espacios comunitarios como el consejo local de discapacidad, el clops, la uat de atención a víctimas, la red del buen trato. Entonces hemos identificado que en estos espacios o escenarios de participación desde la secretaria se le hace seguimiento a la ejecución de esas políticas y la cristalización de esas políticas de territorializacion, esas políticas en las comunidades, como se desarrollan, si realmente se están ejecutando o no y requiere de veedores, requiere de esos representantes que se nombran también por decreto del articulo 505 al consejo local de discapacidad donde debe consolidarse a través de una articulación ciudadana, identificamos que participan más las mujeres que los hombres porque la mayoría abandonan a las esposas , de diez mujeres 5 son madres cabeza de familia, esposas que las abandonan cuando se dan cuenta que son niños con discapacidad; para los hombres es muy difícil aceptar que se tiene un niño en condición de discapacidad y se muestran resistentes a aceptarlo así mismo, hay mujeres en familia extendida donde el abuelo y la abuela son los que cuidan de estos niños, como también hay muchas mamás, como una minoría que prefieren abandonar esos niños y dejarlos en los abuelos o parientes más cercanos de la familia extendida.

Entonces la mujer es la que más participa porque le toco o porque realmente una mamá nunca deja de ser mamá en su corazón como sea saca adelante el niño 
¿Cuáles son las razones por las que las mujeres acuden a los programas de asistencia social?

De acuerdo a un informe, las mujeres cuidadoras solamente acuden a la asistencia social para no tener que buscar opciones de empleo y educación.

Ah sí, las mamás participan, la mayoría de mujeres participan, pero algunas mujeres se quedan rezagadas y no participan por el complejo de culpa o sea para ellas es muy difícil acceder a algunos servicios. Uno porque ya esperan que el Estado les de todo, que es Estado las subsidie, que el Estado les dé, que el Estado tiene que darle al hijo, hay otras guerreras que se equipan y son empoderadas por nosotros mismos o en otras instancias como la secretaria de la mujer, el consejo local, bienestar familiar, comisaria de familia, aquí la secretaria de integración social trabaja todas las políticas sociales, entonces en cada proyecto, las fortalecen para que ellas puedan adquirir trabajo u otras formas de ingresos en este momento, por eso en esa convención internacional se está ampliando el campo de trabajo para ellas, es más hasta aquí en la secretaria tienen personas que tienen hijos en condición de discapacidad, y también tienen discapacidad, hasta una esquizofrenia pero medicada y están trabajando para la secretaria de integración y si le está dando por que la convención y las mismas normas y leyes de discapacidad ha permitido que se movilicen para que estas cosas sean desde el senado de la cámara en leyes. Y la convención es la que más en este momento le ha dado un campo de acción alto y un reconocimiento a las personas como sujetos de derechos a las personas en condición de discapacidad y se incluyen pues obviamente las cuidadoras.

\section{ROL SOCIAL Y POLITICO}

\section{¿Evidencia que las mujeres cuidadoras de la Localidad de Bosa han desarrollado habilidades para participar en escenarios de discusión política y social?}

Uy sí, yo llevo aquí varios años y he visto como mujeres cuidadoras se han involucrado en los escenarios de participación política y social como los consejos locales de discapacidad y han defendido los intereses de los niños en condición de discapacidad y a las mismas familias.

Hace como un año, la Alcaldía Local diseñó y puso en marcha un proyecto dirigido a los niños en condición de discapacidad para que participaran en algún escenario deportivo o artístico, la profesional que fue contratada socializó en un Consejo cómo se haría el ingreso y los demás criterios

y fue tenaz, porque las mujeres de una vez le dijeron mira eso no se puede, eso no es así, mejor dicho le dijeron que conocería primero las problemáticas de la comunidad y luego si diseñará el proyecto. 
Ahí uno las podía escuchar y sabían cuáles eran las necesidades de sus hijos y de la comunidad en general es decir, que los años de estudio de la profesional no le sirvieron para darse cuenta de las realidades complejas y que la comunidad sabe de lo que se le está hablando.

\section{¿Las mujeres desempeñan un ejercicio político en la localidad o solamente se debe a un instinto de supervivencia por ser su referente protector?}

Mira, considero que fue un instinto de supervivencia que se convirtió poco a poco en una voz política dentro de los territorios, por amor a sus hijos y al ver la necesidad que los apremia día a día, ellas estuvieron dispuestas a enfrentar sus más grandes temores, a retomar la lectura, a memorizar jurisprudencias, ese factor protector es la base que las impulsa a querer mejorar cada vez más las condiciones de sus familias y de participar con apuntes importantes dentro de los contextos institucionales.

¿Cómo cree que ha sido ese proceso de empoderamiento de las mujeres cuidadoras en un contexto de pobreza, desigualdad social y violencia?

ha partido de la misma necesidad de ellas como te decía, por la necesidad, cuando las personas están en crisis o viven una necesidad están obligadas a buscar otras alternativas de solución, esas crisis, esas situaciones de sus propios hijos y de sus realidades han hecho que ellas cambien esas situaciones aprovechando todo los espacios de participación e inclusión que tiene cada persona en condición de discapacidad y obviamente respaldadas en todo el marco jurídico que tienes las políticas de discapacidad y las políticas en general del plan de gobierno de este momento y de los anteriores gobiernos porque siempre le han sado prelación a las personas en condición de discapacidad.

\section{¿Las mujeres cuidadoras logran multiplicar sus saberes con otras mujeres para permitirles a} ellas y a sus hijos el acceso a programas y servicios?

Definitivamente es algo que las caracteriza, y muchas de ellas han empezado a ejercer un liderazgo por el compromiso y la solidaridad que hay entre ellas, sus ejemplos y experiencias de vida siempre les sirve para apoyar a otras familias y también pues para que ejerzan sus derechos, comparten información frente a rutas de atención por ejemplo, proyectos activos, subsidios vigentes; mejor dicho ellas están en todo y así mismo lo socializan. Son muy buenas multiplicadoras de sus saberes.

Aunque también se ven mujeres que no están interesadas en compartir la información o solo lo hacen con las personas más allegadas. 
¿Las mujeres cuidadoras se ven más expuestas a la exclusión (Social e Institucionalmente) por ejercer el cuidado?:Qué lo lleva a pensar eso?

Pienso que sí, porque están expuestas a muchos factores de vulnerabilidad, no solo son menospreciadas por ser mujeres y tener niños en condición de discapacidad- tu sabes que aun la gente estigmatiza la condición de salud de los niños y culpan a las mujeres por meterse por así decirlo con hombres casados por ejemplo, o sea es una justificación o un producto por sus actos "inmorales"sino que deben enfrentarse a unos contextos familiares muy abruptos en donde no tienen apoyo ni siquiera de los hijos y económicamente viven en las peores esferas de la sociedad y ahí es donde más se evidencia la exclusión, no hay trabajo para ellas por las condiciones de horarios y ubicación de las empresas y tampoco se evidencia alguna intención del sector público o privado por apoyar a estas personas.

¿Las mujeres aprovechan su rol como cuidadoras de NNA en condición de discapacidad para exigir sus derechos como mujeres o es solamente una exigencia para sus hijos?

Yo creo que no, si uno se da cuenta ellas están todo el tiempo en función de sus hijos, creo sí que ya se hacen escuchar porque reconocen que ellas mismas tienen derechos y que por lo mismo deben ser escuchadas y respetadas. O sea es como algo intrínseco pero no muy palpable a la luz de los derechos de las mujeres

¿Son las mujeres cuidadoras de Bosa un grupo reconocido por la comunidad y las instituciones? La verdad para las instituciones que trabajamos con esta comunidad de discapacidad si, pero si uno le pregunta a programa de vejez por ejemplo no tienen idea que existen, digamos que son reconocidas dentro de su mismo contexto pero les falta mostrarse a la comunidad y dar a conocer todos sus procesos.

\section{¿Cuáles son las debilidades de las mujeres cuidadoras?}

Desde mi institución pienso que es la falta de unión entre ellas, las discordias son evidentes y a veces se convierten en disputas internas que fragmentan ese proceso político que realizan

\section{PROSPECTIVA}


¿Cómo mejorar las condiciones de vida de las mujeres cuidadoras y sus familias sin tener que acudir a los múltiples programas de asistencia Social?

Creando una política económica y laboral que les permita mejorar estructuralmente sus condiciones de vida, la única forma para que salgan de la vulnerabilidad es que haya todo un proceso de articulación gubernamental, empezando por la creación de la política publica de cuidadores y mujeres cuidadoras, que se hagan alianzas con las empresas privadas, que se fomente las microempresas y que haya también oportunidad de acceso a la educación para ellas. Pienso además que debe haber un enfoque diferencial frente a las mujeres cuidadoras de la zona urbana como de la rural ya que las condiciones son completamente diferentes.

\section{¿Ha pensado como profesional cómo las mujeres cuidadoras lograrán sobrellevar la vejez, el cuidado de sus hijos e hijas y posibles quebrantos de salud?}

Bueno la verdad no lo había pensado, porque yo misma me pregunto si yo seré pensionada o no. Entonces en este momento yo sí creo que en este momento las mujeres por el mismo empoderamiento que se está dando, las mismas políticas y las misma norma y la misma ley; ellas a través de los consejos han planteado que hagan una acción de cumplimiento y hay abogados interesados en acompañar en todo el proceso de una acción de cumplimiento donde las colectividades con discapacidad y sus familiares ejerzan un presión y presenten propuestas ante los planes de desarrollo o espacios de participación política para presentan proyectos que les dejen como una pensión por ser cuidadores y están en ese proceso y eso ya está como en camino, lo que pasa es que hace falta como mayor incidencia y participación por parte de la comunidad que tiene personas en condición de discapacidad.

\section{¿Hasta dónde, el hecho que las mujeres cuidadoras sigan realizando la labor del cuidado, refleja que el Estado se ha quedado corto en la cobertura de la Protección Social?}

Yo lo veo como trabajadora social, lo veo como un problema social que ha venido a través del tiempo y que no ha sido contemplado por el Estado porque si uno se fija cada vez más, nacen personas en condición de discapacidad o durante el desarrollo salen a la luz. No obstante, es importante reconocer que antes las personas en condición de discapacidad eran guardadas, escondidas, apartadas, excluidas, segregadas. En este momento las políticas son un poco más imponentes, porque la misma comunidad se ha hecho visible, los gobiernos han visto la necesidad de incluirlas dentro de sus políticas como personas que tienen unos derechos y que hay que reconocerles esos derechos. Entonces pienso que es 
un proceso y tanto la comunidad se está despertando como el mismo Estado a través de sus instituciones ejecutando programas, proyectos y planes de acción que benefician estas comunidades que van en proceso ambas, van paralelo.

\section{¿A través de qué acciones institucionales se podría mejorar u apoyar a las mujeres cuidadoras de Bosa desde un enfoque de equidad?}

Seguir acompañando ese proceso de empoderamiento para que sus necesidades sean escuchadas a nivel distrital y Nacional, considero que es fundamental incluirlas dentro de nuestras acciones y por supuesto mirar sus necesidades y sus propuestas. Hay muchos grupos de mujeres cuidadoras que tienen ideas muy importantes y que necesitan es un respaldo económico primero, jurídico para que sean tenidas en cuenta y una voluntad política también para que se empiece a gestionar la Política Publica para ellas.

\section{¿En qué institución ve usted más barreras para lograr un trabajo articulado en la localidad?}

Definitivamente en el sistema de Salud, porque nosotros e igual que e ICBF nos estamos esforzando por dar cumplimiento a la política pública, se está siempre mirando opciones de mejorar coberturas o de implementar otros programas que permitan la atención integral de los niños con discapacidad y sus cuidadoras sin embargo, el esfuerzo llega hasta el momento en que salud no da cumplimiento a lo que debe por obligación hacer y es por eso que nuestra labor se ve como un paliativo porque no hay una verdadera articulación y funcionalidad institucional. El dialogo con el ministerio de Salud se ha realizado infinidad de veces pero no vemos avances al contrario, vemos como decaen cada vez más nuestros chiquitines.

\subsection{Entrevista 3}


Funcionario 3, Secretaria Distrital de Educación

Mi nombre es Funcionario 3, soy trabajadora social y llevo seis años en la Dirección Local de Educación de la Localidad de Bosa en donde he trabajado en el área de inclusión social para Discapacidad, Etnias y población Víctima del Conflicto Armado Interno.

\section{ACCIÓN INSTITUCIONAL}

\section{¿Cuáles son y en qué consisten los programas que promueve su entidad?}

Claro que si, Anggie nosotros desde la Secretaria Distrital de Educación tenemos varios programas enfocados de alguna manera a atender a varias poblaciones al mismo tiempo, el primero de ellos es Atención a Escolares con Discapacidad o Talentos el cual consiste, en La inclusión escolar de niñas, niños y jóvenes con discapacidad en las aulas en donde se encuentran los demás estudiantes o algunos colegios por la cantidad de NNA en esta condición cuentan con aulas especializadas. Se busca que a través del programa se brinde un acompañamiento más personalizado y acorde a la necesidad de estos niños. Para ello se ha contratado algunos educadores especiales o se ha intentado sensibilizar a los docentes titulares. En este momento, Bosa cuenta con 469 NNA en aulas de inclusión. Mira, se trabaja con NNA que tengan Discapacidad cognitiva, síndrome de Down y autismo, Ceguera y baja visión diagnosticada, Sordera e Hipoacusia diagnosticada, Sordo Ceguera, Lesión neuromuscular, Multidéficit y Talentos y capacidades excepcionales.es frente a la discapacidad y tenemos, mejor te los nombro porque son varios programas, está la Atención a la población víctima del conflicto armado, Educación intercultural y atención a grupos étnicos, Sexualidad y Género, Diversidad Sexual (LGBTI+H), Desincentivación del trabajo infantil, Programa Volver a la Escuela, Aulas hospitalarias y Respuesta Integral de Orientación Escolar. Este último casi no lo conozco porque es manejado solo por los orientadores escolares

\section{Actualmente ¿cuántas personas participan en los programas?, ¿Qué profesionales atienden dicha población?}

Considero, aunque no lo tengo muy presente, que se atienden alrededor de 110.000 NNA y adultos. Pues, las profesiones que están dentro de los programas son Licenciados en todas las áreas del conocimiento, Psicólogos, Trabajadores Sociales, Administrativos y educadores especiales aquí, incluimos personas que manejan el tema del braille y el lenguaje de señas. 
¿Considera que los profesionales que brindan atención en dichos programas, cuentan con las habilidades y conocimientos para atender las necesidades de la población?

No podemos generalizar, pero podemos decir que un porcentaje significativo si cuenta con herramientas y esas habilidades que permiten dar como cumplimiento de los programas en cada uno de ellos según la modalidad en que estén sin embargo no hay que desconocer que hay profesionales que bien sea por experiencia o algo personal no cumplen con los objetivos como se quisiera pero son muy pocos.

\section{¿Qué aspectos considera usted, que los profesionales deben fortalecer?}

Yo pienso que el trabajo sería más en la parte de contratación de personal porque es ahí donde se hierra un poco al no identificar y no ser tan claro en el momento de la contratación cual es el perfil que se requiere porque las pruebas y las entrevistas que nos hacen no determinan si se cuentan con esas habilidades sociales que por más de que sea un psicólogo o trabajador social no las desarrolla en el mismo nivel que otras personas pienso que lo que se debería fortalecer es esa área en la contratación y selección de personal y no pequemos en contratar personas que no estén a gusto en la institución.

¿Cómo es el proceso de inclusión de las personas a los programas? - cuáles son los criterios de selección y focalización

No manejamos exactamente criterios de ingreso, aunque para cada modalidad existen los requisitos como diagnostico medico actualizado, carta de desplazados, historia clínica o de hospitalización, en los demás es solamente realizar la solicitud en cualquier punto de las direcciones locales de educación y ya. El tema del riesgo moral como tú me lo explicas, tampoco se ve ya que como derecho la educación es universal, para todo aquel que quiera hacer uso de ella.

\section{¿Considera que la atención a los NNA en condición de discapacidad debe ser centralizada en una sola entidad?}

Yo pienso que todas las instituciones deben intervenir en el tema hablando específicamente de los niños en condición de discapacidad, sin embargo, lo que se está fallando es que no hay articulaciones entre las instituciones entonces si bien es cierto secretaria de integración tiene un proyecto que cubre necesidades, bienestar familiar garantiza derechos, salud provve atención y tratamiento y educación brinda herramientas de aprendizaje para la vida y estimula la inclusión social, no hay un cruce, no hay un trabajo conjunto que nos permita decir si tú ya estas abarcando eso permitamos a otra familia tener las mismas oportunidades, por el contrario vemos que muchas personas que están siendo atendidas por todas las entidades y de alguna manera desconocemos la integralidad en la intervención 
tanto con los niños como con sus familias, entonces pienso que cada uno debería abarcarlo claro que sí, pero articulados con eso podemos darle como una cobertura a más población que se requiere y establecer con claridad los tiempos o el objetivo con claridad del programa.

¿Finalmente en qué institución local considera usted que debe estar la responsabilidad de diseñar, ejecutar y regular los programas de atención integral a los NNA en condición de discapacidad?

No, pienso que debe haber una directriz que puede ser no sé, en este momento se me ocurre la secretaria de salud la que lidere y establezca con claridad los programas, los objetivos, los tiempos y nosotros como darle cumplimiento a eso porque si bien es cierto nosotros le damos acompañamiento a los niños y sus familias, la responsabilidad directa es de salud de cubrir todas las necesidades especiales que tienen estos chiquitos, ellos son los que deberían liderar y darnos como el lineamiento y darnos la línea técnica a nosotros para que nosotros podamos con base en eso podamos establecer nuestros programas.

¿Deben ser finalmente los municipios los encargados de ello o deben ser las instituciones de carácter nacional?

Desconozco, pero pienso que si hace falta de pronto si está estipulado en este momento, más acompañamiento para que los recursos y las directrices que se dan a nivel municipal se cumplan como está estipulado en la ley, hay muchos municipios que si bien esta estipulados en el plan de desarrollo local y demás no se da el cumplimiento pero porque no está el acompañamiento, si estuviera el acompañamiento allí adicional a eso que las necesidades son diferentes de un chico con discapacidad acá en la ciudad a otro chico que está en el área rular por distancias, por terreno pienso que sí que sería más como en el acompañamiento que se debe hacer para que se cumpla lo establecido.

¿En qué medida cambian los programas de su entidad destinados a la atención de NNA en condición de discapacidad y sus cuidadores en las nuevas administraciones?

Debería ser transversal en todos los Gobiernos, pero lamentablemente lo que hemos visto en el ejercicio y lo que el ejercicio nos permite ver es que no se está garantizando la atención de estos niños, porque son niños con derechos vulnerados pero estos programas indirectamente se modifican dependiendo de la persona que este liderando el proceso , a nivel ya hablamos de gobernantes algunos le dan más prioridad que otros y digamos que aunque está el recurso disponible pienso que si depende a veces de los gobernantes. 


\section{¿Los programas ofertados responden a un enfoque de derechos?}

Bueno yo hablo por la DILE, en donde se ha procurado trabajar con base al enfoque de derechos y la necesidad que tenga cada niño, a partir de no solo de su género si no de su condición de discapacidad también, se buscaba atender a las familias con integridad es decir, articularnos lo más rápido posible con otras entidades para el acceso de éstas a los diferentes programas y al mismo tiempo, haciendo un acompañamiento permanente desde el contexto inmediato que son los hogares. De igual manera, desde aquí buscamos sensibilizar a los rectores y demás profesionales para que comprendan la discapacidad y adapten sus planes curriculares a las necesidades propias de los estudiantes.

\section{¿Cómo ve la relación entre familia y Estado frente a la situación actual de los niños en condición de discapacidad y sus cuidadoras?}

Yo pienso que es ahí donde el Estado ha fallado un poco, porque ha generado dependencia de las familias hacia el Estado hablando de que ellos consideran o piensan que el apoyo que le tienen que dar el Estado es obligatorio y si bien es cierto la condición de salud de los niños, no debe ser vitalicio y ellos de alguna manera exigen que sean vitalicio por eso tantos problemas cuando se presenta más que todo cierres en los programas de las demás entidades en las que participan y de ahí la importancia de que el Estado más bien diseñe estrategias empresariales y productivas para que estas familias logren salir por sus propios medios adelante y que lo que te digo si bien es cierto es la responsabilidad del Estado pues, la familia es la que debe liderar ese proceso y hacerse responsable y de buscar otras alternativas.

\section{GÉNERO}

\section{¿Se han incluido a las mujeres cuidadoras dentro de los programas ofertados?}

Pienso que hemos mejorado porque antes la atención estaba como más suelta, si hablamos de unos tres años tal vez para acá se le ha dado prioridad a la atención de poblaciones especiales incluyendo con más claridad estableciendo toda la normatividad, ahora no se requiere que se le haga seguimiento a la inscripción de los niños si no que se le haga el acompañamiento tanto a ellos como a las familias, antes podíamos ver que existía una matrícula formalizada ante la Secretaria de Educación pero, el niño quedaba ahí volando sin seguimiento y obviando que la mayoría de niños que están vinculados vienen de tipologías monoparentales donde la mamá es la que lidera todo el proceso de este chiquito 
a nivel familiar, de salud y demás, entonces la mujer de alguna manera cuando hablamos de inclusión estamos también pensando y articulándonos para que haya una vinculación con el SENA para que estudie, para que se capacite para que ingresen a laborar y para que establezcan todos la orientación productiva.

\section{¿Cuál considera usted que es la situación actual de las mujeres que se dedican al cuidado de los NNA en condición de discapacidad?}

En Bosa podríamos decir que un noventa por ciento las mujeres son madres cabezas de hogar, son muy pocas los que continúan en pareja o hay inclusive una familia que vivía en pareja pero por la condición del niño mas no como pareja vivían como padres mas no como pareja, son mujeres igual que no pueden laborar de tiempo completo que tiene que rebuscárselas, son mujeres emprendedoras digamos en un porcentaje como el mismo pero también hay mamitas que la discapacidad de su hijo hacen que ellas generen dependencia no de los niños hacia ellas sino de ellas hacia los niños, porque son mamás que no se movilizan que son mamás que no los quieren dejar solos ni cinco minutos pero, el gran porcentaje de mamás son mamás que tienen que salir a rebuscar y que si tienen que salir con sus hijos pues se salen pero nosotros también identificamos mamás que tienen ideas productivas muy interesantes y buscamos también como la articulación tanto entre ellas como con las demás instituciones igualmente, ellas tienen claro que si ellas no llevan el recurso a su casa no van a tener con qué garantizar esas necesidades, entonces la red familiar es escasa y definitivamente emprendedoras y luchadoras.

\section{¿Considera que el ejercicio del cuidado está siendo asumido progresivamente por los hombres o considera que las brechas de género se siguen presentando en la localidad?}

Nosotros hemos tenido máximo la participación de 6 hombres sin embargo mira, ellos son los que lideran y representan a los niños, son quienes reciben las visitas, movilizaban las citas asistían a talleres y participaban común y corriente, socializan con el nivel de compromiso hacia sus hijos como si fuera el de la mamá, pienso que si es muy poco y pienso también que depende de la formación que tuvieron ellos porque cuando hacíamos el análisis con los otros casos, son hombres que han vivido en familias constituidas por papá y mamá o a veces con abandono de ese rol paterno por lo cual, sienten la obligación de estar ahí con sus hijos y son ellos los que lideran todo el proceso. 
¿Cuáles son las razones por las que las mujeres acuden a los programas de asistencia social?

No, son mujeres que les gusta salir a trabajar y que si bien es cierto inclusive buscan el espacio en la localidad para movilizarse, son mujeres que no pidieron vivir esa situación y por eso te digo que son mujeres emprendedoras obviamente hay una que otra que son mujeres que se echan como a la pena por la situación y que están en ese proceso de duelo de poder entender y aceptar la situación que está viviendo pero a esas familias son las que mayor atención se les presta para mejorar las condiciones psicológicas de las mismas.

\section{ROL SOCIAL Y POLITICO}

\section{¿Evidencia que las mujeres cuidadoras de la Localidad de Bosa han desarrollado habilidades para participar en escenarios de discusión política y social?, ¿Qué habilidades identifica usted?.}

Tenemos dos líderes muy destacadas en la DILE, inclusive ellas son quienes nos sugieren los temas para desarrollar los talleres, informan irregularidades que evidencian dentro de los procesos de atención, movilizan con otras instituciones y tratan de involucrar a otras mujeres y sus hijos, ellas son las que se movilizan y de empoderan del proyecto, reconocen todo el abordaje que estamos realizando y siempre están dispuestas a dar mini capacitación a sus compañeras que están arrancando o que no están tan pilas como las otras para que gestionen varios beneficios.

\section{¿Las mujeres desempeñan un ejercicio político en la localidad o solamente se debe a un instinto de supervivencia por ser su referente protector?}

Yo pienso que ellas terminan teniendo un rol político inclusive, una de ellas se había postulado y estaba pidiendo votos para estar en el consejo distrital de discapacidad y en ese momento pidió a sus compañeras que la acompañaran y ella decía si estamos allá vamos a conseguir muchas cosas para nuestros hijos y que si yo voy a estar allá yo las voy a representar, es un ejercicio más político aunque, al principio es de supervivencia pero cuando ellas comienzan a identificar y a conocer que es lo que dan las instituciones ellas quieren proponer bueno si tenemos esto pero también podemos tener esto por esto y esto y argumentan totalmente las necesidades de su familia y la obligación que tiene el Estado, ellas son más pilas que uno terminan conociendo la ley más que uno y todas las funciones los programas frente a las familias con discapacidad. 
¿Cómo cree que ha sido ese proceso de empoderamiento de las mujeres cuidadoras en un contexto de pobreza, desigualdad social y violencia?

Mira, sí hablábamos de una dependencia, porque obviamente se genera una dependencia y más en estas familias por sus necesidades, las mismas instituciones nosotros pienso que nos dimos cuenta de que tener esas familias de manera vitalicias no es sano para nosotros porque no estábamos dando cobertura a la demás población que estaba allí, ósea una familia que lleve diez años en la misma situación porque obviamente la condición de discapacidad no le permite a estos chiquitines avanzar académicamente, es un desgaste para la isntitucion e incusive para el propio niño porque es forzarlo a vivir en un ambiente en el cual no se puede desenvolver y por eso pienso que en este momento le apuntamos es a que las familias se empoderen y que ellas se articulen con las instituciones, por eso nosotros invitamos a Secretaria de la Mujer cuando evidenciamos casos de violencia intrafamiliar ósea nosotros somos los principales interesados en que ellas conozcan el tema, conozcan la política, conozcan las instituciones que brindan apoyo porque si bien es cierto lo que decíamos ahora las situaciones iniciales de supervivencia cuando ellos se van empoderando se van soltando inclusive ya sin necesidad de pedirles a las instituciones porque ya generan una independencia cuando constituye por ejemplo una unidad productiva.

\section{¿Las mujeres cuidadoras logran multiplicar sus saberes con otras mujeres para permitirles a ellas y a sus hijos el acceso a programas y servicios?}

Yo pienso que sí, inclusive el respaldo es de la comunidad porque hay muchas familias que llegan a la oficina y cuando nosotros hacíamos la entrevista inicial le preguntamos como supiste del programa y dicen no es que mi vecina vino acá y mi vecina se enteró que había un programa para niños especiales o para niños con condición de discapacidad, entonces ella fue y me contó.

¿Las mujeres aprovechan su rol como cuidadoras de NNA en condición de discapacidad para exigir sus derechos como mujeres o es solamente una exigencia para sus hijos?

$\mathrm{Si}$, logran las dos cosas ellas se empoderan de tal manera que hoy en día se vuelven muy astutas a través del acompañamiento o la exigencia que hacen sobre los derechos de sus hijos y también, lo hacen para ellas entonces, ellas hacen valer sus derechos de esa forma que participan entonces no solo exigen para sus hijos sino también para ellas.

\section{¿Cuáles son sus debilidades?}


Son mujeres que a pesar que han tenido el acompañamiento de psicología por EPS, por salud y por las diferentes entidades donde participan los niños, son muy temerosas a perder a sus hijos, inseguras frente a eso, ósea uno les trabaja todo el tiempo el diagnostico pero cuando los chiquitos presentan recaídas ellas recaen con ellos inmediatamente, son mujeres que generan dependencia en sus hijos yo les digo tu hijito no te necesita aquí al lado veinticuatro horas al día pero como te decía hay mujeres que no salen de sus casas por estar cuidándolos, entonces la dependencia no es del niño hacia ellas si no de ellas hacia el niño y por eso ese mismo miedo porque son mujeres que se dedican cien por ciento a sus hijos y notamos entonces que hay es donde comienzan a presentarse las dificultades a nivel familiar porque se dedican cien por ciento a ser mamas y dejan a sus parejas de lado y también lo que evidenciamos es que como hay esa independencia a su hijitos con diagnostico cuando hay otros hijos se presentan problemas de comportamiento de chicos que terminan con consumo con unas dificultades muy complejas por esa no atención en su momento adecuado entonces hay que reforzar en eso.

\section{PROSPECTIVA}

\section{¿Cómo mejorar las condiciones de vida de estas mujeres?}

Yo pienso que deberíamos hablar más de inclusión, se habla de inclusión en muchos aspectos y en muchas líneas, pero no del adulto mayor poco vas a encontrar digamos que es una población que tenemos desprotegida donde hablamos es de hogares geriátricos y demás, ahora de un apoyo económico también, pero no hemos visto ni identifico ese tipo de población que son adultos mayores con niños con discapacidad porque siempre van a ser niños aunque sean mayores entonces tendríamos que entrar a establecer nosotros estábamos hablando la vez pasada en un programa de formación que hizo secretaria iba una persona que lidera todos los programas de adulto mayor a nivel distrital y nos decían eso la falencia de programas que hay para la población adulta mayor y más cuando se habla que tienen niños en condición de discapacidad hay falencia y hay que comenzar a construir a estipular los programas que abarquen esta población porque ya no hablaríamos de una institución solo para el señor adulto y su hijo en otro si no que podríamos entrar hablar de una institución que abarque este tipo de poblaciones especial porque de verdad se carece.

\section{¿Ha pensado como profesional cómo las mujeres cuidadoras lograrán sobrellevar la vejez, el cuidado de sus hijos e hijas y posibles quebrantos de salud?}


$\mathrm{Si}$, si lo había pensado y es de gran preocupación porque son muchos los casos como tú lo dices que hay donde las cuidadoras son mayores de sesenta años e inclusive con unos adultos de veinticinco años que requiere el acompañamiento para bañar, para comer para cambio de pañal, para todo entonces se genera esa preocupación porque uno dice que va hacer el día de mañana o que falte la señora quien va a cuidarlo a él o esta señora en su codician o en su estado actual de salud que cada vez más se deteriora no va poder cumplir y le va a pasar algo a este chico.

\section{¿Hasta dónde, el hecho que las mujeres cuidadoras sigan realizando la labor del cuidado, refleja que el Estado se ha quedado corto en la cobertura de la Protección Social?}

El Estado se ha quedado corto con muchos programas especialmente con este, si hablamos de una ciudad de inclusión desde antes ósea es un tema que no es nuevo para nosotros y tristemente lo dice uno como trabajadora social que no se ha apuntado el beneficio integral de esas familias entonces pienso que le falta al Estado por eso las mujeres han tenido que apoderarse de esta manera y hacer garantizar los derechos no solo de ellas sino también de sus hijos.

\section{¿En qué institución ve usted más barreras para lograr un trabajo articulado en la localidad?}

Salud lamentablemente, no es digamos algo que podemos tapar, salud no garantiza a una familia a una persona sana sus derechos en cuanto le asigne una cita que lo atienda en una urgencia, las familias que tiene un niño en condición discapacidad es una lucha diaria no es con la sociedad es con salud es con el Estado en cuanto al servicio que se debe prestar, no es justo que el niño que sufra epilepsia tenga que ser hospitalizado porque no le entregan el medicamento y allí si se lo puede colocar entonces pienso que si se hace una restructuración a este sistema de salud, las familias no van a tener la dificultad y seguramente el acompañamiento que van hacer las instituciones del sistema nacional es un acompañamiento y no es suplir obligaciones que tiene que suplir esta entidad.

\subsection{Entrevista 4}

Funcionario 4, Hospital Pablo VI 
Bueno, mi nombre es Funcionario 4, soy fonoaudiología con énfasis en Rehabilitación Basada en Comunidad- RBC- Especialista en gerencia social; he trabajado toda la parte de discapacidad, tanto en fundaciones, en el hospital de Fontibón en toda la parte de salud pública en los territorios y ahorita con Hospital Pablo VI de Bosa hace tres años en Salud Publica también desde el enfoque de Ámbito Familiar.

\section{ACCIÓN INSTITUCIONAL}

\section{¿Cuáles son y en qué consisten los programas que promueve su entidad?}

Bueno, el programa que nosotros manejamos desde el Hospital Pablo VI tiene que ver con Ámbito familiar el cual pues, tiene como objetivo realizar un acompañamiento familiar con enfoque biopsicosocial a las comunidades que presentan condiciones vulnerables y diferenciales. Desde aquí, lo que nosotros hacemos en un primer momento es realizar una valoración integral a la familia que permita definir las necesidades de la familia y de cada uno de los integrantes de ella.

De igual forma, desde el hospital diseñamos y ejecutamos acciones de promoción de la salud y prevención de la enfermedad a través de jornadas didácticas masivas y de talleres en donde damos a conocer los diferentes temas. Qué más?, a bueno, cuando identificamos personas o familias sin afiliación o con problemas de atención en salud articulamos con el área de aseguramiento para que se brinden las respuestas requeridas. Participamos también, en escenarios interinstitucionales en donde buscamos que haya acceso a los diferentes servicios de manera priorizada y damos a conocer pues, todas nuestras acciones.

Y pues también, generamos espacios de participación con las diferentes comunidades en donde buscamos específicamente el empoderamiento como sujetos activos en la toma de decisiones en salud.

\section{Actualmente ¿cuántas personas participan en los programas?, ¿Qué profesionales atienden dicha población?}

Actualmente, estamos atendiendo alrededor de 9.000 mil hogares desde los diferentes enfoques del programa de ámbito familiar. Los profesionales que atendemos la población son de carácter interdisciplinario, entonces tenemos Psicólogos, Trabajadores Sociales, enfermeros, algunos médicos, fonoaudiólogos y terapeutas ocupacionales, ah! Y tenemos el acompañamiento semestral de diferentes practicantes que vienen de varias universidades. 


\section{¿Considera que los profesionales que brindan atención en dichos programas, cuentan con las habilidades y conocimientos para atender las necesidades de la población?}

Pues todas las personas como profesionales, como con los valores que tenemos la capacidad de atender a todo tipo de población ya sea con discapacidad u otra, pero si hace falta preparar a la gente, que conozca la discapacidad y como se debe llegar a ellos. Importante es que somos seres humanos, la población tanto como los cuidadores como los chicos son seres humanos y no ese papel de victimizarlos porque muchas veces se nos ven como hay pobrecitos y uno se aprovecha de eso; pero si falta mucho conocimiento de la gente, sobre todo aquí en el hospital hace falta muchísimo conocer que es la discapacidad porque la gente no maneja el tema como tal.

\section{¿Qué aspectos considera usted, que los profesionales deben fortalecer?}

El conocimiento en la Política de Discapacidad y como tal en todas las discapacidades existentes porque así las intervenciones serían más adecuadas a las realidades de los chicos y sus familias.

¿Cómo es el proceso de inclusión de las personas a los programas? - cuáles son los criterios de selección y focalización.

Bueno, los criterios de selección para el tema de ámbito familiar o mejor, las prioridades que manejamos para el trabajo con las comunidades se basan en alta o media, teniendo en cuenta que la Salud no es solo para unos, intentamos manejar toda la comunidad, aunque tú sabes que es complejo pero lo intentamos. En Bosa particularmente se podría decir que toda la población es de prioridad alta por lo cual, intentamos dar respuesta.

Mira, cuando es prioridad alta hablamos de madres gestantes, menores De 19 Y Mayores De 40 Años Con Antecedente De Enfermedad Crónica O Transmisible, mujeres que no han Iniciado Controles Prenatales, los recién nacidos, Niño Niña A Quien No Se Le Ha Iniciado Controles De Crecimiento Y Desarrollo, condición/Situación De Discapacidad, antecedente De Bajo Peso Al Nacer, Prematurez, Malnutrición, Afección Congénita, víctimas Del Conflicto / Eventos En Salud Mental, Habitante De Calle, LGTBI , Riesgo Ambiental y Carreteros- Recicladores.

Y, lo que denominamos como prioridad media se enfoca en eventos de muerte súbita, personas mayores de 60 años priorizadas, personas pertenecientes a grupos étnicos y personas en ejercicio de prostitución. 
¿Qué estrategias implementa la institución para disminuir el ingreso de personas que no requieren la atención (Riesgo Moral)?

Frente a la pregunta, es importante decir que como ya lo había manifestado, nosotros no tenemos de alguna manera selección para el ingreso de las familias como de pronto si lo tiene integración social, partimos que la salud es un derecho y como tal es universal. No obstante, como el trabajo es articulado y de terreno es muy fácil para nosotros identificar personas que no requieren del acompañamiento por sus condiciones socioeconómicas.

¿Finalmente en qué institución local considera usted que debe estar la responsabilidad de diseñar, ejecutar y regular los programas de atención integral a los NNA en condición de discapacidad?

Una institución como tal no, que las instituciones que hayan porque o sino no estaríamos hablando de una inclusión sino estaríamos excluyendo en una parte donde estarían ellos solos, no. Debe haber una verdadera inclusión donde las personas tanto los docentes como toda la parte educativa, se prepare para trabajar con estos chicos, porque no están preparados, ni siquiera de pronto en la parte a nivel escolar, la secretaria de educación no tienen los docentes preparados para trabajar con los chicos en condición de discapacidad, no están preparados, ellos están haciendo una inclusión, una integración mas no un inclusión.

\section{¿Deben ser finalmente los municipios los encargados de ello o deben ser las instituciones de carácter nacional?}

Pues como opera el distrito digamos que está bien, pero hace falta fortalecer y trabajar a vincular, hacer un trabajo interdisciplinario con todas las instituciones ya que por el transcurrir del tiempo que llevamos nos hemos dado cuenta que las instituciones si trabajan por los derechos y deberes de las personas en condición de discapacidad pero casa una va por su lado. Sabemos que están queriendo cumplir eso pero si hace falta mucha más articulación para poder lograr una atención adecuada a esos niños.

¿En qué medida cambian los programas de su entidad destinados a la atención de NNA en condición de discapacidad y sus cuidadores en las nuevas administraciones?

El proceso de cambio es muy grande, por lo menos ahorita en el cambio de alcalde, de venir con Petro, ahorita Peñaloza, o sea no le apuntó a nada de la discapacidad, entonces retrocedimos muchísimo porque ya todo lo que se había ganado en cuanto a programas y todo eso, pues ya los acabaron. Entonces si se retrocede muchísimo, además porque al cambiar los profesionales, cada 
alcalde, cada director llega con su grupo de trabajo y se hacen otros procesos, porque todos dicen mejor cambiémoslo así y se retrocede completamente

\section{¿Los programas ofertados responden a un enfoque de derechos?}

Si pero le hace falta, le hace falta mucho porque estamos con los derechos y todos pero todavía le hace falta mucho porque lo que te digo, se piensa mucho en cuanto a los derechos que las personas en condición de discapacidad tienen la posibilidad de tomar decisiones, pero hay algunas personas que no tienen la capacidad de tomar decisiones entonces falta como fortalecer esa parte porque si se ve un vació entre esas dos tipos de población.

\section{¿Cómo ve la relación entre familia y Estado frente a la situación actual de los niños en condición de discapacidad y sus cuidadoras? (Complementariedad o Sustitución)}

Bueno el Estado si ha suplido, si ha ayudado y ayuda a las familias en condición de discapacidad, el problema es que las familias creen y lo que siempre yo he dicho, yo tengo una hija en condición de discapacidad pero el Estado no es el culpable de que mi hija haya nacido con condición de discapacidad, el Estado no tiene que suplir todo. El Estado me ayuda pero yo tengo que tener una corresponsabilidad de que se dé una adecuada atención pero no es lo que te digo, yo soy la victima la

pobrecita, dame y el Estado me acostumbro, nos acostumbró hacer unas familias asistencialistas y que pobrecito este y no los estamos formando a que ellas pueden solas. Como dicen es necesario ayudar a pescar y no dar el pescado.

\section{GÉNERO}

\section{¿Se han incluido a las mujeres cuidadoras dentro de los programas ofertados?}

Si y no, porque digamos que en Salud Publica en este momento se ve más enfocado hacia la rehabilitación de los niños, es decir todo el tema de salud y RBC pero no para los cuidadores aunque capacitamos a los cuidadores en temas de liderazgo, empoderamiento y otros. pero nos hace falta pensar, porque desafortunadamente también desde la política pública de discapacidad no se tienen en cuenta los cuidadores, que estamos mal interpretando la política pero no se tiene en cuenta los cuidadores, porque la política esta para las personas en condición de discapacidad no para el cuidador como tal. 
¿Cuál considera usted que es la situación actual de las mujeres que se dedican al cuidado de los NNA en condición de discapacidad?

Una mujer cuidadora pues en general, es una mujer que tiene primero que todo su auto estima se bajó, porque si la pareja la abandonó o le echo la culpa porque tú sabes que la discapacidad se consideraba como un castigo divino o quien sabe su familia que enfermedad tenia y me tocó a mí, entonces tienen su auto estima baja y su proyecto de vida se les acabo completamente, se olvidaron que eran mujeres y empiezan a vivir es por el chico. Muchas veces se olvidan hasta de sus demás hijos y empiezan a que vengan el hijo mayor o menor que no tiene discapacidad que me tiene que ayudar al cuidado y se quedan un poco en su núcleo familiar. Primero se olvidan de ellas y al estar pendiente de él, mi obligación como hacer la comida, estar pendiente de las cosas de la casa, de lo del chico lo dejan a un lado; entonces empieza a ver como ese deterioro a nivel familiar porque no hay una integración del núcleo o a nivel familiar.

Es muy difícil si no cuenta con una red de apoyo en el cual ellos puedan dejar al chico en condición de discapacidad al cuidado de alguien es difícil que ellas puedan trabajar. Primero que todo porque cumplir un horario es un poco complejo. Llegar a las 8 de la mañana llegar a las 5 de la tarde bueno eso altera el cuidado del niño. Pero además a todas las personas les toca pedir permiso y no todas las personas dan el permiso porque mi hijo se enfermó, además uno no sabe en qué momento puede convulsionar o enfermarse es difícil cumplir un horario o si trabajan por días y no tienen con quien dejar el niño no lo pueden llevar allá porque mi hija es muy hiperactiva entonces le destruye la casa a la señora entonces no puedo. Para ellas es muy difícil conseguir un trabajo y por lo general trabajan con venta de revista o vendiendo la empanada, haciendo tamales y vendiendo. Es muy complejo como tal.

\section{¿Considera que el ejercicio del cuidado está siendo asumido progresivamente por los hombres o considera que las brechas de género se siguen presentando en la localidad?}

Pues en la mayoría si nos ponemos hacer el porcentaje en la mayoría son mujeres, pero ya estamos viendo un porcentaje de hombre en los cuales las mujeres han abandonado a sus hijos y se los han dejado a sus hombres. Yo creo que un 10\% son cuidadores hombres que han tomado como este riesgo, estas riendas para hacerlo. Aunque cuentan con el apoyo de su mama, de la abuelita del niño y pues eso les ayuda un poco.

¿Cuáles son las razones por las que las mujeres acuden a los programas de asistencia social? 
Pues se ve de las dos, se ve todo un poquito, pues hay un 80 o $90 \%$ de las personas que en verdad si necesitan el apoyo del estado. El otro porcentaje es más porque me acostumbre a que el estado me dé todo por tener casa, carro y beca y si el Estado me va a dar mis $\$ 130.000$ pues chévere rico y no tengo que hacer nada, entonces se ve de todo un poquito si hace falta un apoyo al hogar que debería llegar a todos los estratos no solo al uno y al dos porque la discapacidad está afectando a todos los estratos y yo puedo ser estrato 3 pero al tener mi chico en condición de discapacidad llega un momento en que mi cuestión económica llega a verse deteriorada, puedo vivir en apartamento propio y tengo que mantenerlo y para eso para poder mantenerlo tengo que buscar una ayuda, un auxilio para poderme beneficiar.

\section{¿Tiene hijos en condición de Discapacidad?}

Sí, tiene 19 años, ella tiene una discapacidad múltiple asociada a una epilepsia de difícil manejo, esta discapacidad fue ocasionada por isquemia cerebral a las 18 horas de haber nacido.

\section{¿Cómo es el proceso de inclusión escolar en la etapa en la que esta su hija?}

La tengo haciendo cursos que tiene la secretaria, perdóname, en la casa de la igualdad de la mujer, desafortunadamente no hay universidades donde uno pueda apostarle a este tipo de discapacidad. Si hay inclusión a nivel del Rosario, la Javeriana o algo pero es más para una discapacidad visual, auditiva o física como tal. Pero múltiple que tenga una discapacidad cognitiva de grado moderado es muy difícil de encontrar.

\section{Las barreras de acceso a la educación superior se deben a la posición económica?}

No, sobre las barreras es que he visto que el personal no está capacitado para manejar este tipo de discapacidad tanto que hasta ahorita se están preparando para eso pero el Gobierno como tal nunca se había preguntado ni se había puesto a pensar, oiga los chicos cumplen 18 años y que vamos hacer con ellos. El gobierno piensa que cumples 18 años y se les acaba la discapacidad, entonces saquémoslos de los Centros Crecer, saquémoslos de todo y que toca pues los papás tenerlos en la casa como trabajar en como tenerlos a ellos. 


\section{ROL SOCIAL Y POLITICO}

\section{¿Evidencia que las mujeres cuidadoras de la Localidad de Bosa han desarrollado habilidades para participar en escenarios de discusión política y social?}

Son echadas para adelantes son mujeres que se vuelven... hacen las cosas muy rápido, se vuelven enfermeras, se vuelven amas de casa, se vuelven abogadas se vuelven de todo porque el estado, si mi hijo se enfermó y convulsionó yo tengo que saber cómo reacciona y si a mi hijo le dio algo tengo que saber qué hacer. Entonces se vuelven de todo y aprenden de todo un poquito. Hay varias que se vuelven abogadas, enfermeras conozco ahorita una cuidadora que la niña le falleció el año pasado, ahoritica está estudiando auxiliar de enfermería porque ella aprendió muchas cosas entonces quiere como profesionalizarlo para ayudar a la gente y era una dura para hacer tutelas, derechos de petición, eso no es venga todo el mundo ayúdeme sino que necesito hacer las cosas, si hay varias.

\section{¿Las mujeres desempeñan un ejercicio político en la localidad o solamente se debe a un instinto de supervivencia por ser su referente protector?}

Hay unas que si ejercen un rol político por lo que te digo son buenas lideres, son delas personas que empiezan a buscar a nivel local a nivel del donde puedo incluir a mi hijo, que puedo hacer para esto y son buenas lideres pues porque no quedan con la información sino que la multiplican y llaman a las mamas vengan consegui esto, hagamos esto, son lideres buenas. Entonces eso depende de cada una y de como uno quiera ayudándoles a que eso no es solo de uno si no es de un bien común, logramos una cosa y lo logramos para todas.

¿Cómo cree que ha sido ese proceso de empoderamiento de las mujeres cuidadoras en un contexto de pobreza, desigualdad social y violencia?

Primero pues teniendo en cuenta de cómo o con qué oportunidades a nivel local se cuenta, te voy hablar dese Salud Pública, los agentes de cambio los líderes que tenían ahí, ayudaban muchísimo en esa capacitación y es como ayudar a esa persona a descubrir, venga tu eres líder aunque no lo creas y es la manera como se va descubriendo esa parte.

¿Las mujeres cuidadoras se ven más expuestas a la exclusión (Social e Institucionalmente) por ejercer el cuidado? 
Lo que pasa es lo que te digo, hay para las personas en condición de discapacidad y no para la cuidadora como tal, hasta ahora que se está empezando hacer trabajos para la cuidadora pero en sí, no se les estaría cerrando la puerta porque se les está abriendo para atender a su hijo en condición de discapacidad pero tal como a la cuidadora no se le está dando nada y no hay a nivel de cuidadoras; hay mujeres que han sido excluidas porque tienen hijo en condición de discapacidad y en su trabajo no les daban el permiso y por no tener quién lo cuide les tocaba llevarlos al trabajo, entonces ellas se sienten excluidas y muchas veces hay actividades para cuidadores, como una obra de teatro pero lo primero que dicen es que no se pueden llevar, entonces no participas porque con quien lo dejas.

¿Las mujeres aprovechan su rol como cuidadoras de NNA en condición de discapacidad para exigir sus derechos como mujeres o es solamente una exigencia para sus hijos?

No, porque lo que te digo no hay una política para cuidadores que permita establecer los derechos del cuidador o los deberes del cuidador, no la hay entonces no se está haciendo.

\section{¿Cuáles son sus debilidades de las mujeres cuidadoras de Bosa?}

Que sean asistencialistas que quieran poner a su hijo pero que le tengan es pesar, tengo un hijo con discapacidad entonces tengo que tener un trabajo, entonces yo creo esa es su debilidad.

\section{PROSPECTIVA}

\section{¿Cómo mejorar las condiciones de vida de las mujeres cuidadoras y sus familias sin tener que acudir a los múltiples programas de asistencia Social?}

Considero que lo fundamental es que desde las políticas de Trabajo y Economía el Gobierno establezca proyectos dirigidos exclusivamente para cuidadores, en donde las condiciones de trabajo sean dignas y se adapten a las necesidades de las mujeres es decir, que hayan lugares en donde los chicos se puedan quedar mientras ellas trabajan y reconozcan la importancia de contribuir al proceso de rehabilitación de los mismos. De igual manera considero que la Educación es muy importante, desde que se abran espacios académicos para las cuidadoras se pueden establecer en mejores trabajos y mejores opciones de vida.

\section{¿Ha pensado como profesional cómo las mujeres cuidadoras lograrán sobrellevar la vejez, el cuidado de sus hijos e hijas y posibles quebrantos de salud?}


Si lo pienso porque yo soy una de ellas, me afana mucho pensar que el Estado no tiene unas acciones puntuales para hacerse cargo de los chicos una vez sus cuidadores lleguen a la vejez o fallezcan porque, la interdicción es proceso obsoleto dado la falta de redes de apoyo de las personas en condición de discapacidad. Ahora el país no esta preparado para enfrentar ni la vejez ni la discapacidad y por tanto no habría forma de afrontarla de manera digna.

\section{¿Hasta dónde, el hecho que las mujeres cuidadoras sigan realizando la labor del cuidado, refleja que el Estado se ha quedado corto en la cobertura de la Protección Social?}

Yo pienso que el Estado debería garantizar una pensión para las cuidadoras, que hay muchas que trabajaron y que tenían que tener tantas semanas para asumir una pensión pero que de verdad ratifiquen que son cuidadoras porque no todo el mundo es cuidador entonces si es importante que la Protección Social se enfoque en las particularidades de sus ciudadanos en ese sentido, es una PS muy débil e ingenua.

Existen países en los que el tema de cuidado es considerado como una profesión y es paga por el Estado, entonces Colombia debería pensar cómo lograr eso y darle tanto a las personas en condición de discapacidad como a sus cuidadores garantías de vida.

\subsection{Entrevista 5}

Funcionario 5, Consejo Local de Discapacidad, Localidad Bosa. 
Bueno mi nombre es Funcionario 5, mi profesión es Abogado estuve desempeñándome como apoyo jurídico en el Consejo Local de Discapacidad desde el mes de mayo del año 2015 hasta el 20 de septiembre de este año, bueno pues mi recorrido profesional antes trabaje en unas entidades privadas específicamente en el sector financiero luego trabaje con 2 entidades públicas, trabaje en un tribunal disciplinario que es una unidad administrativa especial que es como el equivalente del consejo superior de la judicatura para los profesionales de la contaduría, luego hice también llene como unos remplazos en el mismo consejo superior de algunos compañeros y como antes trabajaba por contrato prestación de servicios con las entidades públicas pues también litigaba en el área administrativa porque mi especialidad es el derecho administrativo, actualmente pues ya estando en el COLDIS específicamente empecé mis funciones con el apoyo a las personas en condición de discapacidad, entonces esa al día de hoy es mi experiencia.

\section{ACCIÓN INSTITUCIONAL}

\section{¿Cuáles son y en qué consisten los programas que promueve su entidad?}

El Consejo Sectorial de Discapacidad o como lo conocen la mayoría de las personas Consejo Local de discapacidad, fue reglamentado por el Decreto 505 de 2007 “"Por el cual se reglamenta el Consejo de Gobierno Distrital y los Comités Sectoriales". El objetivo principal del consejo a nivel distrital es adoptar y formular todas las políticas de discapacidad y es el escenario de coordinación de su ejecución conforme al artículo 33 de la Ley 152 de 1994.

Ahora bien, en el área local es la instancia de articulación para que se pueda dar la adopción y formulación de políticas y estrategias y también, es el escenario para el seguimiento a su ejecución. Para que me puedas comprender mejor, las funciones que desarrollamos allí son pues, de formular y concertar las políticas de discapacidad de la localidad, tenemos que articular la ejecución de todos los programas en cabeza de los demás sectores locales, hay una función muy importante y es, verificar que se cumplan las políticas adoptadas y formuladas desde la interinstitucionalidad, debemos, consolidar y presentar todos los documentos y estrategias que se desarrollen en las sesiones de participación al orden distrital, presentar los análisis correspondientes de cada uno de los programas y proyectos desarrollados por los integrantes y los balances de ejecución de la política a las entidades participes de los consejos sectoriales.

\section{¿Considera que la atención a los NNA en condición de discapacidad debe ser centralizada en una sola entidad?}


Bueno yo si considero que debe haber una entidad centralizada porque el hecho de que la atención se esté prestando de manera atomizada en diferentes entidades ha decantado de que la asignación de recursos por parte del Estado no se esté utilizando en debida forma, lo puedo decir porque dentro de los programas de gobiernos de todos los gobiernos que han pasado en nuestro país siempre hay unos proyectos que tienen que ver con la inversión social y en cuanto a los proyectos de inversión social se manejan tantos proyectos a nivel nacional, a nivel departamental y a nivel territorial con los municipios y en este caso con el distrito capital hablando de Bogotá pero que pasa con esos recursos, que se crean diferentes programas que a veces van definidos para la misma situación entonces es posible que estas personas estén recibiendo de las diferentes entidades territoriales los mismos auxilios en razón que su hijo tiene una condición de discapacidad es decir aquí se está rompiendo la coordinación que debe existir entre las entidades gubernamentales para prestarle una debida atención pero también, eso nos lleva a decir que hay personas que producto de que otros no están utilizando el recurso debidamente en forma no reciben el recurso entonces eso quiere decir que efectivamente se debe centralizar para tener registradas cuales son las personas que están recibiendo los beneficios y de esa manera también manejar de manera más eficiente y eficaz la asignación de los mismos, por ejemplo a mí se me ocurre que si el ICBF es la entidad líder en el departamento de la prosperidad social ellos deberían ser los que canalicen todos esos recursos porque, no es posible si bien es cierto la administración central en este caso hablando de Bogotá de la alcaldía mayor de Bogotá tiene unos recursos para inversión social, esos recursos deben ser administrados por ICBF cuando de por medio este la atención de niños, niñas y adolescentes.

En ese orden de ideas, no podemos decir con la experiencia que yo tengo hoy que hay una persona que no le puedo dar la atención porque no tenemos los recursos y que como pasa siempre el consejo haga un discurso político para el control del señor alcalde y diga que no se invirtió si no del cien por ciento de los recursos que había para inversión social el treinta o el cuarenta y el resto de recursos donde está, el resto de recursos queda pendiente porque como hay contratos con operadores que es lo que maneja la administración central hace que esos contratos vallan hasta el treinta y uno de diciembre y muy seguramente cuando inicia el año siguiente la ejecución de los recursos no puede ser hasta que haga el contrato mientras que si nosotros vemos la atención de entidades como el ICBF es una atención permanente porque es una entidad de orden nacional por eso yo digo que sí debería estar centralizada pero se necesita que haya mayor coordinación en el tema de inversión social y en el tema de la política, que se debe maneja para las personas en este caso específicamente que tiene condición de discapacidad 


\section{¿En qué medida cambian los programas de su entidad destinados a la atención de NNA en condición de discapacidad y sus cuidadores en las nuevas administraciones?}

Bueno como lo decía cuando empezamos la entrevista, son diferentes proyectos que se presentan cuando hay cambios de Gobierno, es una obligación ya porque el departamento de planeación nacional DNP exigen que se registren los proyectos de Gobierno entonces como es una obligación no es posible llegar a la idea de que haya una continuidad de las políticas que quiere cada mandatario cuando llega a un cargo de dirección ya sea en la Alcaldía ya sea en la Gobernación o ya sea el señor Presidente de la Republica.

Ahora, hay que tener en cuenta las ideologías que no llega cualquier persona a la presidencia o a la alcaldía, si no que detrás de esa persona ese mandato viene toda una ideología y toda una corporación que le está diciendo, oiga usted tiene que cumplir con sus políticas porque pertenece a un grupo político, ese es el problema que tiene Colombia, Colombia presenta divergencia en la ejecución de proyectos por eso nosotros vemos que así sea una persona que viene con una línea en un Gobierno y la persona ejerció determinados cargos, cuando llega la oportunidad de desempeñar el cargo saca a relucir todos sus ideales para montar una política que lo identifique y ahí es donde vienen los cambios de los proyectos, entonces para el gobernante que creyó que era indispensable la inversión social para el otro ya no consideró que fuera importante si no pensó que para él era más importante el desarrollo de las infraestructuras de las ciudades entonces ese es el problema porque no tenemos una política definida y porque nosotros los ciudadanos tampoco hemos exigido que eso sea así entonces yo creo que el gran inconveniente acá primero que todo, tiene que ver con las ideologías segundo, que el mandatario cuando llega a poner en marcha su proyecto político por el cual llego al cargo público solamente tiene que ver con sus intereses a veces se aleja de la parte social y es todo lo que nosotros venimos viviendo como Colombianos por eso vemos que hay proyectos que a veces quedan a media marcha o incompletos, porque el que llego al turno considera que no era suficiente e inicia otro proyecto y entonces el que llega lo va a dejar a medias y ese es el inconveniente que le ha pasado a Colombia

\section{¿Los programas ofertados responden a un enfoque de derechos?}

Bueno yo considero que Colombia es un país donde sucede de todo y al suceder de todo llama la atención y yo lo digo ya como profesional en derecho y no solamente por ser parte del Consejo Local, el tema es que es una costumbre que en Colombia las decisiones políticas están pasando por encima del derecho nosotros decimos que Colombia es un Estado Social de Derechos y es una República Unitaria donde está por encima de la constitución que es nuestra norma fundamental pero, debajo de 
la constitución encontramos las demás normas y es lo que nosotros vemos que cuando hay decisiones políticas pasan por encima de esos derechos y a que voy con el tema de niños niñas y adolescentes, que se crean programas para los niños que buscan restablecer los derechos pero que una vez ocurrido el cambio de administración es posible que ese programa se acabe porque no obedece o no encaja en el proyecto político que trajo el nuevo mandato en ese orden de ideas, si se están cumpliendo los derechos porque nuestra obligación es garantizar los derechos de los niños niñas y adolescentes pero con los recursos que el Estado tiene asignados para ellos y entonces vemos que al final del año se está haciendo una reforma tributaria y dicen que hay que recortar presupuestos para la inversión social. Ya con esa sola figura, vemos que se van a ver perjudicados los niños entonces si todas las políticas que buscan mejorar a veces de manera indirecta afectan con el cumplimiento de los derechos porque es algo que no se puede ocultar que para nosotros poder ejecutar políticas públicas fuertes que ayude a restablecer los derechos de los niños de por medio esta la asignación de recursos que el Estado puede hacer para eso.

\section{¿Trabajan desde el enfoque diferencial?}

No, si hay un enfoque diferencial por lo menos, en eso se ha avanzado en Colombia, de hecho que haya una ley para las personas en condición de discapacidad que los proteja ya eso significa que hay un enfoque diferencial que efectivamente se están protegiendo; necesitamos es seguir desarrollando políticas para que este derecho no se quede solamente en el papel si no que realmente se pueda ejecutar se pueda materializar y defender precisamente uno de esos objetivos es el apoyo permanente del Consejo Local de Discapacidad y su enfoque veedor.

\section{¿Cómo ve la relación entre familia y Estado frente a la situación actual de los niños en condición de discapacidad y sus cuidadoras?}

Yo creo que el tema del Estado digamos no está claro el concepto para las personas vuelvo y digo el Estado somos todos, el Estado no solamente es el que debe dar el que debe de ayudar si no el Estado es el que también debe ser construido.

En cuanto a la relación de las familias con el Estado, no podemos dejar de un lado que venimos de una concepción de Estado paternalista y no nos hemos alejado de ella es decir, que el Estado siempre ha intervenido a través de las instituciones para proteger ese núcleo de la sociedad sin embargo, Hay muchas falencias en cuanto los recursos que se tiene que brindar ya sea por el ministerio de hacienda o la autoridad que corresponda, son casi insuficiente porque somos un país subdesarrollado, somos un país donde está afectada la mayoría de la población por los recurso económicos que son familias 
desplazadas y la mayoría de desplazados hablando precisamente lo que sucede en Bogotá, están llegando al distrito capital en ese orden de ideas, los recursos en Bogotá siempre van hacer insuficientes para cubrir el total de la población. Y en cuanto a la relación, se evidencia que si ha mejorado por que el Estado se ha preocupado más por las familias, el tema de los niños niñas y adolescentes es más complejo porque muchas veces los que reciben los recursos son los padres porque son los que representan a esos muchachos y es muy difícil, hacer un seguimiento para verificar si esos recursos se están invirtiendo en el bienestar de esos niños porque uno ve que no avanza la familia ve que no hay prosperidad o inclusive a veces las familias quedan estancadas y pueden durar tres o cuatro años, en un programa que nunca mejoran porque realmente el recurso no se utilizó bien y de pronto no intentaron una actividad productiva porque el recurso como ni iba a ser eterno ellos tienen el poder de salir de esa decisión en ese orden de ideas, las relaciones si han mejorado pero hay que hacer mucho esfuerzo no solamente para brindarles recursos económicos para la familia sino para brindarles acciones donde ellos se den cuenta que si pueden ser productivos.

\section{GÉNERO}

\section{¿Se han incluido a las mujeres cuidadoras dentro de los programas ofertados?}

Yo hago una crítica constructiva respecto de las madres cuidadoras en qué sentido, nosotros en el Consejo Local hablando actualmente hemos reflexionado frente a un ejemplo nacional, cuando empezaron las madres comunitarias y las madres comunitarias fue una solución para el desarrollo de la sociedad, en donde las familias empezaron a requerir que tanto la mamá como el papá trabajaran y tener un lugar seguro donde cuidar a sus niños pero esta situación, no es ajena ni diferente cuando hay un niño en condición de discapacidad, el problema radica en que no tenemos madres comunitarias especializadas para cuidar niños en condición de discapacidad por ello, estas familias se vieron en la obligación ya sea el padre o la madre de quedarse en la casa para poder cuidar a ese niño generalmente, las mujeres, porque no tenemos lugares especializados para cuidar a esos niños en condición de discapacidad, lo que uno podría preguntarse o criticar es por qué se está discriminando a los niños en condición de discapacidad y no se crean unas madres comunitarias para criar a estos niños porque si existen unas madres comunitarias para cuidar niños en condiciones normales debería existir también unas para cuidar a estos niños entonces en ese sentido, claro que se han excluido porque, lo más lógico es que el Gobierno en vez de estar implementando o destinando recursos para internados o seminternados, pues implementen las madres comunitarias que cuiden a los niños en condición de discapacidad y que sean ellas mismas las que se encarguen de mantener a sus niños en condiciones adecuadas de acuerdo con la discapacidad que presentan generando, un clima de confianza entre dichas madres entonces se debería dar la oportunidad a ellas que sean vinculadas 
como están las madres comunitarias normales y de esta manera empezar a tener una cobertura integral sin necesidad de recurrir a identidades especializadas porque que más especializadas que ellas con su experiencia para cuidar a estos niños.

Ahora bien, desde el COLDIS progresivamente las cuidadoras han venido participando no solo como comunidad dentro de los procesos de participación y veeduría sino como verdaderos sujetos políticos y empoderados que permite que su experiencia sea escuchada al interior del grupo. Siento como ya lo manifesté, que si ha existido exclusión hacía ellas porque no son un grupo reconocido dentro de la institucionalidad y la discapacidad pues sea enfocado únicamente en la persona que la padece y no, en ese entorno inmediato en el que se desenvuelven.

\section{¿Cuáles son las características de las mujeres que ejercen el cuidado de NNA en condición de discapacidad?}

Las características de estas mujeres primero, el compromiso de tener a su hijo protegido de toda situación que ellas consideran adversa por ejemplo, no deja al niño en una institución o con una persona diferente al grupo familiar y a veces ni a con la familia porque consideran que por la discapacidad pueden tratar al niño mal y se convierten en madres más sobreprotectoras que una madre normal, porque una madre normal empieza a confiar en su hijo en la medida que se va desarrollando y va tomando autonomía en sus decisiones "mama voy a ir al parque, ve tranquilo hijo" eso es confianza, mientras que una mamá que tiene un niño en condición de discapacidad no lo hace, siempre esta con los ojos encima en ese niño entonces se vuelve súper protectora y al ser súper protectora se vuelve una madre con mayor compromiso en el cuidado de estos niños, ellas conocen muy bien la situación de sus hijos y el rol que desempeñan ellas en el desarrollo es fundamental porque, así mismo esta empoderado a esa situación y lo que hace es general un ambiente para que sus hijos se sientan muy bien, me doy cuenta cuando uno está con ellas y sus hijos en diferentes actividades, ellas establecen un lenguaje que no existe en otro lugar por ejemplo con la sola mirada ellas ya saben que sus hijos les están pidiendo algo y eso no se ve en la sociedad normal y solamente es una cualidad que desarrollan ellas por la situación de sus hijos tanto así que entre ellas ya saben que requieren sus hijos por eso si considero que la forma de ellas actuar y como se han empoderado es algo que es de admirar pero que necesita más atención del Estado. 
¿Cuál considera usted que es la situación actual de las mujeres que se dedican al cuidado de los NNA en condición de discapacidad?

Digamos que por la experiencia que he tenido en Bosa, uno identifica que encuentra de todo, encuentra familias con niños en condición de discapacidad victimas del desplazamiento forzado, víctimas del conflicto armado, encuentran familias disfuncionales precisamente por el factor de la discapacidad del niño a veces son abandonadas por sus esposos y suena feo que se halla hecho costumbre que en la sociedad Colombiana las madres siempre tengan que salir a proteger a sus niños entonces poniendo un ejemplo, de cien familias dos o tres personas son los únicos padres que están viendo por sus hijos.

\section{¿Considera que el ejercicio del cuidado está siendo asumido progresivamente por los hombres o considera que las brechas de género se siguen presentando en la localidad?}

Podría decir que se han convertido en unas madres, ellos son personas que tienen ese rol protector o por no decirlo súper protector lo han demostrado porque están con sus hijos y son los que sacan adelante a esos muchachos, eso nos da a entender que los padres también pueden ser garantes de los derechos de los niños en condición de discapacidad porque son personas muy comprometidas pero no dejan de lado su rol de padre es decir salen a trabajar y ellos si se ven en la obligación de confiar en otra persona para que puedan cuidar a su hijo porque ellos saben que tienen que salir hacer actividades para producir y tener ingresos.

\section{¿Cuáles son las razones por las que las mujeres acuden a los programas de asistencia social?}

Es impajaritable que ellas acudan al Estado porque requieren una ayuda es una realidad social que las personas necesitan del Estado y el Estado le tiene que brindar esa protección a través de las diferentes políticas y proyectos que tienen para asistir a esas personas, el problema es que se convierte en costumbre porque lo que puede suceder es que inicialmente vaya a solicitar diferentes servicios y al ver que eso la favorece tanto a ella como a los niños se convierte en una costumbre que ya no quiere hacer otras cosas, el tema es de estar en constante comunicación con las personas de informarlos y orientarlos para que ellos identifiquen que tienen capacidades y habilidades para construir caminos productivos que le permitan tener estabilidad pero, es difícil porque aquí también uno ve en las sesiones que algunas mujeres asisten para ver de qué pueden beneficiarse y no a ejercer control o a dar proyecciones sobre la discapacidad y el cuidado. 


\section{ROL SOCIAL Y POLITICO}

\section{¿Evidencia que las mujeres cuidadoras de la Localidad de Bosa han desarrollado habilidades para participar en escenarios de discusión política y social?}

Si claro, por supuesto se identifica que la mayoría de las mujeres tienen liderazgo unas con más habilidades sociales que otras sin embargo, antes de yo hablar de las habilidades políticas por sí solo, es importante precisar que desde que nacemos somos personas políticas porque obedecemos a políticas públicas que nos asisten ya sea en el tema de salud, en el tema de seguridad social y siempre vamos a estar ligados al sistema político de un país en ese orden de ideas, se evidencia que dentro de esa formación que algunas tienen no fue adquirida en ninguna universidad sino ha sido producto de sus habilidades, del liderazgo, del manejo y son personas con iniciativas de emprendimiento y organización importantes.

\section{¿Las mujeres desempeñan un ejercicio político en la localidad o solamente se debe a un instinto de supervivencia por ser su referente protector?}

No, las mujeres ejercen un rol político sin lugar a dudas yo no puedo desconocer solamente porque estemos hablando de las mujeres cuidadoras de niños en condición de discapacidad si no porque también, tengo que tener en cuenta mi familia y a nosotros los que nos terminan formando o criando como se dice popularmente son nuestras madres y como lo decías ahorita, las madres siempre son las que salen a proteger sus hijos y nosotros cuando empezamos a comunicar y a exteriorizar esas enseñanzas que aprendemos en la familia no es otra cosa que reflejar lo que han hecho nuestras madres, las mujeres juegan un papel político grandísimo en la sociedad no solamente en Colombia, sino en el mundo lo que pasa es que nuestra sociedad está cambiando y venimos de un Estado donde hasta ahora estamos empezando a reconocerle derechos a las mujeres pero cuando ya haya una completa igualdad en los mismos, yo no tengo dudas de que las mujeres sean las que muevan los hilos de este Estado de este país y de muchos Estados porque, empiezan moviendo las familias o sea un ejemplo, es que dice que el núcleo de una sociedad es la familia y si una familia la mueve una mujer y ya estamos encontrando que en la sociedad hay lideres yo no me puedo equivocar al decir que de aquí a mañana vamos a tener una mujer que lidere al país lo que pasa es que nos venimos preparando para eso porque si es cierto las mujeres mueven las familias lo cierto es que en la sociedad el que siempre ha llevado el sustento suena muy machista pero el que ha llevado el sustento o el brazo económico en la familia son los padres o los hombres y eso hace que haya cierto grado de sumisión 
de las mujeres pero hoy en día como las mujeres tienen que salir a trabajar y la misma sociedad nos ha llevado a eso estoy seguro que ellas van a ejercer ese rol político que ejercen en sus familias para exteriorizarlo también en la sociedad.

\section{¿Las mujeres cuidadoras se ven más expuestas a la exclusión (Social e Institucionalmente) por ejercer el cuidado?}

$\mathrm{Si}$, si claro que son excluidas porque si no fuera así sus familias serian estables si no fueran excluidas no estarían buscando la ayuda del estado por el contrario el estado estaría buscando a ellas porque si nosotros vamos a proteger a niños empecemos por los niños en condiciones más vulnerables y en este caso para mí los de más vulnerabilidad pues son los niños en condición de discapacidad que no tienen esa oportunidad que tienen los niños normales entonces si en cierto modo se ven excluidas porque en la práctica los trabajos como los tenemos diseñados en nuestro sistema colombiano esta para que las personas estén constantemente prestando la actividad personal y muy difícil que un trabajo contrate a una persona o le dé un trabajo a una mama que tiene un hijo con condición de discapacidad porque obviamente va tener que estar pendiente de su hijo y no va poder hacer la actividad como lo requiere con toda la dedicación pero es que tampoco se puede desconocer que ya está existiendo el teletrabajo y el teletrabajo y actividades personales que se pueden hacer desde la casa es lo que nosotros debemos enfocarnos para transmitírselos a esas mamas o por ejemplo que se creen como yo lo decía unas madres comunitarias donde las mismas mamas que se han encargado de tener experiencia para cuidar a los niños cuiden a esos niños de otras mamas para que las mamas más jóvenes o que tienen una formación técnica o profesional o que quieren salir a trabajar de una manera eficiente como lo hacen las mamas de niños en condiciones normales puedan llevar a su casa el sustento pero si la pregunta

efectivamente y puntual es si están siendo discriminada claro que si están siendo excluidas porque lo que vemos es que estas mamas a todo momento tienen que pedir la asistencia del estado porque no tienen una oportunidad laboral.

\section{¿Son las mujeres cuidadoras de Bosa un grupo reconocido por la comunidad y las instituciones?}

Si y no, las mujeres que están participando en el consejo local de discapacidad si están siendo reconocida porque tienen ese espacio, o por lo menos son más visibles lo que pasa es que hay algunas personas, madres y padres que no han entrado a esos grupos porque han buscado las asistencias de alguna entidad o de la otra y al no prestarle la correspondiente atención ellos dicen que no insisten más y jamás vuelven a pedir la asistencia del Estado si no solamente en el tema de salud pero el tema de salud no es el remedio para la situación del niño necesita de otras cosas y estas personas se ven muy ligadas a depender lo que le de el sistema de salud entonces en ese sentido no entran ser 
reconocido pero si la pregunta es si en bosa como tal ya hay un grupo de mujeres sí que debería ser más grande también pero pues con las que tenemos actualmente en la localidad de Bosa si hay un reconocimiento para ellas y pues eso ha sido logrado por ellas mismas

\section{¿Cuáles son sus debilidades?}

La debilidad que yo más veo en ellas es el miedo, el miedo a salir de la situación en la que están acostumbradas entonces, una mujer que se acostumbra a cuidar a su niño día y noche pendiente de él siente miedo de dejarlo con otra persona, desconfianza en decir voy a dejar a mi hijo en una institución y voy a salir a trabajar porque no sé qué le puede dar a mi hijo inclusive cómo se acostumbró a estar tanto en la casa, siente miedo como puede interactuar en sociedad porque se ha ensimismado en su problema y no sabe cómo reaccionar con el resto del mundo y eso se ve es por ello que, nosotros necesitamos que dejen de ser espectadoras y que sean parte activa de la sociedad pero eso se ha tenido como costumbre.

\section{PROSPECTIVA}

\section{¿Ha pensado como profesional cómo las mujeres cuidadoras lograrán sobrellevar la vejez, el cuidado de sus hijos e hijas y posibles quebrantos de salud?}

Bueno, esa pregunta fue la que me empezó a cuestionar para decir tengo que ayudar a estas personas con un proyecto para que hagan una empresa no solamente por el tema de que se vayan a envejecer, porque no tengan oportunidad laboral si no porque las medidas de asistencia social no son para siempre y no podemos permitir tampoco que las familias continúen en estado de vulneración. Además, en Colombia las condiciones de envejecimiento son muy complejas para todos y si es importante que ellas vayan construyendo espacios que les permita ahorrar o mirar formas de auto sostenimiento en el tiempo.

\section{¿Hasta dónde, el hecho que las mujeres cuidadoras sigan realizando la labor del cuidado, refleja que el Estado se ha quedado corto en la cobertura de la Protección Social?}


No creo que el Estado se haya quedado corto en cuanto a la cobertura de Protección Social, porque nosotros nos tenemos que dar cuenta que la responsabilidad del Estado no puede ser cargada solamente para el gobierno central y ya existiendo una separación entre el concepto de Estado y Gobierno; Gobierno es el que ejecuta las políticas entre ellas la inversión social y las que tienen que de manera integral proteger a los niños y adolecentes que es nuestro caso y no desligado a eso pues también a sus familias a sus padres, el problema es que nosotros no tenemos los recursos suficientes para llevar un sistema eficiente pero el problema de nosotros en Colombia tiene que ver con el tema político, el tema político cuando se llega al poder y no hay una convicción ética de ejercer los mandatos con transparencia siempre en pro de la ciudadanía eso nos lleva a que estemos atrasados en el sistema entonces, yo voy a poner un ejemplo para darme a entender en los países de primer mundo como Noruega y suiza las personas que llegan al poder no lo hacen con la ambición de tener contratos de que no puedo ejecutar tal cosa funciona diferente porque culturalmente han sido formados para ser un buen país, y para ser un buen país saben que tienen que hacer una buena administración y si hacen una buena administración es con la conciencia que nos va a favorecer a todos el ejemplo claro lo tenemos en Colombia cuando nos damos cuenta por ejemplo en el caso del carrusel de la contratación en el caso de las políticas de inversión social en el choco y que siempre se pierden los recursos Nos están generando un atraso en la sociedad y ese atraso en la sociedad es lo que estamos viviendo en este momento que personas no tienen unos programas para que sean atendidas en debida forma que el sistema de salud este colapsado porque no tenemos recursos pero esos recursos que se pierden en la corrupción son los que nos llevan a que estemos así por ello el tema acá es de cambiar nuestra mentalidad y que no solamente los delincuentes son los que están robando en la calle los celulares quitándole al otro la billetera lo que retiro y consigno porque no tienen como vivir y como esas familias no fueron educadas entones ellos practican esas actividades, pero esas actividades no podemos dejarlas de un lado porque son propias de la corrupción porque si la corrupción no se apropiara de tanto recursos como lo acaba de mostrar un estudio de la procuraduría se podría invertir en la educación y al invertir en la educación estaríamos buscando más bien en la calle los niños que no están estudiando para darles una educación gratis, y darles una buena educación como pasa por ejemplo en otros países y en este caso el referente para mi es Cuba donde en Cuba casi todas las personas son profesionales y son avanzados en la medicina y porque Cuba siendo un estado tan pequeño nos lleva a nosotros tanta ventaja precisamente porque los niveles de corrupción son muy bajos al no haber corrupción los recursos se puede invertir bien y ellos escogieron la línea de la educación y por eso son unos avanzados en la medicina y también en el deporte mientras que nosotros que tenemos representantes muy buenos en el deporte tenemos poquitos porque los demás no pueden acceder porque no tienen recursos ¿pero dónde están quedando esos recursos? En la corrupción y en 
el no ejecución de las obras completas entonces eso nos está generando un atraso y ya manera de ejemplo en algún momento me dijeron que eso era un desabrupto yo considero que los delitos que tiene que ver con la corrupción o con la toma de no ejecución en debida forma de los recursos del estado eso es un delito de la humanidad porque nos está generando un atraso y es aprobado porque lo estamos viviendo, en el Choco no tienen vías para acceso a los municipios pero todos los recursos que se han invertido en el choco donde se han quedado en la corrupción, entonces el problema es de los gobernantes y no del estado porque el estado somos todos y hay personas que son capaces pero no pueden acceder allá porque se han conformado como familias para siempre estar allá en el poder y no darle la oportunidad a los que pueden hacer las cosas bien

\section{¿En qué institución ve usted más barreras para lograr un trabajo articulado en la localidad?}

Bueno yo creo que todas las instituciones en este caso estatales porque las privadas desarrollan un mejor servicio precisamente por ser entidades privadas y que tiene que cumplir con las metas y tienen que ejecutar bien los recursos, casi siempre el problema están en las entidades públicas y las que presentan barreras pues son las entidades de salud obviamente porque no tienen los recursos porque no tienen la disponibilidad de los instrumentos para brindar la atención y las que los tienen que son las privadas no lo hacen porque se la prestan a los que tienen los recursos para acceder a los mismos entonces estamos en ese estado estamental por decirlo así donde el privado beneficia al que tiene y el estado beneficia al que no tiene y como el estado siempre el problema es que no tiene recursos se ven perjudicados estas personas entonces las barreras están en la mayoría de entidades estatales porque no tiene los recursos para la atención específicamente podría decir que el sistema de salud se colapsa porque es demasiada la demanda y entonces como es lo que más se demanda es lo que más se ve en este caso es la entidad que más pone barreras para la atención pero no es porque ellos mismos tengan la culpa si no porque las políticas en cuanto a la inversión social en el tema de salud son muy pocas para la demanda que requieren los ciudadanos. 


\section{Sistematización Entrevistas}

\begin{tabular}{|c|c|c|c|c|c|}
\hline CATEGORIAS & Funcionario 2 & Funcionario 1 & Funcionaria 4 & Funcionaria 3 & Funcionario 5 \\
\hline IDENTIFICACIÓN & $\begin{array}{l}\text { i. Son abandonadas } \\
\text { ii. Presentan otra } \\
\text { unión } \\
\text { iii. Maltrato y } \\
\text { violencia } \\
\text { intrafamiliar }\end{array}$ & 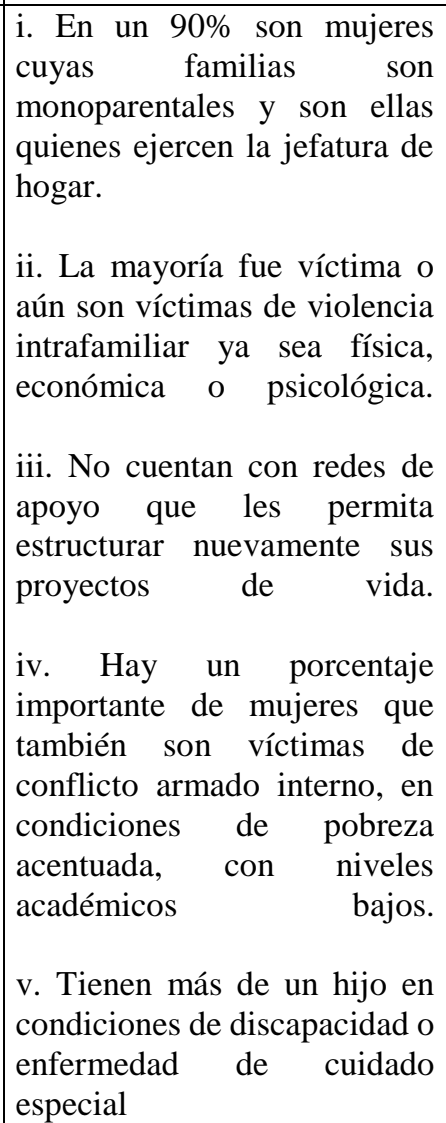 & $\begin{array}{l}\text { i. Es una mujer que tiene } \\
\text { su autoestima baja. } \\
\text { ii. La pareja la abandonó o } \\
\text { le echo la culpa porque tú } \\
\text { sabes que la discapacidad } \\
\text { se consideraba como un } \\
\text { castigo divino. } \\
\text { iii. No cuenta con una red } \\
\text { de apoyo }\end{array}$ & $\begin{array}{l}\text { i. La mayoría de niños que } \\
\text { están vinculados vienen de } \\
\text { tipologías monoparentales } \\
\text { donde la mamá es la que } \\
\text { lidera todo el proceso de } \\
\text { este chiquito a nivel } \\
\text { familiar, de salud y demás. } \\
\text { ii. Son muy pocas las } \\
\text { mujeres que continúan una } \\
\text { relación en pareja. }\end{array}$ & $\begin{array}{l}\text { iii. Ellas conocen muy bien la } \\
\text { situación de sus hijos. } \\
\text { iv. Establecen un lenguaje que } \\
\text { no existe en otro lugar. } \\
\text { v. Se han empoderado. } \\
\text { vi. Familias con niños en } \\
\text { condición de discapacidad } \\
\text { victimas del desplazamiento } \\
\text { forzado. } \\
\text { vii. Familias disfuncionales } \\
\text { precisamente por el factor de la } \\
\text { discapacidad del niño a veces } \\
\text { son abandonadas por sus } \\
\text { esposos }\end{array}$ \\
\hline LIDERAZGO & $\begin{array}{l}\text { i. } \\
\text { evidenciado comos } \\
\text { equipo psicosocial, } \\
\text { que la mayoría son } \\
\text { mujeres las que se } \\
\text { prestan para el } \\
\text { empoderamiento y }\end{array}$ & $\begin{array}{l}\text { i. No se puede desconocer que } \\
\text { los hombres también están } \\
\text { dejando a un lado los } \\
\text { estereotipos de género y han } \\
\text { asumido progresivamente el } \\
\text { cuidado de estos NNA, los } \\
\text { que nosotros evidenciamos }\end{array}$ & $\begin{array}{l}\text { i. Ya estamos viendo un } \\
\text { porcentaje de hombre en } \\
\text { los cuales las mujeres han } \\
\text { abandonado a sus hijos y } \\
\text { se los han dejado a sus } \\
\text { hombres, aunque ellos } \\
\text { cuentan con el apoyo de su }\end{array}$ & $\begin{array}{l}\text { i. Nosotros hemos tenido } \\
\text { máximo la participación } \\
\text { de } 6 \text { hombres sin embargo } \\
\text { ellos son los que lideran y } \\
\text { representan a los niños, } \\
\text { son quienes reciben las } \\
\text { visitas, movilizaban las }\end{array}$ & $\begin{array}{l}\text { i. Podría decir que se han } \\
\text { convertido en unas madres, los } \\
\text { padres también pueden ser } \\
\text { garantes de los derechos de los } \\
\text { niños en condición de } \\
\text { discapacidad. }\end{array}$ \\
\hline
\end{tabular}




\begin{tabular}{|c|c|c|c|c|c|}
\hline & 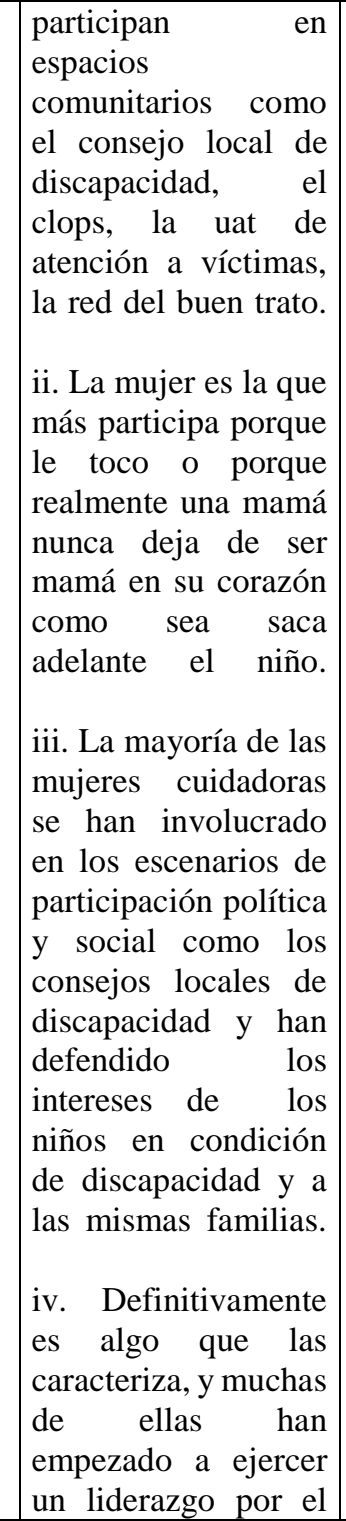 & $\begin{array}{l}\text { son más o menos } 3 \text { o } 4 \text { de } 130 \\
\text { mujeres que se dedican al } \\
\text { cuidado ejercen un liderazgo } \\
\text { positivo, participan en varias } \\
\text { entidades de la localidad pero } \\
\text { al mismo tiempo se encargan } \\
\text { de llevar el sustento } \\
\text { económico a las casas. } \\
\text { ii. Son mujeres que inclusive } \\
\text { desde el analfabetismo se han } \\
\text { transformado en verdaderas } \\
\text { agentes de cambio tanto para } \\
\text { sus familias como para la } \\
\text { comunidad en general. } \\
\text { iii. Es el liderazgo positivo y } \\
\text { asertivo lo que las caracteriza. } \\
\text { iv. El interés de implementar } \\
\text { mecanismos de comunicación } \\
\text { y de incentivar las redes de } \\
\text { apoyo como opción de } \\
\text { exigencia de derechos. } \\
\text { ve } \\
\text { vi. Son mujeres que reconocen } \\
\text { la necesidad y reflexionan } \\
\text { sobre todo acerca del derecho } \\
\text { a la información, ellas están } \\
\text { pendientes siempre no solo de } \\
\text { participar o de promulgar } \\
\text { actividades sino que por el } \\
\text { contrario están como veedoras } \\
\text { de los procesos de } \\
\text { socialización y convocatorias. } \\
\text { anas todo el }\end{array}$ & $\begin{array}{l}\text { mamá y pues eso les ayuda } \\
\text { un poco. } \\
\text { ii. Son echadas para } \\
\text { adelantes son mujeres que } \\
\text { se vuelven enfermeras, } \\
\text { amas de casa, abogadas, se } \\
\text { vuelven de todo. }\end{array}$ & $\begin{array}{l}\text { citas asistían a talleres y } \\
\text { participaban común y } \\
\text { corriente, socializan con el } \\
\text { nivel de compromiso hacia } \\
\text { sus hijos como si fuera el } \\
\text { de }\end{array}$ & $\begin{array}{l}\text { ii. La mayoría de las mujeres } \\
\text { tienen liderazgo unas con más } \\
\text { habilidades sociales que otras. } \\
\text { iii. Las mujeres que están } \\
\text { participando en el consejo local } \\
\text { de discapacidad si están siendo } \\
\text { reconocida porque tienen ese } \\
\text { espacio }\end{array}$ \\
\hline
\end{tabular}




\begin{tabular}{|c|c|c|c|c|c|}
\hline & $\begin{array}{l}\text { compromiso y la } \\
\text { solidaridad que hay } \\
\text { entre ellas, sus } \\
\text { ejemplos } \\
\text { experiencias de vida } \\
\text { siempre les sirve para } \\
\text { apoyar a otras } \\
\text { familias. } \\
\text { v. Son muy buenas } \\
\text { multiplicadoras de } \\
\text { sus saberes. } \\
\text { vi. Son reconocidas } \\
\text { dentro de su mismo } \\
\text { contexto pero les } \\
\text { falta mostrarse a la } \\
\text { comunidad y dar a } \\
\text { conocer todos sus } \\
\text { procesos }\end{array}$ & $\begin{array}{l}\text { tiempo están interponiendo } \\
\text { recursos jurídicos que nos } \\
\text { obligan a dar continuidad } \\
\text { dentro de la medida de } \\
\text { restablecimiento de derechos }\end{array}$ & & & \\
\hline $\begin{array}{l}\text { PROTECCIÓN } \\
\text { SOCIAL }\end{array}$ & $\begin{array}{l}\text { i. El objetivo, es } \\
\text { pues, fortalecer los } \\
\text { procesos de inclusión } \\
\text { de las personas con } \\
\text { discapacidad, sus } \\
\text { familias y cuidadores } \\
\text { en los diferentes } \\
\text { entornos. } \\
\text { ii. Se atienden entre } \\
7000 \text { personas a } \\
8000 \text {. } \\
\text { iii. Los profesionales } \\
\text { rotan mucho porque } \\
\text { no se les da } \\
\text { continuidad en sus } \\
\text { contratos y esto }\end{array}$ & $\begin{array}{l}\text { i. El ICBF se ha preocupado } \\
\text { por atender esta población en } \\
\text { varias modalidades de } \\
\text { restablecimiento de derechos. } \\
\text { ii. Bogotá atiende a } 2.632 \\
\text { NNA en condición de } \\
\text { discapacidad bajo las medidas } \\
\text { de restablecimiento de } \\
\text { derechos que establece la ley } \\
1098 \text { de } \\
\text { iii. La atención en salud } \\
\text { genera incumplimiento en su } \\
\text { quehacer y por ello se ven } \\
\text { afectados los derechos de } \\
\text { estos niños. }\end{array}$ & 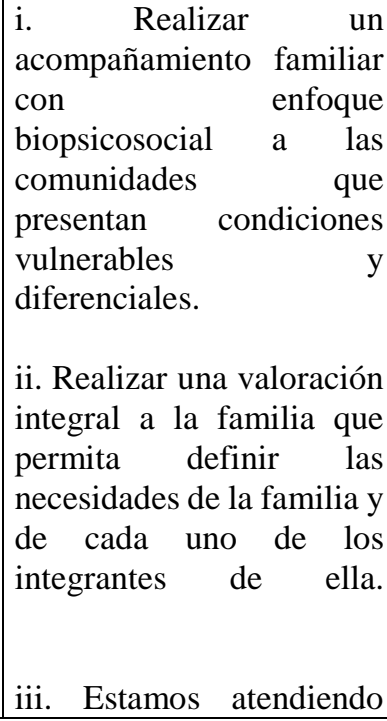 & $\begin{array}{l}\text { i. Nuestro programa es de } \\
\text { inclusión escolar de niñas, } \\
\text { niños y jóvenes con } \\
\text { discapacidad en las aulas } \\
\text { en donde se encuentran los } \\
\text { demás estudiantes o } \\
\text { algunos colegios cuentan } \\
\text { con aulas especializadas. } \\
\text { ii. Se atienden alrededor } \\
\text { de } 110.000 \text { NNA y } \\
\text { adultos. } \\
\text { iii. Son mujeres igual que } \\
\text { no pueden laborar de } \\
\text { tiempo completo que tiene } \\
\text { que rebuscárselas. } \\
\text { Se habla de inclusión en }\end{array}$ & $\begin{array}{l}\text { i. El objetivo principal del } \\
\text { consejo a nivel distrital es } \\
\text { adoptar y formular todas las } \\
\text { políticas de discapacidad y es el } \\
\text { escenario de coordinación de su } \\
\text { ejecución. } \\
\text { ii. Formular y concertar las } \\
\text { políticas de discapacidad de la } \\
\text { localidad. } \\
\text { iii. Hay que hacer mucho } \\
\text { esfuerzo no solamente para } \\
\text { brindarles recursos económicos } \\
\text { para la familia sino para } \\
\text { brindarles acciones donde ellos } \\
\text { se vuelvan productivos. }\end{array}$ \\
\hline
\end{tabular}




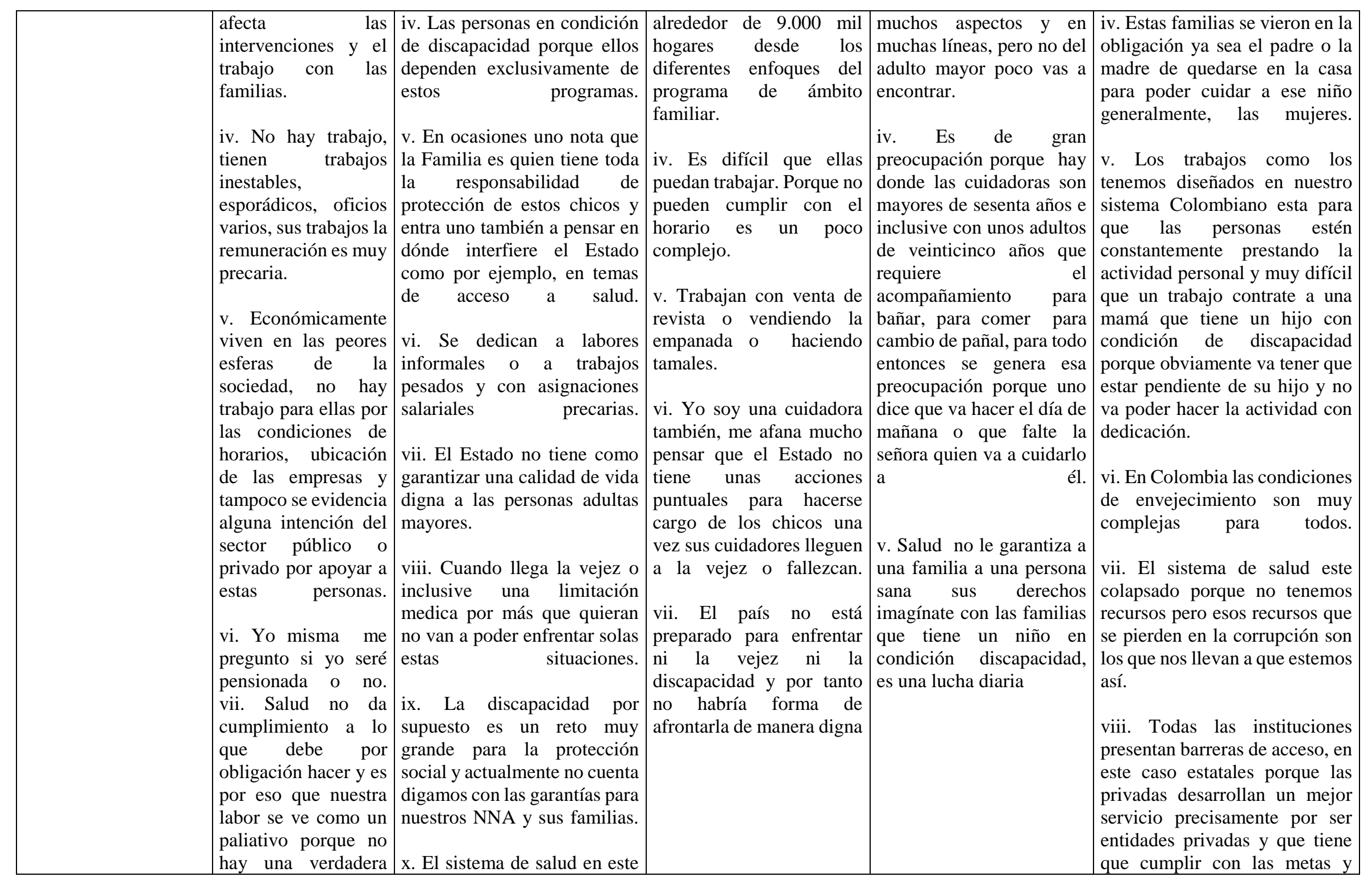




\begin{tabular}{|c|c|c|c|c|c|}
\hline & $\begin{array}{l}\text { articulación } \\
\text { funcionalidad } \\
\text { institucional }\end{array}$ & $\begin{array}{l}\text { momento es tan lucrativo que } \\
\text { sea vuelto un negocio para } \\
\text { diferentes personas o grupos } \\
\text { que realmente lo están } \\
\text { llevando a sus mínimas } \\
\text { expresiones de servicio }\end{array}$ & & & $\begin{array}{l}\text { tienen que ejecutar bien los } \\
\text { recursos }\end{array}$ \\
\hline $\begin{array}{l}\text { RECONOCIMIENT } \\
\text { O INSTITUCIONAL }\end{array}$ & 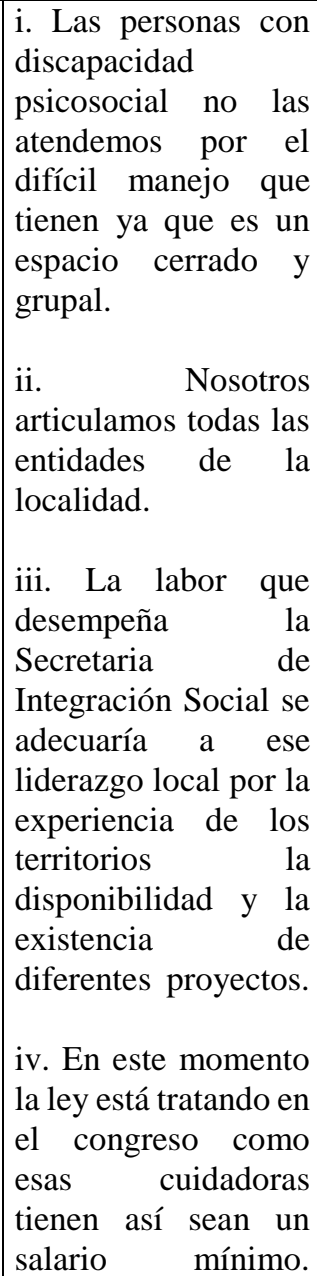 & $\begin{array}{l}\text { i. Las medidas se adoptan } \\
\text { siempre, en el marco de la } \\
\text { verificación de derechos que } \\
\text { efectué la autoridad } \\
\text { administrativa. } \\
\text { ii. Es muy difícil que una sola } \\
\text { entidad garantice al NNA en } \\
\text { condición de discapacidad lo } \\
\text { que se requiere y que } \\
\text { proporcione todo } \\
\text { iii. El hospital pablo VI en } \\
\text { Bosa ha sido un muy buen } \\
\text { apoyo para ICBF en cuanto a } \\
\text { la capacitación de los } \\
\text { representantes legales y en la } \\
\text { oportunidad de brindar } \\
\text { mejores herramientas de } \\
\text { cuidado. yor las } \\
\text { iv. Los municipios y las } \\
\text { localidades deben fortalecer el } \\
\text { tema del diagnóstico, ya que } \\
\text { además de conocer el censo } \\
\text { poblacional, nos permite } \\
\text { conocer desde el enfoque de } \\
\text { ciudadanía las verdaderas } \\
\text { necesidades de } \\
\text { poblaciones. las. } \\
\text { v. Pensar que el Estado está }\end{array}$ & 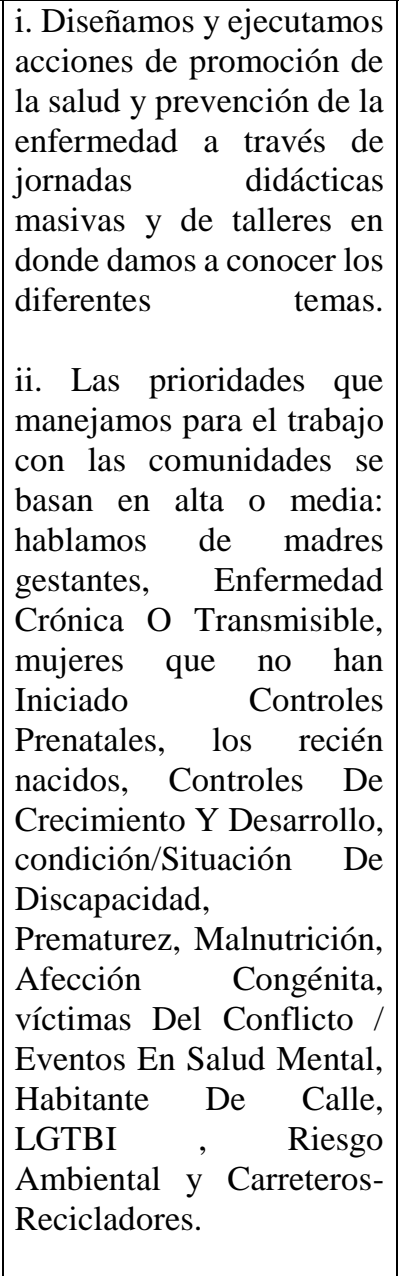 & $\begin{array}{l}\text { i. Se debe mejorar el } \\
\text { proceso de contratación de } \\
\text { personal porque es ahí } \\
\text { donde se puede identificar } \\
\text { las habilidades de los } \\
\text { profesionales para atender } \\
\text { a la población. } \\
\text { n } \\
\text { ii. No manejamos } \\
\text { exactamente criterios de } \\
\text { ingreso para los niños. } \\
\text { iii. La responsabilidad } \\
\text { directa es de salud de } \\
\text { cubrir todas las } \\
\text { necesidades especiales } \\
\text { que tienen estos chiquitos, } \\
\text { ellos son los que deberían } \\
\text { liderar y darnos como el } \\
\text { lineamiento y darnos la } \\
\text { línea técnica a nosotros } \\
\text { para que nosotros } \\
\text { podamos con base en eso } \\
\text { podamos establecer } \\
\text { nuestros programas. } \\
\text { iv. Tener esas familias de } \\
\text { manera vitalicias no es } \\
\text { sano para nosotros porque } \\
\text { no estábamos dando } \\
\text { cobertura a la demás }\end{array}$ & $\begin{array}{l}\text { i. El Estado no solamente es el } \\
\text { que debe dar el que debe de } \\
\text { ayudar si no el Estado es el que } \\
\text { también debe ser construido. } \\
\text { ii. El Estado se ha preocupado } \\
\text { más por las familias. } \\
\text { iii. Nosotros no tenemos los } \\
\text { recursos suficientes para llevar } \\
\text { un sistema eficiente pero el } \\
\text { problema de nosotros en } \\
\text { Colombia tiene que ver con el } \\
\text { tema político, el tema político } \\
\text { cuando se llega al poder y no } \\
\text { hay una convicción ética de } \\
\text { ejercer los mandatos con } \\
\text { transparencia }\end{array}$ \\
\hline
\end{tabular}




\begin{tabular}{|c|c|c|c|c|c|}
\hline & 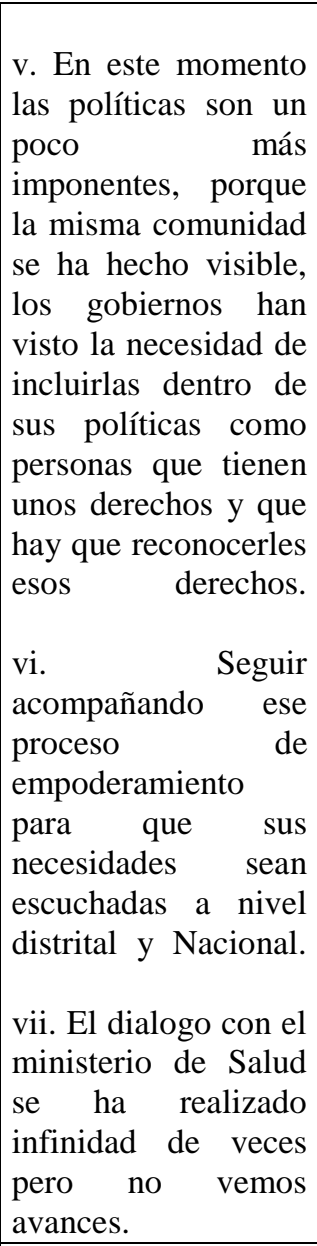 & $\begin{array}{l}\text { asumiendo la labor de la } \\
\text { familia en el tema de la } \\
\text { discapacidad y enfermedades } \\
\text { de cuidado especial, es hablar } \\
\text { desde el desconocimiento } \\
\text { vi. El Sistema de la Protección } \\
\text { Social se está renovando o } \\
\text { adaptando más bien a las } \\
\text { realidades propias de sus } \\
\text { habitantes. } \\
\text { vii. Es un sistema joven que } \\
\text { debe por supuesto enfocarse } \\
\text { en mejorar sus acciones y en } \\
\text { crecer en favor de la población }\end{array}$ & $\begin{array}{l}\text { iii. No puede centralizarse } \\
\text { la atención en una sola } \\
\text { institución porque o sino } \\
\text { no estaríamos hablando de } \\
\text { una inclusión sino } \\
\text { estaríamos excluyendo en } \\
\text { una parte donde estarían } \\
\text { ellos } \\
\text { iv. Bueno el Estado si ha } \\
\text { suplido, si ha ayudado y } \\
\text { ayuda a las familias en } \\
\text { condición de } \\
\text { discapacidad. } \\
\text { v. Salud Publica en este } \\
\text { momento se ve más } \\
\text { enfocado hacia la } \\
\text { rehabilitación de los niños, } \\
\text { es decir todo el tema de } \\
\text { salud y RBC }\end{array}$ & $\begin{array}{l}\text { población que estaba allí. } \\
\text { v. Nosotros somos los } \\
\text { principales interesados en } \\
\text { que ellas conozcan el } \\
\text { tema, conozcan la política, } \\
\text { conozcan las instituciones } \\
\text { que brindan apoyo. } \\
\text { vi. El Estado se ha } \\
\text { quedado corto con muchos } \\
\text { programas especialmente } \\
\text { con este }\end{array}$ & \\
\hline CONFLICTIVIDAD & $\begin{array}{l}\text { i. Hay profesionales } \\
\text { a los que no les gusta } \\
\text { la intervención con } \\
\text { personas } \\
\text { condición en } \\
\text { discapacidad y eso } \\
\text { pues evidentemente }\end{array}$ & 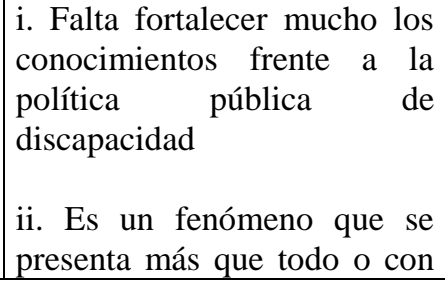 & 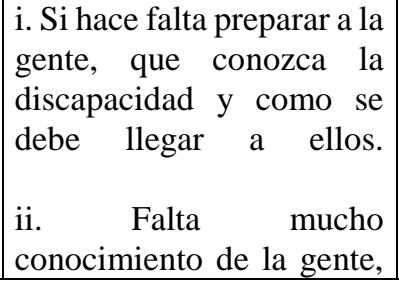 & $\begin{array}{l}\text { i. Hay profesionales que } \\
\text { bien sea por experiencia o } \\
\text { algo personal no cumplen } \\
\text { con los objetivos como se } \\
\text { quisiera. } \\
\text { ii. Estos programas }\end{array}$ & $\begin{array}{l}\text { i. Se crean diferentes programas } \\
\text { que a veces van definidos para } \\
\text { la misma situación, aquí se está } \\
\text { rompiendo la coordinación que } \\
\text { debe existir entre las entidades } \\
\text { gubernamentales. }\end{array}$ \\
\hline
\end{tabular}




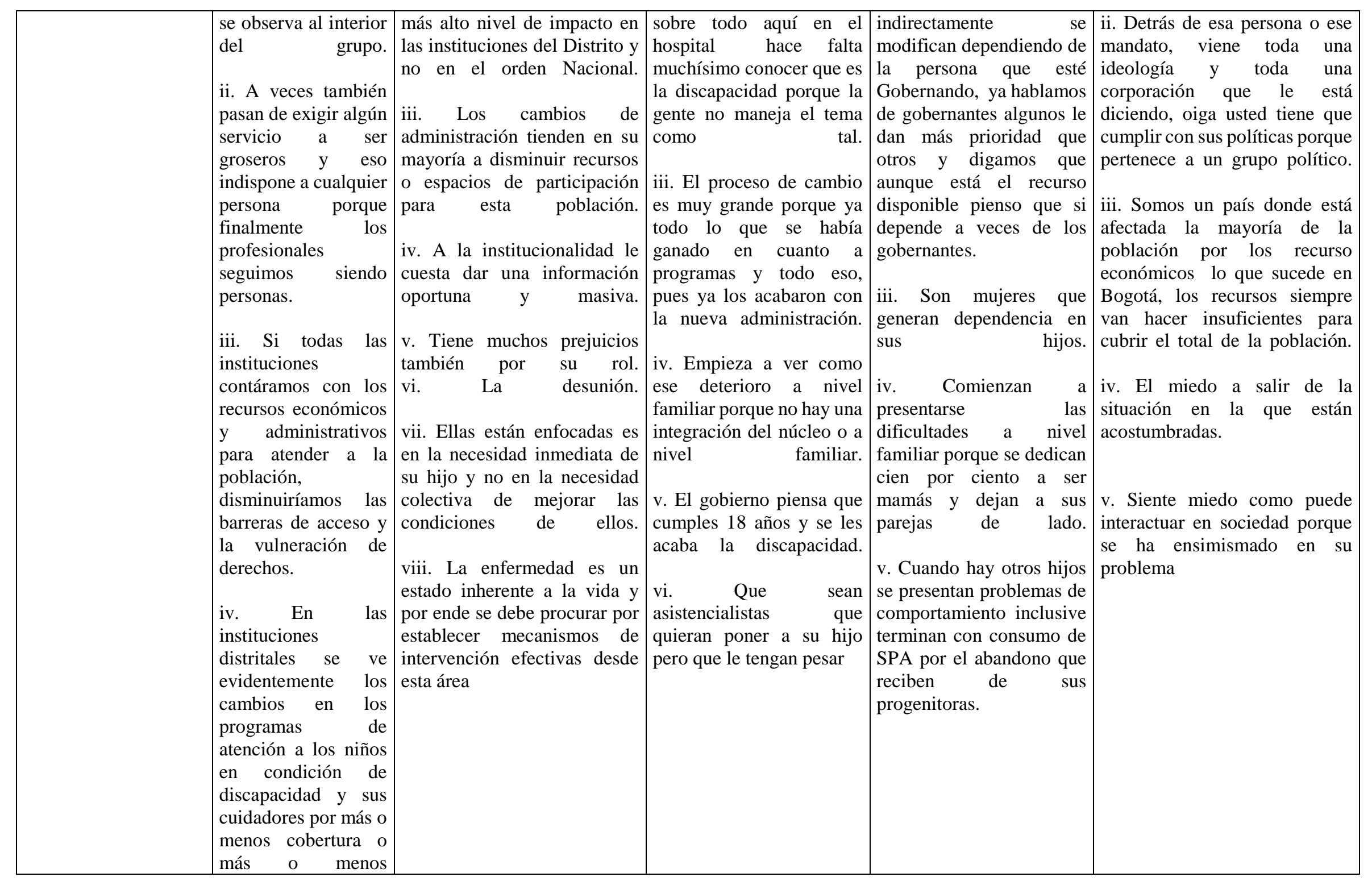




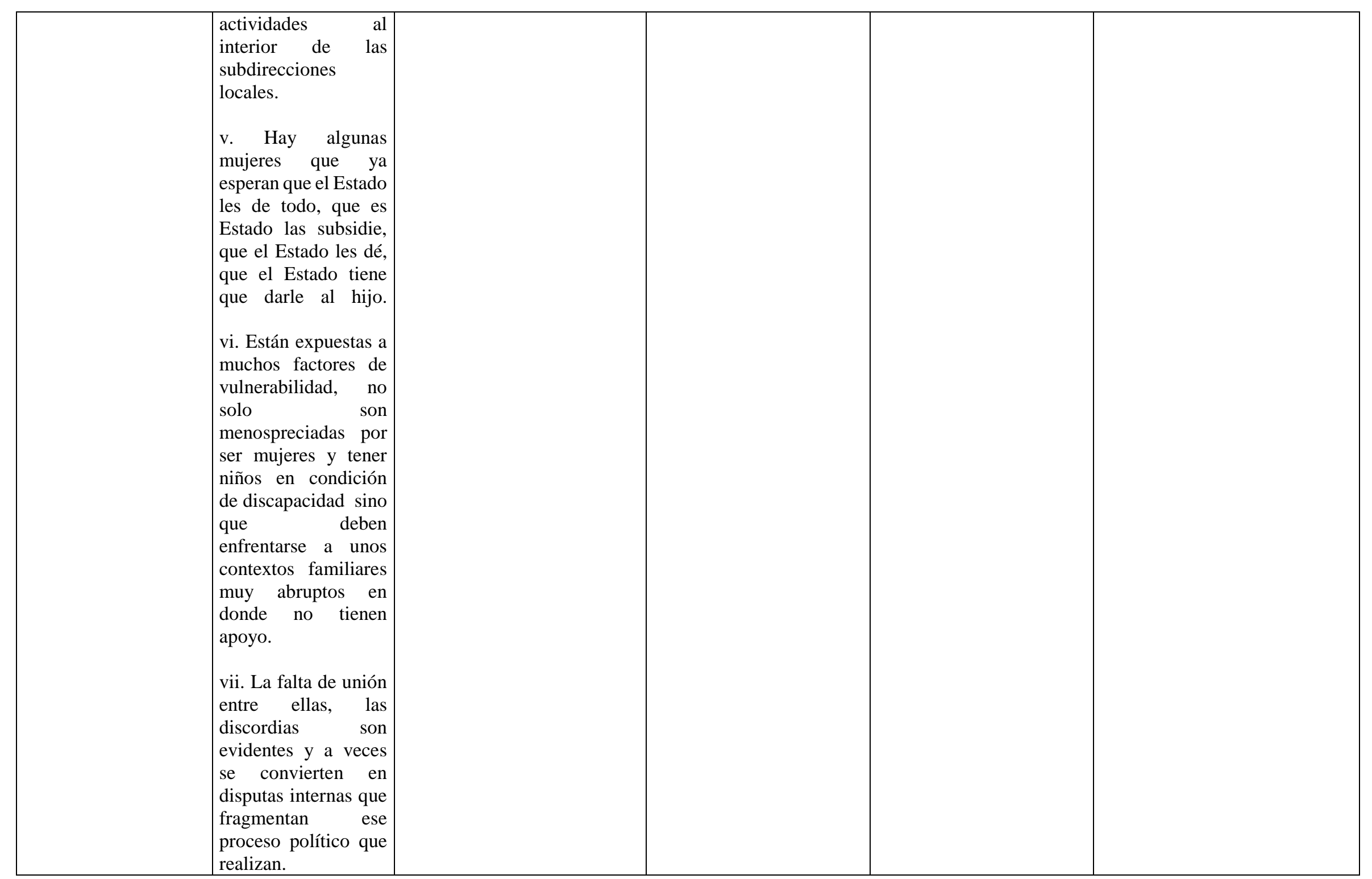




\begin{tabular}{|c|c|c|c|c|c|}
\hline & $\begin{array}{l}\text { viii. Hace falta como } \\
\text { mayor incidencia y } \\
\text { participación por } \\
\text { parte de la } \\
\text { comunidad que tiene } \\
\text { personas } \\
\text { condición en } \\
\text { discapacidad }\end{array}$ & & & & \\
\hline DERECHOS & 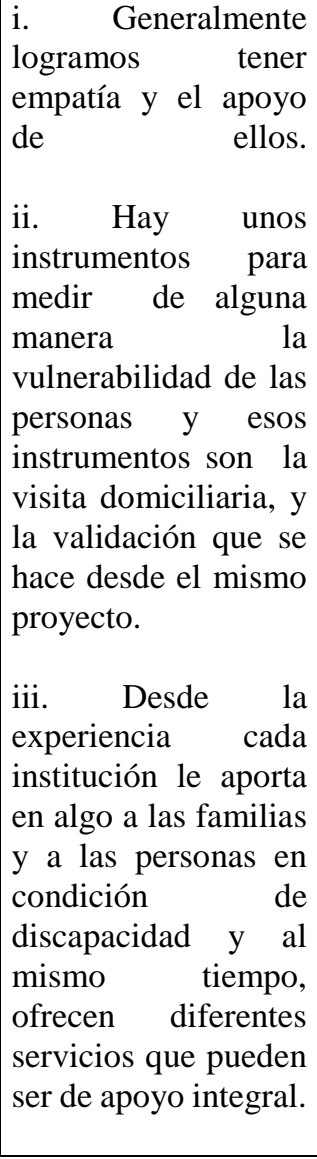 & 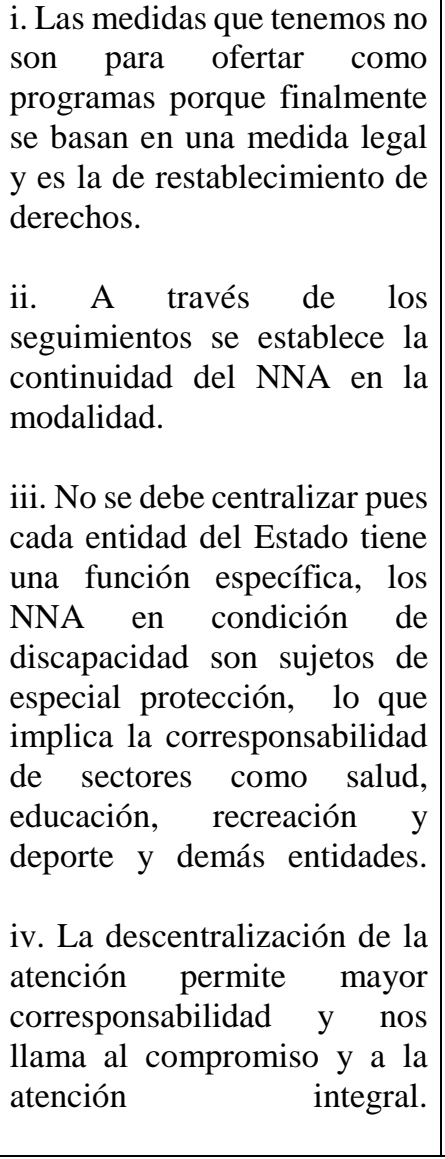 & $\begin{array}{l}\text { i. No tenemos de alguna } \\
\text { manera selección para el } \\
\text { ingreso de las familias, la } \\
\text { salud es un derecho y } \\
\text { como tal es universal. } \\
\text { ii. Las instituciones si } \\
\text { trabajan por los derechos y } \\
\text { deberes de las personas en } \\
\text { condición de discapacidad } \\
\text { pero casa una va por su } \\
\text { lado. a para en } \\
\text { iii. Se piensa mucho en } \\
\text { cuanto a los derechos que } \\
\text { las personas en condición } \\
\text { de discapacidad tienen la } \\
\text { posibilidad de tomar } \\
\text { decisiones, pero hay } \\
\text { algunas personas que no } \\
\text { tienen la capacidad. } \\
\text { iv. Las familias creen y lo } \\
\text { que siempre yo he dicho, } \\
\text { yo tengo una hija en } \\
\text { condición de discapacidad } \\
\text { pero el Estado no es el } \\
\text { culpable de que mi hija } \\
\text { haya nacido con condición }\end{array}$ & $\begin{array}{l}\text { i. La educación es un } \\
\text { derecho universal, para } \\
\text { todo aquel que quiera } \\
\text { hacer uso de ella. } \\
\text { ii. Todas las instituciones } \\
\text { deben intervenir en el tema } \\
\text { hablando específicamente } \\
\text { de los niños en condición } \\
\text { de discapacidad, sin } \\
\text { embargo, lo que se está } \\
\text { fallando es que no hay } \\
\text { articulaciones entre las } \\
\text { instituciones. } \\
\text { iii. Articulados podemos } \\
\text { darle como una cobertura a } \\
\text { más a la población que se } \\
\text { requiere y establecer con } \\
\text { claridad los tiempos o el } \\
\text { objetivo con claridad del } \\
\text { programa. } \\
\text { iv. Articularnos lo más } \\
\text { rápido posible con otras } \\
\text { entidades para el acceso } \\
\text { delas familias a los } \\
\text { diferentes programas y al } \\
\text { mismo tiempo, haciendo }\end{array}$ & $\begin{array}{l}\text { i. Debe haber una entidad } \\
\text { centralizada ya que la } \\
\text { asignación de recursos por parte } \\
\text { del Estado no se está utilizando } \\
\text { en debida forma. } \\
\text { ii. Es una costumbre que en } \\
\text { Colombia las decisiones } \\
\text { políticas están pasando por } \\
\text { encima del derecho. } \\
\text { iii. Que haya una ley para las } \\
\text { personas en condición de } \\
\text { discapacidad que los proteja ya } \\
\text { eso significa que hay un } \\
\text { enfoque diferencial que } \\
\text { efectivamente se están } \\
\text { protegiendo. } \\
\text { iv. El Estado siempre ha } \\
\text { intervenido a través de las } \\
\text { instituciones para proteger ese } \\
\text { núcleo de la sociedad } \\
\text { v. Se convierte en costumbre } \\
\text { porque lo que puede suceder es } \\
\text { que inicialmente vaya a solicitar } \\
\text { diferentes servicios y al ver que } \\
\text { eso la favorece tanto a ella como }\end{array}$ \\
\hline
\end{tabular}




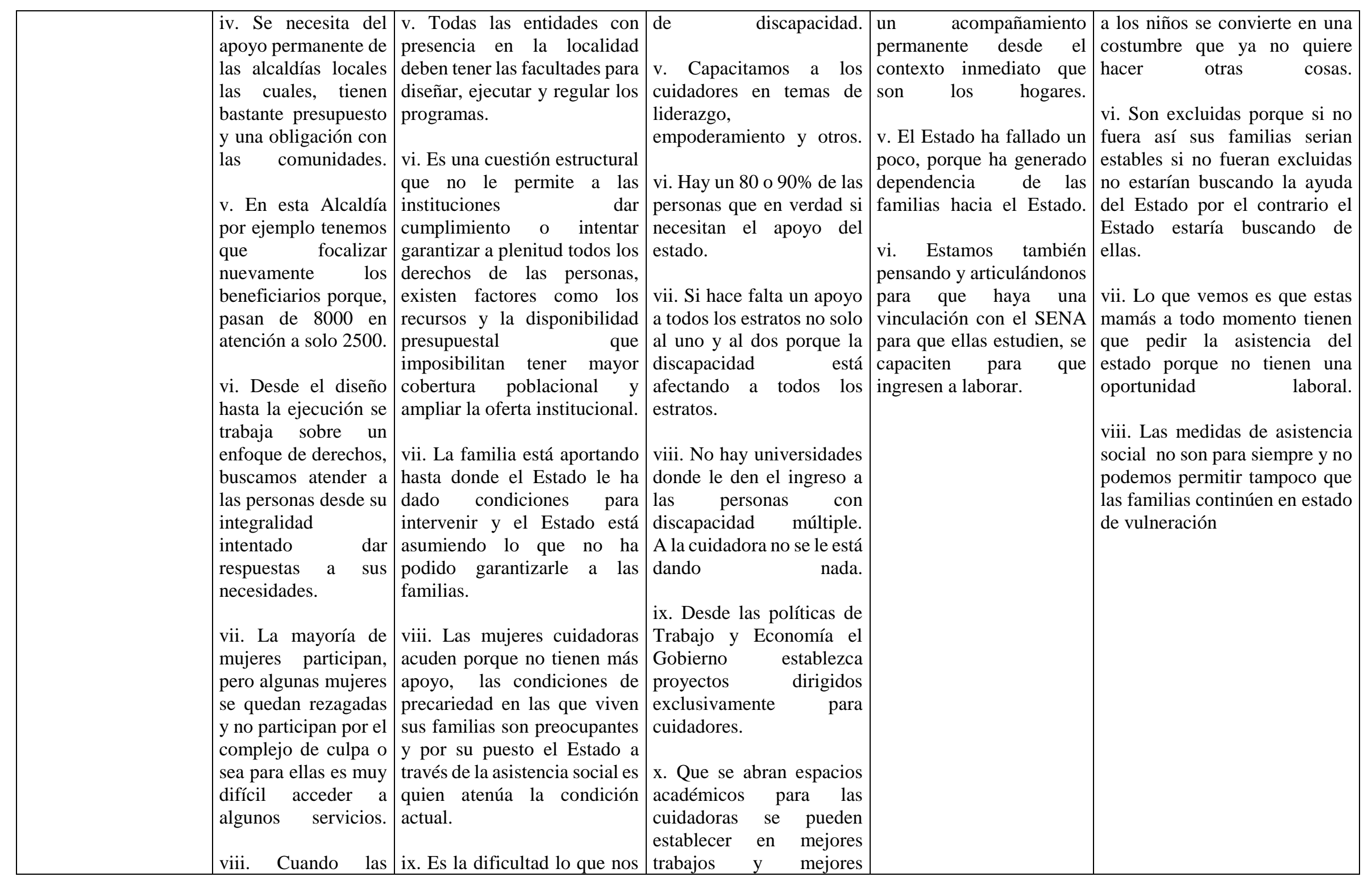




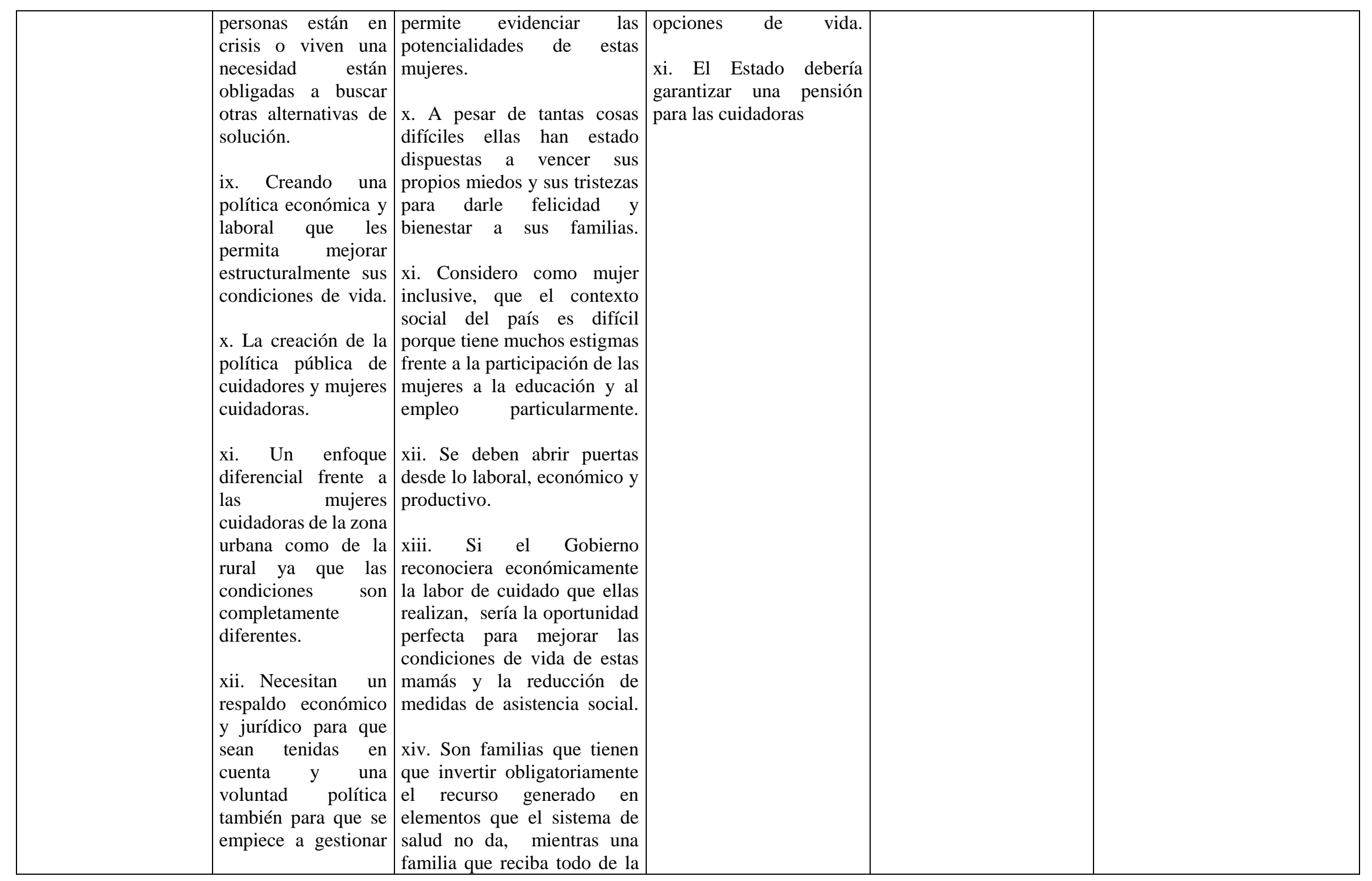




\begin{tabular}{|c|c|c|c|c|c|}
\hline & $\begin{array}{l}\text { la Política Pública } \\
\text { para ellas }\end{array}$ & $\begin{array}{l}\text { EPS para la rehabilitación y } \\
\text { tratamiento de su hijo puede } \\
\text { invertir en otros aspectos }\end{array}$ & & & \\
\hline SUJETO & $\begin{array}{l}\text { i. La intervención } \\
\text { con las familias y el } \\
\text { proceso de inclusión } \\
\text { de los niños y } \\
\text { jóvenes dentro de los } \\
\text { espacios de } \\
\text { participación social y } \\
\text { política. } \\
\text { ii. Dentro de nuestras } \\
\text { funciones y dentro de } \\
\text { nuestro proyecto está } \\
\text { la formación y el } \\
\text { empoderamiento de } \\
\text { las familias que son } \\
\text { cuidadoras o tutores. } \\
\text { iii. Se caracterizan } \\
\text { por el sentimiento de } \\
\text { culpa que casi } \\
\text { siempre no se quita, } \\
\text { no se retira de sus } \\
\text { mentes y sus } \\
\text { corazones. } \\
\text { iv. Participan más las } \\
\text { mujeres que los } \\
\text { hombres porque la } \\
\text { mayoría abandonan a } \\
\text { las esposas. } \\
\text { vPara los hombres es } \\
\text { muy difícil aceptar } \\
\text { que se tiene un niño } \\
\text { en condición de } \\
\text { discapacidad y se }\end{array}$ & $\begin{array}{l}\text { i. Nos falta fortalecer nuestro } \\
\text { conocimiento frente a la } \\
\text { política pública } \\
\text { discapacidad. } \\
\text { ii. Solo fue a partir del año } \\
\text { 2013 a través de una sentencia } \\
\text { de la Corte Constitucional en } \\
\text { donde nos exigen que se debe } \\
\text { realizar un acompañamiento } \\
\text { permanente desde el ámbito } \\
\text { jurídico y psicosocial. } \\
\text { iii. Vemos con preocupación } \\
\text { que los hombres no asumen la } \\
\text { labor de cuidado, abandonan } \\
\text { los hogares y constituyen } \\
\text { otros y además, se } \\
\text { desentienden por completo y } \\
\text { esto se presenta en las familias } \\
\text { relativamente más jóvenes } \\
\text { que las otras, no aportan } \\
\text { cuotas alimentarias y tampoco } \\
\text { generan vínculos afectivos } \\
\text { con los naños. } \\
\text { iv. No hay que desconocer que } \\
\text { habrá mamitas que se } \\
\text { acostumbren de alguna } \\
\text { manera a vivir de los subsidios } \\
\text { y los programas por sus } \\
\text { miedos y temores. } \\
\text { v. Es un rol protector escuchar } \\
\text { a estas mujeres es evidenciar }\end{array}$ & $\begin{array}{l}\text { i. Nos falta tener mayor } \\
\text { conocimiento en la } \\
\text { Política de Discapacidad y } \\
\text { como tal en todas las } \\
\text { discapacidades existentes. } \\
\text { ii. El Estado me ayuda } \\
\text { pero yo tengo que tener } \\
\text { una corresponsabilidad, es } \\
\text { lo que te digo, yo soy la } \\
\text { victima la pobrecita, dame } \\
\text { y el Estado me } \\
\text { acostumbro, nos } \\
\text { acostumbró hacer unas } \\
\text { familias asistencialistas y } \\
\text { que pobrecito este y no los } \\
\text { estamos formando a que } \\
\text { ellas pueden solas. } \\
\text { iii. Nos hace falta pensar, } \\
\text { porque la } \\
\text { desafortunadamente } \\
\text { también desde la política } \\
\text { pública de discapacidad no } \\
\text { se tienen en cuenta los } \\
\text { cuidadores, que estamos } \\
\text { mal interpretando la } \\
\text { política pero no se tiene en } \\
\text { cuenta los cuidadores. } \\
\text { iv. Se olvidaron que eran } \\
\text { mujeres y empiezan a vivir } \\
\text { es por el chico. } \\
\text { Se olvidan hasta de sus } \\
\text { demás hijos. }\end{array}$ & 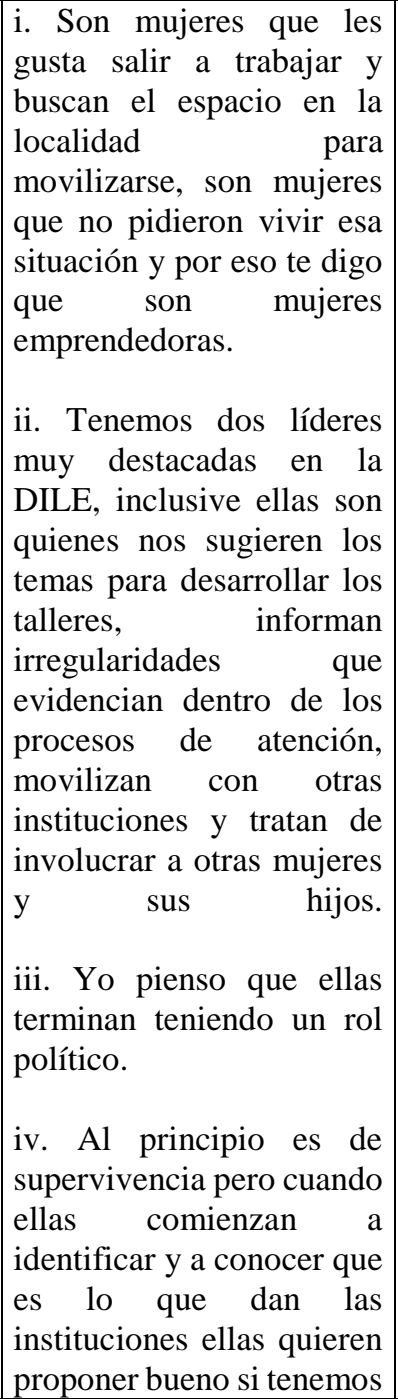 & $\begin{array}{l}\text { i. Las cuidadoras han venido } \\
\text { participando no solo como } \\
\text { comunidad dentro de los } \\
\text { procesos de participación y } \\
\text { veeduría sino como verdaderos } \\
\text { sujetos políticos y empoderados } \\
\text { que permite que su experiencia } \\
\text { sea escuchada al interior del } \\
\text { grupo. } \\
\text { ii. Es impajaralitable que ellas } \\
\text { acudan al Estado porque } \\
\text { requieren una ayuda. } \\
\text { iii. Algunas mujeres asisten } \\
\text { para ver de qué pueden } \\
\text { beneficiarse y no a ejercer } \\
\text { control o a dar proyecciones } \\
\text { sobre la discapacidad y el } \\
\text { cuidado. } \\
\text { iv. Desde que nacemos somos } \\
\text { personas políticas. } \\
\text { v. A nosotros los que nos } \\
\text { terminan formando o criando } \\
\text { como se dice popularmente son } \\
\text { nuestras madres. } \\
\text { vi. Las mujeres juegan un papel } \\
\text { político grandísimo en la } \\
\text { sociedad. a } \\
\text { vii. Ellas van a ejercer ese rol } \\
\text { político que ejercen en sus }\end{array}$ \\
\hline
\end{tabular}




\begin{tabular}{|c|c|c|c|c|c|}
\hline & $\begin{array}{l}\text { muestran resistentes } \\
\text { a aceptarlo. } \\
\text { vi. Hay mujeres en } \\
\text { familia extendida } \\
\text { donde el abuelo y la } \\
\text { abuela son los que } \\
\text { cuidan de estos } \\
\text { niños. } \\
\text { vii. Fue un instinto de } \\
\text { supervivencia que se } \\
\text { convirtió poco a poco } \\
\text { en una voz política } \\
\text { dentro de los } \\
\text { territorios, por amor } \\
\text { a sus hijos y al ver la } \\
\text { necesidad que los } \\
\text { apremia día a día, } \\
\text { ellas estuvieron } \\
\text { dispuestas a } \\
\text { enfrentar sus más } \\
\text { grandes temores, a } \\
\text { retomar la lectura, a } \\
\text { memorizar } \\
\text { jurisprudencias. } \\
\text { viii. Ellas están todo } \\
\text { el tiempo en función } \\
\text { de sus hijos }\end{array}$ & $\begin{array}{l}\text { desde la experiencia una } \\
\text { exigencia permanente por la } \\
\text { justicia y la equidad. } \\
\text { vi. Una mujer que no tiene o } \\
\text { tuvo acceso a educación, que } \\
\text { se encuentra sola, que no } \\
\text { cuenta con redes de apoyo y } \\
\text { que aparte deben responder } \\
\text { por uno o varios hijos que } \\
\text { presentan condiciones de } \\
\text { discapacidad o de cuidado } \\
\text { especial se encuentran } \\
\text { supremamente expuestas a la } \\
\text { exclusión y a la } \\
\text { discriminación. a vida } \\
\text { vii. Ellas viven finalmente en } \\
\text { función de sus hijos es decir, } \\
\text { ellas a veces ni siquiera } \\
\text { reconocen sus derechos y no } \\
\text { les interesa que sus } \\
\text { condiciones de vida } \\
\text { personales mejoren si la } \\
\text { calidad de vida de sus hijitos } \\
\text { sigue igual al a }\end{array}$ & $\begin{array}{l}\text { v. Otro porcentaje es más } \\
\text { porque me acostumbre a } \\
\text { que el estado me dé todo } \\
\text { por tener casa, carro y beca } \\
\text { y si el Estado me va a dar } \\
\text { mis } \$ 130.000 \text { pues } \\
\text { chévere rico y no tengo } \\
\text { que hacer nada. } \\
\text { vi. Tengo una hija en } \\
\text { condición de } \\
\text { discapacidad, ella tiene } \\
\text { una discapacidad múltiple } \\
\text { asociada a una epilepsia de } \\
\text { difícil manejo. } \\
\text { vii. Hay unas que si } \\
\text { ejercen un rol político } \\
\text { porque son buenas líderes, } \\
\text { son delas personas que } \\
\text { empiezan a buscar a nivel } \\
\text { local a nivel Distrital } \\
\text { donde puedo incluir a mi } \\
\text { hijo }\end{array}$ & $\begin{array}{l}\text { esto pero también } \\
\text { podemos tener esto por } \\
\text { esto y esto y argumentan } \\
\text { totalmente las necesidades } \\
\text { de su familia y la } \\
\text { obligación que tiene el } \\
\text { Estado. } \\
\text { v. El respaldo es de la } \\
\text { comunidad porque hay } \\
\text { muchas familias que } \\
\text { llegan a la oficina y } \\
\text { cuando nosotros hacíamos } \\
\text { la entrevista inicial le } \\
\text { preguntamos como supiste } \\
\text { del programa y dicen no es } \\
\text { que mi vecina vino acá y } \\
\text { mi vecina se enteró }\end{array}$ & $\begin{array}{l}\text { familias para exteriorizarlo } \\
\text { también en la sociedad }\end{array}$ \\
\hline
\end{tabular}




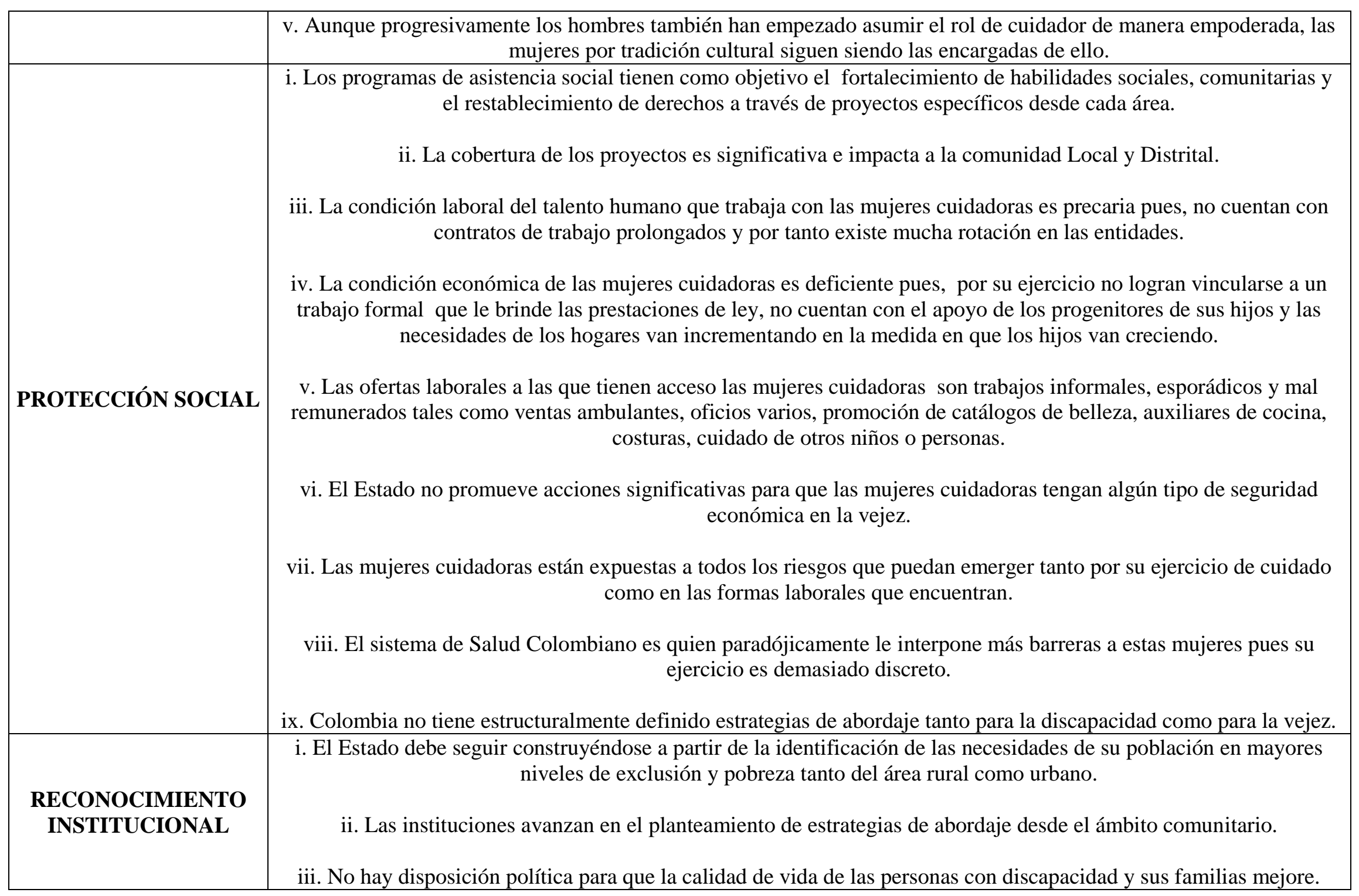




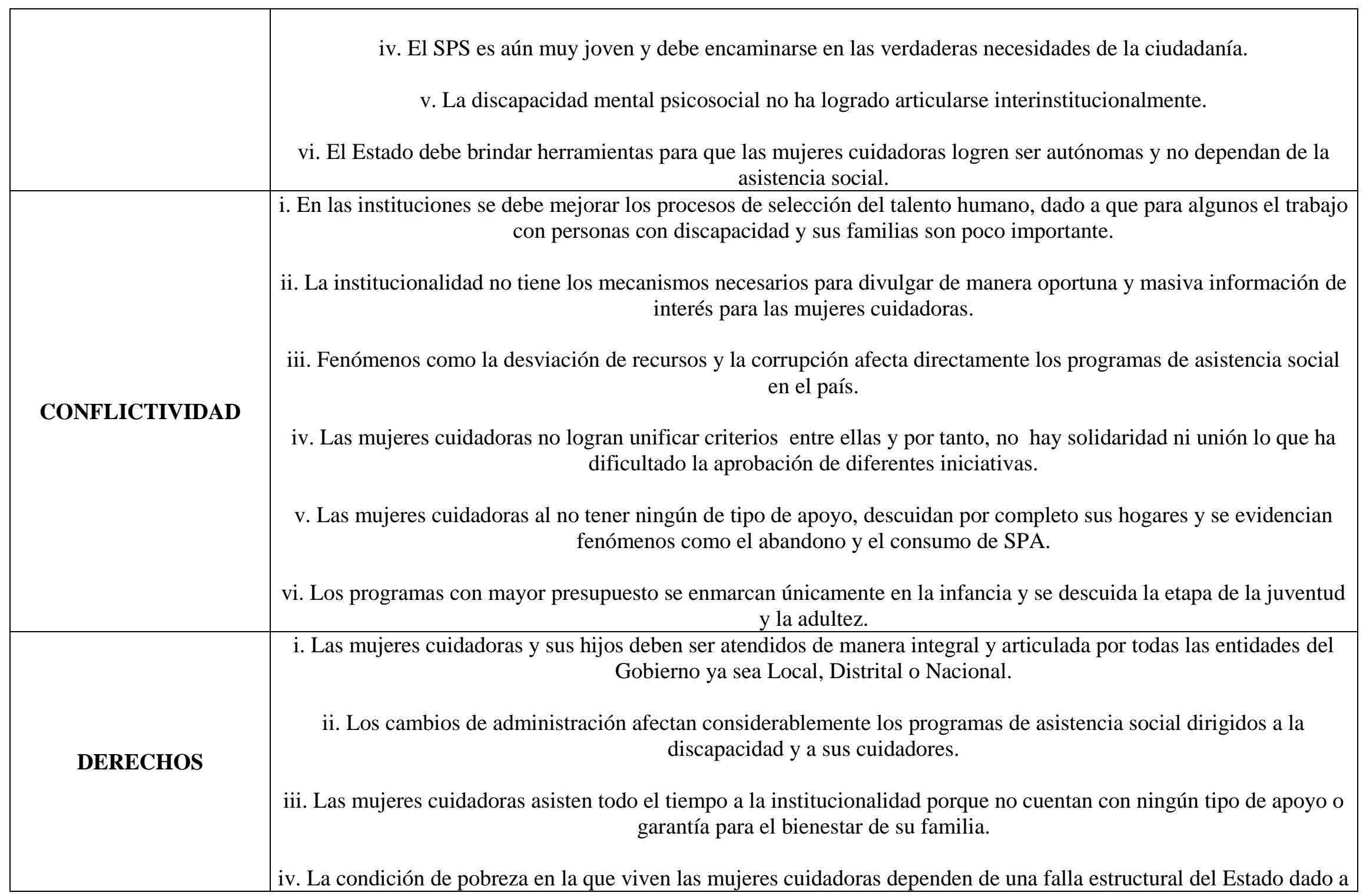




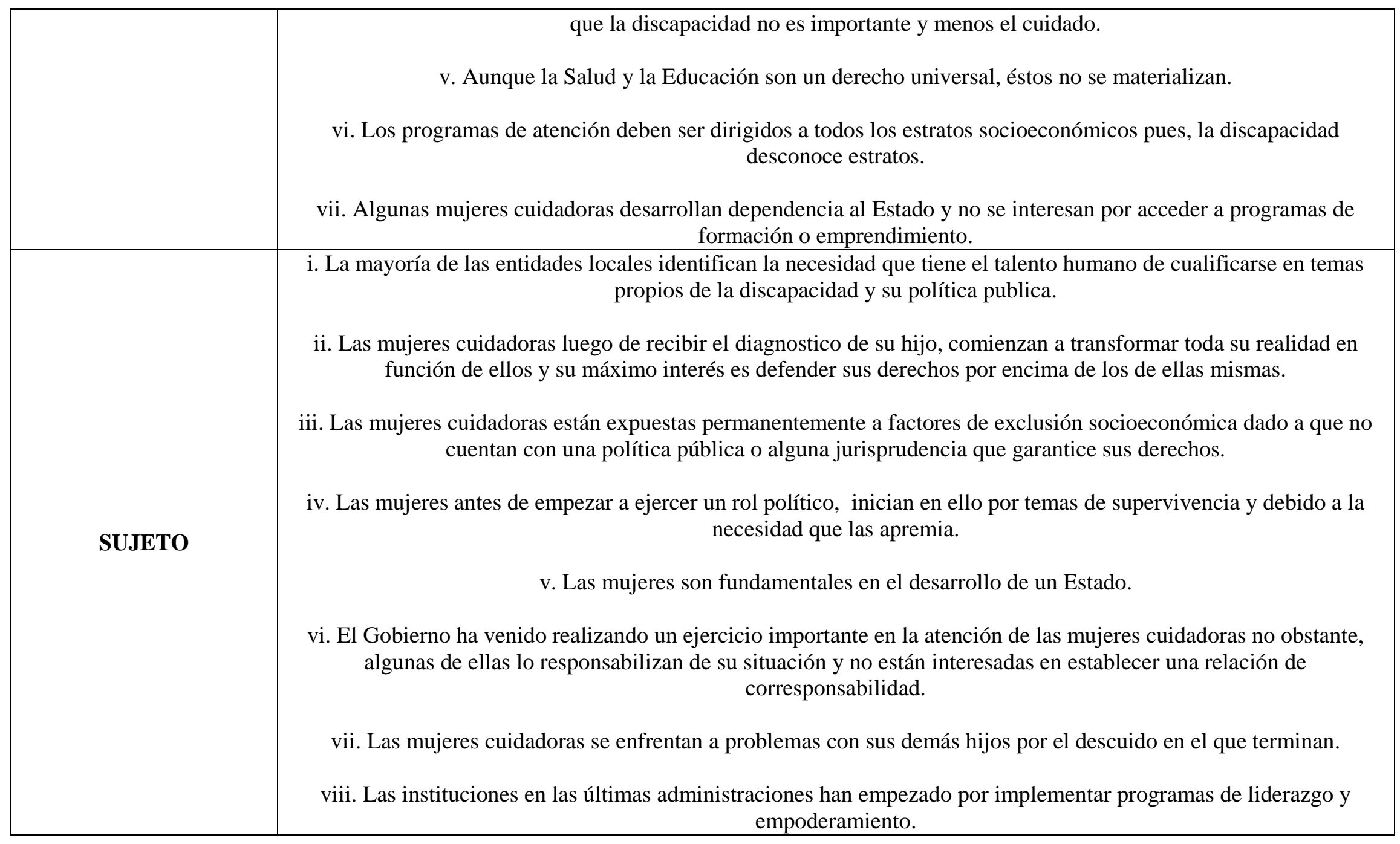




\section{Historias de Vida}

\subsection{Historia de Vida 1}

\section{Cuidadora 1}

Mi nombre es Cuidadora 1, nací el 17 Febrero de 1960 en el municipio de Nocaima, Cundinamarca y actualmente tengo 57 años. Mis padres son José Obdulio Macías y Celmira Bohórquez los cuales, viven todavía en la finca familiar y tienen avanzada edad. Recuerdo que fueron toda la vida luchadores, comprometidos con su familia, responsables, puedo decir que más que unos padres unos amigos con sus hijos. Tengo dos hermanos a parte de mí, que son Oscar Iván y José, la verdad no recuerdo las edades se únicamente que yo soy la del medio (Risa).

Crecí en una familia de agricultores y como verá era un trabajo muy duro y difícil, pero todos colaborábamos ya que ellos nos enseñaron a luchar para poder surgir en la vida. Recuerdo mucho esos tiempos porque hombre, la vida no era tan dura como es ahora, cuando uno es niño no le preocupa nada. Pero bueno.

Tuve una niñez muy cálida y considero que muy inocente también, estuve en casa casi hasta los nueve años ayudando a mi mamá con las labores de la cocina para los obreros que contrataba mi papá, los arreglos de la casa y ayudaba a sembrar y a desyerbar los pastos. No sé por qué pero en este momento no recuerdo muchas cosas de mi pasado, ya lo hablé con el médico y no me dijo así nada, solo que eso les pasaba a varias personas.

Voy a intentar, cuando tenía la edad de dos años nació mi hermano José quien llegó a alegrar nuestra familia ya que mi papá quería tener más hijos y ojala fueran hombres (Risa), en ese momento mi mamá ahora me comenta que sufrió mucho en el parto ya que ella tiene un tipo de sangre diferente al de mi papá y estuvo a punto casi de morir y por esa misma razón no pudieron tener más hijos.

Por esos años, se fue a vivir con nosotros un familiar de mi papá que le decíamos Chepito, quien era por así decirlo quien nos ayudó a criar pues mi viejo estaba todo el tiempo sembrando o arrancando yuca y bajando plátano. A ese señor le debo el cariño y amor con el que pude crecer hasta que ya estuve grande, fue un apoyo incondicional para mi mamá también, pues ella empezó a sufrir de reumatismo y las manos se le estaban hinchando y no podía hacer mucho esfuerzo. 
Él era quien nos ayudaba a vestir, nos preparaba las comidas y también nos enseñaba las labores del campo. Mi hermano mayor en cambio siempre fue desde muy pequeño muy distante conmigo y como era el consentido de papá no lo ponían hacer nada, yo no podía estar fuera de la habitación cuando estaban los amigos de mi papá en casa o cuando venía visita en general. En eso sí, nunca participé. Decían que mi lugar estaba era adentro.

Ya después de que nació , las cosas en la familia cambiaron mucho porque mi papá estaba todo el tiempo de mal genio y empezó a agredir a mi mamá, la golpeaba porque ella no hacía lo que él quería y realmente se transformó, en ese entonces no comprendía los motivos por los cuales había cambiado tanto con nosotros.

Cuando cumplí los seis años recuerdo que mi mamá lloraba mucho y como ella no era compinchera pues no tenía con quién desahogarse, le preguntaba una y varias veces qué era lo que le pasaba y me decía que eran cosas de grandes, lo cierto es que esa noche llegó mi padre y discutieron y cuando sentí fue que cerró la puerta de la pieza donde ellos dormían y corrí a ver qué pasaba y pues llevaba un costal con la ropa; ese momento fue muy difícil para mí porque no entendía nada. Ya fue cuando mi mamá nos dijo que él estaba con otra señora y se iba a vivir con ella. La verdad fue que eso no duró por mucho tiempo, como a los dos días volvió a la casa pero de esa "aventurilla" tengo otros cuatro medio hermanos, mi mamá prefirió no decir nada aunque ella sabía que él seguía con esa señora. En esa época uno como que no se daba cuenta de las cosas como pasa hoy en día.

Ya a la edad de los nueve años fue que entré a la escuela porque el familiar que vivía con nosotros "Chepito" convenció a mis papás para que me dejarán ir, fue muy difícil porque como era zona rural, las instituciones educativas quedaban muy lejos (más de una hora de camino) pero cuando uno quiere sobresalir debe vencer todos los obstáculos.

No tenía cuadernos, sólo una libretica que me regalaron y con esa empecé, no usaba uniforme en esa época y pues me echaban era un fiambre de yuca y papa para las onces. Mi hermano mayor si se dedicó fue a las vacas porque no le gustó el estudio y les decía a mis papás que eso era una perdedera de tiempo y que me sacaran porque en la casa había mucho que hacer.

A José lo criaba mientras tanto mi mamá y ya cuando tenía más edad si lo empezaron a mandar conmigo, nos íbamos solos y así mismo regresábamos, como podíamos hacíamos las tareas porque como mis padres fueron desletrados entonces no teníamos ayuda en casa. 
En la escuelita hice hasta quinto de primaria y luego tuve que esperar como dos años para que me inscribieran en la Normal Nacional de Nocaima, como esta si quedaba más retirado mi mamá habló con una de mis tías para que me arrendará un cuarto y me diera la comida y así poder terminar mis estudios.

Mi adolescencia si fue un poco más difícil porque prácticamente estaba era sola en el pueblo, estudiaba como hasta las dos de la tarde y luego le ayudaba a mi tía con los quehaceres de la casa pues, ella tenía era un negocito de costura. Los fines de semana o sea el viernes apenas salía cogía un carrito que era de don Víctor y me iba para la finca y pues allá si a seguir con el azadón y las chirtadas de café.

La verdad es que con mucho esfuerzo principalmente de mi mamá pude culminar el bachillerato y salir normalista, aunque si soy sincera de pronto por la falta de apoyo perdí tres veces quinto de bachillerato lo que ahora es decimo me parece, casi no lo puedo pasar y para completar en esa época Chepito falleció y eso para mí, fue catastrófico, su ausencia me sigue aun doliendo como la primera vez.

Como ve, salí ya muy adulta de la normal, nunca tuve novios o pretendientes, yo andaba en lo que andaba, no me fije en eso nunca, quizá por mi carácter también porque yo fui criada con amor pero también con temple, nunca me dejé ver la cara de nadie, me caracterizó de pronto por eso, porque yo nunca me ando con mojigaterías, si hay que decirle algo alguien se le dice y ya.

A veces salía por ahí con los compañeros del colegio y con dos amigas que tenía, era sano y lo cuidaban a uno, yo por lo general me quedaba sentada siempre porque no aprendí a bailar (Risa), mi tía igual era estricta y pues no podía hacerlo frecuentemente.

Al salir de la normal pensé en venirme para Bogotá pero la verdad fue que mi mamá me dijo que no hiciera eso, que buscara trabajo por ahí en la zona pero era muy difícil, lo de los palancasos en las empresas no es de ahora, eso siempre ha existido y además me decían que los profesores los contrataba directamente la Gobernación y pues, yo en ese entonces no había venido a Bogotá. Me quedé unos meses más en casa de mi tía ayudándole con los oficios de la casa y cuidando a mis tres primitos que en ese momento eran pequeños, les ayudaba hacer las tareas y estaba pendiente de ellos. Mi tía enviudó muy joven y tuvo que asumir la responsabilidad de esos niños, así que de ella recibí 
muchos consejos sobre los hombres y las relaciones. Pero uno no aprende hasta que no ensaya, creo yo, fue siempre mi apoyo emocional en esa época en la que de verdad me sentí tan sola y desprotegida.

Por un conocido de mi papá entré a trabajar después como de un año, me parece, en una escuela en la vereda Charco Largo, como usted podrá imaginarse no había más de 10 niños pero fue una experiencia muy buena, trabajar con las familias es muy enriquecedor. Allá tuve todas las prestaciones sociales y la opción de apoyar a mi vieja con un tratamiento médico aquí en Bogotá, para mejorar el dolor que sentía por el reumatismo.

En la escuela no más duré dos años porque llegó una profesora de aquí de Bogotá a ocupar la vacante; en ese momento que fue más o menos para el año 86 vine a hablar en la Gobernación y fue cuando me dijeron que eso era muy difícil además que como no era licenciada no podían ayudarme, la persona que me atendió me aconsejó venirme del todo porque según eso aquí había más oportunidades laborales. Me preocupé mucho porque el tratamiento de mi mamá estaba funcionando y pues ya me era muy difícil seguirle pagando el medico particular. Llegué a Nocaima muy desilusionada porque de verdad que el Gobierno a uno no le ayuda en nada, pero vaya uno a ser pillo a ver si no le dan el trabajo de una.

Esas cosas son las que en este momento yo ya no puedo aceptar.

Recuerdo la cara de frustración de mi mamá cuando le dije que no me habían dado la oportunidad de continuar en el trabajo. Me quedé como unos seis meses en la finca cuidando a mis viejos y ayudando a mi papá con una carga de café que iba a venderles a unos señores de Ocaña me parece. Durante ese tiempo conocí al señor Jacobo López quien era el hijo de un compadre de mi papá y estaba trabajando en una finca cercana, él me molestaba y me mandaba saludos, esas cosas que uno hace cuando quiere conquistar a alguien, usted me comprende; sin embargo, yo no le prestaba mucha atención porque me daba vergüenza con mi papá y al mismo tiempo me daba miedo porque como nunca había tenido novio o algo así.

En diciembre de ese año, hicimos un agasajo en casa y llegaron varios vecinos, la pasamos muy bonito y pues desde ahí empecé a salir con él y fue cuando me dijo que quería vivir conmigo y conformar una familia. Les conté a mis padres y ellos pues no me dijeron ni sí ni no únicamente que lo que yo decidiera además porque yo ya era adulta y sabía lo que hacía. 
La familia del señor tenía una casa cerca a la iglesia del pueblo y allá nos fuimos a vivir, de igual manera seguíamos trabajando en la vereda, al inicio como todo, estábamos muy contentos. Al año de habernos ido a vivir juntos quedé en embarazo de Carlos y mi familia estaba muy contenta porque era el primer nieto de mi parte. Dejé entonces de ir a la vereda a ayudar a mis padres y mi esposo me puso un negocito de cerveza para que estuviera en la casa y no tuviera problemas de salud, nos fue muy bien porque para que dice uno que no, la cervecita nos dio para comer y vivíamos bien. La verdad es que frente a los cursos que le hacen a uno cuando está embarazada allá solamente hay un centro de salud y eso no lo hacen como aquí en Bogotá. Siempre me dijeron que estaba bien y nada más, que estuviera pendiente a cualquier dolor pero yo nunca tuve algún malestar.

Carlos nació en el mes de Febrero de 1990 en el centro médico de Nocaima, fue parto natural y al parecer todo estaba bien, nos fuimos para la finca de mis padres para que mi mamá me cuidara en la dieta y todo muy tranquilo muy feliz. Cuando el niño cumplió los seis meses mi cuñada me dijo que le parecía extraño que Carlos no se sentara porque estaba dormido o calladito siempre. En un control médico le informé al doctor que nos atendió y me dijo que eso era normal y que los niños no todos eran iguales. Me fui tranquila ya para mi casa en el pueblo, seguí con el negocito todo lo más de normal.

Ya cuando era tiempo de que Carlos se empezara a sentar solito, me fijé en que no lo hacía por sí mismo sino que tenía que ser yo la que lo sostuviera, hablé con López y le comenté porque ya me estaba preocupando además que no balbuceaba ni nada, él me dijo que viniera a Bogotá y consultara con un médico particular para saber qué era lo que estaba pasando. Así fue como llegué al terminal en donde me estaba esperando una prima de mí esposo que vive todavía en Los Alpes, fuimos a un especialista que quedaba en Teusaquillo, lo examinó y le envío varios exámenes porque para él algo no estaba bien. Yo la verdad no me imaginé todo lo que resultaría.

En esos días estuve fue correr y correr, que vaya para un lado y para otro, la prima de mi esposo fue muy amable y me acompañó todo lo que pudo pues yo si ni idea de dónde quedaban las clínicas. Es que le cuento que Bogotá siempre ha sido un monstruo y como uno viene del campo, pues se siente más temerosos. Ya cuando me dieron los resultados, el médico me informó que Carlos tenía retardo mental y que a eso se debía su proceso de desarrollo, Dios santo!, en ese momento me quedé sin habla, veía únicamente que el medico hablaba pero yo la verdad quedé en paralizada. Susana fue quien estuvo al frente ese día, ella le preguntaba al médico una cosa y otra, pero pues es muy difícil de asimilar porque uno piensa por qué mi hijo y por qué yo, si siempre fui una persona buena. 
Me devolví para el pueblo, hablé con mi esposo y mis padres y pues le conté lo que había dicho el médico y todos los exámenes que tenía que hacerle a Carlos para saber si sus órganos estaban bien o si además de lo cognitivo prestaba alguna falencia en el cuerpecito. Viví casi unos seis meses en San Cristóbal con los familiares de mi esposo, le hace todo lo que dentro de mis posibilidades estuvo, el negocio de cerveza tuve que acabarlo porque no había quién lo atendiera, López era el que me mandaba la plata y pues estaba pendiente de la situación.

Siento que para él también fue muy difícil porque era su primer hijo y de todas maneras en el campo las cosas son muy diferentes que aquí, allá tener un niño con discapacidad era una maldición o un castigo para la familia por haber hecho algo mal; casi la verdad yo no estuve muy pendiente de él porque mi afán era el niño pero mi mamá, me decía que lo veía como achicopalado y que ya no compartía con los vecinos, quizá por miedo o por vergüenza de que le dijeran que él tenía un niño con discapacidad.

Pero yo no podría ser mentirosa y decir que él no me apoyó, estuvo siempre ahí con nosotros y no rechazo al niño ni nada de eso al contrario, jugaba con él y todo. Ya pues después de terminar los exámenes, me dijeron que todo a nivel de los órganos estaba bien, que solo es una cuestión cognitiva. Me devolví con Carlos y pues la verdad es que ya no podía trabajar igual que siempre, quien llevaba el sustento siempre era López y pues la verdad con eso nos bandeábamos para todo. Venia una vez al mes a Bogotá para el seguimiento médico pero la verdad, es que en la medida en que Carlos empezó a crecer su salud empeoraba o le salía otra cosa.

Hablamos con mi esposo y decidimos que lo mejor era venirnos para Bogotá, porque en el pueblo no me lo atendían y allá antes yo sentía que se burlaban del niño, el médico me dijo que él no podía tratarlo porque Carlos era especial y ni siquiera las vacunas se me las ponían porque no sé qué, una mil excusas. López lo que hizo fue hablar con varios conocidos para saber dónde podíamos arrendar aunque fuera una piecita para no incomodar a nadie y mirar también quién me podría acompañar para las citas y eso. Él me dijo que no se podría venir a vivir aquí porque quién cuidaba allá y de todas maneras él solo sabía trabajar en cosas el campo y aquí qué podría hacer. Entonces llegué con Carlos al barrio Roma a un apartamentico a penas para los dos y ya con el tiempo me fui soltando para coger los buses y eso; los conocidos me escribían en un papelito las direcciones y los buses que deba coger y así fue aprendiendo poco a poco.

Hasta ese momento Carlos estaba afiliado al seguro social y pues me lo atendían bien, no se demoraban en darme las citas n nada de eso; empecé a ver discriminación fue en el sector educativo porque en los jardines no me lo recibían por la discapacidad y pues, yo por eso era quien lo cuidaba 
todos los días, eso me hacía sentir muy mal porque a penas lo veían me decían "ay qué tiene", " no señora aquí discapacitados no cuidamos" fue muy duro darme cuenta de que para la gente era más importante una situación de salud más que las otras habilidades que podría desarrollar el niño.

La situación económica se puso muy complicada porque López no podía mandarme dinero suficiente y la verdad, hubieron varios días en los que yo no tuve con qué comer porque o tenia para los pasajes o para mi almuerzo, porque al niño de donde fuera le daba sus tres comiditas y la colada; mis padres pues me mandaban yuca y esas cosas y eso era de mucha ayuda para mí. Ya cuando Carlos cumplió los cuatro años, lo mandaron para terapia ocupacional y pues allí vi mucha evolución en él, se adaptaba más y lograba desarrollar algunas actividades.

A la edad de seis años, la dueña de un colegio pequeñito que queda todavía cerca a la casa en donde vivíamos, me lo aceptó y pues entró a grado kínder, ya las cosas eran un poco más llevaderas en la medida en que podía hacer varias diligencias mientras él estaba en el colegio. Las cosas con el señor López estuvieron creo yo, bien como por un año más. Después empecé fue a notar que él se fue como desentendiendo de todo, ya me llegaron unos rumores de que al parecer se estaba metiendo con una señora que había llegado de la costa y trabajaba como cuidandera de una finca. Mire de verdad que yo tenía tatas cosas por las cuales preocuparme que yo no le preste atención a eso, yo era la que lo llamaba y le decía cómo estaba el niño y así.

Un buen día si señora que me llamó, me dijo que él no podía continuar en una situación de estas y que lo perdonará pero que él se había enamorado de otra persona, yo lo único que le dije fue "No me haga esto" y empecé a llorar pero él me colgó. Le dije a la conocida mía que yo tenía que viajar de urgencia a Nocaima y que yo le cuadraba lo del arriendo en esos días, ella no me puso problema y me fui con mi niño.

Cuando llegué ya ni estaba por ahí, lo busqué por todo lado y no lo encontré, mi papá fue el que me comentó que mirara porque a él le había llegado el rumor de que un señor de la Vega había comprado la casa del pueblo; en fin, una tortura todo eso. Dejó prácticamente todo tirado, vendió, qué vendió, regaló todo lo que teníamos y se fue para la Costa. No me demoré nada allá porque Carlos empezó con mucha fiebre y pues, me devolví.

Desde ese momento mi vida cambió drásticamente, tuve que pedirle a la dueña de la casa un plazo para poder pagar servicios y todo porque pues yo sin trabajo y con todas las terapias y exámenes del niño. Yo afortunadamente conté con el apoyo de mis hermanos quienes me enviaban el dinero para pagar mientras yo lograba vincularme en algo. Mi mamá me dijo que me fuera para allá y que dejará 
de padecer con Carlos aquí en Bogotá, que allá como fuera un plato de comida no nos iba a hacer falta.

Lo pensé pero la verdad fue que pensé en la condición medica de Carlos, porque si uno supiera que allá me le den las terapias y los controles que él necesitaba pues sin dudarlo me hubiera devuelto, es más, yo creo que nunca me hubiera venido, pero la verdad es que pesó por encima de todo mi hijo. Lo iba a sacar del colegio porque no tenía para la mensualidad y de verdad que cuando las cosas son de Dios, la dueña del colegio, doña Mery me dijo que como yo era normalista, podía trabajar con ella, porque no tenía profesores en ese momento y los necesitaba con urgencia.

Yo acepté a pesar de que me pagaba menos del mínimo y tenía que trabajar de lunes a sábado pero como necesitaba el dinero, ni modo, allí aunque fuera estaba pendiente del niño. Los dueños de la casa de Roma vendieron y pues tuve que desocupar, una compañera del aseo me dijo que en Bosa San Bernardino habían varios apartamentos en arriendo y que no era costoso; fui a mirar y pues me vine a vivir a Bosa, me quedaba un poco retirado pero pues era mi única opción. En ese tiempo tuve que afiliarme a pensión y a la EPS y allí fue donde empezaron realmente las dificultades con salud, porque no me autorizaban los exámenes y no me daban las citas a tiempo.

Realmente considero que fue un error parar mí, empezar a pagar EPS porque sigo a la fecha teniendo muchos problemas para todo lo que requiere mi hijo.

Continué en ese trabajo hasta el año 2000, tiempo en el cual Carlos estaba estable y no requería digamos que de muchos exámenes y cosas de esas, me inscribí por intermedio de una conocida al subsidio de vivienda que iba a dar el gobierno y resulté favorecida, para mí fue una de las bendiciones más grandes que he tenido, debía esperar tres años para la entrega pero igual fue una maravilla.

A mediados de ese año, Carlos tuvo una crisis que nunca había tenido, lo llevé de urgencias a Compensar, lo dejaron varios días hospitalizado y me decían que debía esperar el resultado de los exámenes para saber qué era lo que estaba pensando; fue terrible, la dueña del colegio me llamaba todos los días y me decía que ella no le servía que fuera un día si y el otro no, no tenía quién me relevara para cambiarme y comer. Finalmente, me dieron el diagnóstico y me informaron que Carlos tenía esquizofrenia y que debía estar medicado todo el tiempo, ya no podría participar en el colegio y empezó un retroceso tenaz, cognitivamente no tiene mayor funcionalidad y ahora se agredía contra las paredes y yo no podía hacer nada.

Tuve que retirarme definitivamente de trabajar y dedicarme por completo a Carlos. Estando en la Clínica de la Paz conocí a una señora que su hijo también estaba hospitalizado y tenía unas condiciones similares, como los chicos están medicados todo el tiempo, empezamos habar 
frecuentemente y ella pues me invito a participar en una reunión que iban hacer en el Col de Kennedy para los niños con discapacidad, yo le respondí que yo no vivía allá y que no me iban a vincular al niño sin embargo, ella me insistió y fui, allá en la reunión hubo una doctora que fue quien nos dio toda la información sobre el proyecto de discapacidad, yo me acerqué y le informé que vivía en Bosa y ella me dio una hoja para que fuera a Bosa y me inscribieran en lo mismo.

Me presenté al Col de Bosa y allá me dijeron que había mucha gente y que tenía que quedar en lista de espera, llevé todos los papeles y nada que me llamaban. Vivimos un tiempo muy difícil en que ni siquiera tenía con qué darle de comer a mi hijo, estaba debiendo arriendo hacía más de cinco meses y pues la dueña de la casa ya me estaba pidiendo que le solucionará. La dueña del colegio me debía el último pago y por fin se condolió y me pagó, con eso le pague a la dueña de la casa y tuve para los buses para asistir a Compensar porque no me habían querido dar unos medicamentos para la esquizofrenia.

Me humillaron como nadie se puede imaginar, recuerdo que un tipo de esos que atienden me dijo "señora entienda que no hay el medicamento o es que también toca internarla", me dio tanta piedra que lloré hasta que me cansé, una señora se me acerco y me dijo que fuera a poner la queja en atención al ciudadano, fui hable allá y les comenté la situación de mi hijo y me hicieron una carta para que internamente se hiciera la autorización, recuerdo que la señora Patricia funcionaria de Compensar fue quien me ayudó como nadie. Ella me dijo, "mire por las buenas su merced no va a conseguir nada, váyase a la Defensoría del Pueblo y exponga su caso", me dio dirección y el nombre de un señor, allá fui y pues me ayudaron mucho por lo menos con los medicamentos que tanto me afanaban. El abogado me dijo que cualquier cosa le avisara y también me recomendó tomar el nombre de las personas que me atienden para ir poniendo las quejas y no permitir que esas situaciones de irrespeto se volvieran a presentar.

Con la ayuda de la señora Patricia empecé a participar en un programa de Compensar que se llama Enlaces, allí nos enseñaron cómo cuidar a los niños con condiciones mentales complejas, a estar pendientes de los signos de alerta frente alguna crisis pero también, fu un primer acercamiento al liderazgo pes, nos dieron unas charlas muy bonitas frente al valor que tenemos la cuidadoras, los derechos que tenemos y cómo empezar a exigirlos.

Ya fue cuando me dieron la casita y eso fue un descanso para mí, era menos el afán aunque sea para el arriendo. Mi madre vino a Bogotá y me ayudó un tiempo con el dinero para hacer mercado y para los pasajes, cuidaba a Carlos aunque, por el descontrol que maneja él tuve que pedirle a mi mamá que 
no lo cuidará más porque cuando yo llegaba, ella estaba asustada o inclusive golpeada. Carlos es de un manejo tenaz.

Fui otra vez al Col de Bosa y llevé una carta con todos los soportes de la situación, me vincularon a un comedor comunitario mientras se le liberaba un cupo, allá empecé a asistir pero, no pude volver porque Carlos se alteraba y se agredía contra las paredes y eso empezó también a asustar a las demás personas. El coordinador de ahí viendo la situación, me dio autorización para ir por los almuerzos y llevarlos a la casa. La verdad fue que no pude volver ni siquiera a eso, yo no podía dejarlo solo ni siquiera 10 minutos, cuando volvía estaba lleno de sangre porque se pegaba durísimo en la cabeza.

Tuve un problema terrible con una de las funcionarias del Col porque ella fue hacernos la visita y me insultó prácticamente, me dijo que había gente que necesitaba el comedor y que yo no hacía nada más si no tomar del pelo, que era irresponsable y que después no fuera a pedir más porque no me iban a tomar en cuenta. Me dio mal genio y yo la saqué de la casa, le dije que primero estudiara la situación y luego si juzgara.

Al poco tiempo me comuniqué con el abogado de la Defensoría del Pueblo para que me ayudará y pues como yo casi no tenía para los pasajes, él me dicto más o menos cómo podía hacer un derecho de petición por el teléfono y pues así, fue como pude presentar la petición para el proyecto de discapacidad nuevamente. Ya salí favorecida, asistí siempre que pude a los talleres y estuve al pendiente de todo. Puse también, un letrero en la casa para ayudar hacer tareas y desde ese entonces vivo de lo que la gente me paga por los trabajos.

En el proyecto 721 acabé de aprender temas de liderazgo y algunas rutas de atención como el Punto por la salud, me di cuenta además que todo funciona es con derechos de petición y a las malas, porque ni la EPS ni el ICBF ni en Integración Social había cabida para mi hijo, pese a que de verdad necesitábamos el apoyo. Creo que el Gobierno nos excluye porque los entes estatales creen que como nuestros hijos no le van a prestar ningún beneficio al Estado no nos tienen en cuenta y además, los encargados de crear leyes no conocen del dolor y necesidad del pueblo que los eligió.

Ya en las reuniones del 721 conocí a muchas más cuidadoras con unas situaciones parecidas a las mías y me informaron que en el ICBF daban un bono de $\$ 320.000$ que me servía mucho. Fui hice la solicitud y esa si se demoró solo como un mes y me dieron la oportunidad de ingresar sin embargo, hice un derecho de petición solicitándole al Bienestar el cupo para Carlos para una especie de Colegio en donde le podía dar manejo a la situación médica de él y al mismo tiempo podría seguir aprendiendo algo en medio de sus posibilidades. 
En el año 2012 empecé hacer el curso de agente de cambio dado por el hospital Pablo VI, ahí comprendí que si quería que la calidad de vida de mi hijo mejorara debía recorrer un camino pero con sabiduría para poder vencer todos los obstáculos o barreras mediante la ayuda de las pocas herramientas (políticas públicas) para poder hacer valer los derechos de mi hijo que en ocasiones son vulnerados por la sociedad.

Desde que hice el curso de Agente me invitaron a participar en el Consejo Local de Discapacidad pero la verdad es que primero, yo no creo en eso, solamente le dan a los que están en la rosca y yo para eso no sirvo y lo otro es que a mí no me queda tiempo porque estoy trabajando haciendo los encargos que me mandan hacer y cuando llega Carlos a eso de las 3 de la tarde debo estar dispuesta a recibirlo y estar con él.

Desde que he empezado a participar en diferentes cosas siempre que puedo le informo a varias cuidadoras de los proyectos y estoy siempre pendiente de las ofertas institucionales, ya muchas me conocen y me llaman para contarme sobre sus situaciones, yo les ayudo con los derechos de petición y o escritos y ellas me dan lo que puedan por ellos.

Finalmente, en Diciembre del año 2015 falleció mi padre querido en la finca, tuve que viajar y estar acompañando a mi mamá durante unos días, ya uno podría decir que esta acostumbrada al dolor y a las tristezas pero la verdad, todos los días lloro por su ausencia. Mi madre actualmente vive conmigo pero también es difícil, por su situación médica y a veces mis hermanos son los que cuidan de ella cuando las crisis de Carlos aumentan.

Tengo un mensaje muy importante y es que las cuidadoras tenemos que dar la lucha para que el Gobierno se dé cuenta de nuestras necesidades porque mire ahora con esta edad, no poder contar ni siquiera con una pensión porque yo coticé pero las semanas no me alcanzó y deje de trabajar no por conchuda sin pro fuerza mayor, porque isi nosotras no cuidamos de nuestras personas con discapacidad quién estaría dispuesta a protegerlos?. 


\subsection{Historia de Vida 2}

\section{Cuidadora 2}

Mi nombre es Cuidadora 2, nací en un pueblito que se llama Tibaná que queda en Boyacá el 30 de Julio de 1956, soy la segunda hija de ocho hermanos y la primer mujer de mis hermanos. Mi madre se llamaba (porque ya falleció lastimosamente) Ana Dolores Galindo y se dedicaba en ese momento a los oficios de la casa, el cuidado de mis dos hermanos varones y de mí (En ese entonces solo éramos los tres) y el trabajo de la tierra, mi padre por su parte se llama Miguel Arcángel Rodríguez quien se dedicaba a labrar la tierra también y a los negocios de venta de animales (Marranos, Gallinas y vacas). Vivimos en Boyacá hasta cuando yo cumplí siete años pues, mi padre en un viaje de negocios que hizo aquí a Bogotá fue reclutado por el ejército y se fue a prestar servicio, luego continuo en esa institución durante un tiempo y terminó en el INPEC donde era guardián.

En el momento en que nos trasladamos a Bogotá ya habían nacido mis otros cinco hermanos y no teníamos familia que pudiera darnos posada aquí sin embargo, mi padre insistió en que debíamos viajar para estar unidos como familia. Las condiciones económicas de la familia siempre fueron complicadas porque no teníamos muchas comodidades y entre mas nacían mis hermanos eran más escasos los recursos, la situación no mejoró con el ingreso de mi padre al ejercito porque como siempre viajaba a otras partes del país no nos enviaba el dinero o teníamos como contactarlo.

A los dos meses de nacido mi hermano menor y cuando vivíamos en el barrio San Vicente que queda cerca de Fátima, mi madre viajó a la ciudad de Cali a visitar a mi padre y a pedirle el dinero para poder comer y pagar el arriendo de la casa donde vivíamos pero, cuando mi madre llegó allá se dio cuenta que mi padre tenía otra mujer y es cuando se separan. Ese momento fue muy duro para mí y para mis hermanos mayores, creo que marcó grandemente nuestra familia, porque mi mamá empezó a trabajar en lo que le saliera podía ser ayudando en los restaurantes, haciendo aseo en las casas o vendiendo puerta a puerta diferentes alimentos (carne o frutas), en ese momento yo tuve que asumir el cuidado de todos mis hermanos, hacer de comer y arreglar la casa; ingresé a estudiar casi cuando tenía 9 años y no pude terminar la primaria porque mi mamá me sacó para poder atender el hogar, lo recuerdo con mucha rabia porque yo era una niña y no tenía por qué pagar por los actos de ellos dos aunque, siempre admiré a mi mamá porque pese a no conocer esta ciudad y no ser estudiada no nos dejó morir de hambre, fue una mujer verraca y no se dejó de nadie. 
La relación con mis hermanos ha sido siempre cercana aunque no muy afectiva porque cada uno desde muy pequeños vivió su propia vida y muchos recordamos lo duro que nos tocó en la vida y yo siento también que ellos no reconocen todo el sacrificio que tuve que hacer por ellos, sacrifique mi niñez por darles de comer y pareciera que no les importara.

Como estábamos siempre solos en casa, no tuvimos la oportunidad de participar en actividades del barrio o en cursos ofrecidos por la localidad, solamente sobrevivíamos con lo que teníamos. Nosotros no teníamos casi contacto con los vecinos porque mi mamá nos decía que no debíamos entrar a la casa de nadie y tampoco debíamos dejar entrar a gente extraña, a veces jugábamos con los demás niños pero era muy de vez en cuando y teníamos que asegurarnos que mi mamá no fuera llegando, porque mejor dicho nos daba una muendas terribles. Mi madre por su parte si tenía amigas en el barrio que nos echaban un ojito y le prestaban a ella cosas para cocinar o muchas veces comida, tuvimos muchos accidentes, se nos incendió la casa, se le volteó una olla de agua caliente a uno de mis hermanos y otro se envenenó con unas pepitas de un árbol que había en el patio y en esas ocasiones los vecinos fueron quienes nos ayudaron.

Mis hermanos varones se fueron algunos de la casa y los que se quedaron no me ayudaban con nada y mi mamá tampoco les exigía nada, decía que ellos si podían estudiar porque eran hombres y no tenían que hacer otras cosas en el tiempo libre, les compraba todos los cuadernos y los materiales que pedían en la escuela pero aun así, mis hermanos desertaron de la escuela y se dedicaron a otras cosas. Cuando yo vi que ellos no querían continuar en la escuela le rogué a mi mamá que me diera a mí la oportunidad y lo que me contestó era que yo tenía era que estar lavando y atendiendo la casa. Fue muy dura conmigo recibí de su parte muchos castigos físicos por las necedades de mis hermanos y las tareas que tenía que cumplir eran interminables, yo no sé cómo no me dio algo en la columna o en las manos (Risa), si los demás vieran, las cantidades de ropa que tenía que lavar, ni siquiera mis manos me alcanzaban, mejor dicho una tragedia.

No tuve quién me enseñará acerca del mundo y de las oportunidades que podría tener si estudiaba y me preparaba, es chistoso porque no sabía ni siquiera que el gobierno tenía programas y daba talleres para niños y jóvenes, sencillamente vivía encerrada en la casa. Siempre fui muy tímida, me sentí por mucho tiempo bruta y sin importancia, no valoré nunca mi aspecto físico y lo único que quería era salir de mi casa y vivir otra vida. 
En todo ese tiempo de infancia recuerdo que mi padre nunca se acercó a nosotros, nos abandonó por completo y no supimos de él por mucho tiempo. Su familia lo que hizo fue juzgar a mi madre por separarse de mi padre porque según ellos eso era un delito y un pecado imperdonable, es más, por no querer aceptar que mi papá había sido infiel decían que mi madre era una vagabunda porque tenía a otro hombre y nunca recibimos de ellos alguna ayuda o algo así, mis hermanos más pequeñitos los llevaron con ellos y vivieron las cosas más terribles que le pueda pasar a un niño.

Cuando ya fui un poco más grandecita las cosas no cambiaron para nada, por el contrario, mi madre estableció un nuevo matrimonio y tuvo otros tres hijos y también tuve que cuidarlos pero esta vez, mi padrastro le decía que tenía que ser considerada conmigo y que en vez de yo hacer las cosas de la casa que ella las hiciera pero a ella no se le dio nada. Definitivamente no pude continuar con los estudios a pesar de que era buena en las clases y las profesoras le daban buenas referencias a mi mamá sin embargo, ella continuaba con su posición de NOO. Es por ello que mis intereses también cambiaron, quería salir de esa casa, no quería ser la nana de nadie más y quería ser una persona libre y sin tener que hacer por los demás nada; me sentí siempre muy frustrada y con mucho rencor hacia mis padres y mi hermano el que era antes que yo, por aprovechados e injustos, no sentía apoyo de nadie y tampoco conocía la ciudad ni sabía hacer mayor cosa solo las labores del hogar pero aun así estaba dispuesta a marcharme y conseguir mis propias cosas.

Salí un día de mi casa a escondidas y le dije a una vecina amiga de mi mamá que yo quería buscar trabajo y ella me ayudó a entrar donde trabajaba, eso fue como a los 14 años, recuerdo que tuve que rogarle a mi mamá para que me diera el permiso y también lo solicitara ante la oficina de trabajo. Finalmente me dio el permiso, aunque me dijo que yo tenía que darle el dinero a ella que no me lo podía gastar porque si no, no me daba el permiso, y yo con tal de salir de la casa acepté. El trabajo era en una cadena de restaurantes y yo ayudaba como mesera y auxiliar de cocina, como no tenía ropa, recuerdo que fui durante más de dos meses con el vestido del uniforme del colegio en el que yo había estado, mis compañeros de trabajo se burlaban de mí porque parecía una pura niña. El dueño del restaurante un día me dijo que por qué con el pago no me compraba ropita y pues yo le dije eso a mi mamá que yo me compraba una muda de ropa y que el resto de dinero se lo dejaba a ella; ella aceptó pero me dijo que solo con el pago de un mes que de resto tenía que devolvérselo a ella. Así fue como compré un pantalón y una camisetica, ya por lo menos no me veía como una estudiante.

Empecé a relacionarme con mis compañeros del trabajo y ellos me decían que era importante que le dijera a mi mamá que yo era juiciosa y que debía darme un trato humano y no tan grosero y seco 
como siempre. No ganaba mucho pero era un ingreso para la casa, como era menor de edad solamente me pagaban lo del sueldo y me renovaban el contrato cada año, en ese momento no me habían mencionado nada de pensión y tampoco tenía forma de ahorrar, no iba al médico ni sacaba citas porque me descontaban el día entonces era mejor no ir.

Luego de un par de años nos trasladamos de casa - aunque en el mismo barrio - porque mi padrastro decidió abandonar el hogar y ya no podíamos pagar el arriendo en donde estábamos. Es así como conozco a mi esposo Cesar Augusto Gonzalez quien vivía al frente de mi casa y con quien empecé a compartir tiempo a escondidas. Al principio como todo romance, era un hombre maravilloso, se portaba muy tierno y especial conmigo y me propuso al poco tiempo que nos casáramos y viviéramos los dos lejos de nuestras familias; fue muy difícil poder contarle a mi mamá la situación con Cesar ya que yo era la que le ayudaba económicamente sin embargo, me decidí y le comente, ella se enojó mucho y recuerdo que me trato como mujer de la calle y me dijo que no estaría para el matrimonio y que hiciera lo que se me diera la gana.

Es por ello que me casé con Cesar y nos fuimos a los pocos días para Venezuela en donde nacieron mis dos hijos mayores; no me despedí de mi familia y tampoco tuve contacto con ellos durante cinco años, viviendo allí con la familia de mi esposo me fui dando cuenta que la vida era muy compleja, pues él empezó a cambiar, era agresivo y ya no estaba pendiente de nosotros; vivíamos en unas condiciones económicas terribles, muchas veces no tuve que darles de comer a mis hijos y tampoco tenía forma de conseguir trabajo ya que era un municipio muy lejano y la verdad es que yo luché porque la vida de mis hijos fuera completamente diferente a la mía, así que soporté humillaciones y las peores cosas para que ellos no se sintieran desprotegidos y abandonados.

Cuando vuelvo a Colombia mi matrimonio estaba en su peor momento, sentía que ya no podía seguir aguantando los malos tratos y las infidelidades a la que me sometía Cesar, recuerdo mucho que en una oportunidad llegó a la casa, discutimos y me golpeo. Me sentí completamente desprotegida, no había trabajado desde que nació mi hijo el mayor y el recibimiento de mi familia no fue el mejor, es más, mi madre me dejó quedar unos días en la nueva casa que había construido en Bosa pero me advirtió que solo era por un poco tiempo, ya que algunos de mis hermanos vivían aun allá. Luego de un año, Cesar me dejó y se fue a vivir unos días con una mujer que conoció, le rogué que no se fuera que lucháramos por el hogar pero no me hizo caso. 
Durante ese tiempo conviví con mi papá pero eso si fue peor, él vivía borracho y humillaba a mis hijos por todo, busqué empleo en un almacén como cajera y allá duré como una semana pues mi papá nos echó de la casa. Un buen día Cesar volvió y me dijo que lo volviéramos a intentar, yo acepte porque me di cuenta que yo no tenía la capacidad de asumir a mis hijos sin él; ah! Igual las cosas no cambiaron mucho yo sabía que él seguía teniendo mozas y simplemente lo ignoré, no me quería hacer más daño y quería que mis hijos volvieran a tener un hogar estable.

Luego de 10 años, es decir cuando yo ya tenía casi 45 años y mis hijos ya tenían 22 y 20 años, me enteré en un control médico que estaba nuevamente en embarazo, le pregunté al médico que si estaba seguro, ya que hacía muchos años me habían indicado que no podía tener más hijos por un problema hormonal y desde ese momento no planificaba y nada había pasado ; fue terrible para mí saber que iba a ser mamá otra vez pues primero, yo ya no tenía edad para criar y segundo, mis hijos ya eran muy grandes y no sabía cómo contarles.

En fin, mi hija Ángela nace por cesárea en el año 1999 pero resulta que se demoraron mucho en sacármela de tal forma que le faltó oxígeno en el cerebro y es por ello, que se le diagnostica al poco tiempo parálisis cerebral. Para nosotros fue muy difícil recibir esa noticia porque a pesar de la diferencias de edades, mis hijos estuvieron siempre al pendiente de nosotras y Cesar para que, él cambió mucho desde ese momento, es más, Ángela no conoce ese pasado tan doloroso de la familia. Me sentí la verdad, frustrada y culpable porque creía que había sido por mi edad y mi irresponsabilidad de no haber planificado; todos estuvimos muy ansiosos y angustiados porque no sabíamos a ciencia cierta qué consecuencias tenía la parálisis y qué podíamos hacer por la niña para que no tuviera muchas secuelas.

Para que, desde que la niña nació el sistema de salud ha respondido con todo, peleando pero sea logrado; como mi esposo ni yo pudimos vincularnos en trabajos con todas las prestaciones, hemos estado con el Sisben. El trato que he recibido no siempre ha sido el más adecuado ya que en muchas oportunidades los médicos me juzgaron por la condición de mi hija y hasta en ocasiones me dijeron que era mejor dejarla así, que ella no podía recuperarse.

Me llevó mucho tiempo entender la situación de salud de mi hija pero al mismo tiempo, me convencí que debía luchar por ella hasta donde fuera necesario. Desde bebé tuvo aparatos en las caderitas y en las piernas, le han hecho cuatro cirugías en total y en ellas han sido casi cuarenta procedimientos en cada una. 
En la medida en que ella fue creciendo, también fueron creciendo las dificultades de acceso a salud y a educación pues, cognitivamente Ángela comprende muy bien pero siempre me cerraban las puertas de la secretaria de educación. Me empecé a relacionar con otras mamás cuidadoras en el momento en que Ángela inició terapias con Caballos, allí mientras los niños estaban con los terapeutas, hablaba con las señoras que estaban y empezamos a contarnos los diagnósticos de los niños y también los motivos por los que habían nacido así. En ese momento me di cuenta que el problema con salud y educación eran permanentes pues no nos daban los medicamentos y las citas a tiempo, y entre más tiempo pasaba era peor, ahí sí que nos podíamos quedar esperando!; en el caso de mi hija, una señora me comentó cómo debía hacer para que la secretaria de educación le diera el cupo en lugar adecuado para sus condiciones y cercano a la casa.

Me hice muy cercana a la Señora Patricia que era una mamá que ya tenía mucha experiencia en todo lo de acceso a varias cosas, al principio no sabía cómo había hecho para que le dieran subsidios, las terapias, medicamentos y hasta enfermera. Sin embargo, me dio vergüenza preguntarle al principio cómo lo había conseguido, pero ella siempre estuvo muy pendiente de nosotras, me llamaba y en algunas oportunidades me acompañaba al Cadel y al Col. De esta manera fue que pude contactarme con una fundación deportiva en donde le daban a mi hija la oportunidad de aprender natación y también podía prepararse para participar en diferentes competencias. Esa fue la primer cosa en donde pude meter a la niña sin necesidad de pagar y que sabía que le servía para las terapias y los piececitos; porque a pesar de que mis hijos crecieron y conformaron familia su situación económica nunca ha sido buena, lo que no les ha permitido ayudarnos mucho y mi esposo (jum) antes me toca es cuidarlo también porque resultó con problemas cardiacos y de los pulmones y ya no trabaja en la litografía todo el tiempo, la única temporada que vemos más o menos dinero es en diciembre, pero eso la gente ya no compra ni regala almanaques ni esas cosas.

Teniendo en cuenta todo el apoyo que me dio la señora Patricia, yo empecé a asistir a las reuniones que ella organizaba en el salón comunal o en la casa de alguna mamá y allí las señoras que llevaban más tiempo nos compartían convocatorias, talleres, bonos y todo lo que la localidad estaba ofreciendo, nos decían los papeles que debíamos llevar y también nos pedían que replicáramos la información con otras mamás. Al principio me pareció muy chévere el espacio porque de alguna manera tenía con quién desahogarme. Nadie se imagina la carga emocional que uno tiene encima con todo porque no es solamente estar peleando con las eps y cuidar a la niña, sino también responder en el hogar, estar pendiente de la ropa, la losa y la comida. Si me preguntan yo no voy a una cita médica hace muchos 
años y la última vez que fui, fue porque me sentí rara como débil y fue cuando el médico me dijo que estaba empezando una anemia y que debía cuidarme pues, ni si quiera supe cuando me llegó la menopausia porque yo me la paso corriendo con todo.

En las reuniones escuchaba a varias mujeres que habían logrado conseguir muchas cosas para sus hijas e incluso participan en el consejo de discapacidad, la verdad es que nunca me sentí capaz de hacer eso porque yo no sé hablar en público, me pongo roja por todo y se me pierden hasta las palabras para hablar. Pero pues yo le hice que hijuemadre, he sido multiplicadora de mis conocimientos y siempre que veo a una mamita en esas condiciones les digo a dónde pueden ir.

No ha sido fácil ese proceso porque yo no tengo el tiempo suficiente para participar en todo y algunas señoras yo siento que se molestan porque dicen que las cosas no son solo para ellas. Yo comprendo que es muy importante involucrase con los doctores de la alcaldía y todo, pero no puedo triplicarme con todo. Por eso considero que las organizaciones así como de los desplazados para las mujeres cuidadoras es muy difícil de conseguir porque nosotras tenemos que estar pendientes de muchas cosas y al mismo tiempo, a nadie le importa la discapacidad ni cómo vivimos las familias. Siento inclusive que nos juzgan y como los niños no tienen las mismas capacidades que los demás, entonces no le quieren invertir en alguien que no va poder trabajar o estudiar. He escuchado de varias doctoras que nosotras estamos acostumbradas a tender la mano y a mendigar, que no queremos trabajar y que estamos acostumbradas a que todo nos lo dé el gobierno y yo me pregunto, será que es fácil cuidar a un niño que no se puede valer por sí mismo, exigirle a la eps todo el tiempo que nos de las citas y todo lo que requieren los niños, que nos den empleo, aun sabiendo que no puedo cumplir un horario por más que quiera y que no cuento con la experiencia y el estudio requerido.

Yo estoy segura que si los niños tuvieran un cuidador permanente pagado por el gobierno, nosotras no tendríamos que quedarnos en la casa y podríamos trabajar en lo que sea. Además que hay señoras que yo conozco que son solitas y tienen varios hijos en condición de discapacidad, sus maridos las abandonaron por otras mujeres y yo digo quién las ayuda a ellas.

A mi particularmente me han cerrado una cantidad de veces las puertas pues porque dicen que la discapacidad de mi hija no es severa y que yo cuento con esposo e hijos que deben dar el apoyo económico. Y yo comprendo eso, pero como obligo yo a mi esposo a que me de dinero cuando él toda la vida ha sido complicado conmigo y a mis hijos peor, porque si no les nace yo no puedo hacer nada. Siempre pienso que la única responsable de la niña soy yo y lo que yo no haga por ella, nadie 
lo va hacer, yo quiero que ella estudie y que sea alguien en la vida para que no la humillen como a mí.

También reconozco que hay señoras conchudas que tienen buenos maridos y quien les cuide a los niños, pero prefieren quedarse en la casa, por eso es que yo digo que todas las entidades deberían hacer visitas y corroborar que de verdad uno necesite las ayudas y quitárselas a las que no. Eso sí me ha parecido muy cansón porque no todas las mujeres han sido receptivas y en cambio siempre tienen una disculpa, a varias les comento mi experiencia y que yo siento que no soy una líder reconocida pero que con pequeñas acciones se va viendo el cambio.

Desde el grupo de madres hemos construido varios proyectos tanto de emprendimiento como de cursos y otros recreativos, los hemos pasado a la alcaldía pero siempre nos lo rechazan porque según ellos, no contamos con los espacios para ejecutar ni con la experiencia y que ya el tema de discapacidad está siendo trabajado por otras personas. No es nada fácil este tema, hasta organizando una fiesta del día de los niños, le rogamos a la gente de las tiendas y de los almacenes para que nos apoyen con algo y usted cree! No nos dan mayor cosa y las actividades que programan las instituciones son para niños sin discapacidad.

Yo veo con admiración la labor que cumplimos y que pese a la discriminación que recibimos tanto en la calle como en las casas, estamos sacando adelante a los niños y hemos podido acceder a varios servicios para ellos. Siento también que hay compañeras que tienen un potencial político muy importante, que se hacen escuchar y que tienen aportes importantes; no sé si yo cumpla con ese liderazgo pero lo intento y lo hago también porque me cansé que todo el mundo quiera pasar por encima de uno y uno nunca dice nada. Me canse, ya digo las cosas como son y yo creo que también es la edad porque a mí ya no importa nada, el que se quiera quedar que se quede y que no pues la puerta está abierta.

En este momento veo con mucha preocupación la situación actual de los niños y las cuidadoras porque los alcaldes que entran tanto a Bogotá como a las localidades traen sus propios proyectos y lo que logramos avanzar se cae en un momento, tenemos tantas dificultades económicas y familiares pero al gobierno no le interesan, no hay oportunidades de vivienda propia o trabajo digno que valoren nuestra situación actual pero que no nos exploten con altas jornadas laborales y pagos mínimos. Hemos vuelto a una época en la que la comunidad y los vecinos somos los que logramos apoyarnos los unos a los 
otros, ya los hijos y los esposos no están interesados en apoyar la casa y en ocasiones las mismas mamás abandonan los niños.

Nos sentimos excluidas en esta lucha diaria que libramos porque las políticas son incompletas es decir, solo hay para mujeres o para discapacidad pero no para mujeres que se dedican al cuidado de niños con discapacidad que contamos con situaciones muy particulares y que en ningún lado podemos recibir respuesta completa sino solo por partes y eso es una exclusión finalmente, que nos digan siempre usted no puede ser atendida aquí porque no su marido no la golpea y no se está separando, no la podemos atender aquí porque las opciones de trabajo son esas y no hay permisos para nadie, no le cuidamos el niño porque aquí no es un jardín o colegio de inclusión, no hay acceso porque la discapacidad del niño no es profunda o severa, no porque usted tiene subsidio de vivienda y así siempre encuentran un pero y no se dan a la tarea de revisar las situaciones de cada una de las mujeres. Además que pelear en contra de lo que para todo el mundo está bien, o sea de que las mujeres deben estar sometidas siempre y deben estar cuidando a los hijos y al marido y saber que la familia de uno le dé la espalda porque uno decide participar de otros espacios o irse del hogar por los malos tratos es difícil; cambiarle a la gente la idea de que somos mujeres valientes, entregadas, inteligentes, líderes y gestoras es el trabajo más duro, más que el de cuidar a los niños. Y es allí en donde encuentra uno más barreras, porque siempre hay juicios y la gente siempre los saca a flote y eso mismo se enseña de generación en generación. Crecemos ignorantes y pendejos a la realidad del país.

Mi meta en un par de años es poder sacar a mi hija profesional y consolidarme como una gran líder en Bosa, aprender a hablar en público y a tener los argumentos jurídicos para poder defender mis derechos y los derechos de las demás mamás. Ojala que podamos tener una política como la discapacidad y podamos exigir mayores cosas. 


\subsection{Historia de Vida 3}

\section{Cuidadora 3}

Yo me llamo Cuidadora 3, soy del Municipio de Albania que queda en Santander y nací el 15 de Septiembre de 1960. Desde ahí comienza mi vida, una vida que ha estado marcada por la pobreza y las dificultades. Mis padres fueron Juvenal Castellanos Barrantes y Pastora Vargas de Castellanos, desafortunadamente ya no puedo contar con su presencia para que me ayuden a soportar tantas cosas que lo entristecen a uno; ellos, pues se dedicaban a labrar la tierra (sembraban yuca, café y plátano) y tenían uno que otro animal, como vacas y gallinas. Mis padres fueron personas muy trabajadoras y nobles, así los recuerdo yo. Nunca los vi en malos pasos y estuvieron pendientes de mí.

Tuve 9 hermanos, cinco hombres y cuatro mujeres, yo fui la cuarta hija. Con ellos me crie y tuvimos buena relación, como todo hermano nos peleábamos pero nos contentábamos rápido. La situación económica de la casa era difícil porque no teníamos muchos lujos, vivíamos con lo necesario, no nos faltó la comida pero yo sí creo que nos faltó el afecto de nuestros padres porque ellos, siempre estaban en los quehaceres de la finca. Recuerdo como algo feo, el hecho que mi papá golpeaba a mi mamá cada vez que se emborrachaba y pues nosotros no nos podíamos meter porque éramos pequeños. La verdad, mis hermanos hombres siempre eran los que tenían las mejores cosas, digamos que les servían mejores presas de pollo y a ellos si nos los obligaban a cocinar ni nada de eso, ellos solo se dedicaban a ayudar a mi papá con la tierra y nada más; en cambio a mi mamá y a mis hermanas si nos tocaba estar pegadas al fogón todo el día, cocinar para los obreros y cuidar a los hermanos que iban naciendo.

Mi niñez fue bonita, no tuvimos mayores dificultades ni nada eso, tenía muchas cosas por las cuales estar bien, mi familia y mi casa. En ese tiempo no pude estudiar, porque a uno no lo mandaba a eso, yo me dedique fue ayudar a mi mamá y a cocinar. Ahh tiempos... hasta ahora es que uno se da cuenta lo importante que es estudiar, porque ahí si nadie se la montaría a uno. También creo que esas tradiciones y las formas en que la familia lo cría a uno, no eran las mejores porque solo tenían oportunidades los hombres, como si ellos fueran los que frentearan las cosas.

Viví en Albania hasta que ya era grandecita, como hasta los 13 años y de ahí me fui a vivir con una de mis hermanas mayores al municipio de Puente Nacional, ella ya se acaba de casar y construyó un ranchito en el pueblo, en donde me fui a vivir. Allá la verdad trabajé en lo que usted no se imagina, lavando ropas, arreglando las casas de las personas que trabajaban en la alcaldía, en varias panaderías y restaurantes de ahí; allá había forma de estudiar pero por la edad que tenía no me aceptaron en la normal del pueblo sin embargo, una de la señoras con las que trabajaba era profesora de una escuela de una de las veredas, ella en las tardes me empezó a enseñar a leer y escribir. 
Durante esos años, pues como toda niña, me empezó la necesidad de tener un noviecito (Risa) imagínese eso, pero la profesora me decía que tuviera siempre mucho cuidado, que las personas a veces no eran buenas y que lo que tenía que hacer era salir de allá y buscar mejores oportunidades para mi vida.

Fue una juventud difícil creo yo, porque tuve que trabajar todo el tiempo y el dinero que ganaba era para ayudarle a mi hermana y mandarle a mis papás, sentía que los muchachos se burlaban de mi porque no era bonita y a parte no tenía ni con qué vestirme. Sin embargo, ahora que estoy grande creo que fue un buen tiempo, aprendí a leer y escribir y a prepararme para la vida, las mejores cosas son dolorosas y se consiguen con esfuerzo, siempre lo he dicho!.

Pero pues, a mí la vida me ha tratado duro y por eso aprendí a defenderme y a no importar si tengo que pelear o lo que sea para que me respeten y me garanticen mis derechos. Esto es difícil para mí, porque no me gusta recordar pero, a la edad de 16 años fui violada por un tipo que vivía en el pueblo, yo trabaja en su casa haciendo aseo, no tuve a quién contarle, ni quién me ayudará porque por ahí dicen en pueblo pequeño, infierno grande. No quería que me juzgaran ni que me señalaran cada vez que pasará por las calles. Me sentí miserable e intente quitarme la vida, me tome un poco de pastas que encontré, pero ya ve, no me pasó nada.

Desde esa edad me vine para Bogotá, a mirar que iba hacer con mi vida, porque no quería que eso me volviera a pasar. Llegué a donde una conocida de la señora Tulia, una viejita a la que yo le ayudaba a lavar la ropa y arreglarle la casa.

Doña consuelo me acogió en su casa, ella vivía con su esposo y tres hijos que ya eran jovencitos y casi no se la pasaban en la casa, estuve por un tiempo viviendo en una piecita con estrictamente lo necesario, ella me buscó trabajo en un almacén de telas y allá trabajaba desde las 7 hasta las 11 . Como era menor de edad pues, solo me pagaban un sueldito pero no me pagaban salud ni para lo de eso de la pensión.

Estando en ese almacén conocí al papá de mis hijos, me fui a vivir con él siendo muy pequeña, hasta ahora cumplía 18 años. Tuve mi primer hijo y nos ubicamos en el Amparo en la localidad de Kennedy, todo era color de rosa hasta ese momento, pues Jairo no había sido nunca agresivo ni desobligado con nosotros, digamos que teníamos un hogar bonito porque yo me dedicaba a la casa y él manejaba una tracto mula y se la pasaba viajando todo el tiempo. Desde que ocurrió la violación en mi vida, mi actitud cambió completamente, ya no me dejaba de nadie ni de nada. Digamos señorita, que a mí me tocó aprender a ser verraca y a sacar las uñas. Sin embargo, nunca hubo una mala palabra entre 
nosotros y nos ayudábamos mutuamente, él me comentaba sus problemas en la empresa y yo pues como mujer le daba uno que otro consejo.

Cuando mi hijo mayor cumplió 4 años empecé a ver que Jairo estaba raro como que empezó a cambiar, ahora si era que no paraba en la casa, no llamaba y las cosas en la casa se empezaron a acabar, el mercado y las cosas de aseo. Fue cuando viajé con mi hijo hasta el Tolima para buscarlo porque nadie me daba razón y fue cuando me enteré que tenía un hogar en Honda. Uy Dios! Creo que en ese momento se me desplomo la vida, no sabía qué hacer ni para dónde coger, mejor dicho quedé en ceros.

Volví a Bogotá y me vi obligada a entregar la casa porque no tenía con que seguir pagando el arriendo, pensé en volver a mi tierra con mis hermanos pero no tenía ni para el pasaje, y hablé con mi madre y ella lo que me dijo era que lo buscara y lo perdonara, que esas cosas eran normal en los hombres y por eso no había que acabar con el hogar. Fue terrible...finalmente, la que me recibió fue la señora Consuelo quien me conocía y sabía que yo no era una mala mujer y que no merecía pasar por esa situación.

Fue una época muy dura porque no tenía quién cuidará de mi hijo y menos quién nos diera de comer, ese tipo ni siquiera una llamada para el niño, ni nada. Al cabo de unos días empecé a sentirme mal y me imaginé que era por toda la angustia y la desesperación que estaba pasando, cuando fui por urgencias y resulta que estaba era embarazada, mejor dicho!, fue terminar de completar todo. Doña Consuelo, me dijo que podía quedarme ahí durante el embarazo pero que no podía darle de comer a más bocas.

Me sentí tan humillada en ese momento, que empecé a sacar fuerzas de donde no tuve, conseguí empleo en un piqueteadero y metí al niño al jardín o bueno en ese entonces no se les decía jardín sino donde una vecina, como pude fui saliendo adelante aunque sea para darle de comer al niño y para comer yo. Asistí a todos los cursos esos que le hacen a uno cuando está embarazada, a las citas médicas, mejor dicho, yo sabía que tenía que estar pendiente de la salud del bebé. En esos día Jairo volvió me pidió perdón, yo la verdad lo perdoné no por mí sino por los niños, porque por más que intentaba conseguir trabajo, no era fácil y menos sabiendo que era madre cabeza de familia.

Ya me fui de la casa de la señora Consuelo, le agradecí porque ella hizo por mí, lo que ni familia hizo, ella nunca estuvo de acuerdo en que volviera con Jairo pero nunca me dijo tampoco nada, ella lo único que decía es, es su vida, piense bien las cosas. Ahí fue cuando nos vinimos a vivir aquí a Bosa, en una casita en obra negra que Jairo había conseguido en el sector de San José. 
Cuando nace mi hijo Jose, que eso fue el 15 de Octubre de 1990, el médico, después de la cesárea, porque no pudo nacer por parto normal, me dice que el niño estaba bien de salud y que debía quedarme ese día en observación.

Me fui para la casa con el niño y después de los tres meses, Jose me convulsionó, casi me muero ese día, empezó a botar como babasa por la boca y se pudo morado, lo llevé rápido a urgencias y allá me lo dejaron como una semana, nunca me dieron razón de nada, ya el ultimo día fue que el médico me dijo que el bebé había tenido una convulsión que le había afectado el cerebro y que eso significaba que Jose me iba a quedar como un mongólico toda la vida.

Fue una noticia muy difícil de asimilar, es más, yo a veces pienso que estoy es como soñando y que mi hijo no está mal. Llamé a Jairo y le comenté lo que había dicho el médico y le dije que se viniera rápido para Bogotá porque yo no sabía qué hacer. Llegó como a los dos días como de la costa me parece, fue algo muy difícil de describir, es algo que uno no quiere para nadie y yo lo que hacía era preguntarme qué había pasado, que había sido mi culpa porque como yo me enteré que estaba embarazada cuando ya estaba el bebé grande.

Desde ese momento para mí, la peor institución que puede existir es salud, porque imagínese usted! Nunca detectaron nada malo y después que se le diagnostico la discapacidad a Jose fue como, no hay nada que hacer, esperar a que se muera porque ese niño no sobrevive. Solo Dios sabe lo que yo tuve que vivir durante esos primeros años.

Nunca supe a ciencia cierta de qué dependió la enfermedad del niño pero me cansé de esperar que alguien me dijera, así que yo me iba al San Pedro Claver que era el de ese entonces noche y día, y hablaba con el uno y con el otro para que las citas y los exámenes del niño me los dieran pronto. Una odisea siempre, encontré en ese camino gente comprometida, para que me pongo a decirle que no, pero también encontré gente muy cruel, que calentaban el puesto y se ganaban la plata fácil.

Durante los primeros dos años, Jairo estuvo pendiente de todo sin embargo, cuando Jose cumplió los dos años y medio me dijo que se iba, que él ya no podía vivir conmigo ni con mis hijos. Me imagino que se fue para Honda, la verdad es que mi vida murió cuando le diagnosticaron la discapacidad al muchacho, yo me desentendí de todo; así que nunca más supe de él, a veces los familiares que me encuentro por la calle me dicen que lo vieron, pero yo no me quedo a que me digan mayor cosa. 
Lo único bueno que me dejó fue la casa, porque imagínese (Risa), aunque en este tiempo le puse abogado para que no aparezca de la noche a la mañana y me la quite.

Desde ahí mi vida cambió radicalmente, yo tenía mi carácter, pero el abandono y la situación de salud de mi hijo me permitieron no volverme a dejar de nadie ni de nada, creo que eso me ha caracterizado y hay muchas personas a las que no les caigo bien porque yo no sirvo para guardarme las cosas, si a alguien le tengo que decir algo se lo digo en la cara.

Recuerdo que en los primeros años de Jose, conocí a una funcionaria que trabajaba en el centro médico de Pablo VI - Doña Mireya y ella fue quien me fue como direccionado en todo lo de discapacidad.

En el hospital recién empezaban a trabajar con la política pública y éramos pocas personas, nos reuníamos inicialmente los miércoles y allá le explicaban a uno cómo se caracterizaban las enfermedades y cómo realizar cuidados básicos desde la casa. Ya después, la señora me inscribió al COL lo que ahora se le conoce como Integración Social para recibir mercado, pues mi situación siempre fue de pobreza porque yo no podía trabajar por estar pendiente de Jose y no recibía dinero de nadie más.

Luego en el Hospital, empezaron a dar cursos de la política pública y yo pues me inscribía y participaba mucho, el grupo de cuidadores se fue agrandando y las instituciones también empezaron como a participar en eso y desde ahí yo tomaba nota de los nombres y cargos para poder acercarme y solicitarles información acerca de los servicios que ofrecían.

Ya después me ofrecieron ser parte de un proyecto del hospital que era de Salud Pública para dictar talleres a cuidadores en toda la localidad y visitar las casas, fue una experiencia muy buena para mí porque desde ese trabajo es donde uno conoce la realidad de la gente; me vi identificada con muchas señoras que al igual que yo eran solas y tenían que responder por todo. Recuerdo que fue el primer trabajo que tuve después de chiquita, no me pagaban mucho pero eso me servía para servicios y todo.

Poco a poco fui como sorteando mi suerte con una cosa o con otra, nunca me quedé quieta o esperando que alguien me diera algo por pesar, le conseguí el cupo a mi hijo mayor en un colegio que era muy bueno pero era de religiosas y era costoso, me ofrecía de voluntaria para talleres de padres de familia y fue donde me lancé al consejo de padres. El rendimiento de él no era muy bueno porque desafortunadamente yo no podía apoyarle en las tareas porque escasamente sabía escribir y leer, los profesores le daban clases de refuerzo escolar porque sabían de esta situación. Los fines de semana me iban con ellos dos para el colegio y hacía el aseo y arreglaba la cafetería. 
Fue cuando la comunidad ya empezó a reconocerme y cualquier cosa ellos me buscaban para que les diera orientación de cómo hacer para entrar al COL y cuando les salía ellos me daban cualquier cosa \$2.000 o 5.000 pesos así me ganaba el sustento, aunque fuera para la sopa de los niños. Durante los primeros 10 años de Jose el acompañamiento que recibí por parte de salud fue muy difícil, no lograba conseguir citas, terapias y exámenes y pues él retrocedía con el paso del tiempo, buscaba la oficina de atención al ciudadano para que me brindarán ayuda pero uno no sabía que era peor, recibí regaños y malos tratos y pues, desafortunadamente como ellos son los que tienen el sartén por el mango pero ellos también empezaron a conocerme, yo no me dejaba la verdad, creo que hasta llegue a ser grosera porque yo no les estaba pidiendo limosna.

En ese tiempo conocí a un abogado de la Defensoría del Pueblo quien fue el que me asesoraba y me empezó hacer los derechos de petición y las tutelas y así fue más fácil que me le dieran los tratamientos al muchacho.

En todos los talleres que asistía nos daban iniciativas para conformar grupos de cuidadores de niños en condición de discapacidad, inclusive un médico de la San Rafael me decía " su merced debería crear una fundación o algo que les ayude porque todos los días vienen más familias como ustedes y eso les puede beneficiar si se unen" pero, uno sin saber nada pues le da como miedo y yo le decía algunos conocidos y me decían que no les quedaba el tiempo y que eso era perder más de lo que se iba a ganar.

No siempre tuve para ir a la Defensoría del Pueblo, porque me quedaba muy lejos y no tenía ni para pasajes ni con quién dejar a los niños, entonces le saqué copias a los documentos que ya había radicado en el seguro y los tomaba como ejemplo para hacer los que necesitara.

Fue así como empecé de alguna manera a ganarme con esfuerzo los servicios que necesitaba mi muchacho, me pelie absolutamente todo, desde los pañales hasta la enfermera domiciliaria. En los hospitales y en donde me tocaba ir, conocí personas que al igual que yo estaban peleando con las EPS para los pañales, las ayudas técnicas y las citas a especialistas, así que yo los asesoraba conforme a lo que yo había hecho, nos poníamos citas para hacer los documentos en un café internet y los acompañaba a las EPS para radicar los documentos y pues, en eso ganaba para sostener a mis hijos, no era mucho pero nos servía.

Por lo anterior, en el año 2004 tomé la decisión junto con dos amigas de conformar nuestra propia fundación, para apoyar no solo a nuestros niños y jóvenes en condición de discapacidad sino a los cuidadores que en su mayoría son mujeres cabeza de familia con condiciones económicas precarias. $\mathrm{Al}$ inicio fue algo complicado conseguir donaciones tanto de dinero como en especie, pues necesitaba 
para brindar talleres de emprendimiento, ayuda y empoderamiento así como alfabetización de personas cuidadoras, sin embargo, se abrió un espacio importante dentro de la localidad que fue el Consejo Local de Discapacidad en donde empecé a participar y también a socializar el quehacer de la fundación, allí fue muy importante asistir porque conocí muchas personas de la comunidad y de las instituciones que aportaban de alguna manera a la política de discapacidad.

Durante ese año la Alcaldía Local me brindó ayuda logística para adecuar una parte de la fundación y al mismo tiempo hicimos como una alianza en donde nosotras brindábamos capacitaciones y ellos nos daban refrigerios y los materiales.

Más o menos al finalizar ese tiempo, personalmente me tocó vivir un nuevo golpe emocional ya que, uno de mis hermanos me llamó y me informa que los Paramilitares y la gente esa mala habían llegado al pueblo y que si podía recibir a mis sobrinos porque él ya no los podía tener allá, tuvieron amenazas de esos tipos y le advirtieron a mi hermano que los iban a reclutar.

Recuerdo que mis dos muchachos -Lorena y Sebastián- llegaron al terminal como a mediados de Noviembre, yo fui por ellos y estaban muy tristes porque no se querían venir para Bogotá y menos sin mi hermano y la mamá. Nos acomodamos como pudimos (Deme un momento por favor, aun me duele mucho hablar de eso).

(Sollozo) ya..., a los dos días mi mamá me llamó y me dijo que mi hermano y la esposa habían sido asesinados, fue muy difícil porque no pudimos viajar al entierro, por más que intenté buscar la plata para los pasajes no alcancé a recoger todo. He tenido desde entonces a mis sobrinos a cargo, la niña si validó aquí el Bachillerato y está trabajando en un almacén de carros y pues el muchacho sino quiso y es ayudante de carga en Abastos.

Sentí que ya no podía con más cosas y pensé en acabar con la fundación porque no era tampoco mucho lo que tenía, era más el desgaste de estar llamando a la comunidad y haciendo y haciendo para nada. De todas maneras como en el 2007, la Alcaldía me ayudó con un proyecto que ellos tenían, involucraron la fundación para que fuera como más efectivo la participación de la comunidad y ya desde ahí la fundación se consolidó mejor y hubo mayor presencia de niños en condición de discapacidad y las familias como tal .

En el 2009 fallece mi madre y tuve que traer a mi papá a vivir conmigo porque no se podía quedar allá solo y pues por su estado de salud, mis otros hermanos no me ayudaron nunca con nada y pues, como podía me rebuscaba con amigos y vecinos, en tutelé a Integración Social y logré afiliarlo a lo de vejez. 
Si se fija, a mi todo me ha tocado lucharlo y he tenido que hacerme cargo de todo, sin tener prácticamente nada porque eso es lo que yo les peleo a las instituciones, que porque yo le gané a salud todo pero pues de eso no vivimos y para qué está el Estado si no es para garantizar derechos a sus ciudadanos.

Ya en el año 2014 fui elegida por el Consejo Local de Discapacidad como Representante de las Cuidadoras ante el Consejo Distrital y como representante local de la discapacidad múltiple. En esos espacios la verdad no le he caído muy bien a la gente porque yo no soy muy letrada pero no soy pendeja, inclusive la Consejera Distrital me mandó a sacar en una oportunidad de una sesión porque ellos quieren hacer las cosas como les place y no como la gente realmente necesita. Siento que he conocido mucho y que por lo mismo ya mi trabajo vale al igual que le pagan a cualquier persona por hacer sus quehaceres. Ahora no puedo participar en todos los talleres que hay en las instituciones porque estoy muy ocupada con el Consejo y la Fundación, cuando yo puedo asisto y sino voy cuando puedo. Igual a mí no me pueden obligar a asistir, porque siempre es con la amenazadera que lo van a sacar del 721 y del Hogar Gestor.

Actualmente, estoy trabajando con unos extranjeros que realizan voluntariado para mejorar la misión de la fundación y mirar que otras cosas podemos hacer desde allí.

Considero que las mujeres pero especialmente las cuidadoras, son excluidas social e institucionalmente porque no son tomadas como sujetos de derechos sino porque piensan que nos están haciendo un favor al garantizar los derechos de nuestros muchachos, nadie da trabajo porque saben que no podemos estar tiempo completo, el pago es algo miserable y la verdad es que la Localidad y el Distrito no ofrecen garantías para las personas en pobreza extrema.

Las mujeres cuidadoras de Bosa no estamos tampoco trabajando para el mismo lado, conozco a muchas mujeres que prefieren quedarse en la casa sometidas que participar en las actividades del consejo y esa es un gran debilidad que se evidencia, porque no hay unión. No les gusta que yo les hable de frente entonces eso hace que ellas formen otros grupos y no fortalezcan los que ya existen. Le hace falta mucho a la discapacidad para ser incluida dentro de la sociedad pero más le falta a los cuidadores que no comprenden la importancia de su trabajo.

Estoy convencida que a las mujeres cuidadoras nos hace falta un reconocimiento jurídico es decir, que sea un hecho la Política Publica de personas cuidadoras y que haya un espacio importante para las mujeres que somos quienes más ejercemos ese rol; de igual manera, que el Ministerio del Trabajo implemente acciones para evitar la discriminación de nosotras, que fortalezca a las microempresas y que genere garantías para que podamos estar en el trabajo con nuestros hijos, es decir que en las 
empresas hayan espacios adecuados para que podamos ir con ellos y así podamos cumplir con los objetivos.

Como líder la comunidad creo que el logro más importante es que el Distrito tenga una representante Cuidadora de la localidad de Bosa, porque puedo dar a conocer las necesidades que tenemos y el sentir que llevamos como cuidadoras de la discapacidad, la vejez y las víctimas del conflicto armado. Finalmente, las metas que tengo en este momento es consolidar la fundación a nivel Distrital en donde no solo las mujeres de Bosa puedan participar, sino la de todas las localidades de Bogotá a tal punto que podamos ser reconocidas a nivel nacional así como los sindicatos y creo que una de las más importantes, impulsar la política pública de personas cuidadoras para que se nos garanticen unos derechos y tener las herramientas legales para hacerlos cumplir. 


\subsection{Historia de Vida 4}

Cuidadora 4

Cuidadora 4 es mi nombre, nací en Bogotá el 24 de Diciembre de 1972 y actualmente tengo 44 años, vivo en la Localidad de Bosa desde hace más de 22 años, edad actual de mi hijo mayor.

Nací y pasé la mayor parte de mi vida en una familia de origen Huilense, residentes del Barrio La Fragua en la Localidad de Puente Aranda; Mis padres son Silvestre Rios Herrera e Inés Amezquita quienes se dedicaban al comercio informal de marroquinería en el Barrio Restrepo, tengo tres hermanos llamados Giovanny, Alex y Luz que tienen más o menos 40,38 y 34 años.

Hice parte de una familia humilde y de creencias católicas, con normas establecidas por mi padre quien era el jefe de hogar, vivíamos en arriendo en una casa de un piso la cual, se encontraba en obra negra y no contaba al inicio con todos los servicios públicos. Como fui la primera hija del matrimonio, gocé de muchas bendiciones, amor y mucha atención, participé en varios eventos organizados en el centro comercial en donde trabajaban mis padres y obtuve distinciones tanto por los disfraces como por los reinados que se hacían allí. De verdad que fue la mejor etapa de mi vida, conté siempre con el afecto y la sabiduría de mi padre especialmente, que hoy en día extraño tanto.

Ingresé a los tres años al Jardín comunal del barrio, en donde compartí con varias personas e inicié mi proceso académico como tal, me caracterizaba por ser tímida y pero muy solidaria con los compañeros. El barrio era muy diferente a lo que en este momento uno puede observar, como llevaba poco tiempo de fundado, las condiciones de las vías, acceso a servicios públicos y los temas de economía eran complejos y las familias eran numerosas y no tenían mayores ingresos.

Un año después de haber ingresado al jardín, nació mi hermano Guillermo y pues las cosas en mi casa empezaron a cambiar, ya pues no teníamos como el mismo dinero para sortear las necesidades y el negocio de mis papás no estaba dejando ganancias. Sin embargo, fueron épocas divertidas y pues la llegada de mi hermano me permitió empezar a conocer el sentido de la solidaridad pues, cuando uno tiene que compartir muchas cosas aprende a no ser egoísta.

Como el barrio no tenía colegios cercanos, no fue posible que mis papás pudieran meterme a temprana edad a estudiar en la escuela, pues porque a ellos les quedaba muy complicado estar llevándome y trayéndome con el negocio y todo lo que eso acarreaba, a parte del cuidado de mi hermano y que no 
tenían cómo pagar un privado. Cuando iba a cumplir los seis años nació mi hermano Alex y debí estar en casa con mi mamá todo el tiempo para cuidarle la dieta y cuidar a mi hermano Giovanny, no conocí nunca tíos o abuelos por parte de mis papás así que el único apoyo que ellos tenían era yo. Aprendí desde esa edad a arreglar la casa y hacer varias tareas en el hogar, también empecé a cocinar pues, mi padre la verdad nunca ayudó con las tareas del hogar.

Por todo eso, hasta los siete años de edad fue que pude entrar al colegio Público Alquería de la Fragua a cursar grado primero, me caractericé por ser una niña comprometida y juiciosa con todas las actividades. Cuando cumplí los 10 años nació mi última hermana, no la esperábamos la verdad porque la familia ya era numerosa, pero ha sido una gran bendición en nuestras vidas y trajo mucha unión entre mis padres.

En este colegio como decía, inicié y terminé mi Bachillerato, de esa etapa de mi vida tengo bonitos recuerdos porque fue cuando tuve mi familia completa y pude tener la oportunidad de estudiar y salir adelante. Ya a los 19 años empecé a trabajar por turnos en un almacén de ropa en el sector de Chapinero, no me ganaba ni siquiera el mínimo, no recuerdo bien cuánto me pagaban el día, pero pues no pague salud ni pensión tampoco. Entrar a la esfera laboral fue muy difícil porque no estaba digamos acostumbrada a tener que servirle a la gente y rogarle prácticamente para que comprara y poder mantener el trabajo, sabia de todas maneras que debía soportar a veces malos tratos de los dueños del local porque podía comprarme lo que yo necesitaba con ese dinero y ayudarle a mis papás para la comida y servicios, además que mi papá siempre nos decía que él más estudio no nos podía dar y que debíamos defendernos como pudiéramos, sin embargo mira que mi papá no lo decía por mala gente e inclusive todo el tiempo recuerdo sus palabras, busquen un buen hombre y buenas mujeres que los ayuden a salir adelante y que nunca les vayan a levantar la mano, ni que ustedes vayan a ser atravesados. (Risa) ahora que uno es mamá se da cuenta del valor de los consejos.

Ya cuando recién iba a cumplir los 20 años conocí al papá de mis dos hijos mayores, un hombre maravilloso, cariñoso y dedicado a mi inicialmente y a los niños también, él era policía e iba frecuentemente por donde yo trabajaba y pues empezamos a hablar y como pues, empieza toda relación, que un detalle e invitaciones a salir; como yo no había tenido una relación de noviazgo con nadie, me daba miedo que me hiciera daño o que en mi casa no les gustará porque yo conocía el carácter de ellos, sin embargo me dijo varias veces que yo le gustaba entonces pues tomé la decisión de ennoviarme, nos fuimos a vivir al poco tiempo en Kennedy, no me fui bien de mi casa, mis papás 
no estaban de acuerdo con que las cosas fueran tan rápido y porque ellos decían que había algo en él que no les gustaba.

Sabía que él se estaba separando, que tenía hijos pero pues cuando uno es sardino y está enamorado esas cosas como que uno no le para bolas, mi papá dejó de hablarme y pues no fue como un apoyo para mí, quedé en embarazo y la verdad es que mientras yo conviví con él todo era maravilloso, vivíamos bien, nos queríamos y a nosotras nada nos faltaba. Me incomodaba si, el hecho que estuviera tanto tiempo por fuera de la casa pero era su trabajo, ya cuando nació la niña mi padre pues cedió un poco, la consentía y la cuidaba pero conmigo nada volvió a ser igual, nunca me preguntaba cómo estaba o cómo sentía.

Con la familia de él creo que había buena relación sin embargo, ellos tampoco estaban de acuerdo con que mi esposo estableciera una nueva relación así que siempre estuvimos alejados de ellos. Dos años después, nace mi hijo mayor y pues llegué a creer que tenía la mejor vida de todas, nos trasteamos para Bosa La Estación en donde vivíamos en arriendo pero, teníamos la casa para nosotros solos, no volví a trabajar porque me dediqué al hogar y al cuidado de mis hijos, fui muy feliz de verdad.

Pero como lo bueno dura poco, él fue víctima del conflicto armado de nuestro país y fue brutalmente asesinado hace 21 años, desde ahí mi vida cambió radicalmente, tuve que salir a buscar trabajo nuevamente y ahora con más años y sin mayor experiencia, busqué a mis padres porque no tenía quién más me ayudará, no me sentí nada cómoda volver, además porque la sensación que tenía era de "yo se lo advertí" pero no tenía más opciones, no volví a saber mayor cosa de los abuelos de los niños y tampoco quise ponerme como en esa posición de ir a pelear por la pensión o algo, la verdad ahora me arrepiento!, porque la pensión la tiene la primera esposa y los hijos y yo no reclamé nada porque no sabía cómo hacerlo, era muy joven todavía, el dolor me invadió y mis hijos ahora necesitan muchas cosas que yo no les puedo dar.

Busque trabajo como vendedora, haciendo aseo y así me mantuve durante un tiempo, mis padres me apoyaron con el techo y el cuidado de los niños, pero yo creo que vivía era como por inercia, dejé de comer, me descuide mejor dicho, lloré y sufrí su ausencia mucho tiempo.

Ya cuando mi hija mayor cumplió ocho años, conocí al papá de mis dos hijos menores, los niños que tienen discapacidad, me dejé envolver seguramente... en fin, me fui a vivir con él a Soacha y la verdad fue un tiempo de malos tratos, de humillaciones, de maltrato físico y de aguantar hambre. Nació mi hijo Juan y a los ocho días el médico del hospital Santa Clara me informó que el niño había 
nacido con una afectación cognitiva, que no iba a tener un desarrollo normal y que se desconocía el motivo. Uyy Dios, eso fue mejor dicho una locura, no lo creía busque citas médicas en otros hospitales, lo bauticé, hasta que a los seis meses empecé como a asimilarlo y a buscar en los médicos las explicaciones mientras tanto, mi compañero se volvió prácticamente alcohólico, llegaba y me daba unas tundas y siempre me echó la culpa de todo, aguante mucho tiempo hambre y la verdad tuve que pedir limosna para los pasaje. Un infierno pero me daba miedo dejarlo, no podía volver a mi casa porque a mis hermanos les parecía el colmo que yo no aprendiera y me metiera según ellos con lo primero que encontraba y pues mis papás, me dijeron desde el principio "se va pero no la volvemos a recibir porque no estamos dispuestos a alcahuetearle más".

Me sentí completamente sola, culpable e inservible, no tenía espíritu para nada, creo que conocí en ese momento lo peor de mí sin embargo, cuidaba de mis hijos e intentaba sonreír a lo malo porque qué más. Planificaba con la T pero, al año quedé embarazada nuevamente (Llanto), perdón....

Mis hijos mayores me dijeron que ellos no querían seguir viviendo conmigo y mis papas la verdad, fueron quienes los apoyaron en casi toda su adolescencia. Seguí en las mismas durante todo el embarazo, casi no podía ir a las citas prenatales porque no tenía con qué, una vecina fue la que me daba bienestarina y me inscribió para recibir un mercado mensual y así viví. Nace mi hijo menor y pues las cosas no mejoraron, me fui a vivir con una cuñada mientras la dieta y un buen día, ese man se fue, me llamó y me dijo que mirara que iba hacer porque él no iba a seguir manteniéndome.

Fue cuando me fui a vivir con mis suegros, allá nos daban el techo y a los niños les daban la comida y las onces para el colegio, yo mientras tanto le ayudaba con el aseo a mi otra cuñada y con lo que ella me daba pagaba el agua y daba para algo de mercado. Cuando el chiquitín entró al colegio, me llamaron y me informaron que era importante llevarlo al médico porque él no se podía estar quieto y era sumamente agresivo con los otros niños. Como pude le saque cita y finalmente después de correr de un examen a otro y de llevar a Juan también a todo lo que le ordenaban, le diagnosticaron esquizofrenia.

Ya decía a mí no me puede pasar nada más porque de verdad que Dios se empecinó conmigo y mi familia, tuve que sacarlo de estudiar porque se alteraba mucho y no media la fuerza, lo cuide en casa pero mis suegros ya me dijeron que no podían más con nosotros, el niño también era grosero con ellos y me dijeron que lo mejor era que me fuera. Me vi obligada a pedirles posada a mis padres y pues ellos habían recién comprado una casa en Bosa Piamonte, me dijeron arriba esta la terraza mire a ver cómo se acomoda, no podemos ayudarle con más. 
Me quedé en casa por varios años porque desafortunadamente en Colombia no hay interés por la atención de personas con discapacidad Mental Psicosocial y no podía dejar a mi hijo menor con nadie; ocasionalmente iba donde una vecina a ayudarle con el aseo y ella me reconocía $\$ 10.000$ que me servían para el diario, ella me ayudó mucho porque empezó a recomendarme con otras señoras del sector y con eso sobreviví algún tiempo.

En el año 2010 mi hija mayor terminó el bachiller y a la vez quedó en embarazo, me sentí muy frustrada porque yo a ella la aconsejé mucho pero pues digamos que yo tampoco me siento con la autoridad moral para decirle, no quisiera que se sintiera sola y menos humillada; el papá del bebé no respondió y terminó yéndose del barrio donde vivía así que a mi tocó asumir los gastos; mi segundo hijo estaba finalizando noveno de bachiller y mi tercer hijo entraba a sexto aunque, presentaba muchas dificultades académicas por su mismo diagnóstico.

Como en el año 2012 mi hijo menor tuvo una crisis muy fuerte y lo internaron por una semana en la Clínica de la Paz, no podía verlo, lo tenían completamente sedado y con una camisa de fuerza, mire la verdad ese día dije No más!, me armé de valor pero sobretodo de indignación por las condiciones en las que tenían a mi hijo, hablé con el médico y lo trate mal porque me hablaba como si yo le estuviera mendigando algo.

Llegué a la casa, me metí en internet y empecé a leer, a mirar artículos y todo sobre las enfermedades de mis hijos, tengo un cuaderno donde iba anotando todo, también hice como un directorio con las instituciones de la localidad y empecé a mirar normas jurídicas me pudieran respaldar. Así fue como llegué al Hospital Pablo VI a la Sede de Salud Pública que queda en el Barrio Carbonell, pues en ese momento empezaban talleres sobre Política Publica de Discapacidad la cual, desconocía completamente.

Los talleres eran los Martes y los Jueves de dos de la tarde a cinco y media, allá inicialmente nos dieron como una inducción con todo los temas, las talleristas se presentaron y nos dieron los números de contacto por si teníamos dudas o alguna novedad, eso me pareció muy chévere porque no eran las funcionarias de escritorio sino que nos dieron la oportunidad de estar en contacto con ellas.

Durante los talleres tuvimos espacios de relajación y de psicología lo que me sirvió personalmente, ya que tenía muchos sentimientos represados; fue de verdad una gran experiencia, de igual forma conocí muchas mujeres en las mismas condiciones que yo y eso también le permite a uno establecer como redes e ir mirando posibilidades de agruparnos y eso. La capacitación del Hospital duró un año completo y nos dieron al final un certificado y recuerdo que fue una funcionaria de Integración Social 
de la localidad para comentarnos los programas que ellos manejaban y los requisitos, le comenté mi caso y le llevé los diagnósticos médicos y me afiliaron los niños al proyecto 721 .

Y a los tres meses creo yo, una de las mamitas del grupo me comentó que ella iba a ir al Bienestar Familiar de la localidad para solicitar un bono que les daban a los niños y me indicó los documentos que tenía que llevar. Estuve haciendo esas vueltas como una semana y quedaron de avisarme si quedaban elegidos o no, fueron hacerme una visita y de verdad que ahí fue cuando las doctoras se dieron cuenta de las condiciones en las que yo vivía. Desde ese entonces estoy recibiendo también el Hogar Gestor pero solo de Juan y a mi hijo menor le dieron el cupo en una fundación que queda en Kennedy donde está entre semana y hace diferentes actividades.

En el año 2014, la Secretaria de Salud implementó un Plan Piloto que se llamaba “ cuidando a cuidadores" en donde nos formaban en política pública, empoderamiento social y liderazgo; ya al poco tiempo me formé como agente de cambio en el Hospital Pablo VI y allí mismo me dieron un contrato laboral para formar a otras cuidadoras en RBC- Rehabilitación Basada en Comunidad-.

Con ese empleo me logré estabilizar económicamente y ya podía darles digamos que suplir sus necesidades sin tener que estar mendigando o eso; allá en el hospital si me pagaron todo lo ley y usted puede verificar que son las únicas semanas que tengo cotizadas en pensión.

Ese proceso de empoderamiento fue difícil en la medida en que mis padres consideraban que era una pérdida de tiempo y que además que los dejaba en ridículo con los vecinos porque era ventilar las condiciones en las que estaba la familia. Sin embargo, yo no tenía nada que perder al contrario, podía aunque fuera aprender y ya dejar de ser boba con los médicos y todo el mundo que querían hacer con uno lo que se les diera la gana.

Empecé también a asistir al Consejo Local de Discapacidad que eran los segundos jueves de cada mes de ocho de la mañana a una de la tarde, la Secretaria del Consejo fue una persona que le dio cabida a la comunidad y que permitió nuestra participación en los subgrupos que ellos conformaron; esto fue un avance porque normalmente asistían las mismas personas de siempre y no trasmitían la información por eso los beneficios llegaban a unos pocos. Me metí en el subgrupo de educación y la idea era ser como veedores de los procesos de inclusión de las personas en condición de discapacidad y estar siempre en contacto con los funcionarios de la Dirección Local de Discapacidad.

Ese trabajo en el Consejo me hizo ver lo importante que es la participación de las cuidadoras dentro de los procesos de inclusión social pues, finalmente quienes estamos velando por los derechos de las personas con discapacidad somos nosotras. Por otro lado, considero que fue un escenario para que a comunidad me conociera y confiara como en mi labor, lo que agradezco inmensamente. 
Ya en el año 2015 nos reunimos con varias mujeres cuidadoras y empezamos a mirar la opción de conformar una asociación que nos permitiera consolidarnos como grupo y de la misma forma ir diseñando proyectos que nos permitieran involucrar a la discapacidad y el cuidado en todos los temas comunitarios. Sin embargo, fue una idea que no se pudo desarrollar inicialmente pues, empezaron las divisiones dentro del grupo, considero que fue más por temas de malos comentarios y chismes. Además, en el mes de Abril me empecé a sentir indispuesta y sin alientos como de levantarme, lo que normalmente hacía, fue cuando acudí al médico quien me ordenó varios exámenes y en ese momento me detectaron Cáncer de Seno en una etapa avanzada.

Que te podría decir de eso, fue muy duro recibir esa noticia porque finalmente todo el dolor que había vivido tenía solución, pero la salud es algo delicado y yo lo único que pensaba era ¿qué va ser de mis hijos sin mí?, pero mira que tampoco fue una noticia que me devastara, la verdad creo que fui consiente siempre de que estaba actuando bien y pues que el control de todo lo tiene Dios, entonces me sentí en medio de todo tranquila. Me atormentó mucho las recomendaciones de los doctores cuando iba a iniciar la quimioterapia, ya que tenía que cortarme el cabello y pues digamos que mi apariencia si me angustiaba.

Mis padres desde ahí me han apoyado y están al pendiente de mis hijos, mis hermanos también empezaron a acercarse de nuevo y digamos que tuve un apoyo importante para enfrentar la situación. Duré siempre 10 meses en tratamiento, aún estoy en controles médicos pero yo intento no pensar en eso, pues me afana más saber que Juan ahora está desarrollando conductas de autolesión, no puede estar en ambientes cerrados y le está costando compartir con más personas.

Ahorita a mediados de Julio retomé nuevamente como mi labor comunitaria, la idea de la Asociación no se logró por muchas cosas especialmente, por inexperiencia y desconocimiento sin embargo, conformamos una Red de Cuidadoras que se encuentra desarrollando en este momento procesos de participación y socialización de experiencias con toda la comunidad; estamos también programando varias actividades de carácter comunal como bazares y diferentes actividades que nos permitan recaudar fondos para desarrollar actividades artísticas con los niños en condición de discapacidad.

Para este diciembre tenemos programada una actividad de finalización de año, en donde queremos regalarle una sonrisa a esos niños que nadie tiene en cuenta, esperamos recolectar 150 regalos y pues los refrigerios correspondientes. En esa labor, no nos ha ido nada bien la verdad, hemos tocado varias puertas como la Alcaldía Local y el ICBF y nos dijeron que ellos no tenían competencia para eso, Integración también nos dijo que no tenía formas de apoyarnos. Desde este año no pudimos seguir participando en el Consejo Local porque la nueva secretaria prohibió el ingreso de la comunidad y no 
habido forma de que eso pues termine y nos vuelvan a vincular a ese proceso, por tanto apoyo de ellos no tenemos. La verdad quienes han apoyado más a la Red han sido los pequeños comerciantes del sector pues, no ha sido cantidad la ayuda pero de todas maneras es un apoyo importante. Nosotras hacemos de todo, somos animadoras, organizadoras, publicitas mejor dicho todo lo hacemos nosotras por ver felices a nuestros chiquitines.

Quisiera hacer unas reflexiones puntuales frente al tema de las mujeres cuidadoras:

Primero, la posibilidad de organización entre nosotras es algo que debemos seguir fortaleciendo dada las condiciones de vida de las mujeres en Bosa, porque yo soy solo una pequeña muestra de las violencias a las que estamos expuestas todo el tiempo pero, hay casos en los que de verdad el Estado falla. Es por ello, que nos encontramos empoderando a las mamitas cuidadoras para que también dejemos un precedente que más que cuidadoras seguimos siendo mujeres.

Segundo, la exclusión social es evidente porque de verdad que ya nos volvimos indiferentes ante el dolor del otro y el sufrimiento, siempre se piensa es que si no me pasa a mi pues de malas, considero que la exclusión inclusive se evidencia a la hora de formular y presentar proyectos ante las diferentes instituciones y es porque el Estado, segrega cualquier clase de discapacidad y siempre se encuentran trabas y puertas cerradas pero, como ya estamos formándonos estamos en la lucha por que se escuchen todas nuestras necesidades y poder lograr el reconocimiento de todas las clases de discapacidad y aunque tenemos el acuerdo 002 de 2007 es muy luchada la inclusión laboral

Por otro lado, dejar el precedente que Bosa es una localidad con una cantidad de dificultades y necesidades por ser cubiertas y de esa misma manera las mujeres cuidadoras se ven expuestas a violaciones a sus derechos como personas, hay una posición muy machista inclusive por parte de nosotras mismas, sin embargo hay intenciones de mejorar las cosas y progresivamente la comunidad va a tener que adaptarse.

Así mismo, quiero manifestar nuestros intereses también para que el Gobierno adapte sus políticas y nos garanticen un empleo digno con horarios flexibles para las cuidadoras que tengan sus hijos en inclusión educativa o en fundaciones, que las cuidadoras de tiempo completo puedan ser formadas como auxiliares de enfermería y ser contratadas por las prestadoras de servicios de enfermería domiciliaria para el cuidado de sus propios hijos pero sobre todo, una pensión o auxilio económico a los cuidadores que no tienen estas opciones ya que todas y todos los cuidadores también tenemos necesidades que suplir en lo personal.

Esta ha sido mi vida, agradezco el interés de poder estudiar desde la academia nuestra situación, de verdad que son muchas cosas que quizá no tuve presentes pero, demuestra la dificultad con la que 
nacemos, crecemos y envejecemos también; finalmente espero con mucha fe conformar una organización de cuidadores y cuidadoras legalmente constituida a nivel Distrital que genere el impacto que anhelamos y los cambios en el pensar y actuar frente a las personas con discapacidad. 


\section{Síntesis de Historias de Vida}

\begin{tabular}{|c|c|c|c|c|}
\hline CATEGORIAS & Cuidadora 1 & Cuidadora 2 & Cuidadora 3 & Cuidadora 4 \\
\hline IDENTIFICACIÓN & $\begin{array}{l}\text { i. Tengo } 57 \text { años } \\
\text { ii. Tengo dos hermanos } \\
\text { iii. Crecí en una familia } \\
\text { de agricultores y como } \\
\text { verá era un trabajo muy } \\
\text { duro y difícil, pero todos } \\
\text { colaborábamos } \\
\text { iv. Estuve en casa casi } \\
\text { hasta los nueve años } \\
\text { ayudando a mi mamá } \\
\text { con las labores de la } \\
\text { cocina para los obreros } \\
\text { que contrataba mi papá, } \\
\text { los arreglos de la casa y } \\
\text { ayudaba a sembrar y a } \\
\text { desyerbar los pastos. } \\
\text { v. Mi papá quería tener } \\
\text { más hijos y ojala fueran } \\
\text { hombres } \\
\text { vi. Un familiar de mi } \\
\text { papá nos ayudó a criar } \\
\text { pues mi viejo estaba } \\
\text { todo el tiempo } \\
\text { sembrando o arrancando } \\
\text { yuca y bajando plátano. } \\
\text { vii. Yo no podía estar } \\
\text { fuera de la habitación } \\
\text { cuando estaban los } \\
\text { amigos de mi papá en } \\
\text { casa. }\end{array}$ & $\begin{array}{c}\text { i. Tengo } 62 \text { años } \\
\text { ii. Soy la segunda hija } \\
\text { de ocho hermanos y la } \\
\text { primer mujer de mis } \\
\text { hermanos } \\
\text { iii. Mi madre se } \\
\text { dedicaba en ese } \\
\text { momento a los oficios } \\
\text { de la casa, el cuidado } \\
\text { de mis dos hermanos } \\
\text { varones y de mí (En } \\
\text { ese entonces solo } \\
\text { éramos los tres) y el } \\
\text { trabajo de la tierra, mi } \\
\text { padre se dedicaba a } \\
\text { labrar la tierra } \\
\text { también y a los } \\
\text { negocios de venta de } \\
\text { animales } \\
\text { iv. Cuando mi madre } \\
\text { llegó allá se dio } \\
\text { cuenta que mi padre } \\
\text { tenía otra mujer y es } \\
\text { cuando se separan } \\
\text { v. Ingresé a estudiar } \\
\text { casi cuando tenía } 9 \\
\text { años y no pude } \\
\text { terminar la primaria }\end{array}$ & $\begin{array}{l}\text { i. Tengo } 57 \text { años } \\
\text { ii. Tuve } 9 \text { hermanos, cinco } \\
\text { hombres y cuatro mujeres, } \\
\text { yo fui la cuarta hija } \\
\text { iii. Mis padres fueron } \\
\text { personas del campo muy } \\
\text { trabajadoras y nobles } \\
\text { iv. Mis hermanos hombres } \\
\text { siempre eran los que tenían } \\
\text { las mejores cosas, digamos } \\
\text { que les servían mejores } \\
\text { presas de pollo y a ellos si } \\
\text { nos los obligaban a cocinar } \\
\text { ni nada de eso, ellos solo } \\
\text { se dedicaban a ayudar a mi } \\
\text { papá con la tierra y nada } \\
\text { más }\end{array}$ & $\begin{array}{l}\text { iii. Tengo tres hermanos } \\
\text { iv. Hice parte de una familia } \\
\text { humilde y de creencias católicas, } \\
\text { con normas establecidas por mi } \\
\text { padre quien era el jefe de hogar. } \\
\text { v. Gocé de muchas bendiciones, } \\
\text { amor y mucha atención, participé en } \\
\text { varios eventos organizados en el } \\
\text { centro comercial en donde } \\
\text { trabajaban mis padres. } \\
\text { vi. Ingresé a los tres años al Jardín } \\
\text { comunal del barrio, en donde } \\
\text { compartí con varias personas e inicié } \\
\text { mi proceso académico como tal. } \\
\text { vii. No fue posible que mis papás } \\
\text { pudieran meterme a temprana edad a } \\
\text { estudiar en la escuela. } \\
\text { viii. Aprendí desde esa edad a } \\
\text { arreglar la casa y hacer varias tareas } \\
\text { en el hogar, también empecé a } \\
\text { cocinar pues, mi padre la verdad } \\
\text { nunca ayudó con las tareas del hogar }\end{array}$ \\
\hline
\end{tabular}




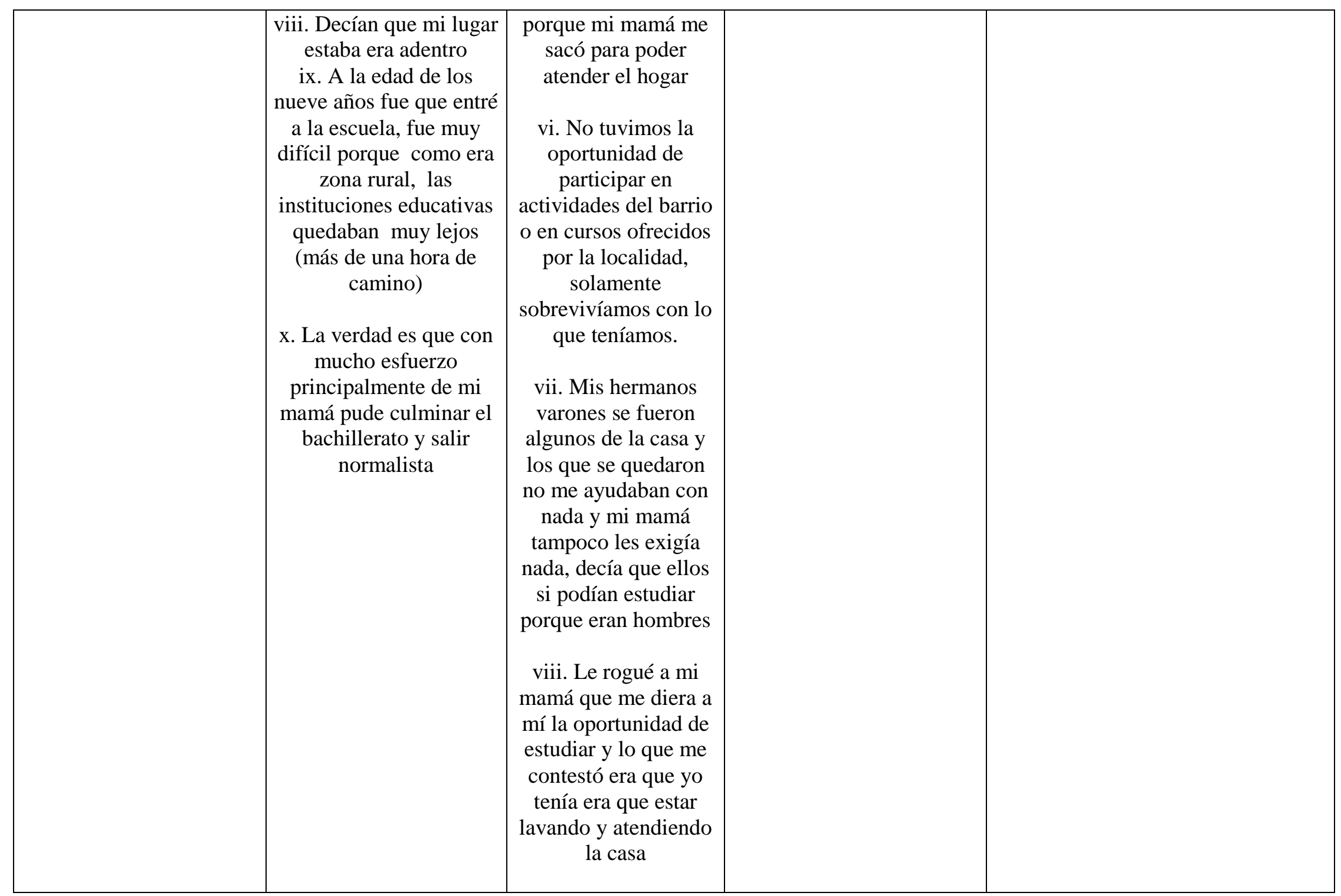




\begin{tabular}{|c|c|c|c|c|}
\hline & & $\begin{array}{l}\text { ix. Me sentí por } \\
\text { mucho tiempo bruta y } \\
\text { sin importancia, no } \\
\text { valoré nunca mi } \\
\text { aspecto físico y lo } \\
\text { único que quería era } \\
\text { salir de mi casa y } \\
\text { vivir otra vida }\end{array}$ & & \\
\hline LIDERAZGO & $\begin{array}{l}\text { i. Me quedé como unos } \\
\text { seis meses en la finca } \\
\text { cuidando a mis viejos. } \\
\text { ii. } \\
\text { Ya con el tiempo me fui } \\
\text { soltando para coger los } \\
\text { buses y eso; los } \\
\text { conocidos me escribían } \\
\text { en un papelito las } \\
\text { direcciones y los buses } \\
\text { que deba coger y así fue } \\
\text { aprendiendo poco a } \\
\text { poco. } \\
\\
\text { iii. Conocí a una señora } \\
\text { que su hijo también } \\
\text { estaba hospitalizado y } \\
\text { tenía unas condiciones } \\
\text { similares, como los } \\
\text { chicos están medicados } \\
\text { todo el tiempo, } \\
\text { empezamos habar } \\
\text { frecuentemente y ella } \\
\text { pues me invito a } \\
\text { participar en una reunión }\end{array}$ & $\begin{array}{l}\text { i. Me convencí que } \\
\text { debía luchar por ella } \\
\text { hasta donde fuera } \\
\text { necesario } \\
\text { ii. Me empecé a } \\
\text { relacionar con otras } \\
\text { mamás cuidadoras, } \\
\text { hablaba con las } \\
\text { señoras que estaban y } \\
\text { empezamos a } \\
\text { contarnos los } \\
\text { diagnósticos de los } \\
\text { niños y también los } \\
\text { motivos por los que } \\
\text { habían nacido así } \\
\text { iii. Yo empecé a } \\
\text { asistir a las reuniones } \\
\text { que ella organizaba en } \\
\text { el salón comunal o en } \\
\text { la casa de alguna } \\
\text { mamá y allí las } \\
\text { señoras que llevaban } \\
\text { más tiempo nos } \\
\text { compartían }\end{array}$ & $\begin{array}{c}\text { i. A mí me tocó aprender a } \\
\text { ser verraca y a sacar las } \\
\text { uñas } \\
\text { ii. En el hospital recién } \\
\text { empezaban a trabajar con } \\
\text { la política pública y } \\
\text { éramos pocas personas, } \\
\text { nos reuníamos } \\
\text { inicialmente los miércoles } \\
\text { y allá le explicaban a uno } \\
\text { cómo se caracterizaban las } \\
\text { enfermedades y cómo } \\
\text { realizar cuidados básicos } \\
\text { desde la casa } \\
\text { iii. Yo tomaba nota de los } \\
\text { nombres y cargos para } \\
\text { poder acercarme y } \\
\text { solicitarles información } \\
\text { acerca de los servicios que } \\
\text { ofrecían } \\
\text { iv. Nunca me quedé quieta } \\
\text { o esperando que alguien } \\
\text { me diera algo por pesar, le }\end{array}$ & $\begin{array}{c}\text { i. Me armé de valor pero sobretodo } \\
\text { de indignación por las condiciones } \\
\text { en las que tenían a mi hijo, hablé } \\
\text { con el médico y lo trate mal porque } \\
\text { me hablaba como si yo le estuviera } \\
\text { mendigando algo. } \\
\text { ii. Me metí en internet y empecé a } \\
\text { leer, a mirar artículos y todo sobre } \\
\text { las enfermedades de mis hijos, tengo } \\
\text { un cuaderno donde iba anotando } \\
\text { todo, también hice como un } \\
\text { directorio con las instituciones de la } \\
\text { localidad y empecé a mirar normas } \\
\text { jurídicas me pudieran respaldar. } \\
\text { iii. Ya al poco tiempo me formé } \\
\text { como agente de cambio en el } \\
\text { Hospital Pablo VI y allí mismo me } \\
\text { dieron un contrato laboral para } \\
\text { formar a otras cuidadoras en RBC- } \\
\text { Rehabilitación Basada en } \\
\text { Comunidad. } \\
\text { iv. Empecé también a asistir al }\end{array}$ \\
\hline
\end{tabular}




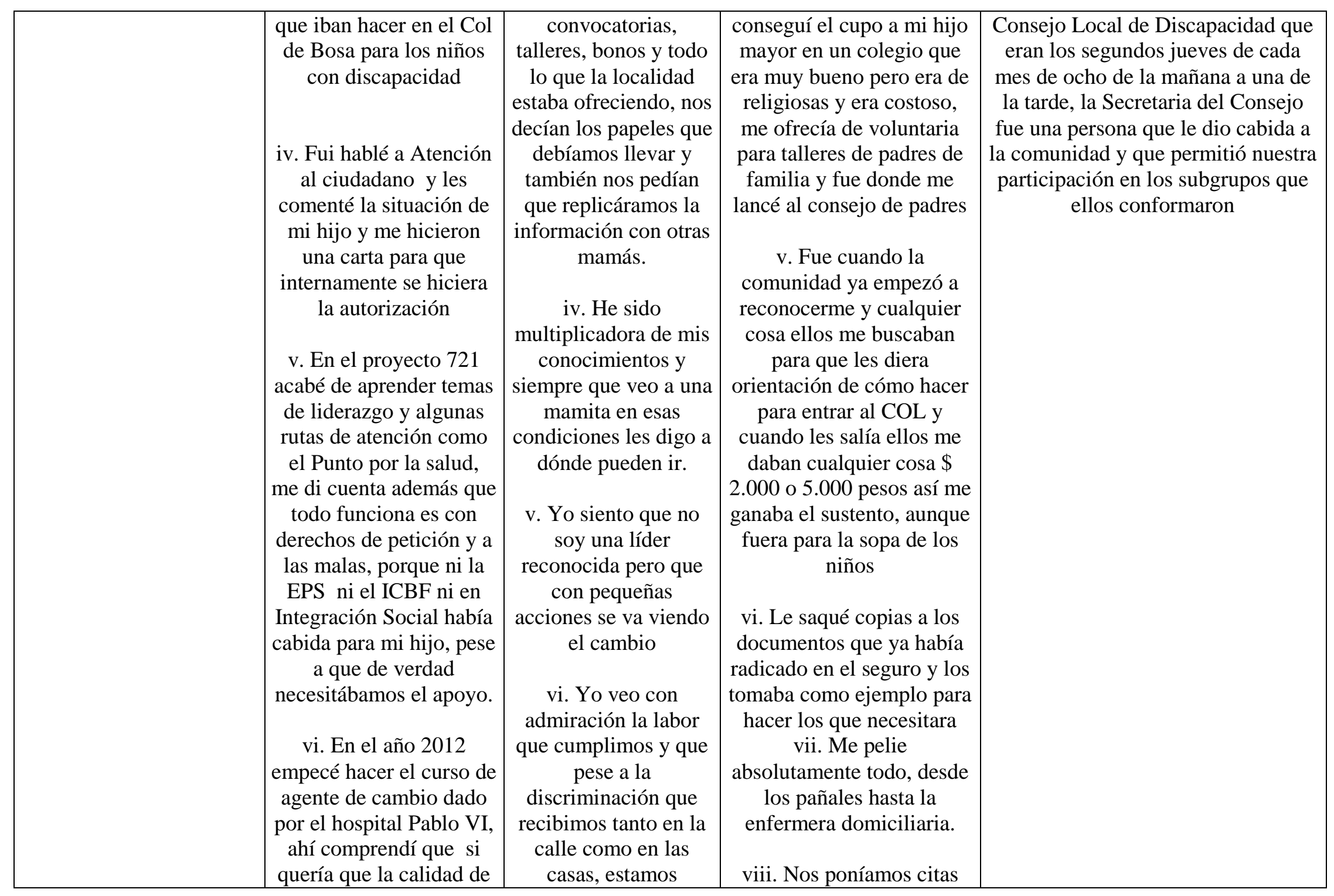




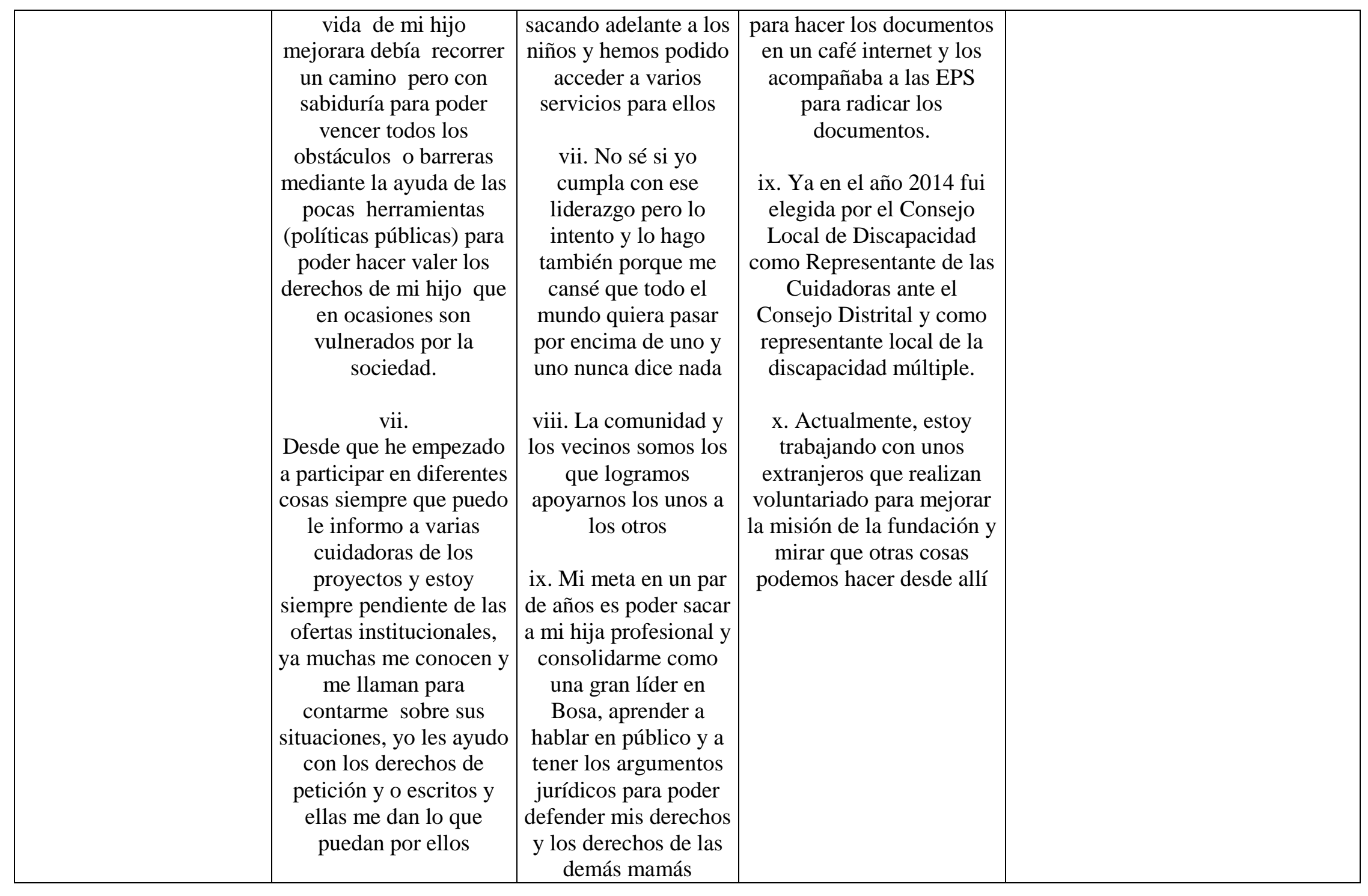




\begin{tabular}{|c|c|c|c|c|}
\hline $\begin{array}{l}\text { PROTECCIÓN } \\
\text { SOCIAL }\end{array}$ & $\begin{array}{c}\text { i. Lo de los palancasos } \\
\text { en las empresas no es de } \\
\text { ahora. } \\
\text { ii. } \\
\text { Los profesores los } \\
\text { contrataba directamente } \\
\text { la Gobernación y pues, } \\
\text { yo en ese entonces no } \\
\text { había venido a Bogotá } \\
\text { iii. } \\
\text { Trabajar con las familias } \\
\text { en el campo es muy } \\
\text { enriquecedor } \\
\text { iv. } \\
\text { Tuve todas las } \\
\text { prestaciones sociales y } \\
\text { la opción de apoyar a mi } \\
\text { vieja con un tratamiento } \\
\text { médico } \\
\text { v. } \\
\text { Llegó una profesora de } \\
\text { aquí de Bogotá a ocupar } \\
\text { la vacante } \\
\text { vi. } \\
\text { más oportunidades } \\
\text { laborales }\end{array}$ & $\begin{array}{l}\text { i. No teníamos familia } \\
\text { que pudiera darnos } \\
\text { posada aquí en } \\
\text { Bogotá } \\
\text { ii. Las condiciones } \\
\text { económicas de la } \\
\text { familia siempre } \\
\text { fueron complicadas } \\
\text { porque no teníamos } \\
\text { muchas comodidades } \\
\text { y entre más nacían } \\
\text { mis hermanos eran } \\
\text { más escasos los } \\
\text { recursos } \\
\text { iii. Mi madre por su } \\
\text { parte si tenía amigas } \\
\text { en el barrio que nos } \\
\text { echaban un ojito y le } \\
\text { prestaban a ella cosas } \\
\text { para cocinar o muchas } \\
\text { veces comida, } \\
\text { tuvimos muchos } \\
\text { accidentes, se nos } \\
\text { incendió la casa, se le } \\
\text { volteó una olla de } \\
\text { agua caliente a uno de } \\
\text { mis hermanos y otro } \\
\text { se envenenó con unas } \\
\text { pepitas de un árbol } \\
\text { que había en el patio y } \\
\text { en esas ocasiones los } \\
\text { vecinos fueron }\end{array}$ & $\begin{array}{l}\text { i. La situación económica } \\
\text { de la casa era difícil } \\
\text { porque no teníamos } \\
\text { muchos lujos, vivíamos } \\
\text { con lo necesario, no nos } \\
\text { faltó la comida pero yo sí } \\
\text { creo que nos faltó el afecto } \\
\text { de nuestros padres } \\
\text { ii. A los } 13 \text { años empecé a } \\
\text { trabajar en lo que usted no } \\
\text { se imagina, lavando ropas, } \\
\text { arreglando las casas de las } \\
\text { personas que trabajaban en } \\
\text { la alcaldía, en varias } \\
\text { panaderías y restaurantes } \\
\text { de ah. } \\
\text { iii. Me buscó trabajo en un } \\
\text { almacén de telas y allá } \\
\text { trabajaba desde las } 7 \text { hasta } \\
\text { las } 11 . \\
\text { iv. Como era menor de } \\
\text { edad pues, solo me } \\
\text { pagaban un sueldito pero } \\
\text { no me pagaban salud ni } \\
\text { para lo de eso de la } \\
\text { pensión } \\
\text { v. Teníamos un hogar } \\
\text { bonito porque yo me } \\
\text { dedicaba a la casa y él } \\
\text { manejaba una tracto mula }\end{array}$ & $\begin{array}{l}\text { i. El negocio de mis papás no estaba } \\
\text { dejando ganancias. } \\
\text { ii. A los } 19 \text { años empecé a trabajar } \\
\text { por turnos en un almacén de ropa en } \\
\text { el sector de Chapinero, no me } \\
\text { ganaba ni siquiera el mínimo, no } \\
\text { recuerdo bien cuánto me pagaban el } \\
\text { día, pero pues no pague salud ni } \\
\text { pensión tampoco } \\
\text { iii. No volví a trabajar porque me } \\
\text { dediqué al hogar y al cuidado de mis } \\
\text { hijos, fui muy feliz de verdad. } \\
\text { iv. Tuve que salir a buscar trabajo } \\
\text { nuevamente y ahora con más años y } \\
\text { sin mayor experiencia. } \\
\text { No volví a saber mayor cosa de los } \\
\text { abuelos de los niños y tampoco } \\
\text { quise ponerme como en esa posición } \\
\text { de ir a pelear por la pensión o algo. } \\
\text { v. Busque trabajo como vendedora, } \\
\text { haciendo aseo y así me mantuve } \\
\text { durante un tiempo, mis padres me } \\
\text { apoyaron con el techo y el cuidado } \\
\text { de los niños. } \\
\text { para algo de mercado. } \\
\text { vi. Mientras tanto le ayudaba con el } \\
\text { aseo a mi otra cuñada y con lo que } \\
\text { ella me daba agaba el agua y daba } \\
\text { para alo }\end{array}$ \\
\hline
\end{tabular}




\begin{tabular}{|c|c|c|c|c|}
\hline & $\begin{array}{c}\text { vii. } \\
\text { Seguíamos trabajando en } \\
\text { la vereda } \\
\text { viii. } \\
\text { Mi esposo me puso un } \\
\text { negocito de cerveza para } \\
\text { que estuviera en la casa } \\
\text { y no tuviera problemas } \\
\text { de salud } \\
\text { ix. } \\
\text { La cervecita nos dio para } \\
\text { comer y vivíamos bien } \\
\text { x. } \\
\text { El negocio de cerveza } \\
\text { tuve que acabarlo } \\
\text { porque no había quién lo } \\
\text { atendiera, López era el } \\
\text { que me mandaba la plata } \\
\text { y pues estaba pendiente } \\
\text { de la situación. }\end{array}$ & \begin{tabular}{|} 
quienes nos ayudaron \\
iv. Salí un día de mi \\
casa a escondidas y le \\
dije a una vecina \\
amiga de mi mamá \\
que yo quería buscar \\
trabajo y ella me \\
ayudó a entrar donde \\
trabajaba, eso fue \\
como a los 14 años \\
\\
v. Me dijo que yo \\
tenía que darle el \\
dinero a ella que no \\
me lo podía gastar \\
porque si no, no me \\
daba el permiso \\
\\
vi. El trabajo era en \\
una cadena de \\
restaurantes y yo \\
ayudaba como mesera \\
y auxiliar de cocina \\
vii. No ganaba \\
mucho, como era \\
menor de edad \\
solamente me \\
pagaban lo del sueldo \\
y me renovaban el \\
contrato cada año, en \\
ese momento no me
\end{tabular} & $\begin{array}{c}\text { y se la pasaba viajando } \\
\text { todo el tiempo } \\
\text { vi. Me vi obligada a } \\
\text { entregar la casa porque no } \\
\text { tenía con que seguir } \\
\text { pagando el arriendo } \\
\text { vii. Por más que intentaba } \\
\text { conseguir trabajo, no era } \\
\text { fácil y menos sabiendo que } \\
\text { era madre cabeza de } \\
\text { familia } \\
\text { viii. Conseguí empleo en } \\
\text { un piqueteadero y metí al } \\
\text { niño al jardín o bueno en } \\
\text { ese entonces no se les } \\
\text { decía jardín sino donde } \\
\text { una vecina. } \\
\\
\text { ix. Nadie da trabajo porque } \\
\text { saben que no podemos } \\
\text { estar tiempo completo, el } \\
\text { pago es algo miserable y la } \\
\text { verdad es que la Localidad } \\
\text { y el Distrito no ofrecen } \\
\text { garantías para las personas } \\
\text { en pobreza extrema. }\end{array}$ & $\begin{array}{l}\text { vii. Ocasionalmente iba donde una } \\
\text { vecina a ayudarle con el aseo y ella } \\
\text { me reconocía } \$ 10.000 \text { que me } \\
\text { servían para el diario, ella me ayudó } \\
\text { mucho porque empezó a } \\
\text { recomendarme con otras señoras del } \\
\text { sector y con eso sobreviví algún } \\
\text { tiempo. } \\
\text { viii. Con ese empleo me logré } \\
\text { estabilizar económicamente y ya } \\
\text { podía darles digamos que suplir sus } \\
\text { necesidades sin tener que estar } \\
\text { mendigando o eso; allá en el } \\
\text { hospital si me pagaron todo lo ley y } \\
\text { usted puede verificar que son las } \\
\text { únicas semanas que tengo cotizadas } \\
\text { en pensión. } \\
\text { ix. En el mes de Abril me empecé a } \\
\text { sentir indispuesta y sin alientos } \\
\text { como de levantarme, lo que } \\
\text { normalmente hacía, fue cuando } \\
\text { acudí al médico quien me ordenó } \\
\text { varios exámenes y en ese momento } \\
\text { me detectaron Cáncer de Seno en } \\
\text { una etapa avanzada. }\end{array}$ \\
\hline
\end{tabular}




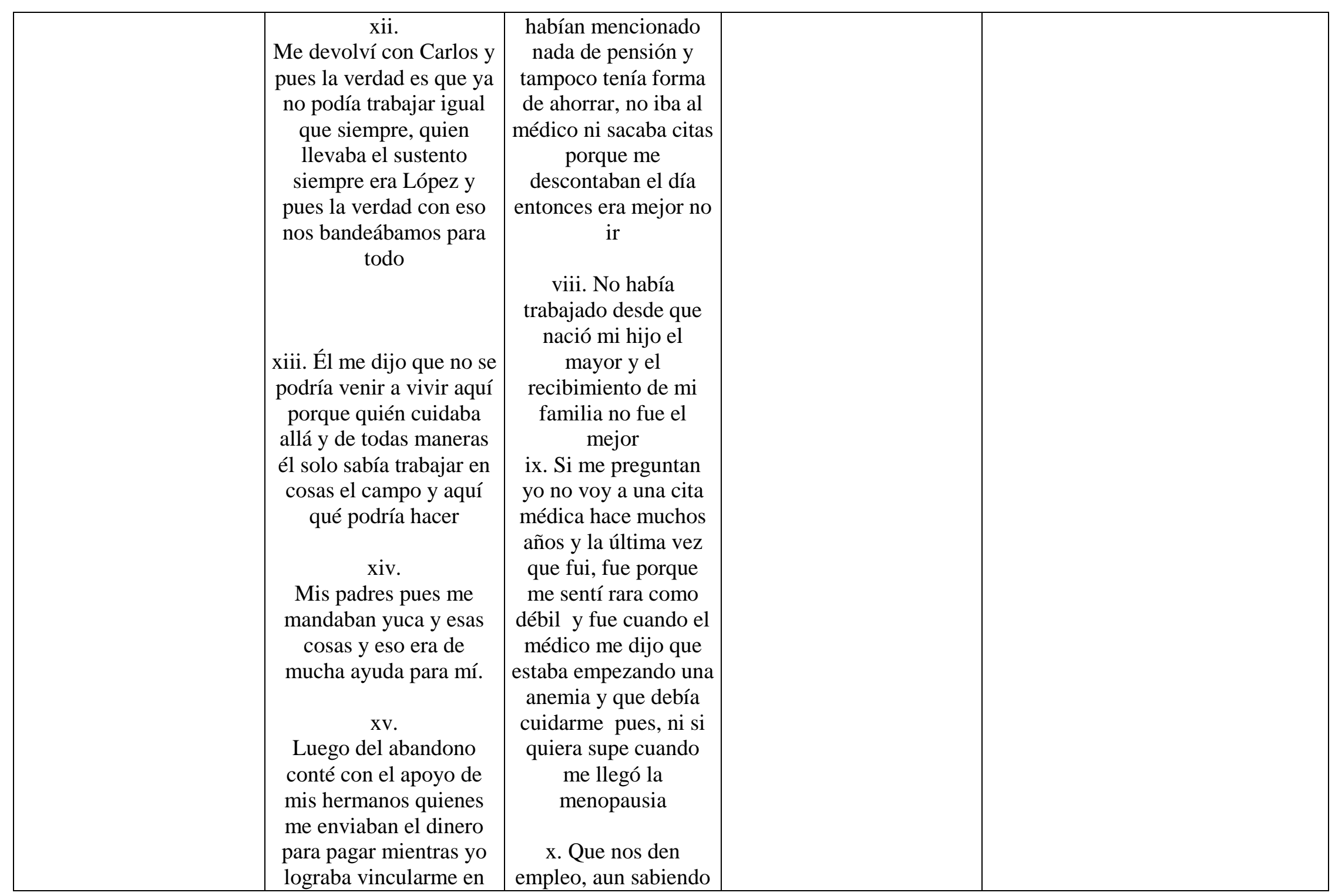




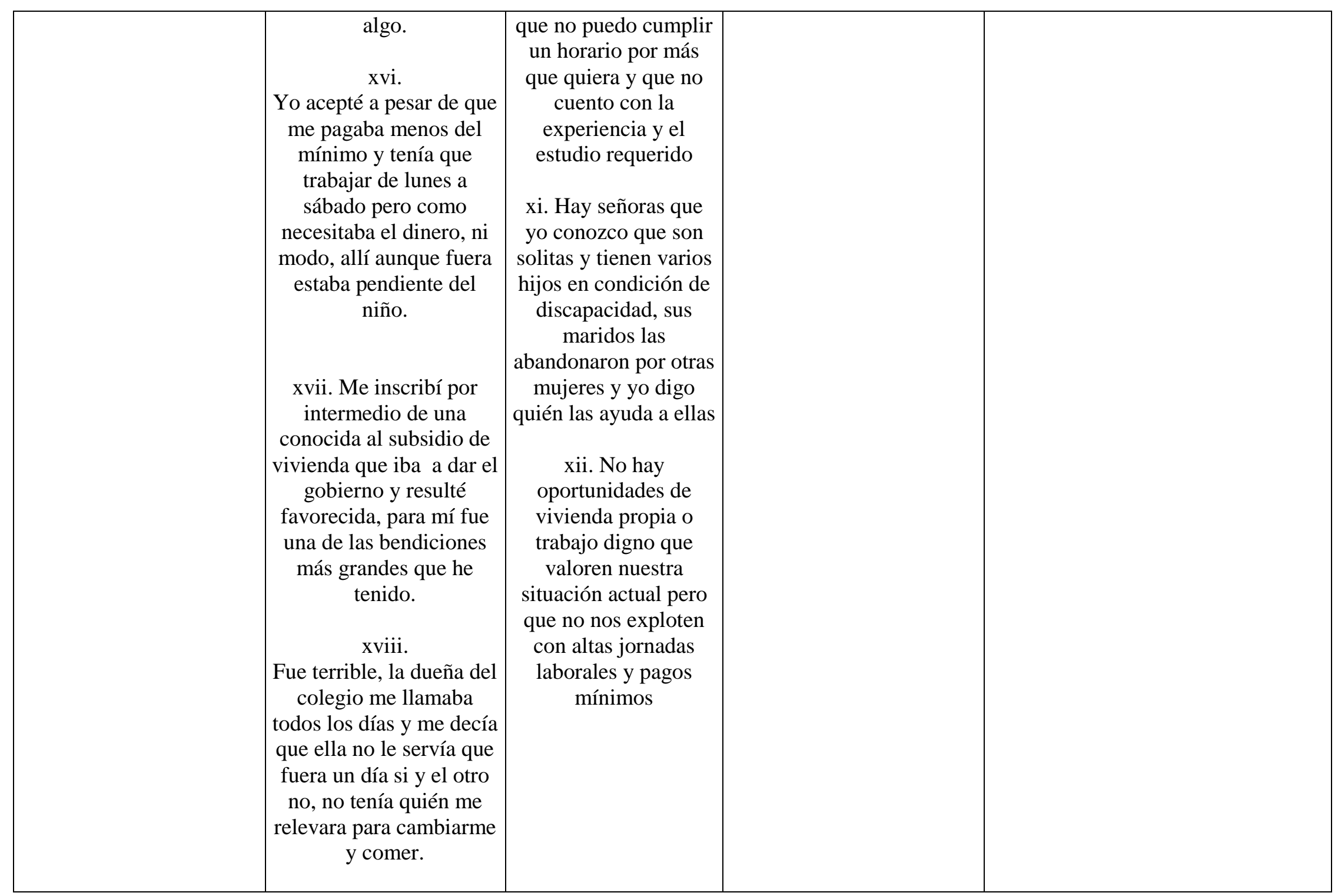




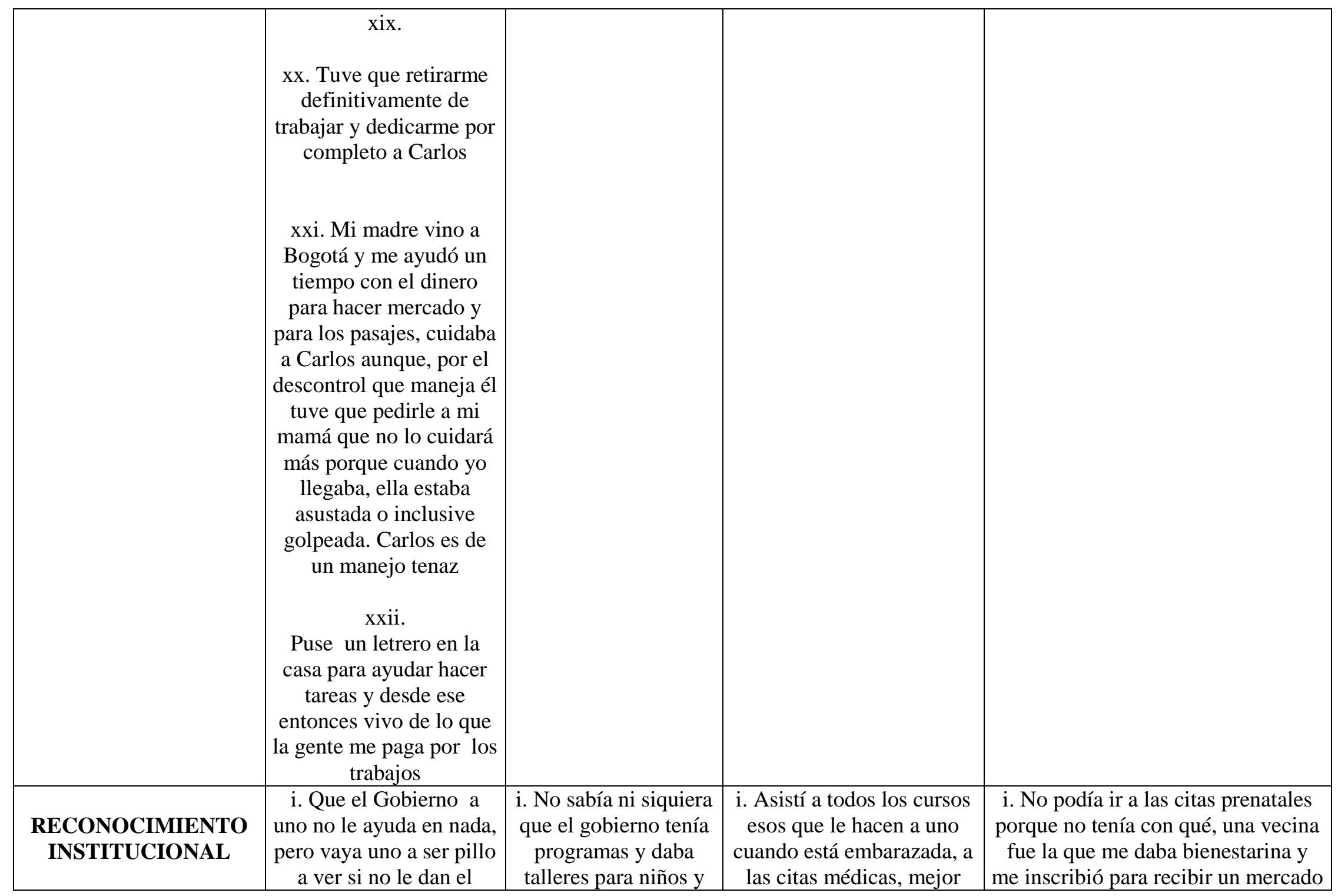




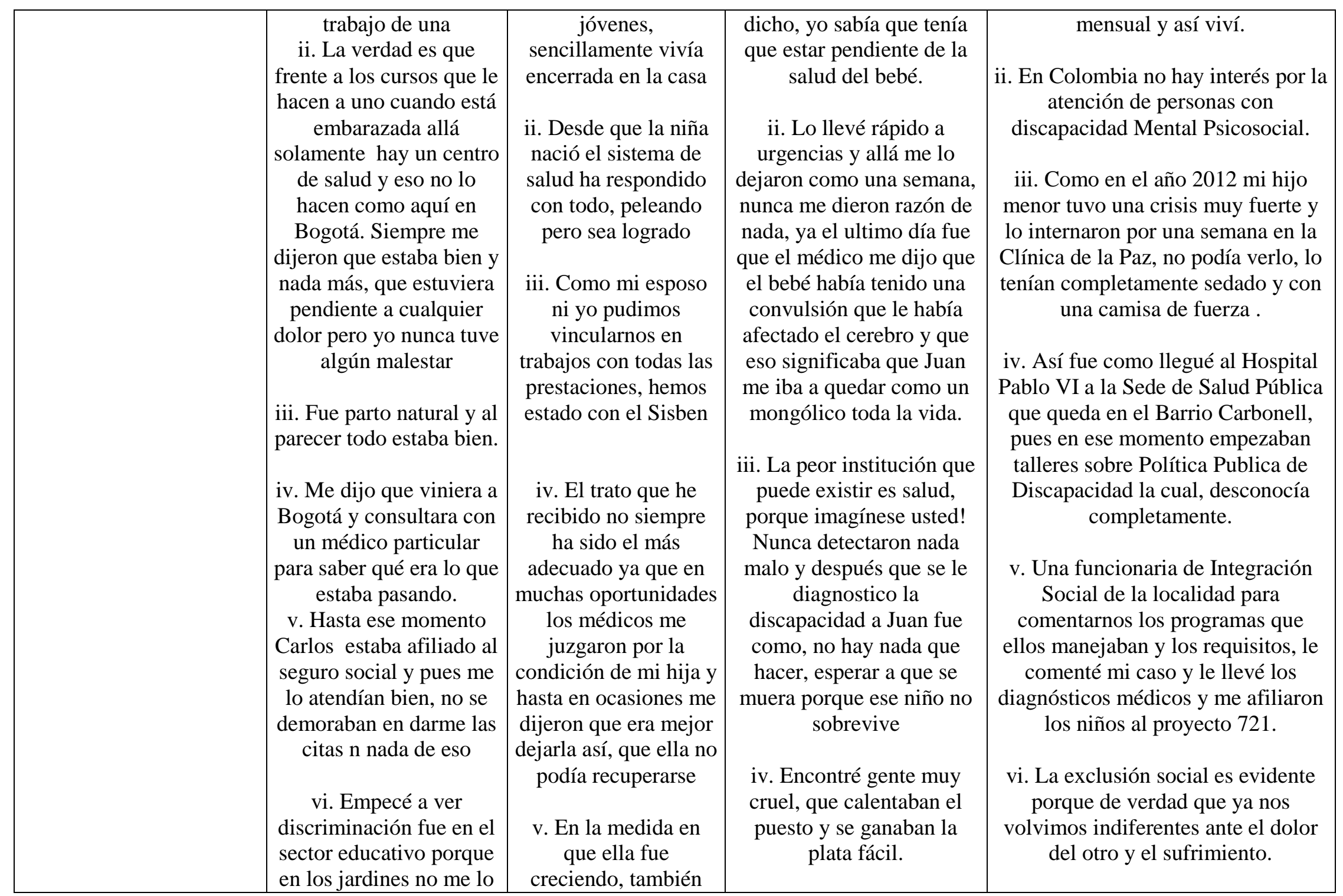




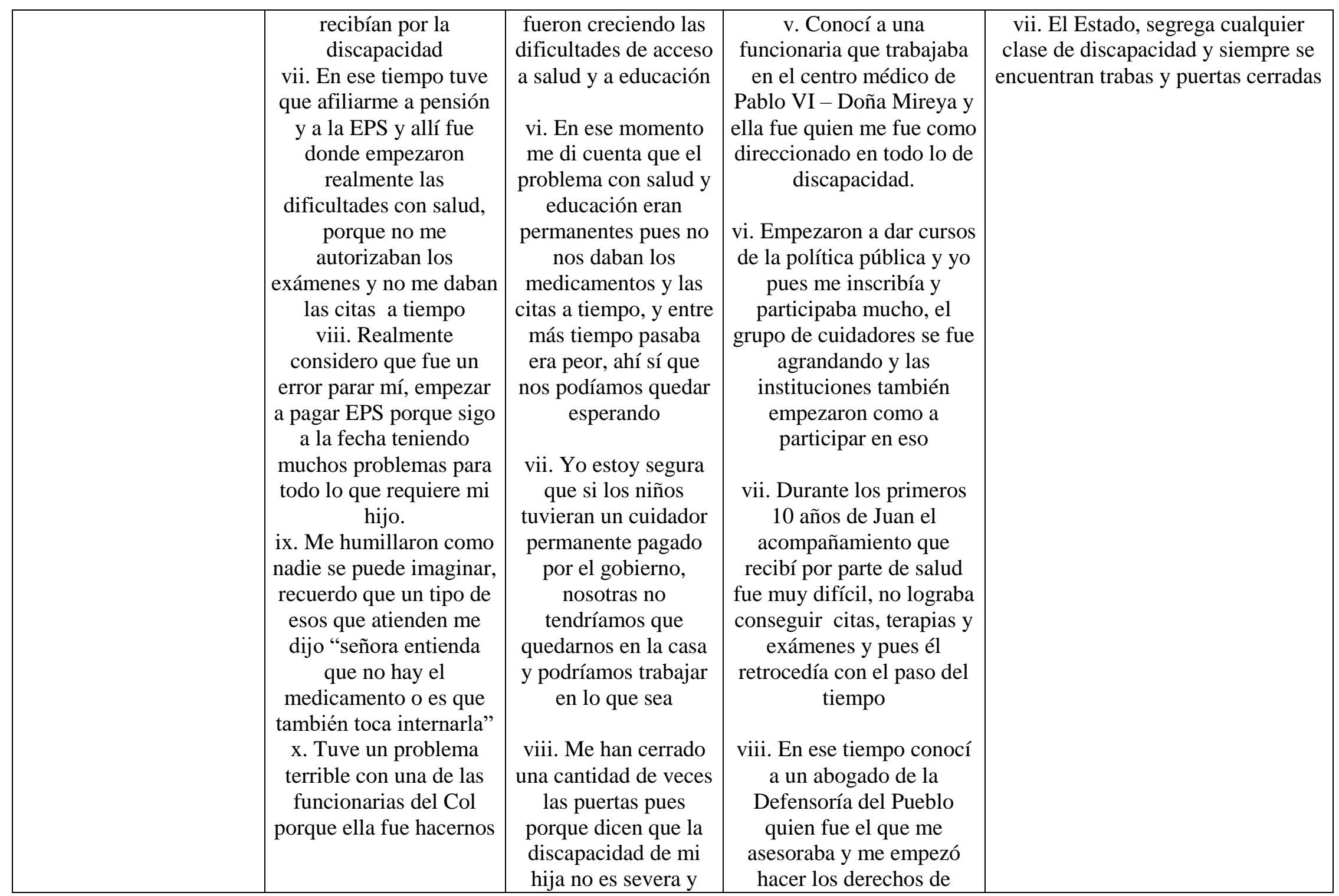




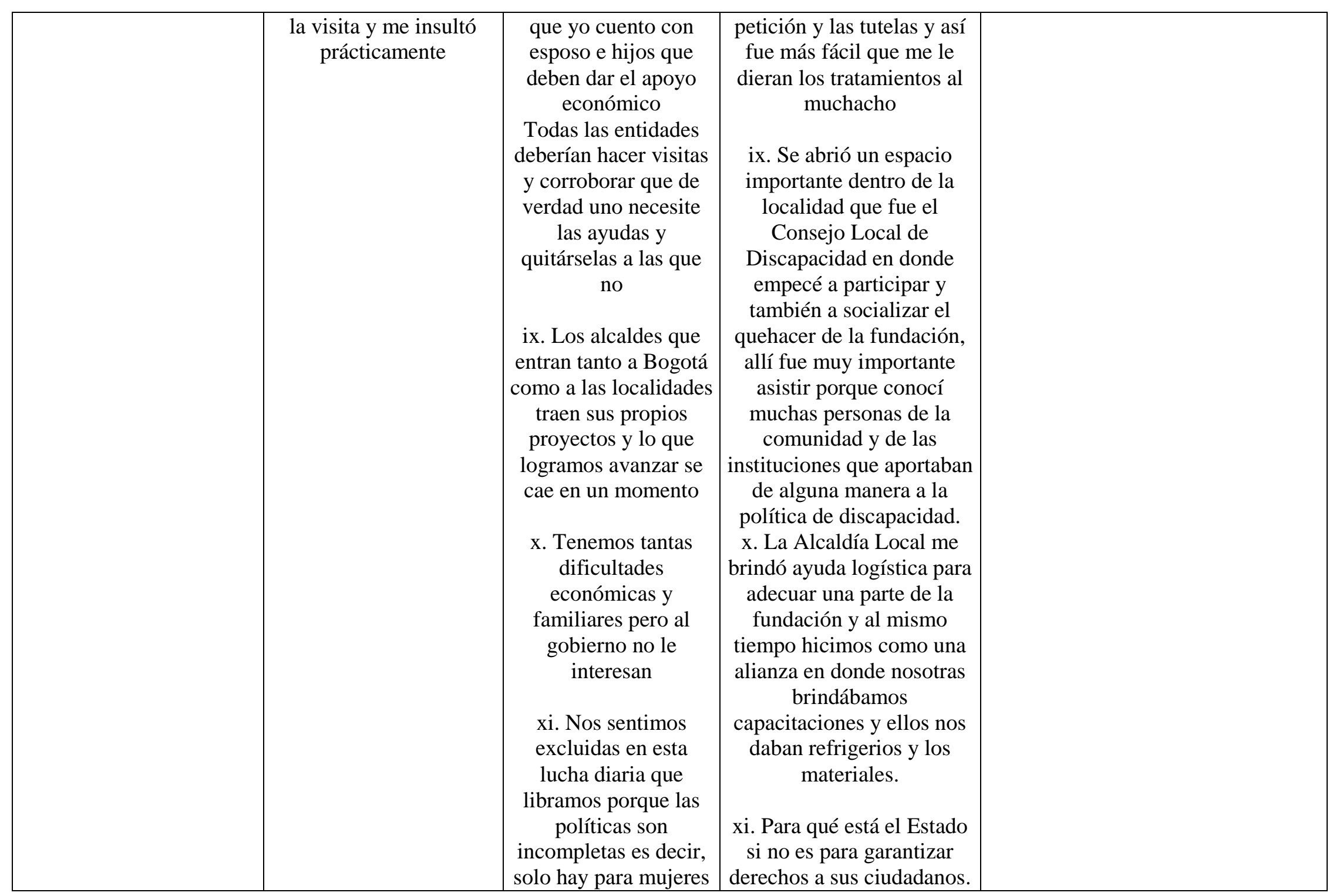




\begin{tabular}{|c|c|c|c|c|}
\hline & & $\begin{array}{l}\text { o para discapacidad } \\
\text { pero no para mujeres } \\
\text { que se dedican al } \\
\text { cuidado de niños con } \\
\text { discapacidad }\end{array}$ & $\begin{array}{l}\text { xii. La Consejera Distrital } \\
\text { me mandó a sacar en una } \\
\text { oportunidad de una sesión } \\
\text { porque ellos quieren hacer } \\
\text { las cosas como les place y } \\
\text { no como la gente } \\
\text { realmente necesita. } \\
\text { xiii. Le hace falta mucho a } \\
\text { la discapacidad para ser } \\
\text { incluida dentro de la } \\
\text { sociedad pero más le falta } \\
\text { a los cuidadores que no } \\
\text { comprenden la importancia } \\
\text { de su trabajo. } \\
\text { xiv. El Ministerio del } \\
\text { Trabajo implemente } \\
\text { acciones para evitar la } \\
\text { discriminación de } \\
\text { nosotras, que fortalezca a } \\
\text { las microempresas y que } \\
\text { genere garantías para que } \\
\text { podamos estar en el trabajo } \\
\text { con nuestros hijos }\end{array}$ & \\
\hline CONFLICTIVIDAD & $\begin{array}{c}\text { i. Fuimos a un } \\
\text { especialista que quedaba } \\
\text { en Teusaquillo, lo } \\
\text { examinó y le envío } \\
\text { varios exámenes porque } \\
\text { para él algo no estaba } \\
\text { bien }\end{array}$ & $\begin{array}{l}\text { i. Mi mamá empezó a } \\
\text { trabajar en lo que le } \\
\text { saliera podía ser } \\
\text { ayudando en los } \\
\text { restaurantes, haciendo } \\
\text { aseo en las casas o } \\
\text { vendiendo puerta a } \\
\text { puerta diferentes } \\
\end{array}$ & $\begin{array}{l}\text { i. Mi papá golpeaba a mi } \\
\text { mamá cada vez que se } \\
\text { emborrachaba } \\
\text { ii. Fue una juventud difícil } \\
\text { creo yo, porque tuve que } \\
\text { trabajar todo el tiempo y el } \\
\text { dinero que ganaba era para }\end{array}$ & $\begin{array}{l}\text { i. Sabia de todas maneras que debía } \\
\text { soportar a veces malos tratos de los } \\
\text { dueños del local porque podía } \\
\text { comprarme lo que yo necesitaba con } \\
\text { ese dinero y ayudarle a mis papás } \\
\text { para la comida y servicios. } \\
\text { ii. Mi papá siempre nos decía que él }\end{array}$ \\
\hline
\end{tabular}




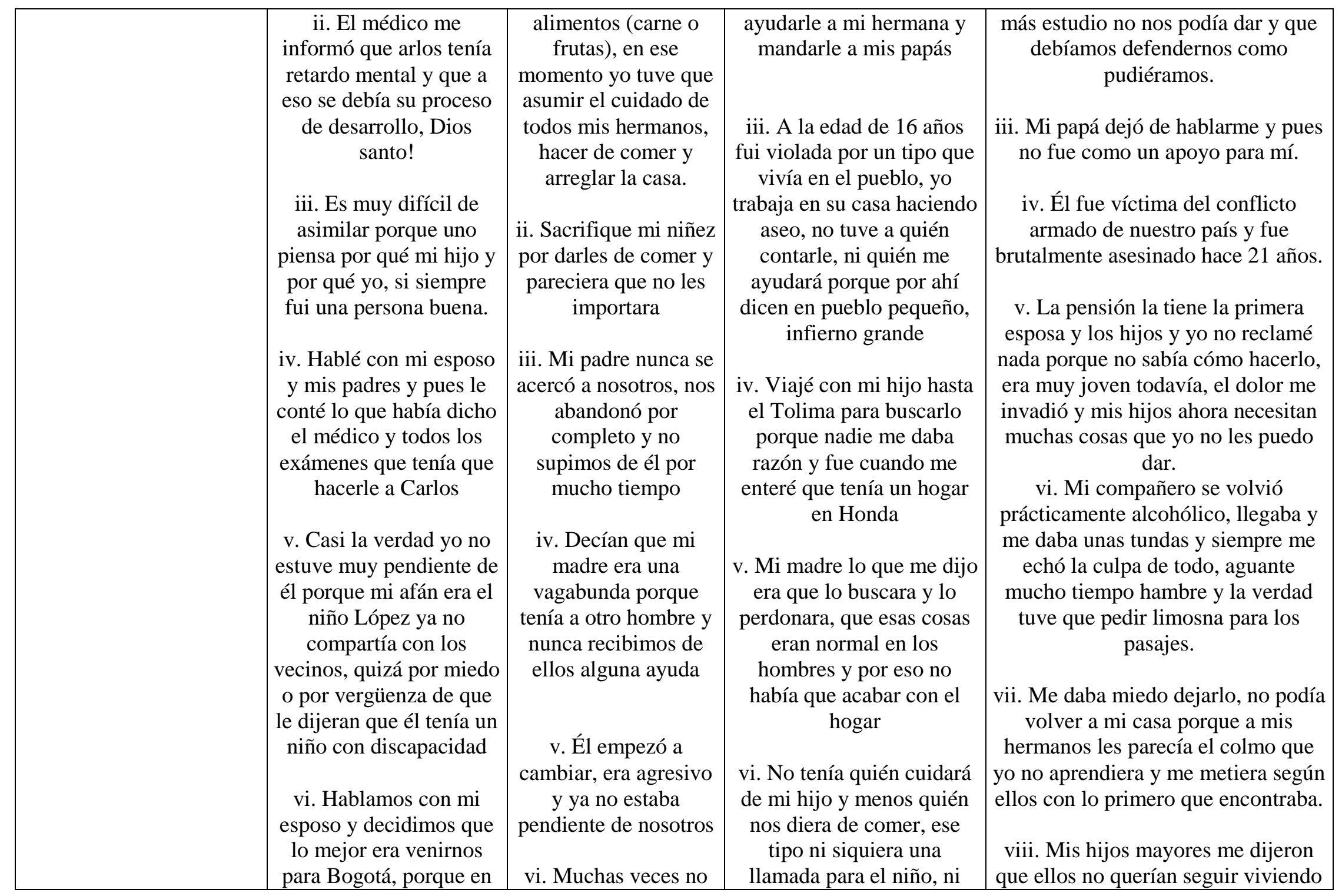




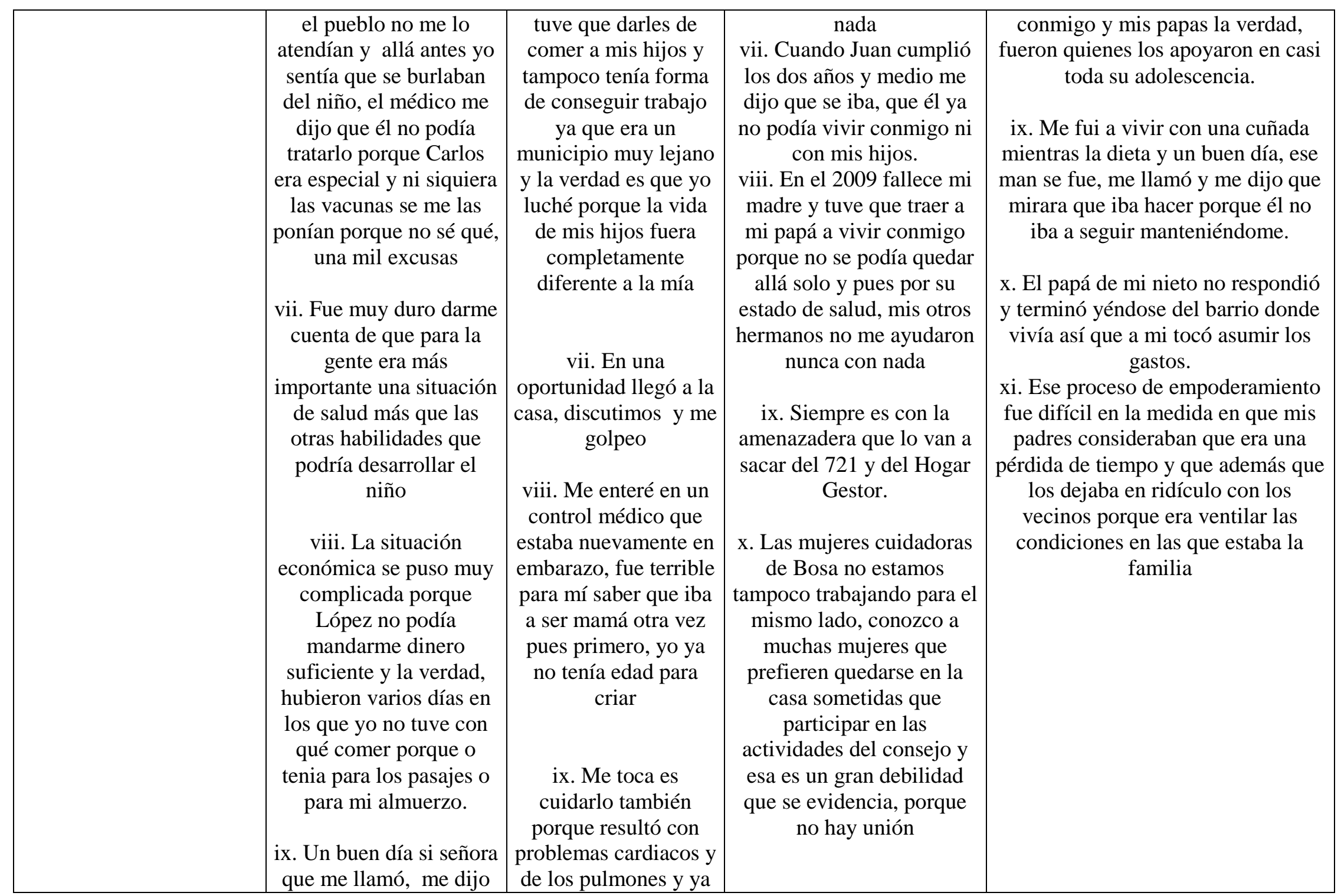




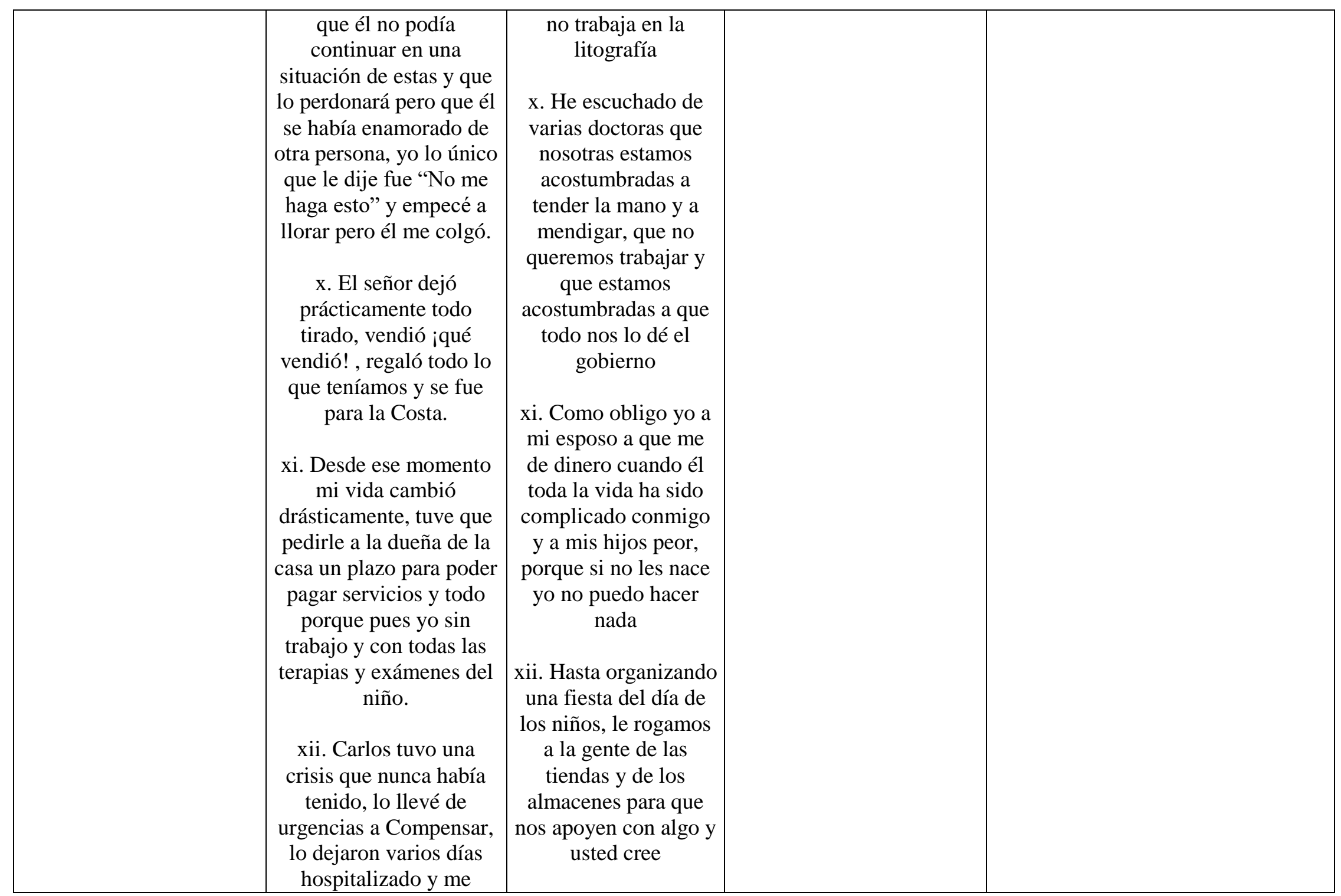




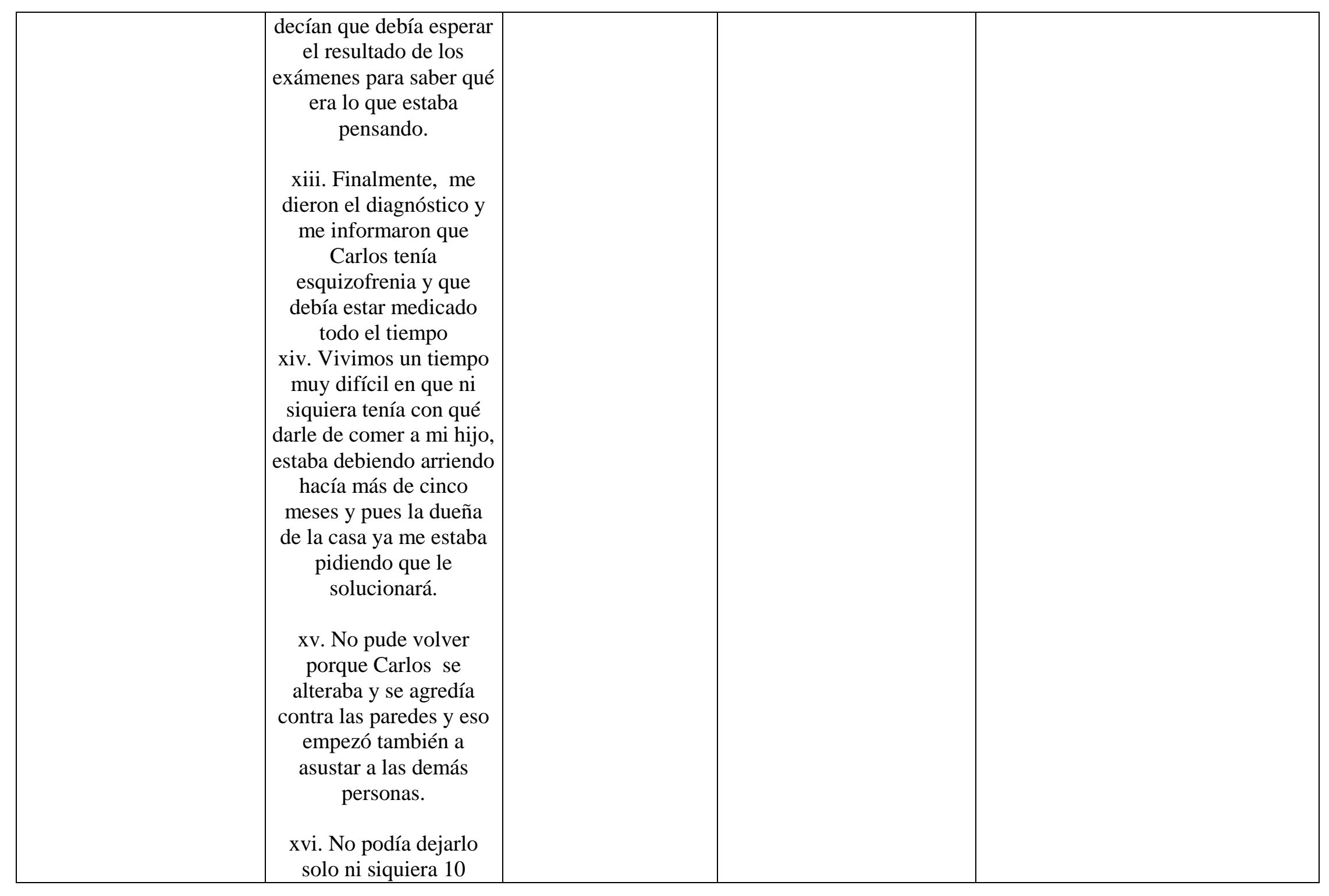




\begin{tabular}{|c|c|c|c|c|}
\hline & $\begin{array}{l}\text { minutos, cuando volvía } \\
\text { estaba lleno de sangre } \\
\text { porque se pegaba } \\
\text { durísimo en la cabeza }\end{array}$ & & & \\
\hline DERECHOS & $\begin{array}{c}\text { i. En un control médico } \\
\text { le informé al doctor que } \\
\text { nos atendió y me dijo } \\
\text { que eso era normal y que } \\
\text { los niños no todos eran } \\
\text { iguales. } \\
\text { ii. Me presenté al Col de } \\
\text { Bosa y allá me dijeron } \\
\text { que había mucha gente y } \\
\text { que tenía que quedar en } \\
\text { lista de espera, llevé } \\
\text { todos los papeles y nada } \\
\text { que me llamaban } \\
\text { iii. Con la ayuda de la } \\
\text { señora Patricia empecé a } \\
\text { participar en un } \\
\text { programa de Compensar } \\
\text { que se llama Enlaces, } \\
\text { allí nos enseñaron cómo } \\
\text { cuidar a los niños con } \\
\text { condiciones mentales } \\
\text { complejas, a estar } \\
\text { pendientes de los signos } \\
\text { de alerta frente alguna } \\
\text { crisis. } \\
\text { iv. Me vincularon a un }\end{array}$ & $\begin{array}{l}\text { i. Mi hija Ángela nace } \\
\text { por cesárea en el año } \\
1999 \text { pero resulta que } \\
\text { se demoraron mucho } \\
\text { en sacármela de tal } \\
\text { forma que le faltó } \\
\text { oxígeno en el cerebro } \\
\text { y es por ello, que se le } \\
\text { diagnostica al poco } \\
\text { tiempo parálisis } \\
\text { cerebral } \\
\text { ii. Ella siempre estuvo } \\
\text { muy pendiente de } \\
\text { nosotras, me llamaba } \\
\text { y en algunas } \\
\text { oportunidades me } \\
\text { acompañaba al Cadel } \\
\text { y al Col } \\
\text { iii. No ha sido fácil } \\
\text { ese proceso porque yo } \\
\text { no tengo el tiempo } \\
\text { suficiente para } \\
\text { participar en todo y } \\
\text { algunas señoras yo } \\
\text { siento que se molestan } \\
\text { porque dicen que las } \\
\text { cosas no son solo para } \\
\text { ellas }\end{array}$ & $\begin{array}{l}\text { i. Cuando fui por urgencias } \\
\text { y resulta que estaba era } \\
\text { embarazada } \\
\text { ii. Cuando nace mi hijo } \\
\text { Juan, que eso fue el } 15 \text { de } \\
\text { Octubre de 1990, el } \\
\text { médico, después de la } \\
\text { cesárea, porque no pudo } \\
\text { nacer por parto normal, me } \\
\text { dice que el niño estaba } \\
\text { bien de salud y que debía } \\
\text { quedarme ese día en } \\
\text { observación. } \\
\text { iii. La señora me inscribió } \\
\text { al COL lo que ahora se le } \\
\text { conoce como Integración } \\
\text { Social para recibir } \\
\text { mercado, pues mi situación } \\
\text { siempre fue de pobreza } \\
\text { porque yo no podía } \\
\text { trabajar por estar pendiente } \\
\text { de Juan y no recibía dinero } \\
\text { de nadie más. } \\
\text { iv. Recibí regaños y malos } \\
\text { tratos y pues, } \\
\text { desafortunadamente como } \\
\text { ellos son los que tienen el } \\
\text { sartén por el mango }\end{array}$ & $\begin{array}{l}\text { i. Nació mi hijo Juan y a los ocho } \\
\text { días el médico del hospital Santa } \\
\text { Clara me informó que el niño había } \\
\text { nacido con una afectación cognitiva, } \\
\text { que no iba a tener un desarrollo } \\
\text { normal y que se desconocía el } \\
\text { motivo. } \\
\text { ii. Le diagnosticaron esquizofrenia } \\
\text { tuve que sacarlo de estudiar porque } \\
\text { se alteraba mucho y no media la } \\
\text { fuerza, lo cuide en casa pero mis } \\
\text { suegros ya me dijeron que no podían } \\
\text { más con nosotros, el niño también } \\
\text { era grosero con ellos y me dijeron } \\
\text { que lo mejor era que me fuera. } \\
\text { iii. Conocí muchas mujeres en las } \\
\text { mismas condiciones que yo y eso } \\
\text { también le permite a uno establecer } \\
\text { como redes e ir mirando } \\
\text { posibilidades de agruparnos y eso. } \\
\text { iv. Ya en el año 2015 nos reunimos } \\
\text { con varias mujeres cuidadoras y } \\
\text { empezamos a mirar la opción de } \\
\text { conformar una asociación que nos } \\
\text { permitiera consolidarnos como } \\
\text { grupo y de la misma forma ir } \\
\text { diseñando proyectos que nos }\end{array}$ \\
\hline
\end{tabular}




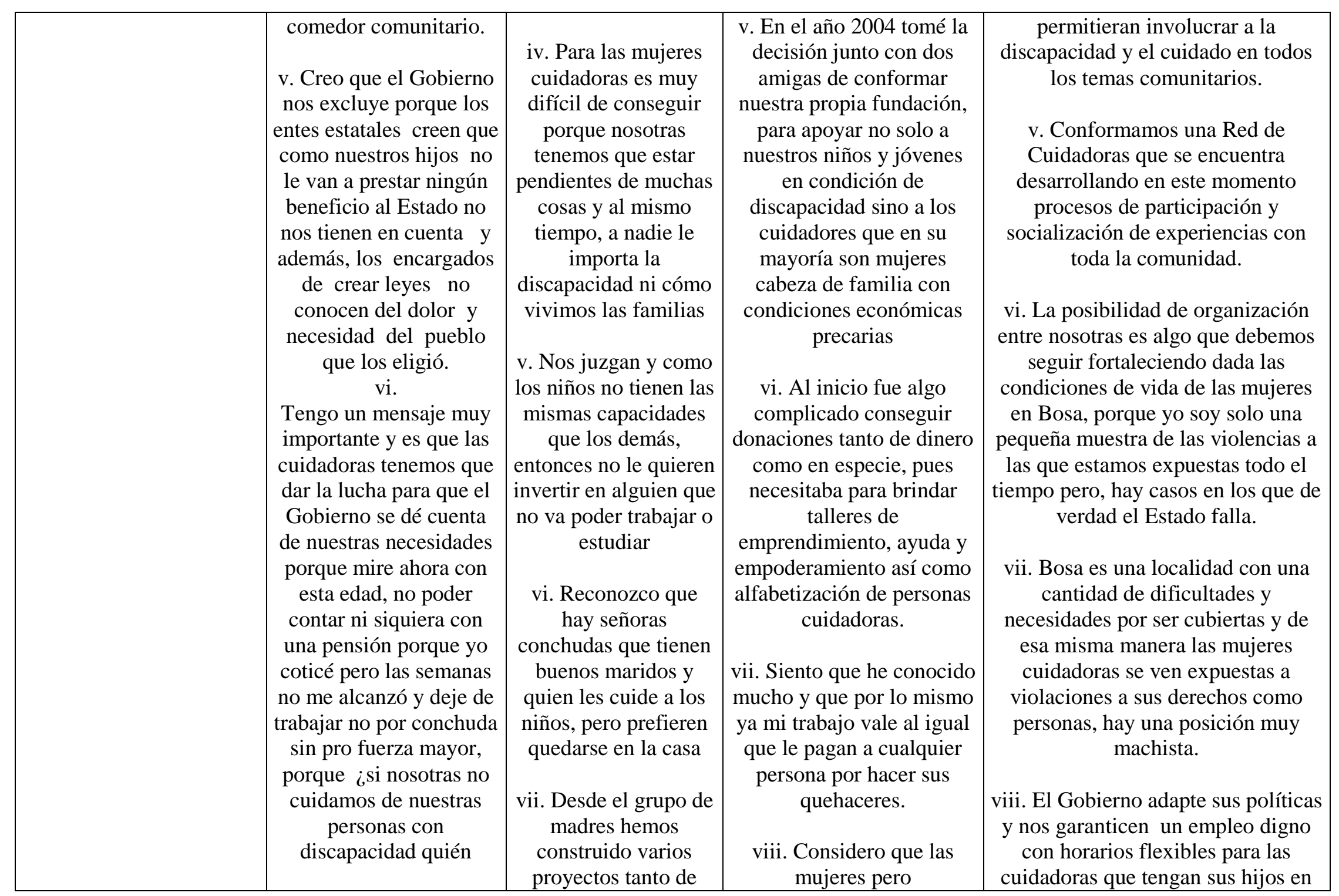




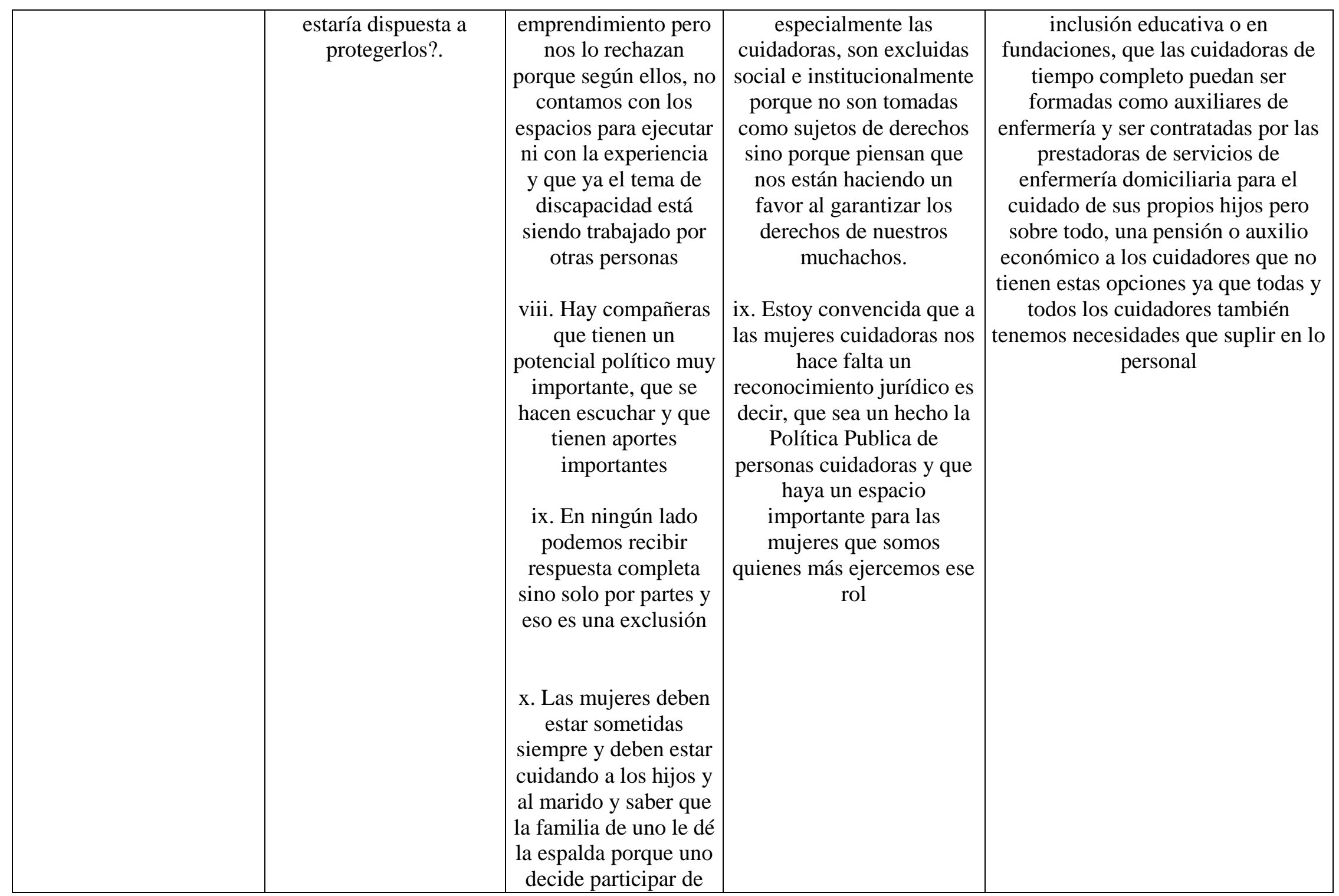




\begin{tabular}{|c|c|c|c|c|}
\hline & & $\begin{array}{l}\text { otros espacios o irse } \\
\text { del hogar por los } \\
\text { malos tratos es difícil }\end{array}$ & & \\
\hline SUJETO & $\begin{array}{c}\text { i. Empecé a salir con él } \\
\text { y fue cuando me dijo } \\
\text { que quería vivir } \\
\text { conmigo y conformar } \\
\text { una familia } \\
\text { ii. Quedé en embarazo } \\
\text { de Carlos y mi familia } \\
\text { estaba muy contenta } \\
\text { porque era el primer } \\
\text { nieto de mi parte } \\
\\
\text { iii. Siento que para él } \\
\text { también fue muy difícil } \\
\text { porque era su primer } \\
\text { hijo y de todas maneras } \\
\text { en el campo las cosas } \\
\text { son muy diferentes que } \\
\text { aquí, allá tener un niño } \\
\text { con discapacidad era una } \\
\text { maldición o un castigo } \\
\text { para la familia por haber } \\
\text { hecho algo mal. } \\
\text { iv. Desde que hice el } \\
\text { curso de Agente me } \\
\text { invitaron a participar en } \\
\text { el Consejo Local de } \\
\text { Discapacidad pero la } \\
\end{array}$ & $\begin{array}{c}\text { i. Quería salir de esa } \\
\text { casa, no quería ser la } \\
\text { nana de nadie más y } \\
\text { quería ser una persona } \\
\text { libre y sin tener que } \\
\text { hacer por los demás } \\
\text { nada } \\
\text { ii. Empecé a } \\
\text { compartir tiempo a } \\
\text { escondidas, me } \\
\text { propuso al poco } \\
\text { tiempo que nos } \\
\text { casáramos y } \\
\text { viviéramos los dos } \\
\text { lejos de nuestras } \\
\text { familias } \\
\text { iii. Yo no tenía la } \\
\text { capacidad de asumir a } \\
\text { mis hijos sin él } \\
\text { iv. Me sentí la verdad, } \\
\text { frustrada y culpable } \\
\text { porque creía que } \\
\text { había sido por mi } \\
\text { edad y mi } \\
\text { irresponsabilidad de } \\
\text { no haber planificado }\end{array}$ & $\begin{array}{l}\text { i. Nos tocaba estar pegadas } \\
\text { al fogón todo el día, } \\
\text { cocinar para los obreros y } \\
\text { cuidar a los hermanos que } \\
\text { iban naciendo } \\
\text { ii. Aprendí a leer y } \\
\text { escribir y a prepararme } \\
\text { para la vida, las mejores } \\
\text { cosas son dolorosas y se } \\
\text { consiguen con esfuerzo, } \\
\text { siempre lo he dicho!. } \\
\text { iii. A mí la vida me ha } \\
\text { tratado duro y por eso } \\
\text { aprendí a defenderme y a } \\
\text { no importar si tengo que } \\
\text { pelear o lo que sea para } \\
\text { que me respeten y me } \\
\text { garanticen mis derechos } \\
\text { iv. Estando en ese almacén } \\
\text { conocí al papá de mis } \\
\text { hijos, me fui a vivir con él } \\
\text { siendo muy pequeña, hasta } \\
\text { ahora cumplía } 18 \text { años } \\
\text { v. Me sentí tan humillada } \\
\text { en ese momento, que } \\
\text { empecé a sacar fuerzas de } \\
\text { donde no tuve }\end{array}$ & $\begin{array}{l}\text { i. Vivo en la Localidad de Bosa } \\
\text { desde hace más de } 22 \text { años. } \\
\text { ii. Ya cuando recién iba a cumplir } \\
\text { los } 20 \text { años conocí al papá de mis } \\
\text { dos hijos mayores, un hombre } \\
\text { maravilloso, cariñoso y dedicado a } \\
\text { mi inicialmente y a los niños } \\
\text { también. } \\
\text { iii. Tomé la decisión de ennoviarme, } \\
\text { nos fuimos a vivir al poco tiempo en } \\
\text { Kennedy, no me fui bien de mi casa, } \\
\text { mis papás no estaban de acuerdo con } \\
\text { que las cosas fueran tan rápido. } \\
\text { iv. Quedé en embarazo y la verdad } \\
\text { es que mientras yo conviví con él } \\
\text { todo era maravilloso, vivíamos bien, } \\
\text { nos queríamos y a nosotras nada nos } \\
\text { faltaba. } \\
\text { v. Ya cuando mi hija mayor cumplió } \\
\text { ocho años, conocí al papá de mis } \\
\text { dos hijos menores, los niños que } \\
\text { tienen discapacidad, me dejé } \\
\text { envolver seguramente. } \\
\text { vi. No lo creía busque citas médicas } \\
\text { en otros hospitales, lo bauticé, hasta } \\
\text { que a los seis meses empecé como a }\end{array}$ \\
\hline
\end{tabular}




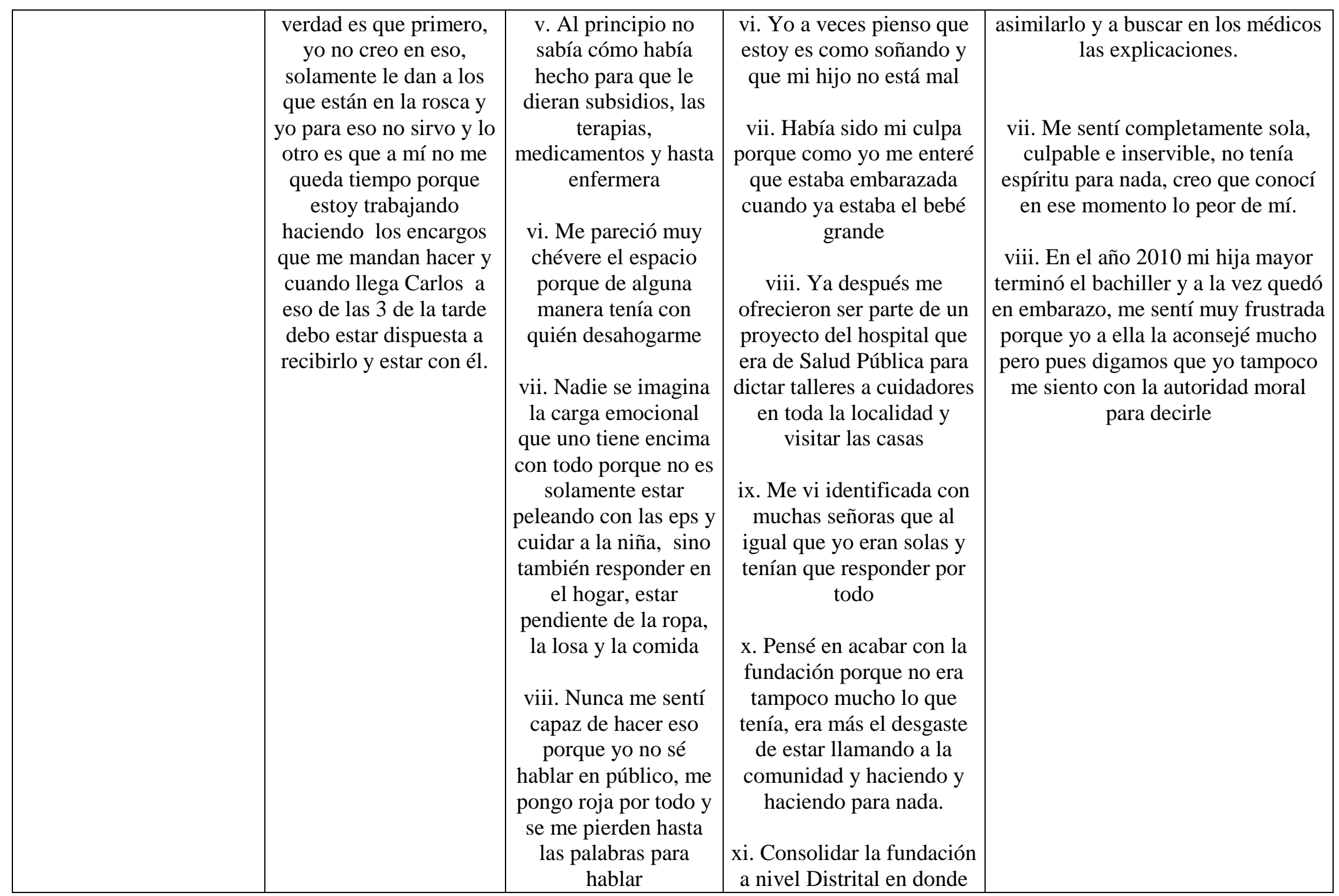




\begin{tabular}{|c|c|c|c|}
\hline & & $\begin{array}{c}\text { ix. La única } \\
\text { responsable de la niña } \\
\text { soy yo y lo que yo no } \\
\text { haga por ella, nadie lo } \\
\text { va hacer } \\
\text { x. Somos mujeres } \\
\text { valientes, entregadas, } \\
\text { inteligentes, líderes y } \\
\text { gestoras es el trabajo } \\
\text { más duro, más que el } \\
\text { de cuidar a los niños }\end{array}$ & $\begin{array}{c}\text { no solo las mujeres de } \\
\text { Bosa puedan participar, } \\
\text { sino la de todas las } \\
\text { localidades de Bogotá a tal } \\
\text { punto que podamos ser } \\
\text { reconocidas a nivel } \\
\text { nacional así como los } \\
\text { sindicatos y creo que una } \\
\text { de las más importantes, } \\
\text { impulsar la política pública } \\
\text { de personas cuidadoras } \\
\text { para que se nos garanticen } \\
\text { unos derechos y tener las } \\
\text { herramientas legales para } \\
\text { hacerlos cumplir }\end{array}$ \\
\hline
\end{tabular}




\section{Análisis Historias de Vida}

\begin{tabular}{|c|c|}
\hline CATEGORIAS & ANALISIS \\
\hline IDENTIFICACIÓN & $\begin{array}{l}\text { i. Las mujeres cuidadoras se encuentran entre la etapa de la adultez y la ancianidad dentro del desarrollo humano. } \\
\qquad \text { ii. Provienen de familias patriarcales y numerosas. } \\
\text { iii. La procedencia de la mayoría de mujeres cuidadoras obedece a la ruralidad. } \\
\text { iv. Las labores del hogar, la agricultura, el cuidado y la crianza fueron asumidas por las mujeres cuidadoras desde } \\
\text { su infancia. } \\
\text { v. Las mujeres cuidadoras tuvieron un primer acercamiento a la educación inicial en edad avanzada. } \\
\text { vi. Para la mayoría de mujeres cuidadoras no existió interacción social o comunitaria. }\end{array}$ \\
\hline LIDERAZGO & $\begin{array}{l}\text { i. La condición de discapacidad de los niños fue la motivación para que las mujeres empezarán a involucrarse en } \\
\text { escenarios comunitarios e institucionales. } \\
\begin{array}{r}\text { ii. Desde el ejercicio diario y la experiencia cotidiana, las mujeres cuidadoras fueron adquiriendo habilidades } \\
\text { sociales y jurisprudenciales para la exigencia de derechos. }\end{array} \\
\text { iii. Los sectores institucionales de salud y asistencia social aportaron a la construcción de mujeres líderes y } \\
\text { empoderadas. }\end{array}$ \\
\hline PROTECCIÓN SOCIAL & $\begin{array}{l}\text { i. La economía en los hogares de las mujeres cuidadoras era precario e inestable. } \\
\text { ii. La mayoría de mujeres cuidadoras migraron del campo a la Ciudad de Bogotá por las oportunidades que les } \\
\text { ofrecía para mejorar su calidad de vida. } \\
\text { iii. Las mujeres cuidadoras iniciaron su vida laboral en la adolescencia. } \\
\text { iv. Las condiciones laborales iniciales que enfrentaron las mujeres cuidadoras se enmarcaron en la explotación } \\
\text { laboral, en el pago inequitativo de su oficio y la inexistencia del pago de seguridad social. }\end{array}$ \\
\hline
\end{tabular}




\begin{tabular}{|c|c|}
\hline & $\begin{array}{l}\text { v. Las mujeres cuidadoras al conformar una familia regresaron al ámbito privado encargándose exclusivamente de } \\
\qquad \text { los oficios del hogar, la crianza, el cuidado de sus hijos. } \\
\text { vi. En algunas oportunidades las mujeres cuidadoras recurrieron a la informalidad para cubrir sus necesidades } \\
\text { básicas. } \\
\text { vii. En la mayoría de casos existió violencia económica por parte de sus familiares o parejas. } \\
\text { viii. Luego de las crisis o la separación de sus esposos, las mujeres cuidadoras intentan ingresar al campo laboral, } \\
\text { encontrando como únicas oportunidades la informalidad. } \\
\text { ix. Una vez diagnosticaron a sus hijos con algún tipo de discapacidad, las mujeres cuidadoras no lograron } \\
\text { vincularse a empleos con horarios extendidos y normas establecidas. } \\
\text { x. Su conocimiento frente al liderazgo y la exigencia de derechos se convirtió en la única fuente de recursos } \\
\text { económicos para ellas y sus familias. }\end{array}$ \\
\hline $\begin{array}{l}\text { RECONOCIMIENTO } \\
\text { INSTITUCIONAL }\end{array}$ & $\begin{array}{l}\text { i. La mayoría de mujeres cuidadoras manifiesta que la discapacidad de sus hijos obedeció a la negligencia del } \\
\text { sector salud. } \\
\text { ii. De acuerdo a las mujeres cuidadoras el régimen subsidiado les ha permitido acceder a más tratamientos, } \\
\text { cirugías y rehabilitaciones que el contributivo. } \\
\text { iii. Para las mujeres cuidadoras los profesionales de la salud no cuentan con la sensibilización correspondiente } \\
\text { para trabajar con las personas con discapacidad y sus familias pues, encuentran prejuicios, barreras de acceso, } \\
\text { poca información y canales de comunicación inadecuados. } \\
\text { iv. Las mujeres cuidadoras han tenido que recurrir a Atención al ciudadano de los hospitales y a entes de control } \\
\text { para el acceso a algún tipo de servicio. } \\
\text { vresentaba barreras de acceso pues, no contaban con programas para niños con discapacidad, los colegios no } \\
\text { tenían disposición para aceptar a los niños o los docentes no estaban capacitados para ello. } \\
\text { vi. Una de las mujeres cuidadoras insiste en que la discapacidad Mental Psicosocial no cuenta con ningún }\end{array}$ \\
\hline
\end{tabular}




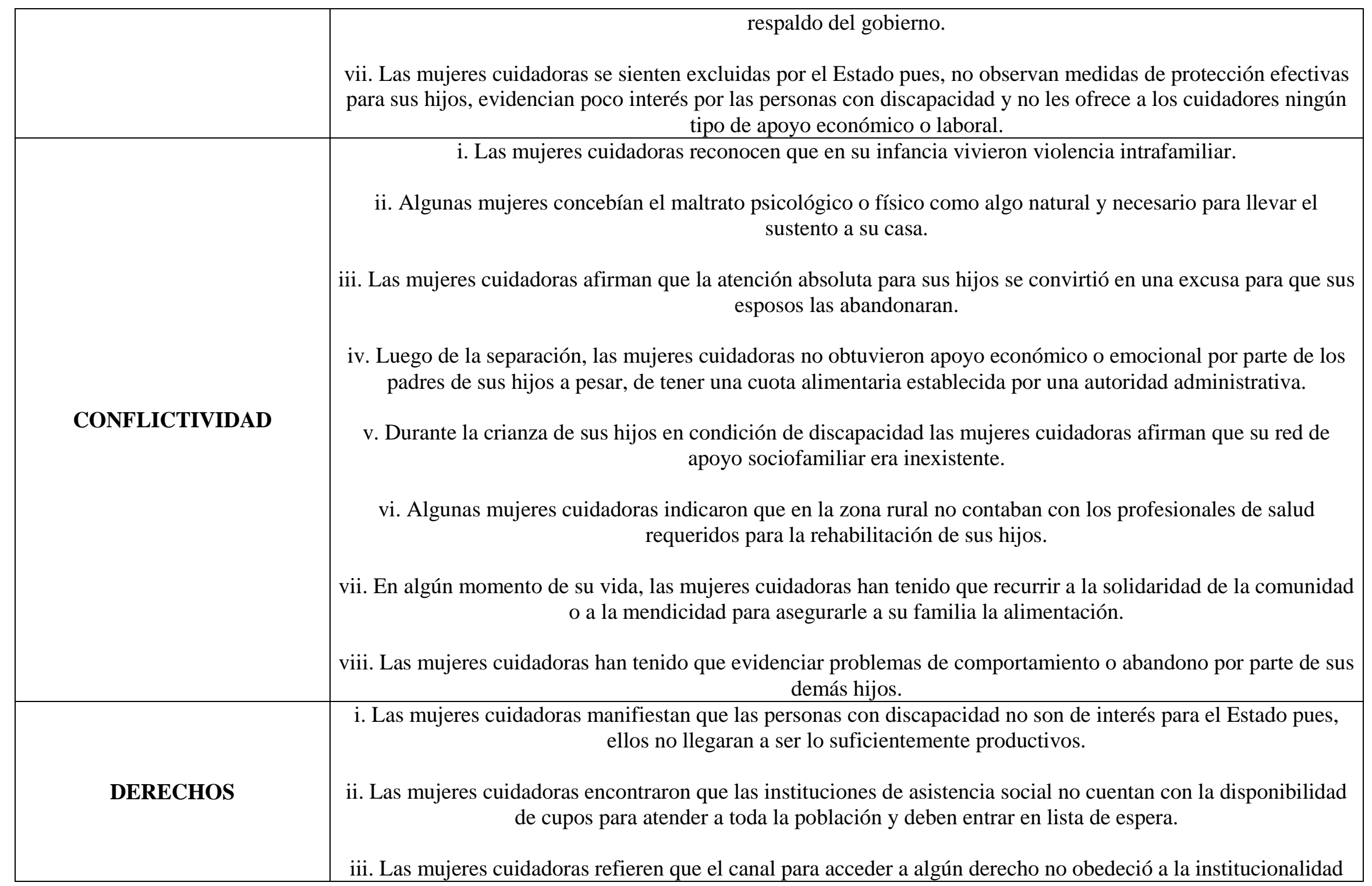




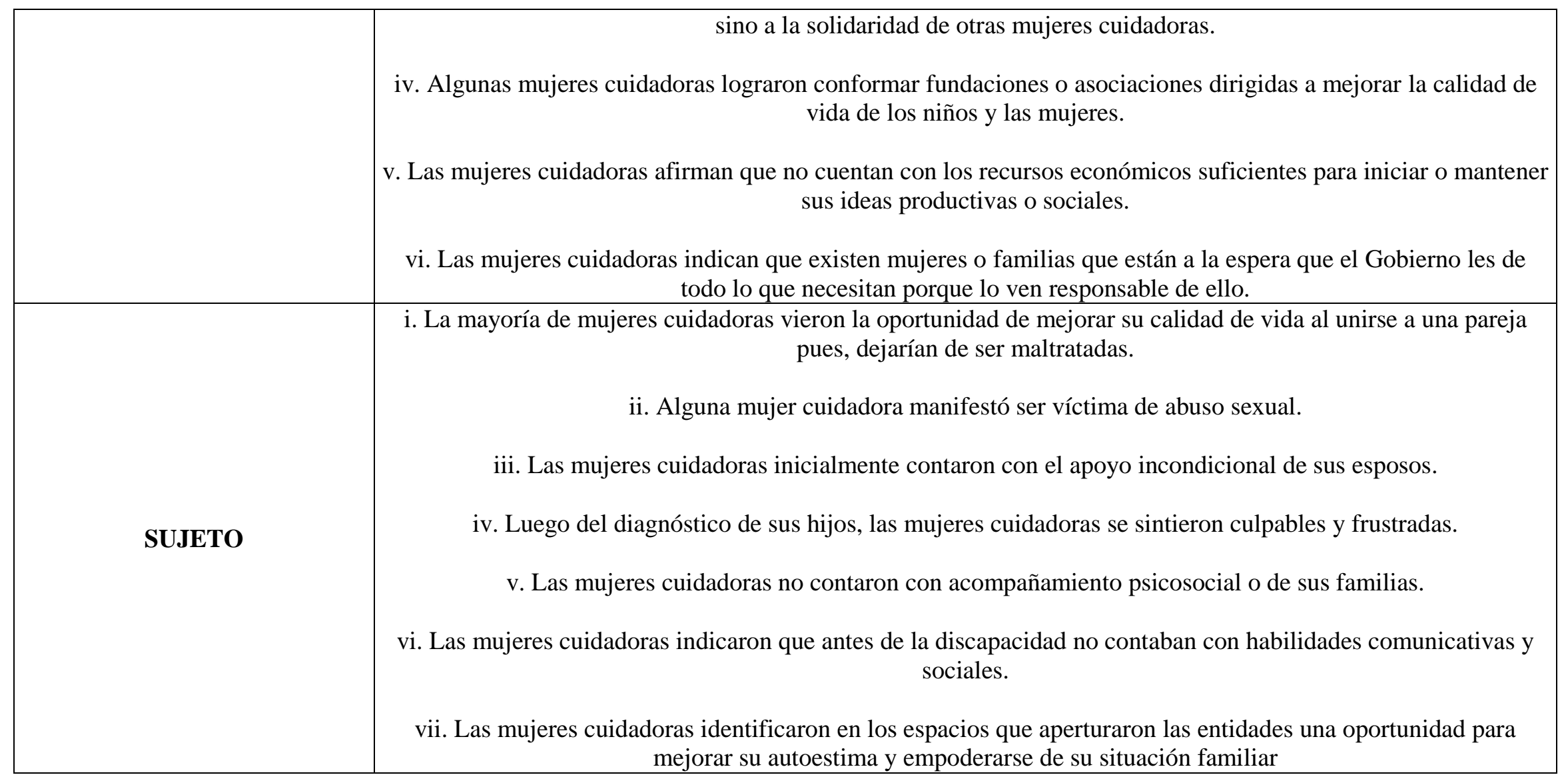

